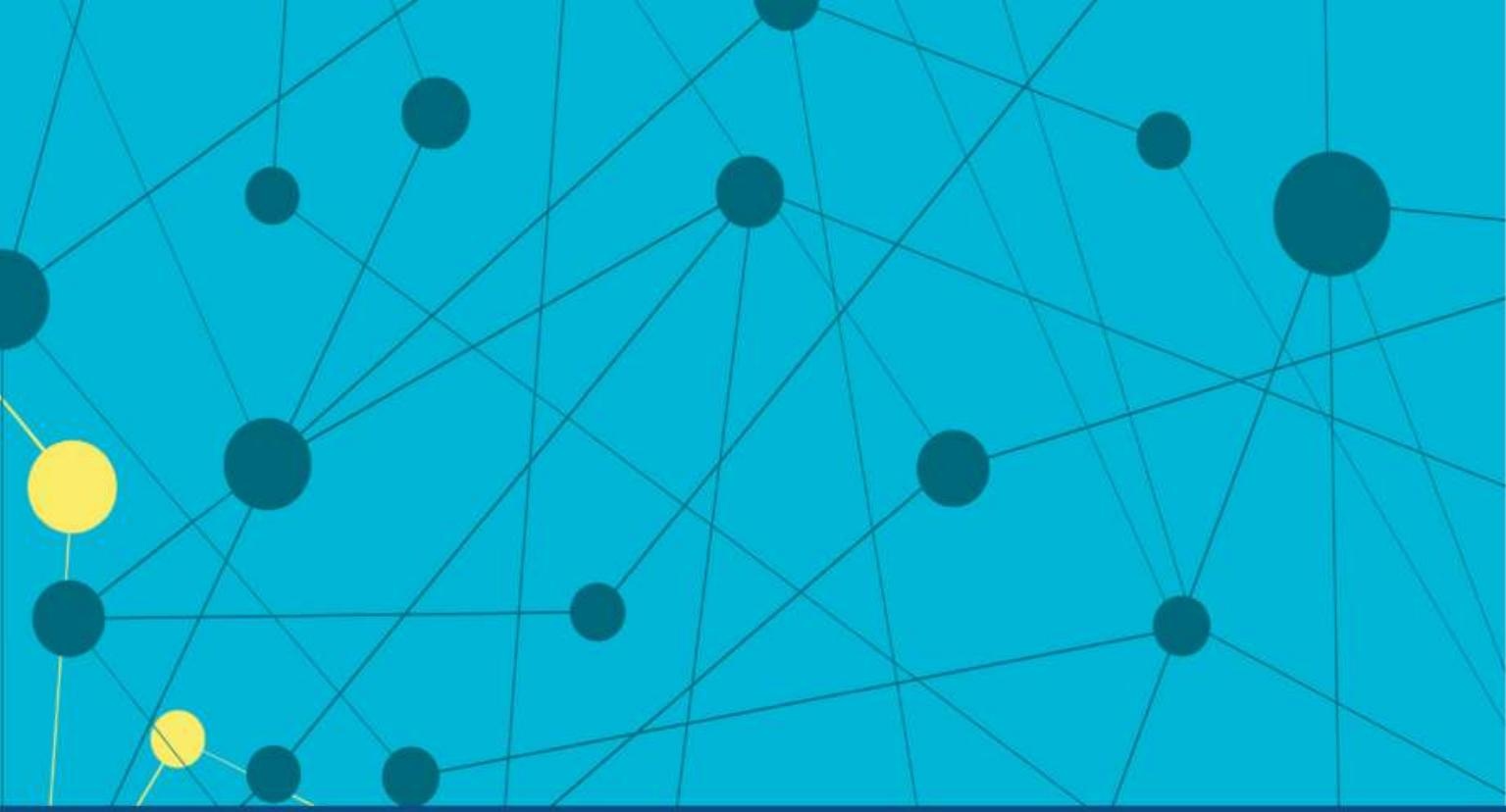

Social Perspectives on Ageing and Later Life

AGEING AND COVID-19

MAKING SENSE OF A DISRUPTED WORLD

Edited by

Maria Łuszczyńska and Marvin Formosa

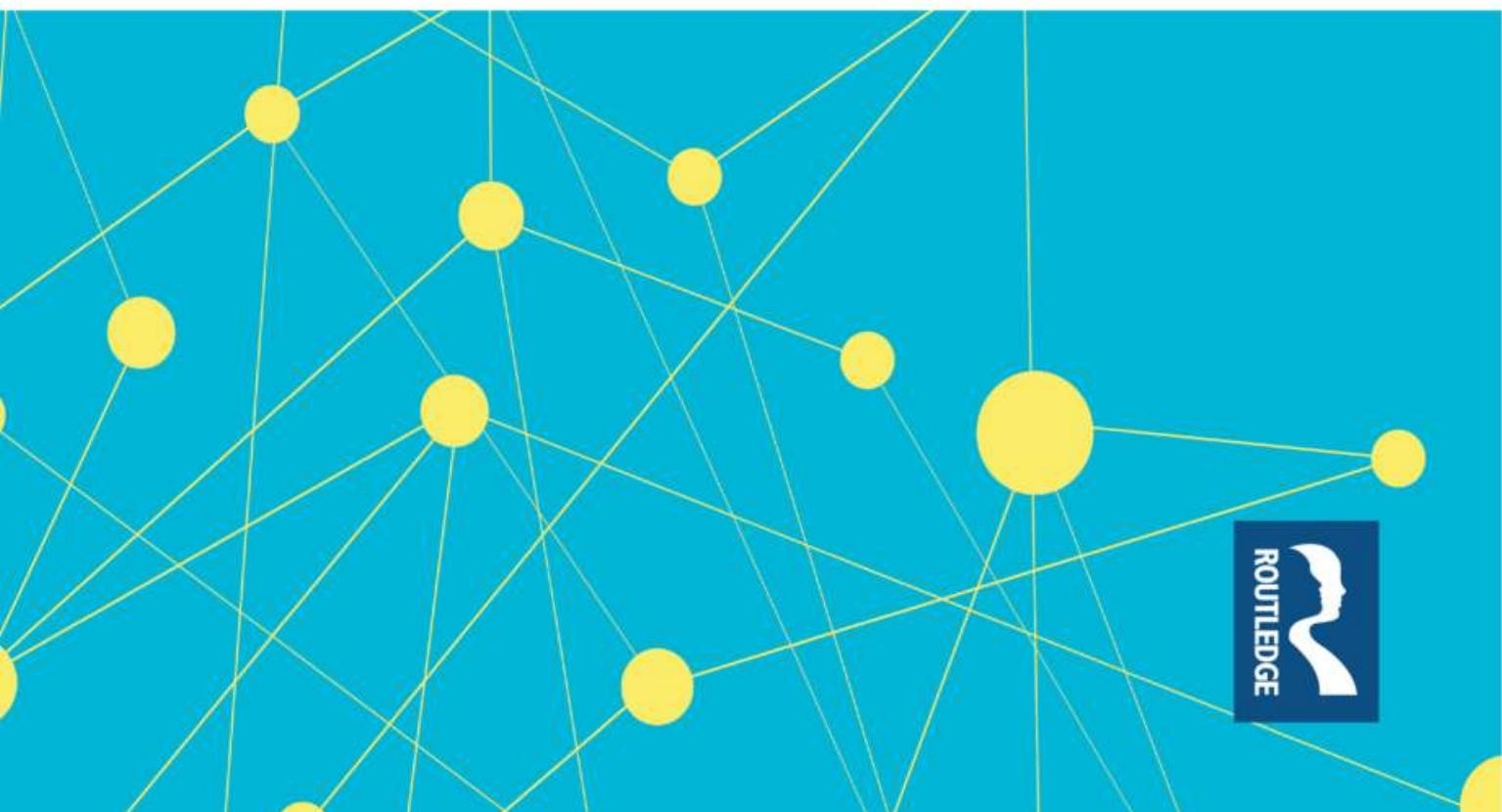




\section{Ageing and COVID-19}

This volume presents a range of research approaches to the exploration of ageing during a pandemic situation. One of the first collections of its kind, it offers an array of studies employing research methodologies that lend themselves to replication in similar contexts by those seeking to understand the effects of epidemics on older people. Thematically organised, it shows how to reconcile qualitative and quantitative approaches, thus rendering them complementary, bringing together studies from around the world to offer an international perspective on ageing as it relates to an unprecedented epidemiological phenomenon. As such, it will appeal to researchers in the field of gerontology, as well as sociologists of medicine and clinicians seeking to understand the disruptive effects of the recent coronavirus outbreak on later life.

Maria Luszczyńska is Assistant Professor in the Faculty of Social Sciences at the Pontifical University of John Paul II in Krakow, Poland. She is the editor of Researching Ageing: Methodological Challenges and their Empirical Background.

Marvin Formosa is Associate Professor in the Department of Gerontology and Dementia Studies, Faculty for Social Wellbeing, University of Malta, Malta. Recent publications include The University of the Third Age and Active Ageing and Population Ageing in the Middle-East and North Africa (with Abdulrazak Abyad). 


\section{Social Perspectives on Ageing and Later Life}

This series publishes scholarly monographs and edited volumes concerned with the social aspects of ageing and later life, with particular emphasis on issues such as social exclusion and the lived environment, poverty, health and illness, access to services, the family, connectedness and independence, as well as work centred on research methods in relation to ageing.

Titles in this series

Ageing and COVID-19

Making Sense of a Disrupted World

Edited by Maria Luszczyńska and Marvin Formosa

\section{Ageing as a Social Challenge}

Individual, Family and Social Aspects in Poland

Maria Łuszczyńska

For more information about this series, please visit: https://www.routledge. com/sociology/series/SPALL 


\section{Ageing and COVID-19 \\ Making Sense of a Disrupted World}

\section{Edited by \\ Maria Łuszczyńska and \\ Marvin Formosa}

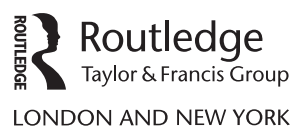


First published 2021

by Routledge

2 Park Square, Milton Park, Abingdon, Oxon OX14 4RN

and by Routledge

605 Third Avenue, New York, NY 10158

Routledge is an imprint of the Taylor \& Francis Group, an informa business

(C) 2021 selection and editorial matter, Maria Łuszczyńska and

Marvin Formosa; individual chapters, the contributors

The right of Maria Luszczyńska and Marvin Formosa to be identified as the authors of the editorial material, and of the authors for their individual chapters, has been asserted in accordance with sections 77 and 78 of the Copyright, Designs and Patents Act 1988.

All rights reserved. No part of this book may be reprinted or reproduced or utilised in any form or by any electronic, mechanical, or other means, now known or hereafter invented, including photocopying and recording, or in any information storage or retrieval system, without permission in writing from the publishers.

Trademark notice: Product or corporate names may be trademarks or registered trademarks, and are used only for identification and explanation without intent to infringe.

British Library Cataloguing-in-Publication Data

A catalogue record for this book is available from the British Library

Library of Congress Cataloging-in-Publication Data

Names: Łuszczyńska, Maria, 1977- editor. | Formosa, Martin, editor. Title: Ageing and Covid-19: making sense of a disrupted world / edited by Maria Łuszczyńska and Martin Formosa.

Description: 1 Edition. | New York, NY : Routledge, 2022. | Series:

Social perspectives on ageing and later life | Includes bibliographical references and index.

Identifiers: LCCN 2021038845 (print) | LCCN 2021038846 (ebook) | ISBN 9781032194677 (hardback) | ISBN 9781032194691 (paperback) | ISBN 9781003259329 (ebook)

Subjects: LCSH: Aging-Research-Methodology. | Social gerontology-Methodology. | COVID-19 (Disease) - Social aspects. Classification: LCC HQ1061.A4244116 2022 (print) | LCC HQ1061 (ebook) | DDC 362.6-dc23/eng/20211013

LC record available at https://lccn.loc.gov/2021038845

LC ebook record available at https://lccn.loc.gov/2021038846

ISBN: 9781032194677 (hbk)

ISBN: 9781032194691 (pbk)

ISBN: 9781003259329 (ebk)

DOI: $10.4324 / \mathrm{b} 22774$

Typeset in Times New Roman by codeMantra 
The publication is created within the project Global Ageing Research Partnership. The project is financed by the Polish National Agency for Academic Exchange. 

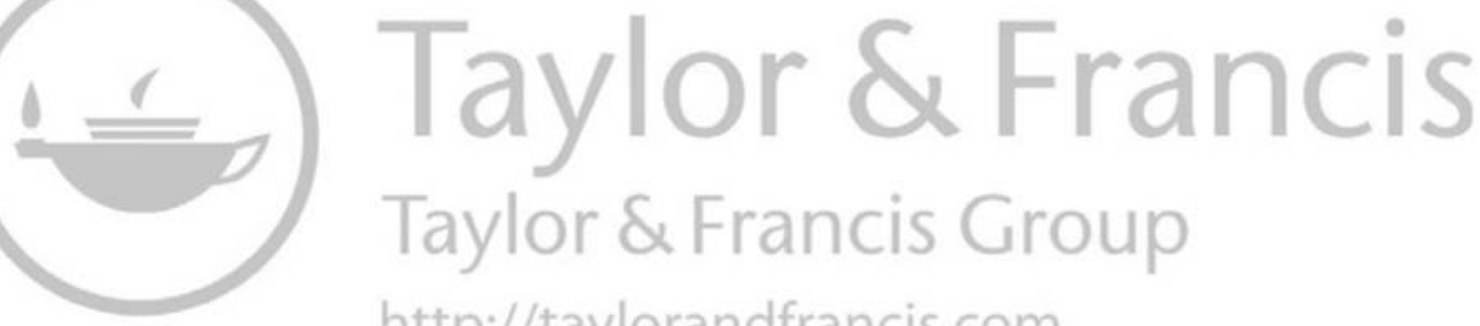
http://taylorandfrancis.com 
Maria Luszczyńska dedicates the book to those who support and bring her to be creative and revealing, especially to her daughter Kalina

Marvin Formosa dedicates the book to Fiona, friend and wife, and to Emma and Julian, each of whom has a special place in his heart 

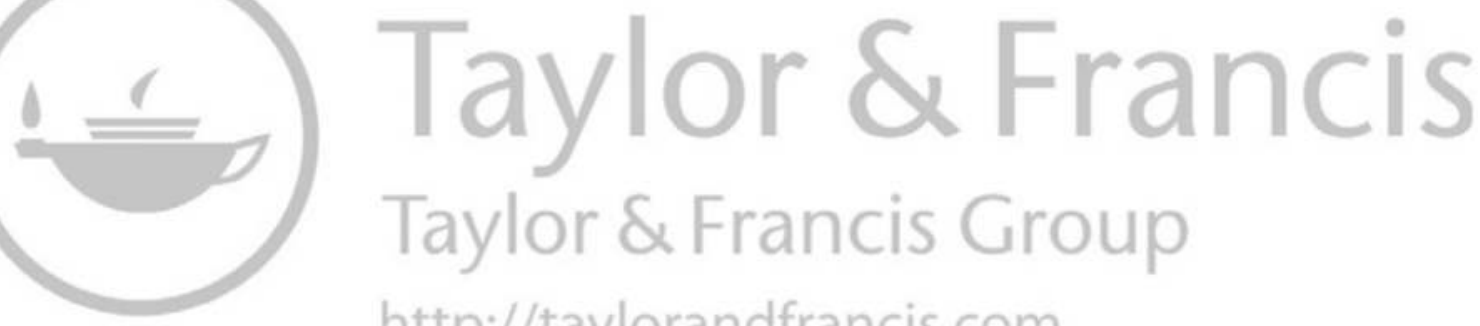
http://taylorandfrancis.com 


\section{Contents}

List of contributors $\quad$ xiii

Introduction: the challenges facing ageing during COVID-19

MARVIN FORMOSA AND MARIA ŁUSZCZYŃSKA

\section{PART 1}

COVID-19 as the unknown

1 The phenomenon of the COVID-19 pandemic against the background of its era

BOHDAN W. WASILEWSK I

2 COVID-19 lockdown and social distance measures:

a 'perfect storm' for social isolation and loneliness in later life

3 Death and dying vs. COVID-19: a hermeneutic approach toward understanding the social process

MARIA ŁUSZCZYŃSKA

PART 2

Social attitudes and strategies

4 Unmasking features of the state of the epidemic: what is the uniqueness of the position of older people in Poland? 
6 Age division and ageism in the public debates regarding COVID-19: intergenerational solidarity and antagonisms in the era of the coronavirus pandemic

JAROSLAVA HASMANOVÁ MARHÁNKOVÁ

7 Older adults' coping strategies in a pandemic situation: a Polish case study

CELINA TIMOSZYK-TOMCZAK, BEATA BUGAJSKA, AND KLAUDIA PIOTROWSKA

8 Support for older adults during COVID-19: how did local authorities in the Pomeranian region respond to the challenge? ANITA RICHERT-KAŹMIERSKA

PART 3

Social life

9 Geragogy of everyday life: the COVID-19 perspective ZOFIA SZAROTA

10 Online learning for older persons during the COVID-19 pandemic in Malta: the good, the bad, and the ugly MARVIN FORMOSA

11 Grandparents raising grandchildren during coronavirus pandemic: a challenge or a threat? JOANNA BOROWIK

12 "Keeping a project during the COVID-19 pandemic alive": experiences with co-researchers of the participatory STARK project

HELENE VON STÜLPNAGEL, JULIA PIEL, AND ASTRID EICH-KROHM

13 The experience of loneliness in older adults during the COVID-19 pandemic: a Polish perspective

EWA GRUDZIEWSKA

14 Older adults' religiosity during the COVID-19 pandemic: Catholic Church in action 
PART 4

Social care and support

15 To care or not to care? What have we learned from COVID-19 about our attitudes towards older adults?

LINDA GARCIA, LOUISE BÉLANGER-HARDY, AND MARTINE LAGACÉ

16 Institutional care for older people in Poland during pandemic: regulations, practice and thoughts about the future JOANNA M. SALACHNA AND ANNA SZAFRANEK

17 Internet-telephone consultation service for older persons SŁAWOMIR TOBIS, KATARZYNA WIECZOROWSKA-TOBIS AND AGNIESZKA NEUMANN-PODCZASKA

18 Everyday reality at nursing home care facilities experienced during the COVID-19 pandemic

MAŁGORZATA HALICKA, JERZY HALICKI AND KRZYSZTOF CZYKIER

19 Feedback from French nursing staff in gerontology: health reorganisation acceptance related to COVID-19 crisis RABIER, VINCENT AUGUSTO, CAROLINE DUPRÉ, SOLÈNE DORIER, JESSICA GUYOT AND NATHALIE BARTH

Conclusion: ageing, COVID-19 and 'new normality' 

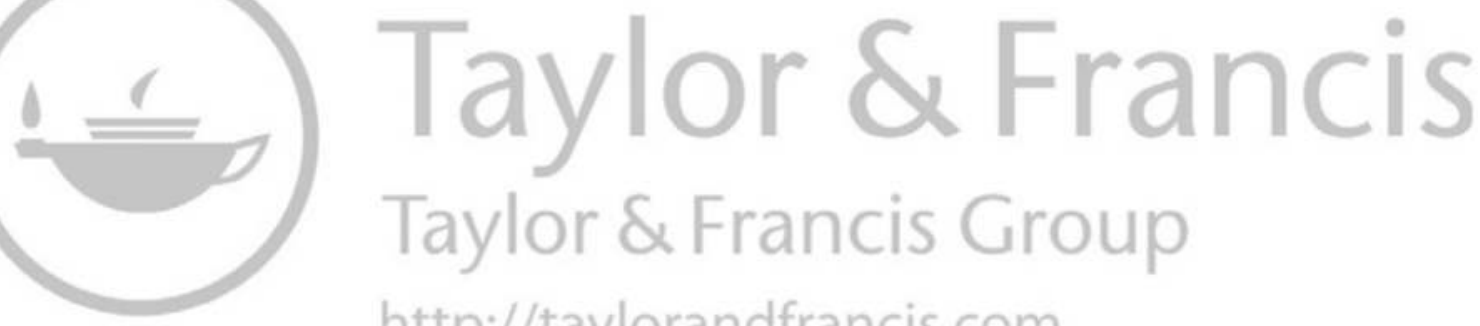
http://taylorandfrancis.com 


\section{Contributors}

Vincent Augusto, Mines Saint-Etienne, Clermont Auvergne University, CNRS, UMR 6158 LIMOS, Centre CIS, F-42023 Saint-Etienne France. Mr Vicent Augusto is the director of the Center for Biomedical and Healthcare Engineering (Mines Saint-Étienne). He is specialised in performance evaluation and in care systems engineering. His work heads towards health decision aid (discrete optimisation, stochastic optimisation, meta-heuristics). $\mathrm{He}$ also works in health process forecast and in medical decision aid.

Nathalie Barth, Auvergne-Rhône-Alpes Gerontology Centre; Jean Monnet University, Chair at Senior Citizens Healthcare Prevention Engineering. Mrs Nathalie Barth is a doctor in the Sciences and Techniques of Physical and Sports Activities (2007) specialised in sociology of health, aging and adapted physical activities. She is particularly interested in the promotion of health through "sport," and questions of accessibility, "care" of people with chronic diseases, weakened by age and/or social conditions. In charge of the university research for the Aging Health Chair (Jean Monnet University of St Etienne), she integrated the Gérontopôle AURA as project manager.

Louise Bélanger-Hardy, B.A, B. Soc Sc, J.D., LL.M., Full Professor, Faculty of Common Law, University of Ottawa, Canada. Professor Louise Bélanger-Hardy's research interests include professional responsibility, consent in the medical and research settings, liability of mental health professionals and tort compensation for mental harm. She has been a member of several Research Ethics Boards, and is currently associated to the LIFE Research Institute and the Centre for Health Law, Policy and Ethics, both at the University of Ottawa. Her current research interests focus on liability issues in the context of private home care for older adults, and issues linked to human rights of older adults.

Joanna Borowik, PhD, education, University of Białystok, Faculty of Educational Sciences. Her research areas of interest include life satisfaction of life of older adults, intergenerational relations, especially in the context of formal and informal care of grandparents for grandchildren, educational awareness from a generational perspective, perception of childhood and youth by grandchildren raised by grandparents 
Beata Bugajska, PhD, Associate Professor of Social Sciences in the field of Pedagogy. Department of Social Science, Institute of Pedagogy, University of Szczecin, Poland. Head of the Department of Social Issues of Szczecin's City Hall. Research interests: social gerontology, care for the older adults, social services for older people. Vice Chairperson of the Board of the Main Polish Association of Gerontology. She has authored over 60 titles, including 'The Ninth Stage in the Cycle of Life - Reflections on E.H. Erikson's Theory' in Ageing \& Society (2017).

Krzysztof Czykier, PhD in social sciences, lecturer in the Department of Andragogy and Educational Gerontology at the Faculty of Education of the University of Bialystok. Areas of scientific interest: andragogy, social pedagogy, social work. Areas of research interest: biographical narratives of early adulthood, widowhood, participation of multi-generational rural families in audiovisual culture, old people in the perception of youth. Member of research projects. Author and co-author of books and scholarly articles.

Solène Dorier, Auvergne-Rhône-Alpes Gerontology Centre. Mrs Solène Dorier is a social psychologist specialised in Health Promotion and Education. She is a project manager at Gérontopôle Auvergne Rhône-Alpes. She supports several projects around the aging of the population and themes such as housing, technological and social innovations, health, etc.

Caroline Dupré, Jean Monnet University, Chair at Senior Citizens Healthcare Prevention Engineering; Technical Support and Training Centre for Health Examination Centres. Mrs Caroline Dupré is a biostatician in the Aging Health Chair (Jean Monnet University of St Etienne). She is specialised in prevention and public health, epidemiology, aging, cognitive aging through cross-sectional and longitudinal studies.

Astrid Eich-Krohm, PhD in sociology and two nursing degrees: as a registered nurse and nursing educator. Since 2016 she is the PI of the Core Project of the research cluster "Autonomy in Old Age" funded by the EU. Her research is based on qualitative methods and focuses on the social world of the aging population in Saxony-Anhalt, Germany. She is a senior research associate at the Institute for Social Medicine and Health Systems Research, Faculty of Medicine, Otto-von-Guericke-University Magdeburg.

Marvin Formosa Ph.D. is Associate Professor at the Department of Gerontology and Dementia Studies, Faculty for Social Wellbeing, University of Malta, and Rector's Delegate for the University of the Third Age (Malta). Prof. Formosa also occupies the post of Director of the Institute on Ageing United Nations - Malta, Chairperson of the National Commission for Active Ageing (Malta) and was the lead author of the National Strategic Policy for Active Ageing: Malta 2014 - 2020. His interests include 
active ageing, critical gerontology, educational gerontology and older adult learning. Prof. Formosa is the author of various articles and books, and occupies the role of Country Team Leader (Malta) of the Survey of Health, Ageing, and Retirement in Europe (SHARE).

Linda Garcia, PhD, Director and Professor, LIFE Research Institute, University of Ottawa. Field of interest: older adults, dementia, transitions, communication, social relationships, caregivers, interdisciplinary research. Her research interests focus on the impact of physical and social environments on the functioning of individuals with neurological disorders, especially dementia. Working with colleagues from other professions, she strives to understand and offer solutions for capitalising on ways to facilitate the social integration of individuals with functional limitations. She is interested in developing interventions that include approaches based on human interactions. She is keenly interested in improving quality of life in long-term care. Prior to joining the University of Ottawa in 1993, Professor Garcia worked for over ten years in a large teaching hospital as a Speech-Language Pathologist and department head. After completing her PhD with Dr. Yves Joanette, she worked as a professor in the Audiology and Speech-Language Pathology Program. She then moved on to help create the Interdisciplinary School of Health Sciences and became its first Director in 2010, prior to becoming Vice-Dean of the Faculty of Health Sciences in 2014 and the Director of the LIFE Research Institute in 2019. She has been a member of the Steering committee for the Champlain Dementia Network for over 15 years, represents the University of Ottawa at the Council of Ontario Universities' Ontario Interdisciplinary Council for Aging and Health, and more recently sits on the Board of the Eldercare Foundation of Ottawa, being tasked with developing the innovation plan for the foundation, which focuses on long-term care in Ottawa's publicly funded homes.

Chloé Gaulier, Auvergne-Rhône-Alpes Gerontology Centre. Mrs Chloé Gaulier is a project manager at Gérontopôle Auvergne Rhône-Alpes. She is specialised in Health Promotion and Education. Actually she particularly investigates impacts of COVID-19 in the olders and caregivers.

Dobroniega Glębocka, is Associate Professor and sociologist, employee of the Faculty of Sociology at University of Adam Mickiewicz in Poznań, Poland. She specialises in the issues of social assistance and integration, social work, family assistants, social services. Her research interests include sociology of social problems (disability, ageing, violence), sociology of social work and sociology of social policy. She is a member of Children's Ombudsman Experts Council, the member of the Sociology of Disabilities Section and the member of the Social Work Section of the Polish Sociological Association, and the member of the board of the Polish Association of Social Work Schools. 
Grzegorz Godawa, Professor of the Pontifical University of John Paul II in Cracow, Institute of Pedagogy and Family Studies at the Pontifical University of John Paul II in Cracow. He is interested in the axiological foundations of social life and education as well as in social support. He is a researcher who explores the field of hospice care, particularly its thanatopedagogical dimension. He deals with education on various levels and areas of its implementation. He is the author of more than 80 academic publications.

Pauline Gouttefarde, Auvergne-Rhône-Alpes Gerontology Centre. Mrs Pauline Gouttefarde is a social psychologist specialised in Health Promotion and Education. She is a project manager at Gérontopôle Auvergne Rhône-Alpes. She supports several projects around the aging of the population. Her researches are focused on ageism and its consequences.

Ewa Grudziewska, PhD, Institute of Social Prevention and Social Work at the Maria Grzegorzewska University in Warsaw, Poland. She works at The Maria Grzegorzewska University in Warsaw, at the Department of Social Policy and Social Work. She is an author of articles, editor and co-editor of publications on social work (professionalisation of social workers), rehabilitation pedagogy (probation officers, prisons) and therapeutic interactions for children and adolescents with behavioural disorders. Head of postgraduate studies in judicial and extrajudicial mediation and sociotherapy.

Jessica Guyot, Jean Monnet University, Chair at Senior Citizens Healthcare Prevention Engineering. Mrs Jessica Guyot is a doctor in Education Sciences. She is in charge of the university research for the Aging Health Chair (Jean Monnet University of St Etienne). She is particularly interested in public health, sociology of aging, prevention of loss of autonomy and in ageism.

Malgorzata Halicka, Professor of the University of Białystok, sociologist, gerontologist, Head of the Department of Sociology of Education and Social Gerontology at the Faculty of Education of the University of Białystok. Areas of scientific interest: sociology of older adults, social gerontology, social work; areas of research interest: the quality of life of older people, life satisfaction, educational awareness from a generational perspective, violence against older people. Coordinator of many research projects. Author and co-author of numerous books and scholarly articles in national and international journals.

Jerzy Halicki, Professor of the University of Białystok, social gerontologist, educator, Director of the Branch of the University of Bialystok's in Vilnius, Head of the Department of Andragogy and Gerontology at the Faculty of Education of the University of Białystok. Areas of scientific interest: andragogy, gerontology social gerontology, social work; areas of research interest: intergenerational transition of culture among Polish people in Belarus, the quality of life of older adults, violence against 
older people. Head coordinator of many national and international research. Author and co-author of numerous books and scholarly articles in national and international journals.

Jaroslava Hasmanová Marhánková, $\mathrm{PhD}$, is an assistant professor at the Faculty of Social Science, Charles University. Her long-term research interest focuses of the sociology ageing, gender and sociology of health and medicine. In her latest researches she focused on the topic of intimacy and on the concepts of active aging. She is currently the principal investigator in the project "Social lives of dementia: cultural representations and subjective attitudes."

Bolesław Karcz, PhD, Faculty of Social Sciences, The Pontifical University of John Paul II in Krakow. Member of Polish Familiological Association, Catholic Association of Journalists in Poland (President of the Main Board in 2005-2014), Polish Theological Society, Theological Society in Lviv (Ukraine).

Martine Lagacé, PhD in Psychology, Full Professor, Department of Communication/School of Psychology, University of Ottawa, in Canada. Professor Lagacé was Vice-Dean, Governance at the Faculty of Arts from 2014 to 2018, and Director of the Department of Communication from 2011 to 2012. Her field of interest and research interests center around the psychosocial aspects of aging, particularly the impact of age-based discrimination. In the francophone community, her academic work on ageism has been groundbreaking.

Maria Luszczyńska Ph. D. is Associated Professor at the Department Sociology and Social Work, Social Sciences Faculty, Pontifical University of John Paul II in Krakow. The research areas of interest include social gerontology - the social situation of the older adults and education to old age, counteracting social marginalization or the social experience of passing and death, and intergenerational relations; She is also developing the helping professions professionalisation in Poland, with particular emphasis on the development of social work - development and transformations of the social welfare system, dilemmas of social workers, strengthening of social workers, new methods and techniques in welfare professions (Motivational Dialogue, Solution Focused Approach, Supervision, Local Community Organization, Family Group Conferences, Video Interaction Guidance and other resource-based techniques), preventive measures and inclusive education in the broader social sense. An author of over 30 articles and chapters in gerontology and social work; an expert of the Polish Ministry of Family and Social Policy and other local governmental institutions. Coordinator of the international project Global Aging Research Partnership (GARP). She edited the book Researching Ageing: Methodological Challenges and their Empirical Background, Routledge 2020. 
Agnieszka Neumann-Podczaska, PhD, Ass. Professor, Geriatrics Unit, Chair and Department of Palliative Medicine, Poznan University of Medical Sciences. Poznan, Poland; Expert of the Pharmaceutical Care Team at the Ministry of Health; Awarded by the Council of the Polish-U.S. Fulbright Commission; Discipline: Pharmaceutical Sciences, Research interests: Pharmaceutical care, Drug interactions.

Julia Piel, research associate at the Institute for Social Medicine and Health Systems Research, Faculty of Medicine, Otto-von-Guericke-University Magdeburg and PhD student in the EU-funded research project "Autonomy in Old Age." Her research focuses on aging in close relationship and methods of qualitative research in the fields of critical gerontology, biographical and life span studies.

Klaudia Piotrowska, Master of Social Work, PhD student at the Doctoral School of the University of Szczecin in the field of pedagogy. Research interests focus on gerontology. Employee of a non-governmental organisation that runs the Senior Center. Member of the Polish Society of Gerontology. Doctoral School of the University of Szczecin.

Sébastien Rabier, Jean Monnet University Chair at Senior Citizens Healthcare Prevention Engineering. Mr Sébastien Rabier is a biostatician in the Aging Health Chair (Jean Monnet University of St Etienne). He is specialised in epidemiology and public health. He works on the link between physical activity and the cognitive impairment in aging.

Mariola Raclaw is Associate Professor and sociologist in the Institute of Applied Social Sciences at the University of Warsaw, Poland. Her research interests include sociology of population (among others disability, ageing), sociology of family and sociology of social policy. She is a member of the Government Population Council and the Co-Founder and Vice-President of the Sociology of Disabilities Section of the Polish Sociological Association. Currently, she is engaged in a research project carried out at Warsaw University Policies for independent living in Poland and Norway dealing with personal assistance for people with disabilities, funded by a Norway grant.

Anita Richert-Kaźmierska, Ph.D. Eng., Gdańsk University of Technology Faculty of Management and Economics. Academic research fields: Economics of ageing, Seniors Policy, Social Policies, Regional Polices, Age Management, Entrepreneurship. Coordinator and researcher of several international projects: Best Agers Lighthouses (2012-2014), Age@WorkBuilding Capacity for Age Management in Human Resources (20202021), INBETS Innovative Business Transfer Models for SMEs in the BSR (2018-2021). She is an expert and Member of Senior Policy Council at the Ministry of Family and Social Policy (Council Secretary), Member of the Pomeranian Senior Policy Council (advisory body of the Marshal 
of the Pomeranian Province), Expert in BSLF for Sustainable Working Life - Thematic Working Group Age management and working conditions, Expert of Governmental Program for Seniors' Activation, Ministry of Family and Social Policy, Member of the Gdansk Seniors' Affairs Council (advisory body of the President of the City of Gdansk), Kolbudy Commune Mayor's Proxy for Seniors' Affairs.

Joanna M. Salachna, Professor of legal studies; Professor at Lomza State University of Applied Sciences - Faculty of Social Sciences and Humanities; solicitor (legal counsel); specialised in public finance law and administrative law. Author of nearly 200 research studies.

Anna Szafranek, PhD in Sociology, specialisation: Social Gerontology, adjunct in the Department of Law Sciences, Faculty of Social Sciences and Humanities at the Lomza State University of Applied Sciences, member of the Polish research group within three international projects DAPHNE III covering the topic of violence towards older women, author/co-author of numerous publications in the field of gerontology, laureate in two contests organised by Polish Gerontological Society for the best master degree thesis and $\mathrm{PhD}$ thesis in the field of gerontology and geriatrics.

Zofia Szarota, PhD, Professor at University of Warsaw, Head of the Department of Continuing Education and Andragogy at the Faculty of Education at University of Warsaw. Among her scientific interests there are the issues of adulthood in educational contexts as well as problems accompanying old age and aging. Her research interests focus on the problems of adult learning, social integration, equality as well as social gerontology and geragogy. She is the author of over 140 publications. She is a member of editorial committees of several foreign and country scientific journals. She is also a member of the Polish Academic Andragogical Association and Association of Social Gerontologists as well as an educator at the Universities of the Third Age, lecturer of non-formal adult education. She is the secretary of the Gerontology Section of the Committee of Pedagogical Sciences of the Polish Academy of Sciences (2020-2023). She is a member of the Expert Team for Older Citizens at the Ombudsman.

Celina Timoszyk-Tomczak, PhD, scientific interests: psychology of emotions and motivation, psychology of time, the psychology of aging. Member of the Polish Society of Gerontology, Department of Social Science, Institute of Psychology, University of Szczecin, Poland.

Stawomir Tobis, $\mathrm{PhD}$ (Art), $\mathrm{PhD}(\mathrm{Sci})$, Chair of Occupational Therapy, Poznan University of Medical Sciences, Poznan, Poland; member of Polish Gerontological Society, Polish Psychiatric Society and Association of Polish Art Photographers; Discipline: Health Sciences; Research interests: Older adults, Functional capacity, Cognitive capacity, Art therapy, New technologies in therapy and care. 
Helene von Stülpnagel, a gerontologist and works at the Institute for Social Medicine and Health Systems Research, Faculty of Medicine, Otto-von-Guericke-University Magdeburg in the project "social participation and self-determined aging through participatory social and digital applications in the Kannenstieg district" (STARK). Her research activities focus on aging in urban social space and participatory social research.

Bohdan W. Wasilewski, Prof. Dr hab. med. graduated in 1970 in medicine, worked in the following institutions: Psychosomatic Institute in Warsaw, where he completed specialisation in psychiatry and received the title of Doctor of Medicine; University of Warsaw as deputy head of the Department; Medical University for Postgraduate Studies in Warsaw as head of the Department of Psychosomatics and Sexology and, until now, at the Psychosomatic Institute in Warsaw, as medical director and extraordinary professor. For two years he worked in the Psychiatric Clinic of the University of Munich, he also completed shorter research visits at the University of London, Harvard University and the University of Moscow. He has published 164 papers, he is also the author or co-author of 48 book publications, including books that have been translated into four foreign languages. Bohdan Wasilewski is a member of many scientific societies and an editorial board member in four scientific journals.

Katarzyna Wieczorowska-Tobis, MD, PhD, professor, Geriatrics Unit, Chair and Department of Palliative Medicine, Poznan University of Medical Sciences. Poznan, Poland, President of Polish Gerontological Society, Member of the European Commission Expert Panel on Effective Ways of Investing in Health; Discipline: Medical Sciences; Research interests: Care needs in older individuals, Polypharmacy. 


\section{Introduction}

\section{The challenges facing ageing during COVID-19}

\section{Marvin Formosa and Maria Łuszczyńska}

The COVID-19 pandemic struck like a lightning on a clear sunny day. When reports surfaced on the probability of a new pandemic in the first two months of 2020, the public felt no need for alarm. Many remembered the 2009-2010 H1N1 flu pandemic, which affected an estimated 61 million people, but caused only an estimated 275,000 hospitalisations and 12,500 deaths, and failed to entrench itself in most countries (Centers for Disease Control and Prevention 2009). Such a reaction could not be farther away from the future situation as the COVID-19 pandemic proved to be a totally different matter. Its rate of transmission was incredibly contagious and its death rate amongst older persons was extremely high. Hopes that COVID-19 will not break out from China were soon confounded as it ravaged Northern Italy and brought hospitals and intensive care units in this region to breaking point. In a matter of weeks, other countries registered thousands of cases and an approximately $3.5 \%$ mortality rate when this figure for $\mathrm{H} 1 \mathrm{~N} 1$ flu pandemic was solely $0.2 \%$ (Baldo et al. 2016). It is therefore understandable that since mid-2020 the scholarly arena has been now awash with policy reports and empirical research focusing on the aetiology and the wide-ranging economic, social and psychological impacts of the COVID-19 pandemic (Kumar \& Dohle 2020; Lupton \& Willis 2021; Riegelmen 2020).

\section{COVID-19 and the life course}

COVID-19 brought an end to the world as we know it, and affected everyone, irrespective of one's position in the life course (Azzopardi et al. in press). For instance, at the start of the pandemic women who did not have a negative swab test were separated from their babies following birth (Vassallo 2020). However, following the publication of a study on pre-term care during the COVID-19 pandemic (Minckas et al. 2021), the World Health Organization (WHO) provided guidance that even mothers who were COVID-19 positive should not be separated from their babies and be encouraged to breastfeed (World Health Organization 2021). The experience of birthing partners was also negatively impacted by the restrictions imposed as a result of an upsurge in COVID-19 cases. In Malta, for instance, while partners were 
allowed to be with the mother during birth, they could then only visit for one hour a day (Calleja 2021). School closures impaired academic learning and resulted in loss of connection with friends and teachers with implications for overall wellbeing (Engzell et al. 2021). As online lessons at home became the norm, children also found themselves increasingly exposed to exploitation and online bullying (United Nations Children's Fund 2020). School closures added a layer of stress for parents, especially those of young children. Online schooling increases the difficulties of balancing work and family life, and in some cases, was engaged within a context of increased economic difficulties. Some researchers have alerted that this may result in children being more vulnerable to abuse and violence, with some predicting an increase in the risk of the maltreatment of children (Abramson 2020; Griffths 2020). Brooks and colleagues recently reported that parents had more conflicts with their children during the pandemic (Brooks et al. 2020). Moreover, child maltreatment may have been underreported during lockdowns due to social welfare workers having less contact with children and their families, and as protective interventions which in the pre-pandemic situations were normal became unavailable (Riegelmen 2020).

The COVID-19 pandemic is not devoid of gender and ageing trends. Since women perform over $75 \%$ of all of the world's unpaid work (International Labour Organization 2018), it was unsurprising that Matthewman and Huppatz found that women scholars were unable to conduct as much research due to caring for relatives with the virus and with schools and childcare centres being closed (Matthewman \& Huppatz 2020). Job losses due to COVID-19 impacted more women than men since their jobs are generally in sectors which were affected extremely negatively by lockdown and social distance measures (Crabb 2020). One study found that 'women faced greater odds of loneliness than men, but only among the youngest adults, who were the age group at highest risk of loneliness, and among the oldest adults, who were the age group at lowest risk of loneliness' (Wickens et al. 2021: 106). Another group who experienced further vulnerability as a result of the health crisis included persons experiencing domestic violence as incidences of abuse between partners increased during the COVID-19 pandemic (Bradbury-Jones \& Isham 2020). Unfortunately, home is not a safe space for all and being 'confined' to a violent space with no reprieve or escape as well as the exacerbation of the perpetrator's violent behaviour has led to increased incidence of domestic violence. A frequently cited reason for the rise in rates of domestic violence was that the restrictions safeguarding our health due to the pandemic meant that more people had to stay home (Azzopardi et al. in press). Setting the lens on ageing, it is striking that nearly nine out of ten COVID-19 related deaths reported in the wider European region have been among adults aged 65-plus (United Nations Economic Commission for Europe 2020). Although all age groups are at risk of contracting COVID-19, older persons are at a significantly higher risk of mortality and severe disease following infection, with those over 80 years old dying at five 
times the average rate (Clarke et al. 2020). COVID-19 did not only take a destructive toll on the lives of many older people but exposed long-standing and wide-ranging ageist stereotypes and prejudice. For example, while in the United Kingdom adults aged 70 and older were initially instructed to self-isolate for four months (Paton 2020), in Bosnia and Herzegovina older adults were not allowed to leave their homes for several weeks during the outbreak (Cerimovic et al. 2020) Such impacts of COVID-19 on the lives of older persons were key instigators to the conceptualisation, planning and writing of the chapters herein in this manuscript.

\section{Contributions of the book}

Ageing and COVID-19: Making sense of a disrupted world is another attempt at seeking to understand the impacts of the COVID-19 pandemic on older persons and how public authorities and older people themselves reacted to the pandemic. While it certainly includes some overlap with other literature, this book contributes to ongoing discussion and research in four key ways.

First, and perhaps most importantly, the book includes many chapters which focus on non-English speaking countries (e.g. parts of Canada, Czech Republic, France, Germany and Poland) that generally flew under the radar as far as policy and empirical studies on COVID-19 were concerned. The fact that the book does not include contributions from English-speaking countries is a positive approach in the efforts to de-colonise academic literature. The perils of globalisation biases and neo-liberal hegemony are really testing the established ethos and vision of COVID-19 related literature which is running the risk of experiencing academic imperialism, by being dominated by Western philosophies and modes of practice, and Eurocentric hegemonies as a way of knowing, seeing and understanding the pandemic. Such waves of ideological domination are both hidden and expressed, as they seek to reinforce past and present superiorities of Western social systems over others. This book counters such trends by focusing on Continental European trends in the experience of the COVID-19 pandemic together with one exposition on the island state of Malta.

Secondly, the book provides much focus on social isolation, loneliness and ageism to throw further light on how older persons living in the community or care facilities felt the brunt of the COVID-19 pandemic. Although in pre-COVID-19 times, social isolation and loneliness in later life were already public health issues gaining international recognition as being detrimental to quality of life, the pandemic showcased disparate impacts on societies' most vulnerable populations due to social exclusion. The negative impacts of such experiences on physical and mental health have been incessantly acknowledged in research studies, with some scholars going as far as to state that loneliness and social isolation amongst older persons during the pandemic can be comparable to physical malnutrition. At the same time, COVID-19 did not only take a destructive toll on the lives of many older 
people but has also exposed many ageist stereotypes and prejudice. During the pandemic, there have been many reports of discriminatory practices in access to health services and other critical care resources, especially among older people living in residential long-term care facilities.

Third, some chapters focus upon that interface between dementia care and COVID-19 by providing a more comprehensive understanding of how the pandemic has impacted people living with dementia, their families, informal carers, formal care provision and dementia care systems. Authors highlight how in the scramble of public health authorities, to limit virus transmission via social distance measures and work-from-home strategies, the needs of older persons with dementia and their informal carers were left out in the cold. The fact that dementia day-care centres were closed imposed persons living with dementia to stay at home without any form of premeditated support care. However, on a positive note one finds that many non-governmental and professional organisations have released a number of expert recommendations and key advice on how to provide mental health and psychosocial support for persons living with dementia. Moreover, many multidisciplinary teams started counselling services free of charge for people living with dementia and their carers to minimise the complex impact of the COVID-19 outbreak on dementia care.

Fourth, the book highlights how care technologies - ranging from telephone operating systems to online learning - have become part of the 'new normal' in health and social care of older people since the COVID-19 pandemic. Care technologies have certainly played an important role in this context of health crisis as they were mainly used by social and health care professionals to communicate with the families of patients and to enable patients to get in contact with their families. This was especially the case in acute and long-term care institutions. It results that the telephone was the most used communications tool, followed by videoconferencing, and finally, telemedicine. Such communication tools playing an essential role in maintaining a relationship and open line of communication between social and health care professionals, other professionals, relatives, patient and residents in nursing homes. Yet, difficulties persist, particularly with regard to using these technologies and the presence or absence of functional equipment, to the extent that virtual communications can never compensate for the lack of direct physical and face to face contact.

Finally, the book also addresses the long-standing digital divide between younger and older persons, as well as within the older cohorts themselves. It highlights how digital literacy and inclusion is not just about being online, but also about using the internet skilfully and with confidence. Since the very beginning of the lockdown, the gap between those with good and available internet connection, and between those owning electronic devices and others lacking such tools (which have suddenly become essential goods), was apparent. It therefore advocates that good practices for digital competency in later life require making provisions for older persons who are not 
yet online by ensuring that in the event of future lockdowns one finds ways of directly contacting them, ensuring that technology is age-friendly so that hardware and software can be used by as many people as possible regardless of educational background, and expanding access to broadband, data packages and computer packages, particularly for individuals and families on low incomes who are most likely to be digitally excluded.

\section{Chapters outline}

Ageing and COVID-19: Making sense of a disrupted world includes 19 chapters with Introduction and Conclusion that react to the impact of the COVID-19 pandemic on older persons, especially the reaction of governments to institute lockdown and social distance measures to battle the rising tide of infection and deaths on wellbeing in later life. It discusses the myriad implications related to ageing and the lifeworlds of older people, as their lives seemed to be suspended, and as the international media, social media, and public health officials framed 'older persons' as a homogeneous and vulnerable group - thus, conflating physical impairments common in later life with chronological age. The chapters address a broad span of topics on the range of impacts and challenges faced by older adults, whilst addressing the negative health, psychological and social outcomes on wellbeing in later life. The book is divided into three parts.

Subsequent to the book's introduction, the first part, titled 'COVID-19 as the unknown', includes three chapters. The opening chapter, 'The phenomenon of the COVID-19 pandemic against the background of its era' (Bohdan W. Wasilewski), presents an analysis of the phenomenon of the COVID-19 pandemic, with particular emphasis on the reference to the contemporary moral fabric, its way of understanding the surrounding phenomena, and underlying motivations for taking policy actions. Chapter 2, 'COVID-19 lockdown and social distance measures: A "perfect storm" for social isolation and loneliness in later life' (Marvin Formosa), brings the spotlight on the impact of COVID-19 on loneliness and social isolation in later life by highlighting that although lockdown and social distance measures certainly put many things to rest, and battered many a socio-economic realm, their most devastating impact was certainly on older persons. Chapter 3, 'Death and dying vs. COVID-19: A hermeneutic approach towards understanding the social process' (Maria Łuszczyńska), undertakes a hermeneutic analysis of the phenomenon of death and argues that while death is a universal experience of the human condition, one finds new social processes of society's attitude to death in the era of the COVID-19 pandemic.

The second part is titled 'Social attitudes and strategies'. Chapter 4, 'Unmasking features of the state of the epidemic: What is the uniqueness of the position of older people in Poland?' (Dobroniega Głębocka and Mariola Racław), discusses the politicised nature of the epidemic which was associated with a strong medicalisation of various areas of social life. Chapter 5, 
'Ageing and ageism in COVID-19 time' (Grzegorz Godawa), highlights how during the pandemic chronological 'age' took on a new meaning as older adults became particularly prone to infection, and consequently, certain words and behaviours which discriminate against older adults were uncritically endorsed in different areas of life. Chapter 6, 'Age division and ageism in the public debates regarding COVID-19: Intergenerational solidarity and antagonisms in the era of the coronavirus pandemic' (Jaroslava Hasmanová Marhánková), elaborates on the fact that although COVID-19 was presented in the national media as 'the disease of the old, which mercifully omits children', our current knowledge regarding the effects of this disease does not change the chronology of life and death. Chapter 7, 'Older adults' coping strategies in a pandemic situation: A Polish case study' (Celina Timoszyk-Tomczak, Beata Bugajska, Klaudia Piotrowska), signals how older people dealt better with the pandemic than younger ones, and identify key emotional responses and strategies of coping with stress on the behalf of older people. Chapter 8, 'Support for older adults during COVID-19: How did local authorities in the Pomeranian region respond to the challenge?' (Anita Richert-Kaźmierska), identifies and classifies the forms of support that local authorities in the Pomeranian Region offered to older adults during the first stage of lockdown.

The third part is titled 'Social life' and includes six chapters. Chapter 9, 'Geragogy of everyday life in Poland: The COVID-19 perspective' (Zofia Szarota), describes how during the time of pandemic confinement, social quarantine and official self-isolation orders increased the feeling of loneliness among older persons and resulted in depressed moods, and anxiety and depression ailments, and questions whether relationships and perceptions of values may have as a result changed in later life. Chapter 10, 'Online learning for older persons during the COVID-19 pandemic in Malta: The good, the bad, and the ugly' (Marvin Formosa), reports on a qualitative research study at the University of the Third Age in Malta which, during the COVID-19 pandemic, ceased all its classroom-based education, and adopted an online learning strategy. Chapter 11, 'Grandparents raising grandchildren during coronavirus pandemic: A challenge or a threat?' (Joanna Borowik), discusses how grandparents found themselves in a particularly difficult situation during the pandemic as they struggled with the consequences of being cut off from the surrounding world, but also with fears resulting, among others, from being at most risk to die from the virus. Chapter 12, 'Ambivalence and future perspectives of older people: Critical reflection on the intertwining of diverse life experiences in East Germany during COVID-19' (Helene von Stülpnagel, Julia Piel and Astrid EichKrohm), elaborates upon how the experiences with life in East Germany and during the years of unification could help citizens to better understand and classify the events during the pandemic and offer them a frame of reference and orientation during these times. Chapter 13, 'The experience of loneliness in older adults during the COVID-19 Pandemic: A Polish perspective' 
(Ewa Grudziewska), researched the extent that Polish older persons coped with loneliness during the COVID-19 pandemic and presents the determining factors in augmenting or decreasing their sense of solitude. Chapter 14, 'Older adults' religiosity during the COVID-19 pandemic: Catholic Church in action' (Bolesław Karcz), deliberated how a sense of belonging in the Roman Catholic and other community organisations, manifested in membership and shared responsibility, impacted the daily lives and wellbeing of older persons.

The fourth and final part is titled 'Social care and support' and includes six chapters. Chapter 15 , 'To care or not to care? What have we learned from COVID-19 about our attitudes toward older adults?' (Linda Garcia, Louise Bélanger-Hardy and Martine Lagacé), exposed how the COVID-19 pandemic unveiled some of humanity's finest moments of empathy and solidarity, but also the darker side of human conduct as one witnessed the rise of hate speech, targeting of vulnerable groups and risks of heavy-handed public health responses. Chapter 16, 'Institutional care for older people in Poland during pandemic: Regulations, practice and thoughts about the future' (Joanna M. Salachna and Anna Szafranek), demonstrates how the new realities exposed by COVOD-19 engendered systemic imperfections with regard to institutional care, with particular impacts on frail older persons within such facilities. Chapter 17, 'Internet-telephone consultation service for older persons' (Tobis Sławomir, Katarzyna Wieczorowska-Tobis and Agnieszka Neumann-Podczaska), focuses on how tele-systems and technologies provided a valuable therapeutic service for older person as they were unable to leave their homes. Chapter 18, 'Everyday reality at nursing home care facilities in Poland: Experiences during the COVID-19 pandemic' (Małgorzata Halicka, Jerzy Halicki and Krzysztof Czykier) presents the opinions of the residents in a nursing home regarding their personal experiences as the COVID-19 pandemic affected their daily routines and usual care services. Chapter 19, 'Feedback from nursing staff in gerontology: Health reorganisation acceptance related to COVID-19 crisis' (Chloé Gaulier, Pauline Gouttefarde, Sébastien Rabier, Vincent Augusto, Caroline Dupré, Solène Dorier, Jessica Guyot and Nathalie Barth), focuses on the forced major reorganisation of care in France following the pandemic, as formal caregivers in facilities caring for older persons underwent disproportionately more changes in their work, which led to a range of difficulties that required significant adaptation efforts on their behalf.

The final chapter, 'Conclusion: ageing, COVID-19 and 'new normality' (Maria Łuszczyńska and Marvin Formosa) brings the book to a close by highlighting the salient parts of the chapters in the book, whilst recommending possible future pathways to safeguard the physical, emotional and social wellbeing of older persons both during the COVID-19 pandemic and in post-COVID 'new normality'.

This publication is international in character and constitutes part of the project known as the 'Global Ageing Research Partnership'. The project is funded 
by the Polish National Agency for Academic Exchange (NAWA) within the International Academic Partnerships programme. The project partners include the following: the Pontifical University of John Paul II in Kraków (Poland), the project leader; the University of Applied Sciences Upper Austria (Austria); Jean Monnet University (France); the LIFE Research Institute, University of Ottawa (Canada); and the Sau Po Centre on Ageing, Hong Kong University (Hong Kong). Gratitude also goes to the authors who contributed to this book from Malta, the Czech Republic, Germany and France.

The book commenced at a time when COVID-19 transmission was at its very beginning although it was already known that older adults were particularly vulnerable to its possible negative and mortal impacts. The intention of the editors and authors was to throw light on those social phenomena affecting older persons in relation to the COVID-19 epidemic, which were already visible even from the first few weeks of the pandemic. Hence, the extensive thematic range of individual chapters and thus the richness of content. We believe that more rigorous analysis of the impact of COVID-19 on the daily lives of older persons - whether regarding the health, legal, economic or psychosocial consequences - will emerge in the foreseeable years and that this book will act as one key piece in a complex jigsaw puzzle.

In conclusion, on our and author's behalf and authors we would like to thank our publisher, Taylor \& Francis, for their openness to our idea for the book and for the trust that they showed throughout the entire process of creating and publishing this volume. We would particularly like to thank Neil Jordan, Senior Editor with Routledge, for demonstrating such care for the quality of this publication at every stage of its development. We would also like to thank the many others at the publishing house who have worked on this book. We are also expressing our gratitude to all those important people in each of our lives who, by providing daily support, mobilise us for work and for indefatigable exploration of our suspended lives.

It is our hope that all readers will find in this publication a source of inspiration and encouragement for working to change the situation of older people in the social communities, because the changes that we are able to make now will lay the groundwork for a better experience of ageing for future generations - including ourselves.

\section{References}

Abramson, A., How COVID-19 may increase domestic violence and child abuse, American Psychological Association, Washington, DC, 2020. https://www.apa. org/topics/covid-19/domestic-violence-child-abuse

Azzopardi, A., Clarke, M., Formosa, M., Psaila, C., Suspended lives? The impact of COVID-19 across the life course, Social Studies in Wellbeing, in press.

Baldo, V., Bertoncello, C., Cocchio, S., Fonzo, M., Pillon, P., Buja, A., Baldovin, T., The new pandemic influenza A/(H1N1)pdm 09 virus: is it really 'new'? Journal of Preventive Medicine and Hygiene, 57 (1)/2016, p. e19-e22. 
Bradbury-Jones, C., Isham, L., The pandemic paradox: the consequences of COVID-19 on domestic violence. Journal of Clinical Nursing, 29 (13-14)/2020, p. 2047-2049.

Brooks, S.K., Webster, R.K., Smith, L.E., Woodland, L., Wessely, S., Greenberg, N., Rubin, G.J., The psychological impact of quarantine and how to reduce it: rapid review of the evidence. Lancet, 395 (10227)/2020, p. 912-920. https://doi.org/ 10.1016/S0140-6736(20)30460-8

Calleja, L., COVID hospital rules are creating anxiety for fathers and mothers alike, MaltaToday, 2021. https://www.maltatoday.com.mt/news/national/108337/ covid_hospital_rules_are_creating_anxiety_for_fathers_and_mothers_alike\#. YKOc16gzY2w

Centers for Disease Control and Prevention, 2009 H1N1 Pandemic (H1N1pdm09 virus). Centers for Disease Control and Prevention, Atlanta, GA, 2020. https:// www.cdc.gov/flu/pandemic-resources/2009-h1n1-pandemic.html

Cerimovic, E., Wurth, M., Brown, B., Bosnia and Herzegovina's coronavirus curbs on children and older people are ill-conceived. Balkan Insight, Belgrade, Serbia, 2020. https://balkaninsight.com/2020/04/02/bosnia-andherzegovinas-coronaviruscurbs-on-children-and-older-people-are-ill-conceived/

Clarke, A., Jit, M., Warren-Gash, C., Guthrie, B., Wang, H., Mercer, S. W., Sanderson, C., McKee, M., Troeger, C., Ong, K.L., Checchi, F., Perel, P., Joseph, S., Gibbs, H.P., Banerjee, A., Eggo, R.M., Centre for the mathematical modelling of infectious diseases COVID-19 working group (2020). Global, regional, and national estimates of the population at increased risk of severe COVID-19 due to underlying health conditions in 2020: a modelling study. The Lancet, 8 (8)/2020, p. e1003-e1017. https://doi.org/10.1016/S2214-109X(20)30264-3

Crabb, A., Coronavirus has left Australian women anxious, overworked and insecureWorse off than men again, ABC News (Australia), Sydney, Australia, 2020. https://mobile.abc.net.au/news/2020-05-24/coronavirus-has-set-back-progressfor-womenworkplace-equality/12268742

Engzell, P., Frey, A., Verhagen, M. (2021). Learning loss due to school closures during the COVID-19 pandemic. Proceedings of the National Academy of Sciences, 118 (17)/2021, e2022376118. https://doi.org/10.1073/pnas.2022376118

Griffths, A.K., Parental burnout and child maltreatment during the COVID-19 pandemic. Journal of Family Violence, 23/2020, p. 1-7. https://doi.org/10.1111/ jocn. 15296

International Labour Organization. Care work and care jobs for the future of decent work, International Labour Organization, Geneva, Switzerland, 2018. https:// www.ilo.org/wcmsp5/groups/public/---dgreports/---dcomm/---publ/documents/ publication/wcms_633135.pdf

Kumar Koley, T., Dhole, M., The COVID-19 pandemic: the deadly coronavirus outbreak. London, Routledge, 2020.

Lupton, D., Willis, K., (eds), The COVID-19 crisis: Social perspectives. New York, Routledge, 2021.

Matthewman, M., Huppatz, K., A sociology of COVID-19. Journal of Sociology, 56 (4)/2020, p. 675-683.

Minckas, N., Medvedev, M.M., Adejuyigbe, E.A., Brotherton, H., Chellani, H., Estifanos, A.S., Ezeaka, C., Gobezayehu, A.G., Irimu, G., Kawaza, K., Kumar, V., Massawe, A., Mazumder, S., Mambule, I., Medhanyie, A.A., Molyneux, E.M., Newton, S., Salim, N., Tadele, H., Tann, C.J., ... COVID-19 small and sick 
newborn care collaborative group. Preterm care during the COVID-19 pandemic: a comparative risk analysis of neonatal deaths averted by kangaroo mother care versus mortality due to SARS-CoV-2 infection. EClinicalMedicine, 33/2021, 100733. https://doi.org/10.1016/j.eclinm.2021.100733

Paton, C., Coronavirus UK: elderly to be isolated for four months as part of COVID-19 plans. The National, Abu Dhabi, 2020. https://www.thenationalnews.com/world/ europe/coronavirus-uk-elderly-to-be-isolated-for-four-months-as-part-ofcovid19-plans-1.992514.

Riegelmen, R., COVID-19 lessons learned: Interactive case studies. Burlington, MA, Jones \& Bartlett Learning, 2020.

United Nations Children's Fund, COVID-19 and its implications for protecting children online. New York, United Nations Children's Fund. https://www.unicef.org/ documents/covid-19-and-implications-protecting-children-online

United Nations Economic Commission for Europe, Policy brief: older persons in emergency situations. Geneva, United Nations Economic Commission for Europe, 2020. https://unece.org/fileadmin/DAM/pau/age/Policy_briefs/ECE_ WG1_36_PB25.pdf

Vassallo, C., Mothers in Malta are being separated from their newborns because of COVID-19, even if experts say otherwise, LovinMalta, Malta, 2020. https://lovinmalta.com/news/mothers-in-malta-are-being-separated-from-their-newbornsbecause-of-covid-19-even-if-experts-say-otherwise/

Wickens, C.M., McDonald, A.J., Elton-Marshall, T., Wells, S., Nigatu, Y.T., Jankowicz, D., Hamilton, H.A., Loneliness in the COVID-19 pandemic: associations with age, gender and their interaction. Journal of Psychiatric Research, 136/2021, p. 103-108.

World Health Organization, New research highlights risks of separating newborns from mothers during COVID-19 pandemic, Geneva, Switzerland, 2021. https:// www.who.int/news/item/16-03-2021-new-research-highlights-risks-of-separatingnewborns-from-mothers-during-covid-19-pandemic 


\section{Part 1}

\section{COVID-19 as the unknown}



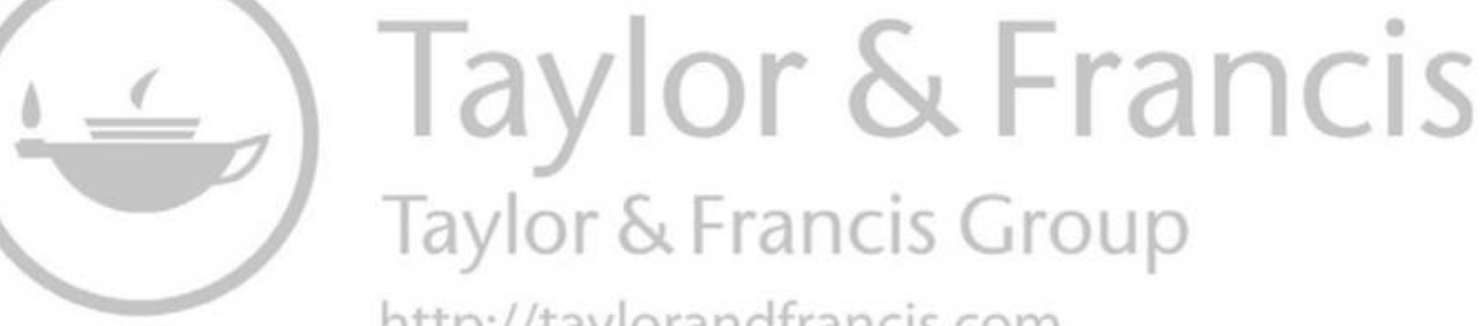
http://taylorandfrancis.com 


\title{
1 The phenomenon of the COVID-19 pandemic against the background of its era
}

\author{
Bohdan W. Wasilewski
}

The main idea behind this chapter combines the concepts of ageing and COVID-19. This chapter covers a wide range of issues concerning older persons confronted with the COVID-19 pandemic, covering a wide range of different scientific disciplines, including philosophy, sociology, psychology, medicine, and cultural studies. It also presents an equally broad coverage of the COVID-19 phenomenon, which, despite the flood of publications on the subject, is still a sparsely covered area in the international literature.

\section{Introduction}

At the beginning, I would like to add a disclaimer as the author, that I consciously raise a number of sensitive topics that deviate from the usual views. The chapter is of a working nature, its main purpose is to provide material and stimulate constructive discussion, including in the area of omitted topics or conclusions. The author is of the opinion that the current situation forces for a more effective and open discussion, a constructive dispute, in which opposing views often intersect, in order to consolidate the actions necessary for our survival as a species and survival of the planet. Therefore, I do not treat any of the presented views as the only truth, I ask the readers only to assume that my intentions are positive when I proclaim these views.

The goal which the editors of this book, dealing with older adult agerelated issues, set for the author as a physician and a psychotherapist was to elaborate an introductory chapter covering analysis of the phenomenon of the COVID-19 pandemic, with particular emphasis on the reference to the mentality of the epoch, its way of understanding the surrounding phenomena and motivation for taking further action.

Percentage of people over 60 years of age in the general population of Poland is growing rapidly. According to the forecast of the Polish Central Statistical Office it will amount to: in $2013-14.7 \% ; 2020-18.9 \%$; $2035-24.5 \%$; $2035-32.7 \%$, which will be accompanied by a decrease in the size of the 
general population and a significant decline in the number of young people who traditionally provided care for older family members in the country. If this is supplemented with a high emigration rate of young people and an unfavorable change in their attitudes regarding the obligation to care for older family members, a full picture of the disadvantageous situation is obtained.

\section{Why has COVID-19 appeared?}

The changes described above, due to the acceleration of the process of civilization changes, are taking place at a very fast pace, which is not followed by the necessary adaptation of the organizational structures of the medical care system, the social welfare system, and the creation of the necessary infrastructure for effective care for the older adults, which will result in a significant percentage of people older people being handicapped in their ability to maintain the quality of health. They will therefore be particularly vulnerable to COVID-19 and other infectious diseases. This view is supported by the analysis of the current course of the COVID-19 pandemic published by the Polish Society of Epidemiologists and Doctors of Infectious Diseases (Flisiak 2021), which includes detailed information on Poles who died due to COVID-19. The reports were prepared on the basis of data from the SARSTer database (as of January 26, 2021) http://www.pteilchz. org.pl/. The data included in this report show that in Poland, 36,780 people died due to COVID-19 in the analysed period, with as much as $94.5 \%$ of COVID-19 fatalities in Poland comprising people over 60 years of age, and almost one-fourth of those who died (22.6\% to be exact) were over 80 .

The COVID-19 pandemic not only hit the older adults right, it also hit the social fabric, institutions, and economic relationships that support them. Acceleration of the progress of civilization with progressive intellectual and physical impairment changes in older people, both related to the progressive aging process, chronic diseases, and the increasing incidence of degenerative brain diseases, causing the growing problem of social exclusion, alienation, and the occurrence of depressive disorders. The large scope of the discussed phenomena makes them one of the main challenges of the post-industrial era in all spheres, including economic, social, moral, and medical.

In the phenomenon of the COVID-19 pandemic, the author distinguishes between a group of medical and biological issues and a group of economic and social issues. Both groups take part in the global civilizational crisis related to the breakthrough of the industrial and post-industrial era and the accumulation of negative consequences of extensive development during the industrial era. The author presents the view that the COVID-19 pandemic is one of the consequences of the industrial era and only a catalyst for the intense phase of the global crisis.

In his previous publications on mental barriers impeding the comprehensive capturing of the COVID-19 pandemic phenomenon (Wasilewski 2020a, 2020b, 2021a), the author pointed out the difficulties in capturing 
the full picture of this phenomenon, which requires a synthetic view taking into account the point of view of various specialties. The problem is the current fragmentation of science into very many hermetic detail-oriented sciences and development of specializations and subspecialisations operating within their own language and their own conceptual and terminological systems, often inconsistent with other specializations. At the same time, despite the technological efficiency of detailed sciences in the selected areas, the perception of the world, which is maintained, is often distant from the present day. Still the dominant understanding of the human being within the in Western civilization is one of a privileged being, different from others, endowed with an immortal soul and distinguished by the ability to think, destined to rule the world. Whereas, progress in biological sciences proves that a man is the same multicellular colony as other living organisms on our planet and is an integral part of the biocenosis, the living surface layer of our planet. Despite many elements of autonomy in moving and acting, man is not able to live independently when cut off from other elements of the living organism, i.e., the biocenosis integrated into an ecosystem with the surrounding biotope.

The COVID-19 pandemic was not an unpredictable incident that unexpectedly disrupted the functioning of a well-operating machine of civilization. The COVID-19 from 2020, compared to its predecessor SARS from 2003 , is in total less deadly, although identical in origin and very similar in structure, and it gives an infected person a greater chance of survival. The secret lies in the 2-4-day latency in the manifestation of disease symptoms, when we infect others without having disease symptoms, and the frequency of asymptomatic or poorly symptomatic courses of the disease during which the carriers infect hundreds of people (Steenblock et al. 2020). Another distinguishing feature of COVID is the significant increase in the number of chronically ill patients with diseases resulting from the course of COVID infection in the respiratory, digestive, and nervous systems. At the outbreak of the pandemic the industrial-era civilization, which dates back to the second half of the 18th century, had already lost its functionality and stability as a result of extensive use of natural resources, including human health. It boasted that it had significantly prolonged human life, but it did so at the expense of its quality (Wasilewski 2018, 2020c). Humans, as an intrinsically integral element of the living layer of our planet (biocenosis, biotope), has been torn from it, and the parent biotope has been severely mutilated. In order to breathe, the human being needs to be supplemented with green lungs, besides, they are closely integrated with the biocenosis in many other areas necessary for survival and is a transfer element of the uninterrupted flow of matter and information exchange, which is the basis of the functioning of the ecosystem.

Human activities in the last 150 years of the industrial era led to a critical disturbance in the functioning of the ecosystem, to the extent that forced its deep reset in the form of the sixth phase of mass extinction of 
species, including the initiation of extinction of humans as a species. Due to the close functional connection of all elements of the biocenosis, its mutilation affects all its elements, including humans. This is most evident in the human population of the Western civilization, the most advanced of the industrial age. The humans of this civilization have largely lost the ability to exist independently, their biological and psychological functioning requires constant support. The degree of human mutilation determines the degree of decrease in human immunity to infections by viruses with which they have lived for millions of years of development. The factual picture of the biocenosis of which man is an element and the biocenosis of every human body significantly differs from the commonly accepted anthropocentric worldview (Wasilewskie 2020a, 2020b, 2020c). The anthropocentric understanding of the world, as discussed earlier, does not allow us to notice a rapid reduction of areas with a rich biosphere that allows for a full-fledged human existence and a rapid depletion of its composition, which is caused by human activity. For the same reason, we see the coronavirus only as a factor alien to our environment, as an enemy that appears unexpectedly and is an instrument of unethical warfare, which we must destroy in order to restore our original way of functioning. The imaginative, monumental image of a man - the Master of Nature, does not allow for the awareness that we are only a mega cell colony, similarly to the other creatures with a cellular structure that surround us and inhabit the biocenosis in which we are part. The anthropocentric view of the world denies the ability to think, feel emotions, fight for survival, even to the closest evolutionarily animals - mammals, massively bred and killed as part of the industrial process of producing food that is our food. For analogical reason the group of subcellular organisms, which are predominant in the animate nature in terms of quantity, and include viruses, viroids, phages, prions, and a number of other integral micronutrients of our biocenosis and our organism, are not included as parts of the living world. The human body contains fewer of its own cells than bacterial cells, the number of which is more than ten times greater than the number of subcellular organisms in our bodies. These micro-organisms reach the interior of our body without major obstacles. The average human body transcytoses $3.1 \times 10^{10}$ phages per day through the membranes of our body cells, and it is believed that this continuous stream of endogenous phages spread through the blood and organs is involved in providing us with antibacterial and antiviral protection (Górski 2020; Nguyen et al. 2017). Each human organism has a specific constellation of phages residing in it, currently we have little information on the factors determining the composition and interaction of phages in the human organism. We know that phages can penetrate lung epithelial cells, protecting against viral infections, and the competitive activity of phages against angiotensin-converting enzyme II (ACEII), which is a target for SARS-CoV and SARS-CoV-2 coronaviruses (Górski 2020; Wasilewski 2010). 


\section{COVID-19 and the human immune system}

At this point, I would like to explain the reasons for a wider discussion of the issues related to the relationship between the COVID-19 pandemic and the functional state of the microbiome - the flora of microbes living in our body. It is related to the view that the microbiome disorder is the basic factor opening the gate that prevents infection. So, if a systemic damage to our immunity is the cause of the current SARS-CoV-2 pandemic, then fighting it will only stifle the pandemic until the next offensive pathogen appears. The functional state of our body's microbiome is closely related to the state of the microbiome of the surrounding biocenosis, the balance of which has also been disturbed. There is a very significant backlog of research into the microbiome, which has made us powerless when confronted with epidemic threats of the magnitude conditioning our survival as a species (Wasilewski 2021a). Within the biotope the human body constitutes a transit element of an uninterrupted stream of exchange of both building elements, that constitute the elements of biocenosis, and information-related material in many ways of transmission. Civilization of the industrial era led to discontinuation or unfavorable modification of this transfer and disturbed our immunity. The framework of the present publication does not allow for a more extensive discussion of this topic. Other publications by the author (Wasilewski 2014, 2018, 2020c) can be referred to for this topic.

The situation at present is worsened by the failure to adequately conduct research to develop new antibiotics and the therapeutic use of phages (Górski 2020; Nguyen et al. 2017). Due to the significant investment risk related to the development of a new antibiotic at a cost of one billion dollars, where resistance to it can develop after several years of use, only a few companies continue to implement them, and to a limited extent. This resulted in a situation in which Carbapenems, the last implemented group of antibiotics - detected as a defense substance of one of the soil bacteria were implemented for treatment 36 years ago. Antibiotics from this group are treated as a last resort drug and should be protected against unjustified use, in accordance with WHO regulations. Meanwhile, their main method of use is massive preventive application in industrial farms for the production of slaughter meat, which, as it has been known for many years, leads to the creation of new antibiotic-resistant bacterial strains. In countries aware of the threat of this problem, the preventive use of last-resort antibiotics was banned in industrial farms for the production of slaughter meat, which, unfortunately, is prevalent in a number of Western countries, including Poland. Antibiotic resistance, according to estimates of the Organization for Economic Co-operation and Development, may cause 700,000 deaths worldwide (quoted after the Polish Supreme Audit Office's report of 2017/2018) (Polish Supreme Audit Office's report of 2017/2018). In 2011-2014, the use of antibiotics in agriculture increased by $23 \%$, and Poland ranks second in Europe in terms of the use of the most potent antibiotics in animal 
husbandry in the treatment of human diseases. The results of screening tests in the field of antibiotic resistance carried out by the Sanitary Inspection bodies are disturbing. Resistance to antimicrobial drugs was found in $25 \%$ of samples of poultry meat, $15 \%$ of beef, and $10 \%$ of pork (quoted after the Polish Supreme Audit Office report of 2017/2018) (Polish Supreme Audit Office's report of 2017/2018). The first case of total resistance to antibiotics was observed in Asia in 2011, and after a short time also in other areas, including Poland in (2011). It mainly refers to a New Delhi Superbacterium, which is the colloquial name of Klebsiella pneumoniae NDM - pneumonia rod, which belongs to the group of intestinal bacteria. The New Delhi bacterium is responsible for life-threatening pneumonia, inflammation of the urinary and digestive systems, meningitis, and many other diseases. Very often it causes sepsis, which ends in the death of every second patient. In Poland, the disease appeared in hospitals in 2011 in Warsaw, and again in 2012 in a hospital in Poznań. However, hospitals did not take appropriate precautions (e.g. infected people were not isolated, which is a necessity) and patients infected each other while wandering between wards. Consequently, in a short time the number of infected began to increase rapidly. According to the data of the National Reference Center for Antimicrobial Susceptibility, in 2013 there were 105 infected people across the country, and in April 2016 this number was 1,100 , most of them in Warsaw. However, these figures are underestimated and there are certainly many more infected. As an indication of its destructive progress, the New Delhi bacterium was detected in a patient of the Department of Cardiac Surgery and Vascular Surgery after a heart transplant on the night of July 22-23 in 2018.

The gene for resistance to colistin (an antibiotic of last resort), called the MCR-1 gene, was discovered by scientists at the South China Agricultural Academy in Guangzhougen in 2015 and was generated in industrial poultry farming. Although five years have passed since this fact, despite the alarming warnings of experts, as was the case with warnings about the threat of a pandemic related to the virus, the implementation of practical countermeasures preventing another epidemic is ignored.

A similar sin of omission concerns delaying the implementation of targeted treatment and prophylaxis of bacterial and viral infections with the use of phages. A practical achievement of the research conducted in the Soviet Union in the first half of the 20th century was the development of a phage-soaked dressing for frontline soldiers. After the collapse of the Soviet Union the research was abandoned. These studies were successfully undertaken and continued in Immunology and Experimental Therapy of the Polish Academy of Sciences in Wrocław, mainly thanks to Andrzej Górski (2020), however, despite numerous efforts, the team of scientists from the Polish Academy of Sciences did not manage to overcome the organizational and financial threshold allowing for the implementation of industrial production of a phage drug. A recently concluded agreement on continuation of implementation research in China gives rise to hopes. 
The triumphant propaganda of success of the industrial era does not allow for awareness of active human participation in the cataclysmic COVID-19 pandemic. The job is supposed to be done by developing a vaccine against the SARS-CoV-2 virus, or by burning the books of wisdom together with their authors, as did the first emperor of China, just to reject the fact of reaching the end of the industrial era, for which nature has billed us. We do not want to accept the fact that the pillaging exploitation of natural resources and of the human organism brought about a disbalance in biocenosis, of which the man is a part and as a result, the human organism lost its capacities to adapt to a harmonious co-existence with micro-organisms, including coronaviruses.

Summing up briefly the importance of the discussed facts about the New Delhi bacterium and for the COVID-19 pandemic, the mechanism of epidemic emergence in both cases is analogous; in both cases the warnings of experts prior to the outbreak of the epidemic are ignored; in both cases there are mental mechanisms that hinder full awareness of the situation. In the case of the COVID-19 pandemic, its course was woven into the steam of a para-war confrontation between the US and China. Crisis phenomena within industrial civilization have been maturing for decades to the stage of revealing themselves now in a form of a global crisis, while the corona virus SARS-CoV-2 was only a catalyst accelerating their avalanche-like disclosure. The global crisis, discussed in the media under the label of the COVID-19 pandemic, is associated with the final collapse of a number of important mechanisms of the industrial era, related to economic, social, ideological, environmental, and medical scopes. They also include the collapse of the global financial system, in which a significant amount of generated cash is not covered in kind, because its main collateral is an excess amount of debt, with a volume significantly exceeding the possibility of paying it off. The existing contractual balance of the interests of the global big players in the financial market has been disturbed, threatening with the collapse of its essential elements.

\section{COVID-19 and the globalization process}

The idea of globalization also collapsed. Due to the division of the world into economic, political, and military blocks, that do not cooperate with one another, and a significant epidemic threat, the collapse affected the flow of strategic raw materials, financial resources, the functioning of international production, and investment lines and the flow capacity of goods and people both as tourists and qualified workforce. The idea of globalization in its 20th-century shape lost its functionality. The myth of the benefits of pan-urbanization of the globe collapsed, although it had been visible for decades, it did not cause correction of the continued large-scale activities (Wasilewski 2019, 2020a). Only the occurrence of previously uncalculated significant economic losses, resulting from side effects emerging in the form 
of visible consequences of human-induced global climate change and mass extinction of species, caused the collapse of economic calculation of the basic activities of the industrial age. However, the main beneficiaries of these activities do not want to pay the bill for the costs caused, instead they separate themselves economically and militarily, and their main way to respond to the critical threat of unemployment, hunger, and local conflicts of existence of millions of people is isolation and arrogance of power. The challenges of the current global crisis and the changes implemented under the protective mask of the epidemic state of emergency take away what is left of the democratic traditions of the state as a community of equal citizens, sovereign, and superior decision-maker, take away the privacy and inviolability of the home and personal property. This causes great ideological challenges which, given the progressive dysfunction of the structures of democratic states and the triumph of centralist China, can be resolved in most countries more often in street confrontation than in democratic institutions intended for this purpose. On the one hand, there is a need for great universal consolidation and individual sacrifices to overcome the great challenges of the global crisis, on the other hand, it is accompanied by a great distrust towards the broadly understood power and the fall of authorities, causing resistance and lack of conviction to pay a tribute of any of one's freedoms. The factor that further complicates mobilization in order to meet the demands of the moment is a significant acceleration of civilization changes and changes in the human environment at the turn of the industrial and post-industrial eras, which exposed human limitations, human difficulties in following the pace of change and processing overwhelming information, all the more so because traditional social structures, that served as the support point for human beings collapsed and unfavorable psychosocial conditions for creative exchange of thoughts and constructive discussion were created. An additional factor hindering the free exchange of ideas is the widespread commercialization and politicization of the media. If we consider that currently the implementation of change processes accelerated hundreds of times - in some cases - thousands of times, whereas previously it used to spread over hundreds of generations, one should rather expect a turbulent course of the process of adapting to new living conditions and a struggle to maintain the shrinking resources of territories with favorable living conditions. The implementation of such a variant of the development of the situation will activate primary mode of thinking which is functional only in a short-term perspective of the battlefield. In a stable situation it impairs mental functioning, radically reduces the efficiency of more complex activities, including creativity, and impedes biological functioning and psychological well-being of people by disrupting vegetative and hormonal balance. The discussed thinking and, more broadly, mental mechanisms, due to the involved emotional and personality components, determine the specific perception of the world by a significant part of people who want to keep the vision of the world in the perspective of a simplified image of the 
world, congruent with its current template. It also is the reason why many people nowadays interpret objectively unambiguous facts in a way unhampered by logic and generally available knowledge. This applies in particular to the COVID-19 pandemic and climate change. A characteristic feature of this type of thinking, the products of which can be seen in its pure form in blogs, is a high degree of emotiveness, symbolic thinking, wishful thinking, and the use of archetypes which were fully functional in primitive communities (the mechanism of returning to the stereotypes of symbolic thinking is described in Wasilewski's book from 2013 (Wasilewski 2013b).

Shifting the mental functioning of citizens to a confrontational, authoritarian mode of thinking has been used and is currently being used to build authoritarian systems or to prepare nations for war. There is a concern that this mechanism could be used as a temporary means of calming the current social unrest and will constitute a barrier to the peaceful consolidation of politically divided people, so necessary today to save our planet. Many people, whose way of mental functioning has been very distant from the discussed archaic forms of thinking so far, have now changed it because of a sense of threat stimulated by the media and politicians, that impregnate people with omnipresent fear and aggressiveness, and overload them with traumatic information that they are unable to organize.

The recent transition of the United States-China conflict from a latent phase into an open conflict phase with the use of economic and propaganda warfare, including the exploitation of the fact of the COVID-19 pandemic, has a strong impact on people's attitudes and their mode of mental functioning. There is a fear that this influence, combined with an increase in governmental authoritarianism will be treated as a way to contain social unrest and prepare for a possible military confrontation. The described mechanism also applies to other countries. The intensity of the information war using the fear of the COVID-19 epidemic is reflected in the wide information campaign undertaken by World Health Organization (WHO): WHO Campaigns/Connecting the world to combat coronavirus/How to report misinformation online (WHO 2020b). The impact of counteractive measures by the WHO when confronted with significant financial and technical resources of the powers involved in the confrontation and used by their armed forces for cyberspace fight have little chance of making an impact, especially when WHO has recently been cut off from the main source of funding. Voters whose mental self-realization and life fulfilment happens through authoritarian ways choose authoritarian leaders. The adoption of an authoritarian, orthodox way of thinking is fostered by the emotional instability of individuals or specific communities. The culminating moment of this impact is the period of the COVID-19 pandemic, but the decades-long process of increasing depression rates in the population of Western civilization is the foundation for the impact that this factor has. Studies conducted over the past decades have shown a significant spread in the incidence of depression in different cultural circles, from 2.0 to $10.0 \%$ of the general population in 
the countries of Far East Asia to 15-25\% (Zeng 2009) in wealthy countries of Western culture (Wasilewski \& Egan 2019; Wasilewski et al. 2020) Affective disorders and related psychosomatic disorders have become 14th main civilization threat in Western culture and one of the main obstacles to its further harmonious development - see data from WHO (WHO 2020a).

\section{COVID-19 and health security systems}

Health security also collapsed, and humans entered the extinction phase as a species despite focal numerical overproduction. Healthcare challenges are discussed in greater detail elsewhere in the text. The obsolescence of the ethos of the superman, a human demigod, the ruler of the planet, and the conqueror of the world, generated in the industrial era, is accompanied by the erosion of the existing social structure, which is an amalgam of various forms of social functioning, which has not been replaced by a new functional structure, which resulted in the breakdown of the existing social support networks, causing negative social effects and health issues such as physical loneliness, mental alienation, depression, and the lack of social interaction necessary for mental functioning, including mutual support.

The outbreak of the COVID-19 pandemic caused a sharp deterioration in the mental state of multi-million populations. The currently available data are being meta-analysed by Salari and colleagues (Salari et al. 2020), the experience of increased stress was found on average in $29.6 \%$ of the respondents (five studies with a total sample size of 9,074), the incidence of anxiety in $31.9 \%$ of the respondents (17 studies with the sample size of 63,439$)$, and the incidence of depression on average in $33.7 \%$ of respondents (14 studies on a sample of 44,531 people). The studies mainly cover the countries of Far East Asia where previously the level of depression was in the range of $2.0 \%-10.0 \%$ and they concern healthy people who are only at risk of the disease and quarantine. The incidence of anxiety, depression, and stress during the COVID-19 pandemic has been shown to be higher in women than in men. Although the older persons are at increased risk of COVID-19 infection and mortality, the results of previous studies show that during the pandemic, the level of anxiety, depression, and stress is significantly higher in the 21-40 age group. The main reason for this seems to be because this age group is concerned about the future consequences and economic challenges of the pandemic. Psychological symptoms were also found to be more frequent among people with higher levels of education, which is probably due to this group's high self-awareness in terms of their own health. In underdeveloped and developing countries, the COVID-19 outbreaks have a greater psychological impact on the population given that these countries are also affected by many other infectious diseases. Uncertainty about the health status, patient observation, treatment care, and its ineffectiveness in these communities can also increase the vulnerability of such communities to the psychological effects of COVID-19. More severe affective disorders and in 
some cases full-blown mental disorders are observed in people suffering from COVID-19, because in some cases the central nervous system is also affected by the disease process. Increased levels of anxiety, depression, and stress in the general population at risk of contracting COVID-19, potentialized by the occurrence of COVID-19-related post-traumatic stress disorder (PTSD), negatively affect the incidence and course of chronic diseases and, by secondary immunity reduction, increase the susceptibility to developing COVID-19. Oncological and cardiological diseases are particularly sensitive to negative psychosomatic effects (Müller et al. 2011; Schulman \& Shapiro 2008; Swardfager et al. 2011). It has been shown that the depressive-anxiety component of the disease process is related to the phenomenon of a proportional increase in the frequency of chronic courses of civilizational diseases and the number of cases of long-term disability or permanent disability. The current observations and research on the COVID-19 pandemic are preliminary, the more so as the full medical, economic, and social consequences are only gradually being fully revealed (Wasilewski 2021b). The discussed relationships are of particular importance for the population of old people, which is affected by a high percentage of chronic diseases and the incidence of emotional disorders, because depressive symptoms increase with the increase in the number of accompanying diseases. The prevalence of anxiety-depressive disorders in the older persons depends on the presence of chronic diseases, the degree of disability and dependence on the help of family and third parties. In some of the studies, older adult individuals forced to use social welfare due to disability or financial problems showed over $70 \%$ tendency to develop depressive symptoms. Depressive symptoms were found in $30 \%-40 \%$ of people diagnosed with bronchial asthma (Wasilewski \& Egan 2018). People after a heart attack show similar results. In some studies, neoplastic diseases caused depressive disorders in $24 \%$ of patients. But there are also observations of groups of patients with cancer, in which $91 \%$ reported depressive disorders (Wasilewski et al. 2021). Depression in the older persons occurs in $30 \%-50 \%$ of people after stroke, where post-stroke depression) is its specific form and occurs after a span of six months to a year after a stroke. Memory impairment (dementia, Alzheimer's disease) is a particular problem in old age. Older persons may have memory impairment, difficulty in concentrating, and short-term memory problems. Recently, scientists have been conducting research on the relationship between depression and Alzheimer's disease. It is believed that depression may be both a contributing factor and a component of Alzheimer's disease. Depression in the older persons is often very symptomatic of Alzheimer's disease, creating diagnostic difficulties and often delaying diagnosis and proper treatment.

The above-described background of rapid civilization changes, their acceleration and instability characteristic of the breakthrough of the civilization epochs make the older persons, who have always been the posthumous children of the preceding civilizational period, be now separated from the current technical, informational, and mental flow to a degree that 
significantly increases their disability and rejection. The existence and material mechanisms that previously maintained the importance of older adults, such as the transfer of a family business or a farm, have mostly disappeared, and the depreciation of all authorities has stripped them of the authority and heroic deeds of the past. Family ceremonies related to the passing and death have been turned into a corridor death in oblivion, which everyone wants to forget as soon as possible. A typically Polish phenomenon of old people maintaining their flat or a farm as their lifetime achievement at the expense of a huge personal sacrifice which is supposed to attract their children back to the country from a temporary emigration, often becomes a pitiful failure. Pious listening to "the wisdom and judgments of the old people", who are now more often treated as shabby gages guilty of failing to provide their children with material values or education, is no longer prevalent.

Better standards of living and opportunities for education were available to their peers from wealthy countries, which have not been affected by the cataclysm of war and occupation. The undertaken countermeasures, such as the universities of the third age, which I personally support, and the actions of local self-governments and social organizations, still cover only a marginal part of the old people community in Poland, which is becoming the dominant social group.

The outbreak of the COVID-19 pandemic caused a sudden worsening of the mental condition of multimillion populations, as referred to above. The current observations and research on the COVID-19 pandemic are preliminary, the more so as the full medical, economic and social consequences are only gradually being fully revealed. The discussed relationships are of particular importance for the population of old people, which is affected by a high percentage of chronic diseases and the incidence of emotional disorders, because depressive symptoms increase with the increase in the number of accompanying diseases. The prevalence of anxiety-depressive disorders in the older persons depends on the presence of chronic diseases, the degree of disability, and dependence on the help of family and third parties. In some of the studies, older adult individuals forced to use social welfare due to disability or financial problems showed over $70 \%$ tendency to develop depressive symptoms. Depressive symptoms were found in $30 \%-40 \%$ of people diagnosed with bronchial asthma. People after a heart attack show similar results. In some studies, neoplastic diseases caused depressive disorders in $24 \%$ of patients. But there are also observations of groups of patients with cancer, in which $91 \%$ reported depressive disorders. Depression in the older persons occurs in $30 \%-50 \%$ of people after stroke, where PSD (Post-Stroke Depression) is its specific form and occurs after a span of six months to a year after a stroke. Memory impairment (dementia, Alzheimer's disease) is a particular problem in old age. Older persons people may have memory impairment, difficulty concentrating, and short-term memory problems. Recently, scientists have been conducting research on the relationship between depression and Alzheimer's disease. It is believed that depression may be 
both a contributing factor and a component of Alzheimer's disease. Depression in the older adults is often very symptomatic of Alzheimer's disease, creating diagnostic difficulties and often delaying diagnosis and proper treatment.

The modern world is economically, politically, and ideologically divided, which results in the division in medicine. Western medicine developed expansively in the last century, a flagship product of the now ending industrial age, which boasted of doubling human life expectancy in the 20th century and promised to bring about immortality. In practice, it built a huge pharmaceutical and medical industry, one of the most profitable industries and one of the largest employers, becoming the proverbial bottomless pit and one of the main financial problems of Western countries. Apart from the undoubted successes of medicine, there are often also apparent ones, difficult to assess in the global balance sheet. Decrease in mortality in Poland, observed after a significant practical inhibition of the universal health service as a result of epidemic restrictions is the evidence of a dead end, in which Western medicine is - dominated by the interests of the pharmaceutical industry and the medical industry. Despite the COVID-19 epidemic the decrease was of $8 \%$ in April this year compared to April 2019. A similar link was observed in the aftermath of the health service lockdown related to health care strikes in Israel, Canada, and California. Modern Western medicine is a product of a toxic industrial civilization that damaged the biotope and disabled vital defense mechanisms of man and the surrounding biocenosis, stepping into its place as an essential element of life support. However, the long-term decline in the quality of the health service, which in the vast majority dealt only with the treatment of COVID-19 cases while neglecting other patients, resulted in a significant increase in the mortality rate of older adults in Poland.

From patient-oriented, classical, point-impact medicine to health emergencies, Western medicine is now evolving into a life-support industry, a production line of poorly coordinated specialists, each prescribing the same preparations, or drugs that collide with each other. Many older people take 15-20 preparations, which causes large-scale side effects. The main suffering of old people is loneliness, a sense of fear and helplessness in the face of progressive infirmity and impending death. Instead of the antidote in the form of hopeful contact with a physician, a living human being, the patient has contact with an analytical machine and a defensive medical officer. As a response to another complaint, the patient is given another drug, leading to absurdity - the most common first action of a geriatrician that the patient has been lucky enough to get in - is to decimate the amount of drugs taken, often duplicating themselves or remaining in toxic interactions with other drugs taken. In practice, the specificity of metabolism and drug response in old age are ignored. Metabolism-related problems in older adults can have various causes. Bad nutrition, the effects of cancer, the effects of medications all of this contributes to problems with the digestive system. The effects of 
dementia disorders also affect nutrition and fitness (forgetting to prepare a meal, incomplete or omitted/too large purchases, etc.). Malnutrition (also dehydration!) or overeating make the body function improperly, which in turn, affects the mental state of an older person. A significant factor is also the lack of physical activity of older adults - regular physical activity increases the overall mental and physical well-being of the older persons. It also reduces the risk of worsening of depressive symptoms, it reduces sleep disorders. Depressive states in older persons people are often associated with the side effects of drugs, including sedatives such as benzodiazepines and haloperidol, chlorpromazine or fluphenazine, which is exacerbated by frequent addictions to tranquilizers and hypnotics. The discussed problems were multiplied by the consequences of the COVID-19 pandemic, such as quarantine with isolation from the loved ones or a significant reduction in the availability of health care. The isolation of old people during a pandemic often poses a risk of not only loneliness, but also lack of supplies of food, medicines, and hygiene products. Under the slogan of protecting their health, contacts with the family, which were so symbolic before, are often suspended. Nursing homes are a separate topic having the highest number of victims during the pandemic. They are focused on minimal costs, they employ staff working in several houses, who are a seedbed of infections, and provide nursing and medical care which usually is insufficient. What is most needed for a modern patient, and especially for an older patient, is a direct contact with a doctor. Not with a robot that speaks a human voice, but directly with a doctor. There are numerous administrative and technical obstacles on the way, and when they are overcome, it turns out that the doctor is not prepared for this conversation, treats the patient as a problem and a threat and tries to delegate another person of support staff to his place or postpone the matter indefinitely. The author discusses in detail the issue of psychological patient-doctor relations as well as the psychological threats associated with the profession of a health care worker in other publications (Wasilewski 2013).

Returning to the topic of depression and anxiety disorders, which are one of the main health problems of older adults, they constitute a particularly important problem during the COVID-19 pandemic, so they should be discussed in more detail. Attempts to solve the problem of affective disorders through the widespread, chronic use of antidepressants have failed. It has not reduced the incidence of affective disorders, although it has massively increased the spending on treatments and the revenues of pharmaceutical companies. In some urban agglomerations, such as New York, water pollution with excreted metabolites of antidepressants has become a serious environmental problem. Lobbying of pharmaceutical companies is one of the reasons of the almost non-existent budgets for research into potential causes of affective disorders other than biological, including the anthropological and cultural approach to the problem of affective disorders, which has been addressed by the author and researchers related to him a long time 
ago already, interested in interdisciplinary cooperation on this problem (Wasilewski 2014, 2018; Wasilewski \& Egan 2019; Wasilewski et al. 2020).

Maintaining a narrow understanding of depression as a disease analogous to all other disease entities and applying an analogous treatment and prevention methods to it, faces significant barriers both in theoretical and practical terms - both treatment and prevention. The declared majority of cases of depression do not meet the nosological criteria for being considered a disease, therefore the terms 'depressive episode' or 'depressive syndrome' are used in diagnosis. Their prevention and treatment are dominated by psychotherapeutic and sociotherapeutic influences and they predominantly have a chronic course associated with somatic diseases. In most cases of depression, a consistent procedure and analogous to the procedure in cases of somatic diseases, leads to invalidity accompanied by a partial or complete withdrawal from professional and personal activity of the patient and adaptation to passive endurance in a separated island of the 'Archipelago of health care' (Wasilewski 2013). In a situation of a rapid increase in the incidence of depression and anxiety disorders in the countries of Western civilization, reaching $25 \%$ of the general population, there are no financial and organizational possibilities to provide for the treatment and prevention of those disorders in an analogical way, typical of somatic diseases treatment and prevention. An additional factor complicating the situation is the rapidly progressing 'psychosomatization' of basic biological diseases, where the psychological component of the disease, including affective disorders, is most often decisive for the transition of the disease into a chronic one, and it becomes the dominant component of the disease. The above-mentioned reasons lead to the view (Wasilewski 2020b; Wasilewski et al. 2020) that most cases of depression accompanying somatic diseases are adaptive symptoms of a defensive-adaptive nature, which are a manifestation of the proper functioning of the body, signaling a disease similarly to pain and leading to the exclusion of an individual from social functions in order for the individual to gain energy to fight disease. In this sense, depressive reactions are an integral part of the symptomatic syndrome of somatic diseases (Szałtys 2014; Wasilewski 2010, 2011, 2013).

Depression, which is a physiological defense reaction, becomes an independent disease in an unfavorable, prolonged course of a somatic disease, constituting a complication of the course of the disease itself. The understanding of depression outlined in this way is clearly visible from the point of view of anthropological analysis or evolutionary psychology. The mechanisms of emotional reactions are very old, inherited from their predecessors in phylogenetic development - such as the anxiety mechanism, which is now one of the main elements of the human social functioning structure. In this sense, anxiety is a defense mechanism if it is in the physiological range of severity and is adequate to the environmental situation, allowing for its constructive use, thus fulfilling the features of a favorable defense adaptive mechanism. According to the author (Wasilewski 2014; Wasilewski 
\& Egan 2019), a similar situation takes place in the case of depressive reactions. According to the author, from the phylogenetic perspective, they are old reaction mechanisms to a biological, psychological, or social threat. The depressive reaction encompasses the whole organism, slowing down its functioning and reducing energy expenditure while at the same time stimulating biological defense mechanisms. Prolonged depressive states and the related stress lead to the inhibition of cellular and humoral immunity. As confirmed by the meta-analysis of 300 studies, a strong inhibitory effect of stress on cellular and humoral immunity has been proven (Salari et al. 2020). Many further studies have shown a stimulating effect of stress hormones both on the formation of neoplasms and their offensiveness and their growth rate. Behaviour related to depression transmits a signal to the rest of the group at the same time, resulting in the group unburdening the individual from effort-related activities and taking care of them. The image of depressive reactions that functioned in anthropoids millions of years ago and in modern man tens of thousands of years ago was significantly different from the one observed today. The living conditions then required frequent movement and a good physical condition. This allowed only for a relatively short period of a limited migration by the herd due to dysfunction of one of its members.

Thus, everything indicates that the depressive reactions occurring at that time were short-term, severe in course, with a strong accompanying somatic reaction supporting recovery. In the absence of a positive effect of this reaction, according to the author's hypothesis (Wasilewski \& Egan 2019; Wasilewski et al. 2020), evolutionary auto-elimination mechanisms are activated, subordinated to the benefit of the group's survival at the expense of the fate of an individual. The process of activation of biological auto-elimination mechanisms was called by the author 'thanatosis' (Wasilewski 2014; Wasilewski \& Egan 2019). The term of thanatosis uses on the one hand the term of functioning in ethology - thus, denoting the behaviour of animals imitating their death in a threatening situation, and the concept of apoptosis from the field of cell biology, where cells activate their self-elimination when they lose control over their own modifications in a way that threatens the rest of the body's cells (Rogers \& Simpson 2014). Despite the progress of civilization development, archaic mechanisms of thinking and acting survived in modern man and they surface in a situation of the social structure destabilization (Wasilewski 2013). Thanatosis can take place as a fast-running process of self-elimination by means of a sudden cardiac death, which remained as a phenomenon mainly in primary cultures, it can also have a subacute or chronic course, carried out by means of inhibition of biological defense mechanisms. Then, the immune defense is suppressed at the humoral and cellular level, which leads to the activation of disease processes with an inflammatory component and neoplastic processes (Müller et al. 2011). 


\section{For further discussion...}

Depressive symptoms worsen becoming a fully symptomatic depression, accompanied by a loss of will to live and, most often, acceptance of moving further away from life. The mechanism of stimulating self-destruction processes through the loss of a partner and social bonds, is documented in studies on the relationship between increased mortality and reduction in social relationships; it is also documented in studies showing a significantly higher mortality from a heart attack in single men (Schulman \& Shapiro 2008). In other studies, the reduction of cellular immunity in people who lost their life partner was confirmed. This supports the thesis that the breach of the interpersonal relationship based on the bonding mechanism leads to the activation of the Thanatosis mechanism. The described dependencies are the reason for a significant deterioration of the course of chronic diseases observed in older adults and the frequency of neoplastic diseases in the situation of loss of a life partner. A similar effect is observed with the breakdown of an internal volitional support and the loss of meaning in life and the will to continue to endure, while it is an independent dimension of mental functioning, only partially related to depression. Only considering the anthropological perspective of perceiving depression, anxiety disorders and chronic civilizational diseases allows for a full picture of the health condition of old people, which until recently was dealt with by diagnosing a senile depression, normally occurring in senile age, and senility and dementia were related to old age.

This chapter describes the conditions that cause the older persons to be particularly sensitive to COVID-19. They are not only the weakest link in the social tissue currently undergoing erosion, but also the weakest link in the biocenosis of which man is an element. This chapter shows the complex structure of interactive connections between biological, psychological, social, cultural, phylogenetic, and civilization factors that determine susceptibility to COVID-19. The author also attempts to make a comprehensive view of the COVID-19 phenomenon, overcoming conceptual and linguistic barriers dividing various fields of science.

\section{References}

Flisiak R. (2021) Dane dotyczace osób zmartych w Polsce z powodu COVID-19 Polskie Przygotowano na podstawie danych z bazy SARSTer (stan na dzień 26 stycznia) Towarzystwo Epidemiologów i Lekarzy Chorób Zakaźnych. http://www.pteilchz. org.pl/

Górski A., Międzybrodzki R., Maciej Zaczek M., Borysowski J. (2010) Phages in the fight against COVID-19? Future Microbiology, 16 April 2020. doi:10.2217/ fmb-2020-0082; https://www.researchgate.net/publication/323699198

Müller N., Myint A.M., Schwarz M.J. (2011) Inflammatory biomarkers and depression, Neurotoxicity Research 19 (2), 308-318. 
Nguyen S., Baker K., Padman B.S., et al. (2017) Bacteriophage transcytosis provides a mechanism to cross epithelial cell layers. mBio 8 (6), e 01874.

Polish Supreme Audit Office's report of 2017/2018; Raport NIK z 2017/2018 r. Wykorzystywanie antybiotyków w produkcji zwierzęcej w województwie Lubuskim, 2018, NIK, Warszawa. https://www.nik.gov.pl/plik/id,16217,vp,18741.pdf

Rogers S.M., Simpson S.J. (2014) Thanatosis. Current Biology 24 (21), 1031-1033. https://doi.org/10.1016/j.cub.2014.08.051

Salari, N., Hosseinian-Far, A., Jalali, R., et al. (2020) Prevalence of stress, anxiety, depression among the general population during the COVID-19 pandemic: a systematic review and meta-analysis. Global Health 16, 57. https://doi.org/10.1186/ s12992-020-00589-w

Schulman J., Shapiro B.A. (2008) Depression and cardiovascular disease: what is the correlation? Psychiatric Times 25 (9), 41-41.

Steenblock Ch., Todorov V., Kanczkowski W., Eisenhofer G., Schedl A., Wong M.L., Licinio J., Bauer M., Young A.H., Gainetdinov P.R., Stefan R., Bornstein S.R. (2020) Severe acute respiratory syndrome coronavirus 2 (SARS-CoV-2) and the neuroendocrine stress axis. Molecular Psychiatry 25, 1611-1617. https://doi. org/10.1038/s41380-020-0758-9

Swardfager W., Herrmann N., Marzolini S., Saleem M., Farber S.B., Kiss A., Lanctot K.L. (2011) Major depressive disorder predicts completion, adherence, and outcomes incardiac rehabilitation: a prospective cohort study of 195 patients with coronary artery disease. Journal of Clinical Psychiatry 72 (9), 1181-1188.

Szałtys D. (2014) Prognoza ludności na lata 2014-2035, GUS, Warszawa. http:// www.stat.gov.pl

Wasilewski B. (2010) How to differentiate among diagnostic psychosomatic disorders, depression, borderline personality disorders and normal health? Psychologische Medizin 21, 57.23.

Wasilewski B. (2011) Psychosomatics — how it should be understood nowadays. Archives of Psychiatry and Psychotherapy 3, 41-48.

Wasilewski B. (2013a) Pitfalls and threats in the doctor-patient relation. Sztuka Leczenia/Art of Healing 51-64.

Wasilewski B. (2013b) Symbolized thinking as the background of toxic memories. In: M. Linden, K. Rutkowski (Ed.) Hurting Memories and Beneficial Forgetting. In Life Spandevelopment, Posttraumatic Disorders, and Social Conflict, Elsevier Insights, Amsterdam, Boston, Heidelberg, London, New York, Oxford, Paris, San Diego, San Francisco, Singapore, Sydney, Tokyo, 93-102.

Wasilewski B. (2014) Psychosomatic functioning of individuals in evolutionary perspective. Psychosomatic Research 76, 519.

Wasilewski B. (2018) Discussion on the position of alternative medicine in the 21 st century. Journal of Traditional Medicine \& Clinical 7, 258, https://doi. org/10.4172/2573-4555.1000258

Wasilewski B. (2019) Psychosomatic medicine in Poland. In: H. Leigh (Ed.) Global Psychosomatic Medicine and Consultation-Liaison Psychiatry: Theory, Research, Education, and Practice, Springer Nature, Switzerland, 345-364. https:// doi.org/10.1007/978-3-030-12584-4-15

Wasilewski B. (2020a) Updating the perception of a human being and its mental functioning. Journal of Psychiatry and Psychiatric Disorders 4 (1), 1-9; 21 Commentary 4 (1), https://doi.org/10.26502/jppd.2572-519X0085 
Wasilewski B. (2020b) The phenomenon of the COVID 19 pandemic against the background of its era. Webinar on Stroke and Translational 2020, Osaka, Japan, October 29, 2020.

Wasilewski B. (2020c) How to understand the COVID-19 epidemic phenomenon. Journal of Clinical Review \& Case Reports 5 (7), 335-343, https://www.researchgate.net/ publication/343098821

Wasilewski B. (2021a) Experience in the functioning of the primary care clinic during the COVID-19 pandemic, the scope of possibilities to maintain the psychosomatic standard of care during an epidemic and further prospects. EAPM 2021 virtual Congress; EAPM-SIG "Primary Care" Session; June 4th, 2021.

Wasilewski B. (2021b) Microbiome - an omitted thread in the COVID-19 discussion. Journal of Experimental Stroke and Translational Medicine (JESTM) 13 (2), 1-14.

Wasilewski B., Egan E. (2018) The Psychosomatic functioning of individuals from an evolutionary perspective, new understandings of depression. Abstracts: Social Pathologies of Contemporary Civilization Conference, November 2 \& 3, 2018, UCC, Cork, Ireland, 2018, 13.

Wasilewski B., Egan E. (2019) Depression and Thanatosis - an evolutionary perspective. Abstracts: 19th WPA World Congress of Psychiatry, Lisabon, August 21-24, 2019. https://doi.org/10.26226/MORRESSIER.5D1A036F57558B317A13FF9F

Wasilewski B., Yourtsenyuk O., Egan E. (2020) Depression as a civilization-deformed adaptation and defense mechanism. Insights Depress Anxiety 4, 8-11, https://doi. org/10.29328/journal.ida.1001013

Wasilewski B., Yourtsenyuk O., Egan E. (2021) Depression as a civilization-deformed adaptation and defense mechanism. In: S. Bag (Ed.) Highlights on Medicine and Medical Science, B P International, London, in printing.

WHO (2020a) Countering misinformation about COVID-19. WHO Newsroom, May 13, 2020, https://www.who.int/news-room/feature-stories/detail/ countering-misinformation-about-covid-19

WHO (2020b) Fact sheets, depression, 30 January 2020. https://www.who.int/ newsroom/fact-sheets/detail/depression

Zeng Y. (2009) Review of work-related stress in mainland Chinese nurses. Nursing \& Health Sciences 11 (1), 90-97. 


\title{
2 COVID-19 lockdown and social distance measures
}

\author{
A 'perfect storm' for social \\ isolation and loneliness in \\ later life
}

Marvin Formosa

Research conducted during the course of the COVID-19 pandemic has showcased an increase in the levels of loneliness and social isolation in later life. Lockdown and social distance measures certainly put many things to rest and battered many a socio-economic realm. However, their most devastating impact was certainly on older persons. COVID-19 brought a 'social connectivity paradox' as a common set of actions simultaneously protected and harmed older adults. While on one hand as the level of an older adult's physical interactions with others increases, it can protect against social isolation and disconnectedness, although it can increase the risk of COVID-19 exposure, on the other hand as the level of an older adult's physical interactions with others decreases, it can increase risk for social isolation and disconnectedness, although it can protect against risk of COVID-19 exposure. Some groups of older persons are affected more negatively than others. Two such groups include persons living with dementia and residents in care homes. The online and virtual world was hailed as a key 'saving grace' to mitigate against the perils of social isolation and loneliness. Nevertheless, all is not well in that interface between information and communication technology and later life due to the age-based digital divide. Rather than seeking to mitigate against the increasing levels of social isolation and loneliness of older persons as the result of the pandemic by augmenting the range of online and virtual services, the most crucial step is to address the barriers and obstacles that they face in taking up and using technology.

\section{Social isolation and loneliness in later life: the pre-COVID-19 context}

The prevalence and experience of social isolation and loneliness in later life were already much researched topics prior to the COVID-19 pandemic. Social 
isolation is best understood as the converse of 'social support' which refers to resources and assistance provided by relatives, neighbours, friends, and welfare institutions, and which may range from emotional, social, physical, financial, to other types of support (Berg-Weger \& Morley 2020). The absence or weakness of the social support network thus forms the basis for identifying individuals who are socially isolated. As regards loneliness, an oft-cited definition links it to an "individual's personal, subjective sense of lacking desired affection, closeness, and social interaction with others" (Davidson \& Rossall 2015: 3). Although loneliness has an unmistakable social aspect, it is also defined by "an individual's subjective emotional state" (Davidson \& Rossall 2015: 3). Loneliness is therefore an emotive sentiment that is felt by individuals who fall short in engaging social contact with significant or general others. This gives rise to a "distressing feeling that accompanies the perception that one's social needs are not being met by the quantity or especially the quality of one's social relationships" (Hawkley \& Cacioppo 2010: 1).

Previous to the COVID-19 pandemic, community studies reported rates of loneliness among adults aged 65-plus of between $2 \%$ and $16 \%$, and up to $32 \%$ of individuals aged over 55 years (Wenger et al. 2016). Social isolation is equally prevalent in later life, as up to $50 \%$ of the global ageing population grouping were found to be at risk of social isolation (Victor et al. 2005). Studies focusing on older persons residing in long-term care registered higher prevalence rates of both social isolation and loneliness (Dragest et al. 2011; Ibrahim et al. 2013). Loneliness and social isolation have wide-ranging detrimental effects on the wellbeing of older persons (Gibson 2000; Victor et al. 2009; Landeiro et al. 2017). They have been identified as a risk factor for morbidity and mortality - with outcomes comparable to smoking, obesity, lack of exercise, and high blood pressure - and were associated with decreased resistance to infection, cognitive decline, and mental health conditions such as depression and dementia, as well as with increased emergency admission to hospitals, longer lengths of stay, and delayed discharges. Older persons in subaltern positions are more susceptible to social isolation and loneliness. Gender and sexuality are key differential factors, as older women and older lesbian, gay, bisexual, transgender, and queer persons are more negatively affected. Never-married and/or single older persons and who live alone, and those who experienced the death of a spouse, partner or close family member are also at a higher risk of facing loneliness and social isolation. The same goes for ethnic minorities, those living in remote and secluded areas and in small households, and older persons experiencing poverty lifestyles, insufficient caregiving provision, and chronic psychological ailments. The carrying out of activities of daily living is also a challenge for older persons experiencing social isolation and loneliness. Albeit relatively under researched, one key factor that makes it difficult for older people to escape the straightjacket of social isolation and loneliness is the stigma associated with such conditions, who are perceived as less adjusted, competent, and resourceful than peers (Kerr \& Stanley 2021). 


\section{COVID-19 as a 'perfect storm' for social isolation and loneliness in later life (1)}

Research conducted during the course of the COVID-19 pandemic has showcased an increase in the levels of loneliness and social isolation in later life. In March 2021, the World Health Organization (WHO) decreed social distance measures as an initial solution to curb the transmission of the virus. This prompted many countries to impose a lockdown by closing their borders and imposing curfews on the movement of people (Bjursell 2020). To reduce the spread of infection, governments mandated their citizens to engage in 'social distancing' which means keeping a physical distance (in the current pandemic, the stipulated space varies between 1.5 and 2 metres) from other human beings. In other words, measures to "reduce personal proximity, an integral part of their social interaction with other people, and thus help reduce the transmission of an infectious disease such as the coronavirus" (Bjursell 2020: 675). For instance, in Malta

[a]11 schools were locked down on March 12. All public servants, university lecturers (including this author) and anyone else who can, is now working 'from home'. All non-essential public gatherings, church functions and sport events are cancelled. Passenger flights in and out of the country are suspended...bars, restaurants, stationers, hairdressers, salons, etc. are closed - and the outcome of missed visits to coiffeurs is now in plain sight ...All businesses are encouraged to consider switching their operations online and to offer delivery services. Those individuals who are caught breaking quarantine are fined 3000 euros for every transgression. Social distancing is encouraged throughout. It has never felt so vital to wash one's hands, thoroughly and frequently. The country, one of the world's most densely populated, is strangely quiet. Traffic has eased. The level of air pollution has already gone down by $50 \%$ over the last month. Many public spaces are deserted.

(Baldacchino 2020: 322)

Such lockdown and social distance measures certainly put many things to rest, and battered many a socio-economic realm. However, their most devastating impact was certainly on older persons. COVID-19 brought a 'social connectivity paradox' as a common set of actions simultaneously protected and harmed older adults (Smith et al., 2020). Undoubtedly, COVID-19related physical distancing recommendations and orders to shelter-in-place and stay-at-home interrupted older adults' social connectivity in terms of structure, function, and quality. In order to protect themselves, older adults were mandated to avoid the people, places, and services they rely on for companionship, support, and resources. At the same time, lockdown and social distance measures forced older persons to restrict their patronage to businesses, community organisations, and healthcare facilities for safety 
reasons which augmented their levels of social isolation and loneliness: "while it is encouraging that older adults have followed recommendations to limit human contact to avoid COVID-19 exposure, these altered and truncated interaction patterns greatly diminish social connectedness and increase older adults' risk for social isolation, loneliness, and depression" (Smith et al. 2020: 3). The myriad implications that such legal and policy decisions had and will continue to have on the lives of older people and ageing in general are immense, especially in terms of age stereotyping and prejudice. As was recently argued:

With the recognition that older people may be at higher risk for infection and mortality related to the virus, we have seen international media, social media, and public health officials framing "the elderly" as a homogeneous and vulnerable group, seemingly conflating physical vulnerabilities common in later life with chronological age. The pandemic has even led to hate speech in the form of monikers such as "Boomer Remover" that could promote generational conflict.

(Meeks 2021: 1)

The COVID-19 pandemic resulted - to use Whitehead and Torossian's terms a "perfect storm" of stress reactivity for older persons as it combined with pre-existing isolation, mobility limitations, financial vulnerability, or elevated heath risk to magnify an already vulnerable phase of the life course (Whitehead \& Totossian 2021). Sources of stress and challenges for older adults during the COVID-19 pandemic clustered around four avenues: pandemic-related worry or anxiety, pandemic-induced restrictions and resulting confinement and isolation, pandemic-related changes in everyday life, social media reports about the pandemic, and overall wellbeing (Whitehead \& Totossian 2021). Other researchers highlighted the series of challenges that have arisen for older persons in the wake of the COVID-19 pandemic (Morrow-Howell et al. 2020). These included economic setbacks (older adults will have a harder time re-entering the workforce and may have lost retirement savings), adverse health and wellbeing effects (older adults have experienced disruption in usual services, lasting emotional effects from increased isolation and anxiety, and those who have contracted the coronavirus may have increased health vulnerabilities), and more than anything else, ageism. Such trends not only lead one to a debate whether older persons were negated their basic human rights during the COVID-19 pandemic, but also how older persons coped with such draconian measures and were so much resilient during a time of extreme socio-economic hardship.

Bjursell (2020) was definitely spot on when claiming that lockdown and social distance measures have caused a 'disjuncture' in older people's lives namely, a disharmony between the world as we knew it and the state of the world during the current pandemic. As already inferred in the introduction, some groups of older persons are affected more negatively than others 
(Bjursell 2020). Two such groups, persons living with dementia and residents in care homes, will be discussed in the subsequent two sections.

\section{The anguishes of persons living with dementia}

The COVID-19 pandemic had, and is still having, a momentous impact on people living with Alzheimer's disease and other dementias (Canevelli et al. 2020; Wang et al. 2020). People living with dementia are at high risk of infection because cognitive symptoms cause difficulty with following safeguarding procedures and living arrangements in care homes tend to facilitate viral spread. Once infected older adults living with dementia are more likely to experience severe virus-related outcomes, including death, than are people without dementia. However, as research into this impact has accumulated throughout the past months, the resulting consensus is that this population is particularly susceptible not only to COVID-19 infection and its effects, but also to the negative effects of the measures to control the spread of the virus. In Portugal, most day-care centres were closed on March 16, 2020 for an undetermined period without specific guidelines or recommendations thus, imposing persons living with dementia to stay at home without premeditated support care (Barros 2020). Likewise, in Malta one strategy to curb the spread of the virus included the shuttering of its only dementia care facility. Such measures are extremely perturbing since psychiatric symptoms caused by social isolation are linked to more severe neuropsychiatric and behavioural disturbances amongst persons living with dementia. As Numbers and Brodaty articulated,

[s]ocial isolation combined with confusion in care home residents with dementia might result in even greater agitation, boredom and loneliness than in residents without dementia, thereby leading to more severe neuropsychiatric symptoms. These neuropsychiatric symptoms seem to arise directly from social restrictions, as longer lockdown periods result in more severe neuropsychiatric symptoms. Furthermore, some experts have suggested that behavioural complications that result from prolonged periods of lockdown in older adults with dementia could become chronic. Some consequences of neuropsychiatric disturbances, such as increased aggression and agitation, can be particularly challenging for carers and care home staff to manage.

(Numbers \& Brodaty 2021: 69)

Alzheimer Europe reported at length how self-isolation and social distancing due to COVID-19 may have a significant impact on people living with dementia, their informal carers, and health and social care professionals responsible for their care (Alzheimer Europe 2021). Primarily, such measures meant that persons living with dementia may find their normal routines disrupted, experience a lack of cognitive stimulation, feel extremely anxious, 
become afraid of being abandoned, and risk increasing bouts of depression. Many experienced a deterioration of their condition, sleep disturbances, a change in behaviour, self-neglect, and even premature institutionalisation. Persons living with advanced dementia, who do not fully understand the intricacies of the COVID-19 pandemic may be affected by the loss of support, and the stress and emotional upheaval caused by pandemic on the people around them. They may have difficulty understanding the cessation of social events and outings, and the use of protective clothing which makes it difficult for them to recognise service providers. This resulted in them feeling trapped, abandoned, confused, and/or scared. As day care centres closed and home care services and visits from friends and relatives were either reduced or stopped, their needs risked going undetected or not being adequately met. Secondly, relatives, partners, and close friends who provided informal care and support to persons living with dementia encountered various challenges during the pandemic such as disruptions of normal routines, loss of support and services, and additional care responsibilities which lead to concerns about their ability to cope. Many felt compelled to cancel the support they provided in an attempt to reduce their risk of infection. Where informal carers live with persons living with dementia in the same household, their increased time together may lead to tension, burnout, and even abuse. Relatives and friends caring for persons living with dementia in care homes had fewer opportunities to verify that the latter are managing and adapting well during the pandemic and to notice any changes in their ability to cope and need for support. Finally, many health and social care professionals strove to provide appropriate and timely treatment, support, and care to persons living with dementia and their informal carers despite fears for their own safety, and increased workloads resulting from reduced levels of staff. The restriction on visitors and the fear and anxiety surrounding COVID-19 also made it difficult for such professionals to maintain the morale of persons living with dementia in care homes and hospital settings. This functioned to increase the risk of loneliness, boredom, and depression, a behaviour which is problematic to manage in both acute and long-term care settings. At the same time, the drive to isolate persons living with dementia in care homes to distant emergency clinics also exacerbated the situation.

This situation prompted scholars to advocate a number of policy recommendations - namely, to prioritise family caregivers and paid carers in vaccination programmes, to implement and maintain remote working and work-life balance policies for family caregivers until the pandemic is over, restart outdoor activities for persons living with dementia, and coordinate safe visits to care homes and long-term facilities (Suárez-González et al. 2021). Another perturbing issue concerns statistics. Focusing again on Portugal, Barros and colleagues noted that as at 27 June 2020 nearly $86 \%$ of the total deaths from COVID-19 were in people aged 70 or more, and $40 \%$ of the total deaths were in nursing homes settings (Barros et al. 2020). Yet, 
it is unknown how many of these fatalities were persons living with dementia, and as the world is entering the post-emergency phase, it is urgent to determine the impact of COVID-19 on parameters that influence the disease's trajectory and quality of life of both persons living with dementia and carers.

\section{The confinement of older persons in long-term care}

The prevalence of social isolation and loneliness has always been a bone of contention in studies on long-term care facilities. On its own, ageing is already characterised by loss due to the death of family and friends, especially widowhood, declining health, impaired mobility, and loss of vision and hearing, which all lead to the reduction of meaningful interaction with others. However, once older persons start residing in long-term care facilities, feelings of social isolation and loneliness are compounded due to the loss of lifelong social environments and related memories. In the pre-pandemic context, the prevalence of loneliness among older persons in residential care settings was found to be at least double that of community-dwelling populations, ranging from $22 \%$ to $42 \%$, and sometimes even reaching $50 \%$, compared with $10 \%$ for older persons dwelling in the community (Victor 2012). More recently, a study used the UCLA loneliness scale in Malaysian nursing homes and found that most residents felt lonely, 25\% moderately and $75 \%$ severely (Aung et al. 2020). A phenomenological study on loneliness in long-term care facilities found that feelings of loneliness had little to do with the number of contacts, getting regular visits, or participating in social activities (Paque et al. 2018). Rather, loneliness was strongly associated with loss of self-determination or autonomy due to institutionalisation and with feelings of grief. This finding was consistent with other research documenting how older persons experience existential loneliness due to an increased dependency on others (Paque et al. 2018). Although the WHO found sparse evidence of the impact of COVID-19 on people who use and provide long-term care services in the community, it nevertheless concluded that the pandemic has had a disproportionate effect on people, especially older people, who live in long-term care facilities (World Health Organization 2020). It testified that data from 21 high-income countries showed that while some countries have had no or very few deaths among residents in long-term care facilities, other countries report that a substantial number of all deaths linked to COVID-19 in the country were of long-term care residents (from $24 \%$ in Hungary to $82 \%$ in Canada). This occurred because once COVID-19 infection is present in long-term care facilities it is difficult to control, in part due to the large number of people living close together in facilities designed for communal living, and in part due to the fact that personal care requires close proximity.

As government officials and medical experts advised citizens to 'stay at home' and 'isolate in place', most care homes refuted entry to both the 
general public and relatives, cancelled group activities, and had residents eating alone in their rooms as communal dining was stopped (Chu et al. 2021). While on one hand such prohibitions certainly decreased the risk of spreading the COVID-19 infection in log-term care facilities, on the other hand served to increase social isolation and loneliness levels amongst residents. Many family members who often visit their relatives in care homes, sometimes even daily, to bring food and to help them with eating, drinking, and personal hygiene, stopped calling to the extent that residents found it difficult to recognise them once visitations were allowed again. Eliminating movement of staff and volunteers to prevent the spread of COVID-19 also terminated some long-standing staff-resident relationships and left residents without access to possible favourite staff members. Another policy exemplar impacting staff-resident relationships was in Wuhan, China, where staff were prevented from leaving the care homes. This emergency measure, which had staff living in longterm care facilities, contributed to increased staff social isolation but had a negative impact on the psychological wellbeing of staff which also affected resident wellbeing (Wang et al. 2020). It is anticipated that the increase in social isolation and loneliness resulting from such COVID-19 mitigating measures will result in a rise in anxiety, depression, cognitive impairment, and mortality levels even in post-COVID and 'new normal' scenarios.

As social distancing guidelines and restrictions meant to protect residents in long-term care facilities inadvertently prioritised 'quantity of life over quality of life', to the extent that they ran the risk of worsening the ongoing social isolation crisis among older adults, there is therefore an urgent need to mitigate such possibilities. Proposed policy strategies and efforts included (Chu et al. 2021):

- Increased monitoring and resident support to identify and mitigate against the negative impacts of visitation restrictions to identify whether residents are experiencing increased anxiety, distress, depression, and other psychological responses.

- Maintaining and supporting safe resident interactions through personcentred and creative approaches to safeguard relationships by preserving staff-resident, family-resident, and resident-resident interactions.

- Formation of a small but dedicated interprofessional force of individuals, responsible for lockdown preparation, collaboration, and communication with families ensures to ensure that critical tasks do not cease.

- Promote technologies as an alternative means of communication for relatives who would otherwise visit the home whilst empowering residents with the cognitive or sensory capacity to use such technologies.

- Clear and timely communication of policies to individual homes as this allows administrators ample time to understand the parameters under which interventions can be implemented and maintained. 
Practical recommendations have also been forwarded. These included the use of name tags, asking families to have at least one family member call a resident in the morning to say 'good morning' and another to call late in the afternoon or early evening to say 'good night', inviting families to visit the outside entrance of facility to sing to residents or hold signs sending love, encouraging families to send cards and letters, ensuring that residents can follow religious service on televisions, and organising solitary leisure activities on behalf of the activity departments (Simard \& Volicer 2020).

\section{The age-based digital divide}

The online and virtual world was hailed as a key 'saving grace' to mitigate against the perils of social isolation and loneliness due to COVID-19 safety measures, as it enables older persons to meet virtually via mobiles, tablets, and laptops connected to each other via the internet. Nevertheless, all is not well in that interface between information and communication technology (ICT) and later life. One issue stands out in particular - namely, the agebased digital divide, sometimes referred to as the presence of digital poverty in later life.

In the United States, $27 \%$ of individuals aged 65 years and older still do not use the internet...The situation is similar in Europe. A nationally representative survey conducted across 17 European countries showed that $51 \%$ of people age 50 and older do not use the internet...Even if older adults do use the internet, they may do so in more basic ways than younger age groups...Many older adults prefer to have in-person interaction and phone communication...[only] 14\% of retirement home residents used the internet.

(Seifert et al. 2021: 3)

While the pattern of increasing internet usage among the older age groups is a truly silver lining, it remains difficult to know how this will affect the digital engagement of future older generations. The crux here is the extent that future older persons, who will be part of a generation who are more digitally engaged than their predecessors, may retain their technologically savviness as they age. Will health problems as people age lead to a decline in digital engagement, particularly if ageing impacts on cognitive and sensory abilities? A change of technology may also mean that future older persons' skills run the risk of becoming obsolete. Challenges even persist amongst that section of the older population who own the necessary ICT hardware and are connected to the internet. This is because older adults lag behind the average population in terms of their levels of digital literacy - defined as a "range of complex and densely interwoven communicative forms that are digitally mediated, as well as the mechanical and navigational competence that is a prerequisite to working on a screen" (Merchant 2007). Older generations 
not only lag behind in technology adoption and use because they cannot afford a computer, internet connection, or smartphone, but because they tend not to have the necessary skills to use digital devices and perform online tasks such as searching for information, online purchasing, banking, and uploading pictures to the web amongst other inabilities (Schreurs et al. 2017). Simply sending and replying to emails and accessing newspapers does not qualify as possessing an adequate level of digital literacy. Generally, digital literacy is gained through experience that goes beyond basic exposure to technology, and older adults often lack the required experience because they are hesitant to try new technologies and also due to possible physical and cognitive impairments in old age.

Older persons' inadequate levels, and sometimes lack, of digital literacy were much evident during the COVID-19 pandemic (Formosa 2021). First, as schools and workplaces went online the first few weeks of the pandemic were characterised by a frantic purchasing of ICT hardware, especially laptops and tablets. Older persons who did not possess such hardware, or whose hardware needed to be replaced, faced a number of quandaries in their attempts of purchasing such goods. They were mostly unknowledgeable which hardware to purchase, some even completely in the dark as what they were actually window shopping for, and many hesitated to spend most of their monthly pension on something which they did not know how to operate. The fact that most ICT stores switched to online sales, and those which did not were not necessarily close to older people residences and even had long queues outside due to indoor social distance measures, put older persons in a Catch-22 situation. They were neither online nor had the necessary purchasing skills, but also could not easily visit stores. Secondly, both beginners and proficient experienced difficulties in setting up and operating online social media sites and video chat assists. Telephone help lines took weeks to set up and when they were launched they were inundated with requests for assistance. Many older persons also experienced difficulties staying connected at all times, either because their internet was unreliable or slow, or due to outmoded computers which did not support the latest technology. Some also had sudden malfunctions in their computer, and due to the COVID-19 health emergency situation, it was not possible to get their hardware fixed in reasonable time frames. Finally, the jury is still out on the effectiveness of online and virtual technology to mitigate against social isolation and loneliness in later life. While one survey $(n=1,620$ individuals aged 50-plus in the United States) showed a link between use of social network sites and increased feelings of connectedness (Yu et al. 2016), another study ( $\mathrm{n}=7,837$ individuals aged 40-plus) in Germany examined the link between social network sites and social isolation (Hajek \& König 2019). Irrespective of age, results indicated that daily online social network users reported lower social isolation scores compared with those with less frequent or no social media use. A more recent study, this time a qualitative one and carried out during COVID-19, found older adults claiming that while 
online social media sites and video chat assists did keep them connected with relatives and friends, as well as enabling them to follow third age learning programmes and religious services, they are not effective in reducing loneliness and social isolation and will never be satisfactory substitutes to meeting people in person as they remove the fun and pleasurable aspects of active, successful, and positive ageing lifestyles (Formosa 2021, in press).

In sum, the findings are mixed, and the fact that most studies were carried out prior to COVID-19 means that future research is urgently required especially on the intensity of using online social network sites and the role that personality factors such as extraversion may play in the link between online social network sites/video chat and loneliness or social isolation among older adults (Hajek \& König 2019).

\section{For further discussion...}

A concern on the impact of COVOD-19 on older persons can never be overstated. Nearly nine out of ten COVID-19 related deaths reported in the wider European region have been among adults aged 65-plus (United Nations Economic Commission for Europe 2020), as the risk of persons aged 80-plus to die a COVID-19 related death was calculated to be five times the average rate (Clark et al. 2020). Nevertheless, such statistics do not condone decisions on behalf of governments to advocate further restraining commands for older persons compared to other high-risk groups such as obese persons and peers with auto-immune illnesses. In Malta, for example, while primary and secondary schools were allowed to open their doors to students for most of the 2020-2021 academic year, the U3A was kept shut, and older persons who were residents in long-term care facilities could not leave such amenities during the period March 2020-June 2021. The absence of any public consultation with older persons themselves prior to the issues of such decrees was nothing short of shocking, ageist, and contrary to both the United Nations Declaration of Human Rights and Principles for older persons (Formosa 2021, in press).

It is certainly not enough for public health authorities to decree the supposedly success of leisure and welfare services to reach their older audiences via online and virtual technologies without addressing the double jeopardy of social and digital exclusion. As was recently concluded, the current pandemic should (i) serve as a reminder of the existing 'digital divide' and the fact that some older adults, as well as other groups, are excluded from a digitally connected society, (ii) be viewed as an opportunity to bring all generations together by helping bridge digital divides, and (iii), highlight the importance of not creating a new form of ageism as people who use the internet tend to have sovereignty over digital information (Seifert et al. 2021). Moreover, older adults who are not using, or are unwilling to use, or who cannot use, the internet or digital online services should not be perceived as 'insurgents' and 'troublesome'. Their decisions 
should be respected and alternatives should be employed (e.g., writing letters) when possible or support should be offered to them to help them use ICTs. Rather than seeking to mitigate against the increasing levels of social isolation and loneliness of older persons as the result of the pandemic by augmenting the range of online and virtual services, the most crucial step is to address the barriers that they face in taking up technology. Such barriers range from a lack of self-confidence and perceiving themselves as not 'technologically minded', a fear that they would something wrong and break the hardware and/or of privacy issues, sensory issues such as the fact that text was too small to be read comfortably or that the buttons were too small, distrust of social media, and the fact that people with whom they wished to keep contact with were not connected to the internet. It is only through such measures that the double burden of social and digital exclusion can be addressed.

\section{References}

Alzheimer Europe. Alzheimer Europe recommendations on promoting the wellbeing of people with dementia and carers during the COVID-19 pandemic. Alzheimer Europe, Luxembourg. https://www.alzheimer-europe.org/Policy/Our-opinionon/2020-Wellbeing-of-people-with-dementia-during-COVID-19-pandemic

Aung, K.T., Nurumal, M.S., Syakihar W.N., Bukhari W. Loneliness among elderly in nursing homes. International Journal for Studies on Children, Women, Elderly and Disabled, 2/2020, p. 71-78.

Baldacchino, G. Coronavirus and Malta: Weathering the storm. The Round Table, 109 (3)/2020, p. 322-323.

Barros, D., Borges-Machado, F., Ribeiro, Ó., Carvalho, J. Dementia and COVID-19: The ones not to be forgotten. American journal of Alzheimer's Disease and Other Dementias, 35 (1)/2020, p. 1-2.

Berg-Weger, M., Morley, J.E. Loneliness and social isolation in older adults during the covid-19 pandemic: Implications for gerontological social work. The Journal of Nutrition, Health \& Aging, 24 (5)/2020, p. 546-558.

Bjursell, C. The COVID-19 pandemic as disjuncture: Lifelong learning in a context of fear. International Review of Education, 66/2020, p. 673-689.

Canevelli, M., Bruno, G., Cesari, M. Providing simultaneous COVID-19-sensitive and dementia-sensitive care as we transition from crisis care to ongoing care. Journal of the American Medical Directors Association, 21 (7)/2020, p. 968-969.

Chu, C.H., Wang, J., Fukui, C., Staudacher, S., Wachholz, P.A., Wu, B. The impact of COVID-19 on social isolation in long-term care homes: Perspectives of policies and strategies from six countries. Journal of Aging \& Social Policy, 2021. https:// doi.org/10.1080/08959420.2021.1924346

Clark, A., Jit, M., Warren-Gash, C., Guthrie, B., Wang, H., Mercer, S.W., Sanderson, C., McKee, M., Troeger, C., Ong, K.L., Checchi, F., Perel, P., Joseph, S., Gibbs, H.P., Banerjee, A., Eggo, R.M. Centre for the Mathematical Modelling of Infectious Diseases COVID-19 working group. Global, regional, and national estimates of the population at increased risk of severe COVID-19 due to underlying health conditions in 2020: A modelling study. The Lancet, 8 (8)/2020, p. e1003e1017. https://doi.org/10.1016/S2214-109X(20)30264-3 
Davidson, S., Rossall, P. Evidence review: Loneliness in later life. AgeUK, London, 2015. https://www.ageuk.org.uk/globalassets/age-uk/documents/reports-andpublications/reports-and-briefings/loneliness/loneliness-report_final_2409.pdf

Drageset, J., Kirkevold, M., Espehaug, B. Loneliness and social support among nursing home residents without cognitive impairment: A questionnaire survey. International Journal of Nursing Studies, 48 (5)/2011, p. 611-619.

Formosa, M. COVID-19 and older persons: Reflections on human rights, ageism, isolation, dementia care and gender. International Journal in Ageing in Developing Countries, 6 (1)/2021, p. 5-19.

Formosa, M. Shifting the University of the Third Age from lecture halls to online classrooms during COVID-19: Achievements, shortcomings and recommendations. In: Shankardass, M.K. (ed.), Older people and COVID-19: The impact of the pandemic, in press.

Gibson, H., Loneliness in later life. Macmillan Press, London, 2000.

Hajek, A., König, H.H. The association between use of online social networks sites and perceived social isolation among individuals in the second half of life: Results based on a nationally representative sample in Germany. BMC Public Health, 19 (40)/2019, p. $1-7$.

Hawkley, L.C., Cacioppo, J.T. Loneliness matters: A theoretical and empirical review of consequences and mechanisms. Annals of Behavioral Medicine, 40 (2)/2010, p. 218-227.

Ibrahim, R., Abolfathi Momtaz, Y., Hamid, T.A. Social isolation in older Malaysians: Prevalence and risk factors. Psychogeriatrics, 13 (2)/2013, p. 71-79.

Kerr, N.A., Stanley, T.B. Revisiting the social stigma of loneliness. Personality and Individual Differences, 171 (March)/2021. https://doi.org/10.1016/j.paid.2020.110482

Landeiro, F., Barrows, P., Nuttall Musson, E., Gray, A.M., Leal, J. Reducing social isolation and loneliness in older people: A systematic review protocol. BMJ open, 7 (5)/2017, e013778. https://bmjopen.bmj.com/content/bmjopen/7/5/e013778.full. pdf

Meeks, S. Gerontology in a time of pandemic: An introduction to the special collection. The Gerontologist, 61 (1)/2021, p. 1-2.

Merchant, G. Writing the future in the digital age. Literacy, 41 (3)/2007, p. 118-128.

Morrow-Howell, N., Galucia, N., Swinford, E. Recovering from the COVID-19 pandemic: A focus on older adults. Journal of Aging \& Social Policy, 32 (4-5)/2020, p. 526-535.

Numbers, K., Brodaty, H. The effects of the COVID-19 pandemic on people with dementia. Nature reviews Neurology, 17 (2)/2021, p. 69-70.

Paque, K., Bastiaens, H., Van Bogaert, P., Dilles, T. Living in a nursing home: A phenomenological study exploring residents' loneliness and other feelings. Scandinavian Journal of Caring Sciences, 32 (4)/2018, p. 1477-1484.

Schreurs, K., Quan-Haase, A., Martin, K. Problematizing the digital literacy paradox in the context of older adults' ICT use: Aging, media discourse, and selfdetermination. Canadian Journal of Communication, 42 (2)/2017, p. 359-377.

Seifert, A., Cotten, S., Xie, B. A double burden of exclusion? Digital and social exclusion of older adults in times of COVID-19. The Journals of Gerontology: Series $B, 76$ (3)/2021, p. e99-e103.

Simard, J., Volicer, L. Loneliness and isolation in long-term care and the COVID-19 Pandemic, JAMDA, 21/2020, p. 966-967. https://doi.org/10.1016/j.jamda.2020. 05.006 
Smith, M.L., Steinman, L.E., Casey, E.A. Combatting social isolation among older adults in a time of physical distancing: The COVID-19 social connectivity paradox. Frontiers in Public Health, 8 (403)/2020. https://www.frontiersin.org/ articles/10.3389/fpubh.2020.00403/full

Suárez-González, A., Rajagopalan, J., Livingston, G., Alladi, S. The effect of Covid-19 isolation measures on the cognition and mental health of people living with dementia: A rapid systematic review of one year of evidence. Medrxiv: The Preprint Server for Health Sciences, 2021. https://www.medrxiv.org/content/10.11 01/2021.03.17.21253805v1

United Nations Economic Commission for Europe. Policy brief: Older persons in emergency situations. United Nations Economic Commission for Europe, Geneva, Switzerland, 2020. https://unece.org/fileadmin/DAM/pau/age/Policy_ briefs/ECE_WG1_36_PB25.pdf

Victor, C.R. Loneliness in care homes: A neglected area of research? Aging Health, 8 (6)/2012, p. 637-646.

Victor, C.R., Scambler, S.J., Bond, J. The social world of older people: Understanding loneliness and social isolation in later life. Open University Press, Maidenhead, 2009.

Victor, C.R., Scambler, S.J., Bowling, A., Bond, J. The prevalence of, and risk factors for, loneliness in later life: A survey of older people in Great Britain. Ageing \& Society, 25 (6)/2005, p. 357-375

Wang, H., Li, T., Barbarino, P., Gauthier, S., Brodaty, H., Molineuvo, J. L., Xie, H., Sun, Y., Yu, E., Tang, Y., Weidner, W., Yu, X. Dementia care during COVID-19. The Lancet, 395 (April)/2020, p. 1190-1191.

Wang, L., Wang, Y., Ye, D., Liu, Q. Review of the 2019 novel coronavirus (SARS$\mathrm{CoV}-2)$ based on current evidence. International Journal of Antimicrobial Agents, 55 (6)/2020, p. 10598. https://doi.org/10.1016/j.ijantimicag.2020.105948

Wenger, G.C., Davies, R., Shahtahmasebi, S., Scott, A. Social isolation and loneliness in old age: Review and model refinement. Ageing \& Society, 16 (3)/2016, p. 333-358.Whitehead, B.R., Totossian, E. Older adults' experience of the COVID-19 pandemic: A mixed-method analysis of stresses and joys. The Gerontologist, 61 (1)/2021, p. 36-47.

World Health Organization. Preventing and managing COVID-19 across longterm care services. World Health Organization, Geneva, Switzerland, 2020. https://www.who.int/publications-detail-redirect/WHO-2019-nCoV-Policy_ Brief-Long-term_Care-2020.1

Yu, R.P., Mccammon, R.J., Ellison, N.B., Langa, K.M. The relationships that matter: Social network site use and social well-being among older adults in the United States of America. Ageing \& Society, 36 (9)/2016, p. 1826-1852. 


\title{
3 Death and dying vs. COVID-19
}

\section{A hermeneutic approach toward understanding the social process}

\author{
Maria Łuszczyńska
}

Being unable to cure

death, wretchedness and ignorance,

men have decided, in order to be happy, not to think about such things.

Blaise Pascal

In this chapter, a hermeneutic analysis of the phenomenon of death will be undertaken. Death is a universal experience of the human condition; however, in the era of the COVID-19 pandemic, the disease can reveal new social processes that may transform society's attitude to death. These reflections aim to answer how the COVID-19 pandemic may affect people's attitude to death and if it encourages or distances them from searching for answers to existential questions. This the first modest attempt to present social phenomena in the perspective of the hermeneutics of death with regards to possible changes in social awareness and identity in the 'COVID-19 era'.

\section{Introduction}

According to anthropologists, awareness of one's impending death is one of the elements that distinguishes humans from animals (Vuillemin 1993). As a universal, future, and inevitable event that affects every member of society, death has always aroused the great interest of both individuals and entire communities. The SARS-CoV-2 pandemic has intensified the social processes of experiencing dying and death, although it still remains unknown to what extent.

COVID-19 spread around the world throughout 2019 and 2020. Although it was disregarded and treated as a local threat at first, within a couple of months, it spread around the world. It began its crusade in the Chinese city of Wuhan and then developed into several dozen mutations typical for various regions of the world at a rather dynamic pace ${ }^{1}$ (https://www.bloomberg.com/news/articles/2020-04-22/iceland-is-the- 
perfect-country-for-studying-covid-19). And it is still attacking. According to statistics published on Bloomberg.com as of 30 April, since January $2020,151,592,370$ people worldwide had been infected with the coronavirus. This means that based on official data, as of 1 May 2021, 2\% of the world's population had been infected with SARS-CoV-2 (https://www.bloomberg. com/graphics/2020-coronavirus-cases-world-map/). These figures certainly do not reflect the pandemic's actual state as they fail to take into account people who self-medicate or have asymptomatic COVID infections. In addition, there may be limitations in the number of cases resulting from disproportionate testing. In many countries, particularly those less industrialized and less developed, national statistics do not reflect the true scale of the phenomenon. Estimates suggest that when considering these factors, the actual number of infections worldwide is ten times higher, i.e., one fifth of the world's population has been infected with Sars-CoV-2 within the last year ${ }^{2}$ (https://covid-model.net/).

This proves the speed at which the virus has spread and the official number of deaths caused by SARS-CoV-2 indicate its danger. As of 1 May 2021, the number of people worldwide whose death is believed to be caused by COVID-19 amounted to 3,184,017 (https://www.bloomberg.com/ graphics/2020-coronavirus-cases-world-map/). These numbers are updated on an ongoing basis. Given that doctors determine the cause of death, it can be assumed that these figures may also be underestimated and overestimated. The difference in numbers is due primarily to discussions about whether COVID-19 itself is a direct cause of death or contributes to the patient's general health condition and occurrence of underlying illnesses. Medical specialists claim that the actual number of deaths caused by the coronavirus pandemic will be significantly higher in coming years due to the unknown magnitude of delayed negative impact on human health.

Due to its magnitude, the COVID-19 pandemic has had an exceptionally significant impact on social life. Among the solutions introduced by certain societies, there have been complete or partial restrictions in social and professional interaction, closures of public space, including educational, cultural, recreational, sports and gastronomical facilities. The pandemic has also affected professional activity and has placed significant limitations on health care services, which consequently that has been dominated by a systemic reaction to SARS-CoV-2 infections. From the state's perspective, these restrictions were based on fear of an economic crisis resulting from extreme loss of human life due to the pandemic. On the other hand, citizens complied with these restrictions out of fear of death. On the one hand, this fear led to aggressive attitudes towards people who had come into contact with the virus (e.g., health care providers or sanitary service officials). On the other hand, it made people realize on a mass scale the common need to support members of a given society whose access to goods and services has been cut off. Fear of death brought to life both the best and worst in people, depending on their ability to control it. 


\section{The social understanding of death: from acceptance to tabooization}

The dying process, brought to an end by death itself, is the most universal of all human experiences. It is also often said that death is the fairest experience that treats everyone equally - regardless of social status, wealth and other factors determining our social position. The process of death occurs in parallel to the process of our lives. Death is a reliable life companion. Over the ages, many philosophers and philosophical thinkers have created multiple theories on human death. Practically every philosopher who has addressed ontological and epistemological issues has offered their own interpretation of human life and dying ${ }^{3}$

(http://www.jednota.pl/archiwum/o-smierci/303-jednostka-wobecmierci).

Personal awareness of this common fact of human existence may elicit various reactions. On the one hand, people may be conscious of their mortality and make decisions regarding different attitudes - namely, feelings, behaviours and thoughts. On the other hand, they can gradually repress knowledge of their inevitable mortality. Death is then experienced indirectlyas an event occurring in other people's lives in various degrees of social proximity. It may also be denied entirely and thus ignored until the final years or months of one's life. Death then remains unexperienced, marginalized, isolated and hidden. In this case, it could be said that the dying process, experienced by all, becomes the most profoundly repressed truth concerning humanity. While reflecting on the social dimension of dying and death, the following elements constructing this dimension can be distinguished:

- the process of shaping social awareness about death, including thanatological education;

- relationships with those dying - social rituals, the social status of dying individuals and attitudes towards these people;

- social rituals associated with fatal illnesses, death and funerals;

- issues relating to procedures and customs of dealing with corpses;

- funeral ceremonies - rituals, cemeteries;

- the commercialization of funeral services;

- the mourning process - people's social situation after losing a loved one;

- society's cult of the dead, notably the departed who enjoy above-average social attraction;

- legacies, insurance, inheritance, wills, and benefits/losses caused by death, not only financially but also in terms of intergenerational transfer.

Over the years, various societies and cultures have created social norms to deal with death in relation to the elements mentioned above.

In particular periods of history, attempts were made to become accustomed to this event by means of developing a set of behaviors and rituals that were to be applied within the communal experience of death. Initially, 
death and all associated ceremonies changed the community's time and space in an essential way. Moreover, it impacted the family and the entire village, local environment, urban residential areas, and larger spaces of social perception. At the dawn of social history, people died in public, and the entire community reacted to their death. In primitive cultures, anyone was allowed to enter the dying person's residence, even if they were unknown to the family. For example, in early Poland, the funeral ceremony consisted in displaying the corpse in the house of the departed (usually for three days) accompanied by all-night mourning and prayer. On the day of the funeral itself, people gathered to take the deceased's body from the home, hitting the threshold three times as a sign of his/her bidding farewell to that place. Afterwards, the body was led to the grave in a funeral procession, followed by a mourning feast (the so-called funeral meal). After these ceremonies had concluded, the mourning process began that customarily lasted a year; however, there were cases in which the mourning period could have lasted for years or until the death of the person in mourning.

In the Middle Ages, death was a universal human experience; awareness of it accompanied people's daily thoughts and actions. The remembrance of death contributed to the emergence of axiological systems upon which the social order was built. Temporal concerns were considered in the context of the 'vanity of life'. The medieval saying memento mori (remember that you have to die) constantly served as a reminder that everyone was mortal and simultaneously functioned as the moral regulator of human behaviour.

Death is also a common human experience in the face of epidemics decimating the population, high infant mortality, frequent wars, all forms of battle, and public executions. Almost every adult has had to confront death and the sight of dead bodies. Moreover, both adults and children die. Cemeteries were located in the centre of the settlement as a reminder of the inevitability of death.

The social understanding of dying and passing was deeply rooted in faith, which gave birth to a specific belief: dying was considered a process of passing, and death was the next stage of life and not its conclusion. This faith enabled people to better cope with dying. Furthermore, death was also treated as an indisputable decision made by God, which evoked fear or even extreme terror, but it was met with passive acceptance rather than resistance. After all, God gives life and decides when it comes to an end. Although there were many emotional reactions to the death of loved ones, including despair and sadness, death was always treated naturally and openly. Moreover, the person dying was generally aware of their condition. Death was preceded by various religious and family rituals that provided those still living with a specific pattern of behaviour in dealing with the situation. According to the Christian tradition, people who were dying had to reconcile themselves with God, say goodbye to their family, convey recommendations concerning the time after their death, and pass on a kind of will. As a rule, property was distributed. This openness to death made it a "tamed death" (Aries 1998). 
Changes in social attitudes towards death can be observed in the Enlightenment era. Developments in science and the progressive secularization of life began to diminish the impact of religious interpretations of death. Traditional rituals of passing also started to disappear; death began to be treated not as a vehicle transporting people from one existence to another but as a transition to nothingness. The role of the clergy, who assisted in carrying out the act of passing and offered interpretations of death to help people accept it, also diminished. The suffering encountered by the dying person, which earlier could be offered to God and treated redemption for sins, slowly ceased to fulfil this role and became an unnecessary and terrifying experience.

These changes triggered an increased fear of death and dying. However, death remained an element of everyday life. Children were not protected against knowledge of it, as is currently the case. At the same time, medical advancements gave the hope that death could be postponed.

An increasingly better understanding of anatomy and physiology and discoveries such as the microscope made it possible to diagnose and treat illnesses more and more effectively. Therefore, death was no longer inevitable when life-threatening situations arose. Such medical achievements offered hope that death can be conquered; however, at the same time, accepting and treating it in a natural way became more difficult.

During the Industrial Revolution, all of these trends intensified. The acceleration of medical advancements and the emergence of new medical technologies meant that once deemed incurable illnesses were commonly treated. Knowledge of aseptic procedures and the possibility of using ether in anaesthetics during surgery contributed to new successes. Personal hygiene and living conditions improved, and the average life expectancy increased. Mortality rates decreased, which was particularly visible in statistics on infant and child deaths.

At the same time, institutional medicine was developing: treatment, and therefore dying, occurred in hospitals increasingly more frequently. As a result, these events were distanced from natural human environments and moved from the sphere of direct family experience to medical facilities. 'Specialists' began to be engaged in the dying process, and those dying were surrounded by doctors and nurses and not their loved ones. People began to be seen as "patients" in categories of "health or illness" and as those dying in profound isolation, often without their families with them, in conditions of sterile isolation.

Distancing younger generations from death in the first half of the 20th century made the death of older people increasingly more noticeable. Visions of incurable illness emerged wreaking fear and havoc and were symbolized by screens and hospital isolation rooms separating/isolating the dying patients to hide their agony. Therefore, the hospital became a place of alienated, defenceless death with a lost individual character.

Patients do not want to die in a hospital; however, dying at home is not possible for many of them. Families and caregivers are not able to provide 
them with the appropriate conditions, around-the-clock care or, for various reasons, are unable or unwilling to do so.

The rise in the power of medicine also led to a re-evaluation of its purpose. Providing treatment and life support up to the final stages of life has become imperative for doctors, and a patient's death is considered a medical failure. Therefore, treatment is initiated even when everything suggests that nothing can be done to save a patient's life. Spectacular healings in hopeless cases indeed occur, which sustain faith in the efficacy of fighting death until the very end. However, such situations are rare, and in the majority of cases, they lead to additional suffering for the person dying, particularly when intensive and aggressive treatments are applied.

Moreover, new ethical problems arise. Such issues include the definition of death and determining the moment it occurs, moral conflicts associated with prolonging life or hastening death, medical experiments and organ transplants from deceased donors, and even questions related to speaking with the dying about their impending death.

Death ceased to be a direct social experience and began to be subject to tabooization - it was forced out of the common social experience. Tabooization intensified more or less in the period of the First and Second World Wars due to vast number of deaths and defensive desensitization to it. In the mid-20th century, death ceased to be a public ceremony and was 'pushed into the realm of deep privacy'. 'Discrete' funerals attended by the deceased's closest family and friends were much more common. The family asked that condolences not be offered, signs of mourning disappeared, and expressing pain and despair after losing loved ones became unnatural and unfashionable. Several factors testify to tabooization:

- reluctance or even avoidance of any contact mediated by the senses, e.g., something or someone associated with dying and death. This tendency can be vividly observed in situations in which someone requires reanimation in a public setting. The reaction of witnesses clearly shows that what occurs in such situations can be described as the depersonalization of death;

- restraint in showing emotions, or suppressing and not flaunting any signs of mourning, the dominance of the denial of death rather than coming to terms with it through experience, as well as efforts aimed at returning to 'normal' as quickly as possible, i.e., life prior to someone's death. In the contemporary experience of mourning, there is not much space for grieving, mourning and resentment;

- the absence of communication (from direct to mediated forms, broadly understood cultural texts and media images), the lack of conversations about issues relating to death and silence in this regard that leads to the belittlement of death and dying. This fact may be associated with reluctance to cause oneself pain, and in a certain way, is related to and directly engaged in the dying process or the death of a close loved one. 
Death and dying are awkward topics. There are euphemisms used that aptly avoid the bluntness of death, i.e., "someone passed away." People began to hide the dying process from the dying themselves, and reluctance to be in their presence has increased. We avoid visiting them, even if they are our close friends. Often, news of an incurable illness results in the patient's social isolation precisely because of the inability to address this complicated topic. New terms emerge, including the death crisis (Bauman 1998), code of silence (Kastenbaum 1973), deconstruction of mortality (Bauman 1998; Berger 1997), denial of death (Gorer 1955), sequestration of death (Mellor 1993), dying of death (Walter 1994), and wish-dream (Gorer 1955). British sociologist and anthropologist Geoffrey Gorer, considered the pioneer of the sociology of death, was the first to employ the term 'tabooization'. Gorer's text is already a classic. However, the thesis taken from his pioneering speech, in many respects, is still today one of the critical issues of debate in thanatology and the sociology of death. Gorer assumed that specific topics and areas of human experience are treated as being inherently scandalous or offensive. Therefore, they are not to be discussed or mentioned openly; and experiencing them is done in secret and associated with feelings of guilt or inferiority. According to Gorer, death as a natural process has become gradually unspeakable, and therefore placed in the sphere of taboo as was previously the case with sexuality. While the taboo of sexuality gave way to the spread of perverted sexuality, taboos on dying have resulted in the eruption of the pornography of death today.

Consequently, natural death is increasingly disguised by prudishness, while violent and unrealistic deaths play a more predominant role in the mass media and pop culture. Death is removed from the horizon of awareness, the sphere of human and emotional experiences, thus allowing the so-called "pornography of death", which means the fashion for ubiquitous and blatant death connected with aggression, slaughter, blood, massacre and violence. In effect, death is trivialized, ridiculed, exaggerated and even treated as amusement. This distorted image of death appears in news broadcasts, pop culture, art, films and advertisements. It could be said that they depict death in the third person - it affects him/her or them. It rarely affects the second person - you (singular), you (plural), and never as me/us. In this manner, the primal human fear of one's own death is neutralized, displacing traditional customs associated with mourning, which points out the extent that contemporary people are not able to cope with fundamental existential problems.

In conclusion, the crisis of death described as 'inverted death' (Aries 1998) is based on pushing death beyond the boundaries of social awareness and that of the individual, a process that is only deepening in the post-modern era. This process is caused by the following factors:

- the medicalization of death - removing death from social awareness due to medical advancements;

- the secularization of life - reducing the significance of death and religious practises related to death; 
- industrialization and urbanization - concentrating social awareness on progress, changes in social structure and environment, and work culture;

- technological progress - associated with medicine and treatment procedures;

- demographic changes - prolonging life, improving its quality, decreasing the number of deaths in children;

- transformations in the hierarchy of social values - in the emerging industrial relations, healthy, non-disabled and productive individuals enjoy greater recognition than the older adults who were once appreciated for their life experience;

- changes in family structures - 'branched', multi-generational families have been replaced by nuclear families characteristic for urban life. Family ties have weakened, and younger generations have started to lose their ties with older family members, who were most often ill and dying.

These tendencies lead to the progressive marginalization of older people and turn society's attention from their problems, illnesses, disabilities and dying process. Consequently, the negation and removal of death from social awareness are deepening, and this phenomenon has dominated people's attitudes towards death since the mid-20th century.

Early cultures, more immune to death, created the model of 'tamed death'. People died at home, surrounded by their close family, reconciled with this fact (Aries 1998; Vovelle 2002, 2008). Today, significantly more people would rather die quickly, painlessly, under anaesthesia, or when asleep. For this reason, the topic of death is ignored, silenced and uncomfortable. Medical advancements have abolished the clear line between life and death and have led to the institutionalization of death. This has also impacted the way death is perceived.

\section{The hermeneutics of dying and death}

The hermeneutics of death, understood as the capability of experiencing and describing the end of one's life, cannot be experienced since the possibility of reflecting on the final moment of one's life ends with death itself. The hermeneutics of death can only be reconstructed indirectly by understanding the death of others, most often that of close friends and family. It is associated with a voluntary and conscious decision to come into contact and in relation with a dying person, which may be difficult due to fear of death.

Since death is inconceivable to human reason, thanatologists have been developing a more accessible version - the hermeneutics of dying, which is emerging as a very 'human', and at the same time, humble and curious reaction to the phenomenon of death. Here, hermeneutic thought returns to its sources. In addition to focusing on understanding, it attempts to determine the conditions for understanding it, and - as a manifestation of the human 
factor - to tear away even a fraction of that which can be grasped by reason, that which cannot or wills not to be understood - i.e., the mystery of death.

That which can be grasped in the hermeneutic perspective is not the state of death but rather the dying process itself. Thus, what is to be understood is never fully comprehended but is constantly being discovered. On the one hand, the subject of hermeneutics is awareness of the inevitability of death as an element of life, a certainty of existence, but also certain paradoxical, and by definition, imperfect anti-experiences of death associated with a lack of experience and knowledge that can only be anticipated as an impression, feeling or imagination. Thus, this inability to experience 'the inability to experience' is absolute philosophically but not existentially.

The hermeneutics of dying concerns situations in which the reality between life and death meet as closely as possible. It is only in this space 'in-between', where life has almost come to an end and death has almost occurred, that it is possible to find out about something that resembles death as closely as possible. The hermeneutics of dying possesses yet another feature that the hermeneutics of death does not - namely, the language by which it is possible to describe what can be understood (Gadamer 2011).

In the context of dying, language is expressed in the message of the deceased's final will, his/her instructions and desire concerning the future, or as a farewell. These messages are connected with the final moments of life and expressed in the presence of witnesses. Today, wills are drawn up at an earlier time, are anticipatory in nature and may be subject to modification. Although expressed in the broader context of life, the words of the will momentarily bring the person expressing their last will into contact with the awareness of their own dying process. One could speak of the anticipatory dimension of the hermeneutics of dying, which concerns me as 'myself' and in the participatory dimension, i.e., concerning my participation in the dying 'you'. The latter is the only possible situation in which an informed hermeneutic description can be made. Furthermore, "my death" is beyond the scope of leaving an inheritance; however, 'your death' is the only area in which dying and death can appear and be constantly described.

Among the authors who have contributed to the hermeneutics of death, predominant hermeneutic thinker Hans-Georg Gadamer should be mentioned. While reflecting on the experience of death, he looked at the accomplishments of technology and pharmacology made for the benefit of not only palliative care but also for supporting human life (or rather the functions of life) beyond its "natural" measure, with slight horror. Thus, death is not only isolated from the public sphere, but it is also "alienated". Gadamer claims that "modern chemistry, equipped with anaesthetics, expropriates the person suffering. (...) At the same time, it also excludes those who have experienced, either by passive or active participation, this event" (Gadamer 2011: 80-81). Therefore, it follows that both death and dying are worth (consciously) experiencing and are an integral and key element of human, and therefore - intelligent existence in the world. 
Thinkers are surprisingly unanimous in terms of the inability to emotionally or intellectually grasp one's own death. Ludwig Wittenstein claims that "death is not an experience of life. Death is not experienced" (Wittgenstein 2000: 81) and therefore, it would be better to remain silent about it. Sigmund Freud expressed a similar view in his text entitled Our attitude towards death when writing that "we cannot, indeed, imagine our own death; whenever we try to do so we find that we survive ourselves as spectators"4 (Freud 1918: 40-41). Martin Heidegger, in turn, wrote that "death, as a possibility, gives Dasein nothing to be 'actualized', nothing which Dasein, as actual, could itself be. It is the possibility of the impossibility of every way of comporting oneself towards..., every way of existing" (Heidegger 1994: 368). Zygmunt Bauman claims that "the only thing that thought cannot grasp is its own non-existence" (Bauman 1998: 21). Similarly, the "father of thanatology", Luis-Vincent Thomas, wrote that "as long as we are alive, death exists in the images it suggests, and in the language that we use to describe it" (Thomas 2002: 11). Attempts to describe the experience of dying and death are possible by understanding it in categories of the mutual relation of I and Thou. Thinkers such as Martin Buber, Emanual Lévinas, and Józef Tischner wrote about the significance of this relation. The mediation of experience in someone else's dying process causes that I better describe the dying process of Thou than my own, because My process is My drama, from which I distance myself or despair over. The dying of Thou, regardless of how painful it is for me because of the relationship of I and Thou, allows for greater awareness of this process with engagement, but without avoiding it. It could be said that participation in the dying of Thou is the foreground to my own death. Some authors have supplemented this relation with the aspect of the love shown to the dying person (Buber 1992; Jankélévitch 1993; Levinas 2012; Tischner 2005, 2006; Ziemiński 2007). By this love, one experiences his/her own death despite the impassible ontological barrier between Thou and I. To the extent that the love-based subjective I-Thou relationship brings to life the new being 'We', 'Us' - to that same extent, the death of Thou turns out to be, to some degree, the death of I. Although the I does not die physically, temporarily, it dies as the object of the I-Thou relationship. The death of Thou destroys the I inasmuch as it was engaged in its relationship with Thou, most often by virtue of love (Ziemiński 2007).

The dying process is rooted in time. From the perspective of $\mathrm{I}$, it is permanently embedded in the future. However, if the I experience the death of Thou, understanding this process may refer to the past, present, and to the future (Jankélévitch 1993).

The knowledge that we obtain thanks to the death of Thou, is a profound, personal existential experience and is something radically new in relation to everything that we had previously known. Before the I was affected by the death of Thou, the I saw was only the objective law of nature in human dying, to which we are all subject. However, after experiencing the death of Thou, an understanding emerges that transcends the ordinary description 
of nature and now engages not only in academic objectivity but also in subjective emotional, intellectual, and often spiritual engagement.

Understanding, language, time and the I-Thou relationship are the elements of the hermeneutics of dying that may be employed when analyzing the impact COVID-19 has on the awareness of dying and social attitudes towards death. Later in the text, they will be used for preliminary analyses of the social reality that has constantly been evolving since the global pandemic outbreak. The main subject of the analyses is that what is currently taking place in the social understanding of death, whose shadow has been the broadest context for all the behaviours, reflections, images and experiences that have organized social life in the COVID-19 era.

\section{The fear of death as a social force that builds the identity of (im)mortality}

The peculiar marginalization of death has contributed to the social distortion of the image of death, which has changed from so-called "tamed death" into "death gone wild", driven out of everyday life. The extent to which death is feared indicates the scale of taboo, but the main problem is found in using such concepts as denial or the two-dimensional fear: conscious unconscious.

In attempts to understand how COVID-19 has impacted attitudes towards dying and death, it is crucial to look at the fear that death invokes and the attitudes people may have in reaction. Makselon distinguishes three main components of the attitude towards death: (1) thinking about death; (2) fear of death; and (3) defence mechanisms (Makselon 1983). In turn, A. Ostrowska believes that fear is the most crucial dimension of the attitude towards death [28]. Judging by the amount of academic work devoted to the particular dimensions of the attitudes towards death, this is currently the dominant opinion (Cicirelli 1998; Feifel \& Branscomb 1973; Gesser et al. 1998; Kaatenbaum 1973; Neimeyer 1994; Tomer \& Eliason 1996; Yalom 2008).

In Gebert's opinion, death can be feared only when it is imagined, and since it is a particular negation of existence, one must first be aware of its existence. From this perspective, the fear of death is one of the most fundamental elements of one's self-awareness; to a great extent, it regulates human behaviour and is inseparably associated with the awareness of one's own existence (Gebert: http://www.jednota.pl/archiwum/o-smierci/303jednostka-wobec-mierci). The fear of death can be viewed in various ways as the fear of one's own death or the death of loved ones, fear of the moment of death or the dying process, fear of what happens to the body after death, and fear of the way we think about death and negative thinking about it. However, fear always engages one's personality, and everyone experiences it uniquely. Ochsmann (Jastrzębski: http://www.psychologia.net.pl/artykul. php?level=209) distinguished six types of the fear of death: 
- fear of encountering death that manifests itself in fear of direct contact with a dying or deceased person;

- fear of mortality expressed as the fear that one's plans and intentions will be brought to nought by death and fear of confronting the sufferings experienced by close friends or relatives;

- fear of the end of one's life expressed in refusal to accept death understood as the definitive end of existence;

- fear of physical destruction linked with an intense fear of what will happen with the body after death;

- fear of life after death triggered by the terrifying perspective of the uncertainty of what will take place after death;

- fear of the dying process and the suffering that accompanies death.

The fear of one's own death refers to the feeling of the irreversible passing of time in human life and development and the end of one's own existence, over which we have no influence. This fear may concern various aspects (Makselon 1983):

- dying, i.e., approaching death;

- destruction of the body after death;

- surviving relatives;

- the unknown, and the unknown moral judgement of God

- apparent death, at times the result of stories of burying people still alive;

- premature death, when one is still fully active;

- the appearance of the body after death;

- a specific type of death;

- social - psychological death - understood as the absence of interpersonal relations

Many factors impact one's attitude towards death. Such factors include an individual's propensity to fear, life-threatening situations, experiencing someone else's death, concern for life and its prolongation, religious and cultural factors that shape various interpretations of death and provide it with meaning. Attitudes towards death change throughout one's life, but they always constitute the social context in which death occurs. Social convictions about death are reflected in customary practises, in legally binding legislation and institutional statuses concerning death that regulate the conditions of dying and significantly determine the interaction between the dying and their environment.

The fact of dying is closely related to attitudes towards death. According to E. Kübler-Ross, the dying process includes stages that differ in terms of the essence and intensity of the dying process and one's acceptance of the inevitability of death. She conducted several hundred conversations with the terminally ill, which in turn allowed her to distinguish five reactions to death, also known as stages of dying: denial and isolation, anger, bargaining, 
depression, and acceptance (Kübler-Ross 1979, 2005). In another typology developed by Szaniawski, the following attitudes are distinguished depending on our personality (Szaniawski 1998):

- ambivalent - is aware that death is a value but constitutes the greatest uncertainty, a sad necessity, the end of hope and a tragedy. One fears death but also attempts to think about it;

- calm - accepts death; according to such people, death is not a tragedy, but a mystery, the path to rebirth and cleansing. Thinking about death motivates them to make changes in their life;

- religious - understands death in the context of faith but does not always live according to it. Such people often think about their own death and that of their close family and friends, but this does not prevent them from having an optimistic outlook on life. Death is understood as unity with the Absolute;

- evasive - they do not think of their own death, do not consider it to be the most important issue and do not consider it a tragedy. Death does not frighten such people; however, they often think of the death of close family and friends;

- terrified - death is the main problem in life and the greatest uncertainty. Such people fear death and often think about it; however, their reflection does not help them live a better life.

According Kaczmarek, the contemporary attitude to death has at least three aspects that impact people's social activity with regards the dying process: (i) adopting an indifferent attitude, treating death as obliteration and negative; (ii) rooting it in a theological horizon that merges dying with the perspective of eternity, the thought of which should guide one's earthly life; and (iii), the 'taming death' effect - hospice movements that are not always related to a particular religious discourse, however, they restore death its social acceptance and reject the indecency of suffering and illness (Kaczmarek 2009).

Summing up these reflections, contemporary social reality in relation to death is characterized by the following phenomena which coincide with:

- the tabooization of death - the avoidance of speaking and thinking about death, removing it and dying from daily life; for the majority of people, dying takes place in hospitals, alone, surrounded by medical specialists; a commercial approach to funeral rites, the family does not participate in preparing the deceased for the funeral;

- pornography of death - death becomes the subject of spectacle and fascination. It is shown, e.g., in sudden, violent death scenes in films, computer games, trivializing and ridiculing death, etc.

- the medialization of death - together with the development of new technologies, new forms of commemorating and mourning the deceased 
have emerged - and its promoter and driving force has been the Internet. Increasing more often, people watch funeral ceremonies on the Internet. Virtual cemeteries, monuments and virtual candles, similar to traditional candles or lamps, or are marked with special graphic signs reflecting grave candles, are increasingly more common. In the scope of this phenomenon, the cult of the dead or famous people - religious figures, people of the arts and culture or celebrities - has emerged, taking on a global character, thanks to the community of mourners worldwide. Examples include the global mourning of the deaths of Princess Diana, John Paul II or Michael Jackson.

- The retabooization of death - the dynamic development of academic thanatological reflection and the development of the hospice movement, palliative care, organized social campaigns for a good and dignified death. An element of retabooization is restoring to funeral rituals and the mourning process a form that assists in overcoming the pain experienced after losing a loved one but simultaneously helps in coming to terms with the awareness of one's own passing.

Admittedly, in response to the process of tabooization, social activities have emerged that are aimed at re-taming death and giving it a humanistic character, including hospice movements, social campaigns (e.g., the 'Dying Humanely'), but changes in thinking about dying occur very slowly. In what way does COVID-19 contribute to accelerating changes in the area of understanding death?

\section{COVID-19 and the social (mis)understanding of death}

If we accept Gennys Howarth's argument that the fundamental problem for sociology is the question of how societies can endure in the face of mortality, the concept of death as a taboo can definitely be treated as an attempt to explain this phenomenon in relation to modern societies (Howarth 2008). However, what is COVID-19s role in the development of the social understanding of death? Does it contribute to even greater tabooization, or does it perhaps introduce a new aspect to the process of de-tabooization due to its global and long-lasting nature? COVID-19 appeared at a time when the social understanding of death could have been viewed as being subject to tabooization than to taming. Social actors awaited a medicine for immortality, medical "specialists" (doctors, nurses) made use of cutting-edge technology in treating people and prolonging their lives. Moreover, the pharmaceutical industry has made huge profits on selling medication and supplements to keep people in good health or extend their lives without death. The global economy has generated profits, and sales markets have produced increasingly more needs to keep the economic wheel spinning. The outbreak of the pandemic was a shock world-wide that revealed the unpreparedness of medical, social, academic and political environments in coping with this 
unknown type of threat. Reactions to the spread of the virus varied, often extreme, resulting in conspiracy theories and explaining the situation with great depopulation narratives.

For the first time in history, a pandemic spread throughout the social life of inhabitants of the Earth to such a great extent. Its emergence revealed people's emotions on a massive scale. The first emotion that guided political, economic and social actions was the fear of death. Although it was not mentioned for months, it was the driving force behind the solutions adopted by specific states. These drastic measures included closing borders, restricting movement, economic lockdown, prohibiting the sale of goods and services unrelated to basic food and medical needs, closing educational institutions (preschools, schools, universities) and socially isolating people infected or suspected of being infected. It can be noted that during the first stage of the pandemic, aside from fear for one's life, feelings of uncertainty, senselessness, crisis, fear of the unknown and the future dominated. For some, this was associated with martial law, only the nature of the opponent was unknown. People employed five basic strategies for social existence:

- disregard - distancing oneself from the situation, functioning as if nothing had happened, not listening to the news, living one's life and avoiding obstacles that appeared in the social environment as a result of COVID-19; extreme forms of disregard may include misunderstanding what is happening and lack of interest in the situation;

- revolt - based on breaking restrictions, searching for conspiracy theories to explain events, refusal to comply with recommended precautions (great discussion on wearing masks), using arguments related to civil liberties, freedom of choice, etc.

- resignation - based on the gradual loss of hope, deteriorating mental health condition, the extreme form of which is panic, nervous breakdown or auto-aggressive behaviours.

- acceptance - coming to terms with uncertainty and change and creating constructive personal strategies adapting to further life; characterized by calmness, hope for the future, and expecting the situation to improve.

- co-operation - based on keeping up-to-date about the pandemic and undertaking action to support those in need and those who have experienced difficulties in coping with the pandemic situation. In terms of co-operation, people have engaged themselves in social campaigns by sewing masks, going shopping for the older adults, caring for the ill, etc.

The activities mentioned above may intertwine or transform from one to the other. This list of activities is also the effect of social observations and requires further social research conducted after a certain period and with a particular distance to investigate the dynamics of such changes. The driving force behind these attitudes was undoubtedly the fear of death - whether conscious or not - driven by the media or political messages. Therefore, the 
COVID-19 situation has been, in principle, thanatological in nature. Various social actors have been involved in the situation that has arisen as a result of COVID-19. Among other examples of the COVID situation referring to the hermeneutics of dying, various situations that build the thanatological character of social experience can be mentioned:

- the ill - "patient" at risk of death

- specialists providing care for those infected with COVID-19 (doctors, nurses, patient services)

- the family of "patients" and later the deceased

- the older adults, who as an age group were more at risk of contracting COVID-19 other groups

- members of a given local community that are potential participants in funerals

Each of these situations is extremely rich in terms of research into the impact on individual and social awareness of dying. These situations reveal the social aspect of attitudes (behaviours, emotions and beliefs) towards the dying process and someone else's death. By examining each of them, it is possible to notice new, unknown or more intensified relations, behaviours and experiences related to death. When analysing them in detail, it must be emphasized that the social role of patients is characterized by being isolated from family and staying in a hospital environment where medical professionals surround them. In addition, due to the sanitary rigour, patients have to deal with unusually dressed personnel with whom sensual contact (by means of sight, sound and touch) is extremely limited. The sight of people dressed in special suits, masks and visors may deepen a dying person's feeling of being in an unreal, absurd and uncertain situation dominated by suffering, fear, loneliness and despair. The accounts given by volunteers who support dying patients bear witness to the enormity of the confusion experienced by those in the dying process. This is undoubtedly an interesting topic for further research since the description of experiencing such dying is certainly more intense and characterized in a way so far unknown.

In turn, the attitudes of the medical personnel towards death are also exceptional and unparalleled in this regard. An element of their profession is the freedom to navigate oneself around the reality of regulations and processes, and having extensive expert knowledge. Their work is performed in hospitals where people fight for their lives, and death is treated as a failure. However, the COVID-19 pandemic has revealed the limitations of the health care system, not only in terms of equipment and capacity but also mental preparation. It has forced medical staff to exert inhumane physical, mental and emotional effort with the burden of the constant threat of their own death (as was the case in every country in which health care workers have died). They have witnessed the multitude of death among their patients and have been faced with the necessity of assessing who should receive their 
help and who has a greater chance of surviving in the context of limited access to medical equipment. The attitude of medical staff and attitudes towards medical staff on the part of those who witness their work and the local communities in which they have been perceived as a potential threat to the health of others - constitute a rich source of research material that could contribute to a better understanding of death as a social phenomenon.

Another group that has encountered the dying process, whether they like it or not, have been the families of 'patients', both those whose access to their loved ones in hospitals has been severed, and those who have lost their loved ones and have had to organize funeral ceremonies in sanitary regimes. Families have not had the possibility of accompanying their loved ones in the dying process, saying goodbye to them, accepting their wills or blessing for the journey ahead. They have also not been able to accompany their dying loved ones to ease their pain. They have been forced to organize modest funerals that could not be attended by all those who desired to pay respects to the deceased. Such families have been witnesses and participants in the 'funeral factory' - they have placed the corpse of their deceased in a family grave or mass cemeteries among hundreds of other graves. They have had feelings of complete alienation from the death of their close family members and friends that have left an unspeakable gap between the last time they met and their absence in family life. This situation has also arisen due to quarantine, and families have not been able to participate in a family member's funeral, thus making the gap even greater. Members of a given community in which someone has passed away have also had similar experiences, although to a lesser extent. Fear of infection, epidemic restrictions, and one's own powerlessness have caused the deceased to disappear from the social horizon in an almost invisible and unknown way, without saying goodbye. In this way, COVID-19 has transformed the character of social mourning. Compared to the pre-COVID era, even public figures (politicians, actors, singers, artists and celebrities) have died with reduced social response, mourning and sadness. It is as if the world has grown accustomed to death over time or has at least become immune to it.

An accurate assessment of the impact of COVID-19 on the development of thanatological knowledge will occur in the future, because distance is essential to reach comprehensive conclusions. It goes without saying that in the context of this historical moment, both negative and positive effects can be observed in terms of coping with death. The former may include the intensified isolation of those in the dying process - removed from family, the local environment, loved ones, and entrusted to health care services. As far as medical sector workers are concerned, their exceptional devotion and enormous effort to care for patients, even at the cost of their own health and lives, is evident. Coming into contact with death to such a great extent has renewed their fundamental motivation to practice their profession. It could be said that it has verified their professional vocation, albeit in connection with enormous effort. 
Undoubtedly, people have also started to reflect on the end of their lives and search for answers to existential questions to a greater extent than previously. However, attitudes of withdrawal and revolt have been noted, along with ones that feed on conspiracy theories. It could be said that the fear of death has intensified, which, on the one hand, could lead to dissent and social revolt, while on the other hand, to a bolder search for answers to questions that people are unwilling to ask. COVID-19 has also verified the quality of our social relations, revealed areas of longing and essential issues unrelated to consumption. It has become a strong incentive, occasion and pressure to reflect on one's own death. To a larger extent, it has confronted societies with the issue of death, and not necessarily from the point of view of dreamers in search of a medicine for immortality.

\section{For further discussion...}

For ages, the ceremonies of 'taming' death have been subject to numerous changes; however, the constant relationship between death and society has never been disturbed. The paradox of everyday life and death remains essentially an 'everyday' topic since it constantly accompanies life changes. However, at the same time, it is denied the most. Although death is a natural stage of human existence, it is simultaneously one of the most unwanted and avoided topics, and a taboo subject. Almost every discussion on this topic is reserved for philosophers, ethicists, theologians and scholars. On the other hand, open discussions about death are avoided and ignored since they evoke unpleasant emotions in people and are even treated as awkward. Changes in attitudes and opening society to the problems of death and the conditions in which it takes place is significant for the way death is experienced by the dying themselves, their close family and friends and the medical staff providing care. The way we feel and think about death, what we believe in, and the values we assign to it greatly impact how society, institutions, and families say goodbye to their departed members.

COVID-19's lesson is not a clear-cut thanatological lesson, but it has undoubtedly contributed to the de-tabooization of dying and death by means of intensifying social emotions around these issues. It has also revealed great constructive and destructive layers in individuals and social groups. Such strong social experiences have made people aware of the need to search for ways of coping with death so that it would bring support and not destruction to one's environment, despite the unrest that COVID-19 has also caused. It could be said that this is the first in a series of lessons on how to live with death and maintain distance and creativity, being grounded in the present and rooted in relationships, peace, joy and care. This lesson has undoubtedly been different than other pandemic experiences due to its more global character. Thanks to the mass media, social media and other forms of bridging social distance, humanity has experienced and is still experiencing this pandemic situation in a new way. COVID-19 has shown the 
important aspects of social relations and that what death has taken from people - family, relationships, health, physical fitness, work - while the long-term effects of this virus remain unknown. While summarising these reflections on understanding COVID-19, I would like to put forward the following claim: COVID-19 is a shocking phenomenon on a global scale that has mainly contributed to intensifying people's fear of death. In certain situations, it has caused that people have cut themselves off from the awareness of their own death even more and have started to celebrate life. Others, however, have initiated thanatological reflection resulting in changes in their attitude towards death or encouragement to do so. It has also grounded thanatological thought in shaping knowledge about dying. Perhaps, if people (not only thanatologists) seriously worked on building awareness of their own passing, they would confront it and engage in open discourse, make use of their resources more creatively and reduce the fear that could be the source of increasing aggression and competition. Furthermore, they would ground themselves in the present to a greater extent, without expectations and memories that often anchor them and hamper their potential. For this to occur, thanatological education and research on the long-term effects that COVID-19 will have on family relationships, the social mourning process and taming death by means of the coronavirus are needed. This topic is certainly a fertile thanatological phenomenon worth further attention.

\section{Notes}

1 Reykjavik-based deCODE, a company that analyses the human genome, has tracked 40 coronavirus mutations. Research results have yet to be published, however this research company can be trusted as key genetic risk factors of various diseases from cardiovascular diseases to cancer have been discovered in their laboratories. DeCODE Genetics tested 9,768 samples taken from Icelanders for SARS-CoV-2, and then subjected the isolated virus to full genome sequencing that revealed certain findings regarding the evolution of pathogens and its transmission chain. The company's director, Kári Stefánsson, announced that 40 mutations had been detected in the inhabitants of the island. One individual was infected with two separate variations of the virus. The Icelandic Ministry of Health tested anyone who had shown signs of infection or were qualified as people at risk of contracting COVID-19. Furthermore, deCODE Genetics tested 5,571 people who did not have any symptoms and were not at risk, but volunteered themselves for testing. It turned out that among them, there were 48 asymptomatically infected individuals. https://www.bloomberg.com/news/articles/2020-04-22/iceland-is-the-perfect-country-for-studying-covid-19 (1.05.2021)

2 Here, reference should be made to two mathematical models created by two academic teams - a research team at Columbia University has constructed a mathematical model that gives a much more complete - and scary - picture of how much virus is circulating in our communities (https:/www.npr.org/sections/ health-shots/2021/02/06/964527835/why-the-pandemic-is-10-times-worse-thanyou-thin). Another mathematical model created by scientists at the University in Białystok based on the number of deaths should also be noted, compare (https:// covid-model.net/). 
3 I intentionally do not refer to specific scholars and specific points of view, because the objective of this chapter is not to provide such an overview. I believe that pointing out selected authors would set out a philosophical perspective in this text, which this would miss the main purpose of this chapter - analyzing the dying process and death in the social perspective. Professor Gogacz provides a solid philosophical overview of the concept of death, cf., http://katedra.uksw. edu.pl/gogacz/artykuly/028_filozof_ujecie_smierci_wydruk.pdf

4 Based on this observation, Freud came to the conclusion that

Our unconscious therefore does not believe in its own death; it acts as though it were immortal. What we call our unconscious, those deepest layers in our psyche which consist of impulses, recognizes no negative or any form of denial and resolves all contradictions, so that it does not acknowledge its own death, to which we can give only a negative content. The idea of death finds absolutely no acceptance in our impulses. (...) The fear of death, which controls us more frequently than we are aware, is comparatively secondary and is usually the outcome of the consciousness of guilt.

https://www.gutenberg.org/files/35875/35875-h/35875-h.htm

\section{References}

Aries, P., Człowiek i śmierć [Images of Man and Death], PIW, Warszawa, 1998.

Bauman, Z., Śmierć i nieśmiertelność, O wielości strategii życia [Mortality, Immortality, and Other Life Strategies], Wydawnictwo Naukowe PWN, Warszawa, 1998.

Berger, P., Święty baldachim. Elementy socjologiczneh teorii religii [The Sacred Canopy: Elements of a Sociological Theory of Religion], Zakład Wydawniczny Nomos, Kraków, 1997.

Buber, M., Ja i Ty [I and Thou], Instytut Wydawniczy PAX, Warszawa, 1992.

Cicirelli, V.G., Personal Meanings of Death in Relation to Fear of Death, Death Studies, 22 (8), 11/1998.

Feifel, H. \& Branscomb, A., Who's afraid of death. Journal of Abnormal Psychology, 81/1973.

Freud, S., Our Attitude Towards Death, [in:] idem, Reflections on War and Death, New York, 1918. https://www.bartleby.com/282/2.html

Gadamer, H.G., Prawda i metoda. Zarys hermeneutyki filozoficznej [Truth and Method], trans. B. Baran, Inter Esse, Kraków, 1993.

Gadamer, H.G., Doświadczenie śmierci [The Experience of Death], trans. A. Przyłębski, [in:] idem, O skrytości zdrowia [On the Secretiveness of Health], Poznań, pp. 79-90, 2011.

Gesser, G., Wong, P.T.P., Reker, G.T., Death Attitudes across the Life-Span: The Development and Validation of the Death Attitude Profile (DAP), OMEGA - Journal of Death and Dying, 18 (2) 03/1988.

Gorer, G., The Pornography of Death, [in:] G. Gorer (ed.), Death, Grief, and Mourning. Doubleday, New York, 192-199, 1955.

Heidegger, M., Bycie i czas [Being and Time], trans. B. Baran, Wydawnictwo Naukowe PWN, Warszawa, 1994.

Howarth, G., Death and Dying. A Sociological Introduction, Polity Press, Cambridge, 2008.

Jankélévitch, V., Tajemnica śmierci i zjawisko śmierci [The Mystery of Death and the Phenomenon of Death], [in:] Antropologia śmierci. Myśl francuska, selection 
and trans. S. Cichowicz, J. M. Godzimirski, Wydawnictwo Naukowe PWN, Warszawa, 1993.

Jankélévitch, V., To, co nieuchronne. Rozmowy o śmierci [The Inevitable. Conversations About Death], PIW, Warszawa, 2005.

Kaczmarek, A., Śmierć. Poszukiwanie znaczenia w kontekstach kulturowych, społecznych i politycznych [Death. The Search for Meaning in Cultural, Social and Political Contexts], [in:] Teka Komisji Politologii i Stosunków Międzynarodowych PAN, 4/2009.

Kastenbaum, R., Śmierć psychologiczna [Phychological Death], [in:] L. Pearson (ed.), Śmierć i umieranie. Postępowanie z człowiekiem umierającym [Death and Dying. Dealing with the Dying], PZWL, Warszawa, 1973.

Kielanowski, T., Przedmowa [Intorduction], [in:] L. Pearson (ed.), Śmierć i umieranie [Death and Dying], PZWL, Warszawa, 1975.

Kolbuszewski, J., Kryzys, pornografia i renesans śmierci [Crisis, Pornography and the Renaissance of Death], [in:] J. Kolbuszewskiego (ed.), Problemy współczesnej tanatologii [The Problems of Contemporary Thanatology], vol. I, WTN, Wrocław, 1997.

Kübler-Ross, E., Rozmowy o śmierci i umieraniu [Conversations about Death and Dying], PAX, Warszawa, 1979.

Kübler-Ross, E., Życiodajna śmierć [Life-giving Death], Księgarnia św. Wojciecha, Poznań, 2005.

Levinas, E., Całość i nieskończoność, Esej o zewnętrzności [Totality and Infinity. An Essay on Exteriority], PWN, Warszawa, 2012.

Makselon, J., Struktura wartości a postawa wobec śmierci [The Structure of Values and Attitudes Towards Death], Katolicki Uniwersytet Lubelski, Lublin, 1983.

Makselon, J., Lęk wobec śmierci. Wybrane teorie i badania psychologiczne [The Fear of Death. Selected Theories and Phychological Research], Polskie Towarzystwo Teologiczne, Kraków, 1998.

Mellor, P., Death in High Modernity: The Contemporary Presence and Absence of Death, [in:] D. Clark (ed.), The Sociology of Death, Oxford University Press, Oxford, 1993.

Neimeyer, R.A. (ed.), Death Anxiety Handbook: Research, Instrumentation, and Application. Taylor \& Francis, Washington, DC, 1994.

Ostrowska, A., Śmierć w doświadczeniu jednostki i społeczeństwa [Death in the Individual and Social Experience], Wydawnictwo IFiS PAN, Warszawa, 1997.

Szaniawski, T., Typy postaw wobec śmierci a osobowość [Types of Attitudes Towards Death and Personality], PAT, 1998.

Thomas L.V., Tworzenie tanatologii [Creating Thanatology], trans. M.L. Kalinowski [in:] Wymiary śmierci, Słowo/obraz terytoria [Dimensions of Death, Word/image territory], Gdańsk, 2002.

Tischner, J., Myślenie wedtug wartości [Thinking in Values], Wydawnictwo Znak, Kraków, 2005.

Tischner, J., Filozofia dramatu [The Philosophy of Drama], Wydawnictwo Znak, Kraków, 2006.

Tomer, A. \& Eliason, G., Toward a Comprehensive Model of Death. Death Studies, 20, 1996.

Vovelle, M., Historia ludzi w zwierciadle śmierci [The History of Humanity in the Light of Death], trans. M. Ochab, [in:] S. Rosiek (ed.), Wymiary śmierci [Dimensions of Death], Gdańsk, 2002. 
Vovelle, M., Śmierć w cywilizacji zachodu. Od roku 1300 po współczesność, Stowol obrazlterytoria [Death in the Western World. From 1300 to the Contemporary Era, Word/image/territory], Gdańsk, 2008.

Vuillemin, J., Śmierć w oczach zwierzęcia [Death in the Eyes of Animals], [in:] S. Cichowicz, J.M. Godzimirski (ed.), Antropologia śmierci. Myśl francuska [The Anthropology of Death. French Thought], PWN, Warszawa, 1993.

Walter, T., The Revival of Death, Routledge, London, 1994.

Wittgenstein, L., Tractatus logico-philosophicus, trans. and introduction by B. Wolniewicz, Wydawnictwo Naukowe PWN, Warszawa, 2000, p. 81, teza 6.431.

Yalom, I.D., Staring at the Sun: Overcoming the Terror of Death, Jossey-Bass, San Francisco, CA, 2008. Reviewed by Yvonne B. Bregman, M.A., M.S.W., Ridgefield, CT.

Ziemiński, I., Twoja śmierć. Próba eksplikacji doświadczenia śmierci [Your Death. An Attempt to Explain the Experience of Death], "Diametros" no. 11, 2007.

\section{Internet sources}

Gebert, K., Jednostka wobec śmierci [The Individual in the Face of Death], http:// www.jednota.pl/archiwum/o-smierci/303-jednostka-wobec-mierci

Gogacz,M.,http://katedra.uksw.edu.pl/gogacz/artykuly/028_filozof_ujecie_smierci_ wydruk.pdf

https://www.bloomberg.com/news/articles/2020-04-22/iceland-is-the-perfectcountry-for-studying-covid-19

https://covid-model.net/

https://www.bloomberg.com/graphics/2020-coronavirus-cases-world-map/

https://www.npr.org/sections/health-shots/2021/02/06/964527835/why-thepandemic-is-10-times-worse-than-you-thin

Jastrzębski, J., Psychologiczny wymiar lęku przed śmiercią [The Psychological Dimension of the Fear of Death], http://www.psychologia.net.pl/artykul.php? level $=209$ 

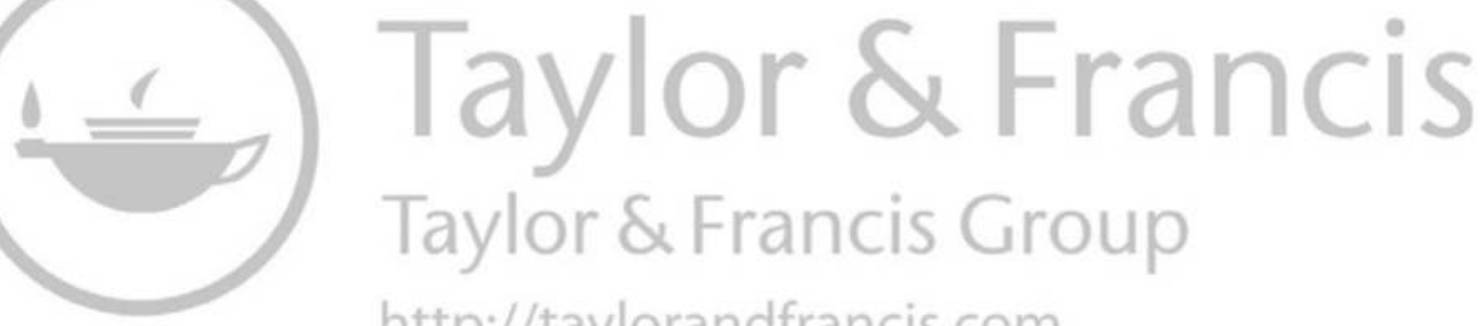
http://taylorandfrancis.com 


\section{Part 2}

Social attitudes and strategies 

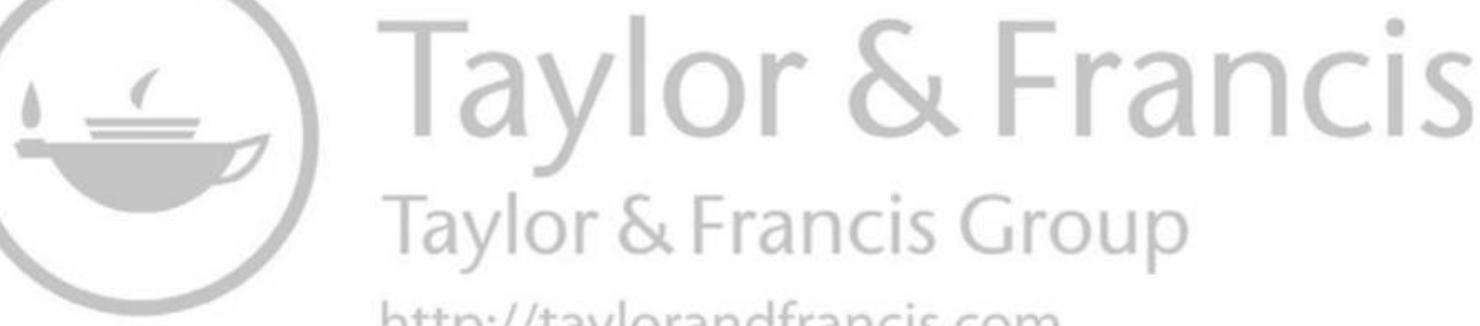
http://taylorandfrancis.com 


\title{
4 Unmasking features of the state of the epidemic
}

\author{
What is the uniqueness of the \\ position of older people in \\ Poland?
}

\section{Mariola Racław and Dobroniega Głębocka}

The chapter concerns the situation of older persons in Poland, observed from March 2020 (the so-called first lockdown) to autumn 2020 , i.e., during the emergence and increase in the incidence of the Covid-19 epidemic. Widespread information on the risks related to the threat and mortality from Covid-19 exposed the critical situation of older people as a sub-population at risk of death from the use of comorbidities. We recognise that the introduction of the state of the epidemic in Poland showed real trends of social isolation and social selection of older adults. It results from the primacy of population survival, rooted in society. Disclosed infections and an increase in mortality in nursing homes, the need to regulate medical equipment, isolation from other social groups, justified public health issues, de facto discovered deficits of various groups to protect of older people. Physical protection of life became the cause of the death in the social dimension. In connection with alarming phenomena we pose questions about ways of enhancement of family care potentials and local community care potentials. In this chapter, we analyse the available data and formulate theses regarding the impact of the medicalisation of old age (intensified by the pandemic) on the position of older adults and their social perception, and the consequences of medicalisation for the development of 'silver social work' in Poland.

\section{Introduction}

In Poland, the first case of SARS-CoV-2 was confirmed on March 4, 2020. The state of pandemic was declared in mid-March 2020. As in many countries, it was a shock event for the society in this country also: We understand shock event as a focusing event (...) that has created considerable stress waves in a society (Kawczyńska-Butrym 1996). Kaufmann and colleagues (Kawczyńska-Butrym, 1996) emphasise that these are sudden events, 
relatively rare, with harmful (or judged as harmful) results for society. Such an event has a social impact, causing a wave of shock among politicians, the media and the public. It focuses attention on the problem, which results in the introduction of specific solutions, often with long-term effects and long duration. Sometimes along with the 'turning point', when people feel that the problem has been solved, social tension disappears and the problem is considered as a thing of the parts.

After over a year of the epidemic in Poland, when the country is struggling with growing economic and social problems (Duszyński et al. 2020), it is difficult to indicate which solutions introduced during the pandemic will be maintained in social life and what processes will be initiated or strengthened by them. It seems to us that what is visible and will probably leave lasting results is the consolidation and acceleration of the medicalisation process of old age in Poland with its social consequences. From the outset, the narrative in the public and political spheres was about public health. According to the Polish sociologist Jan Domaradzki, health and life gained the status of superior values during the pandemic ('Coronavirus victims in Poland: What is the average age 2020'). As all government actions were accepted as necessary to protect the population and health of individuals, this was widespread and unquestioned. Their acceptance was related to the experience of a socio-cultural trauma, as a significant number of Poles lost control over the events in their lives.

The politicisation of the epidemic, understood as its introduction to the political game, was associated with a strong medicalisation of various areas of social life. The epidemic per se is related to health and medical issues. In the initial stage of the pandemic, a lock-down was introduced in Poland, the wearing of masks, hand hygiene, physical distance were ordered, remote work was introduced and service points were closed. The public was informed and continues to be informed about infections, illnesses and deaths caused by COVID-19. This coronavirus-induced medication of social life also meant medication of old age in Poland. The thesis of the chapter is that the visible trends in the medicalisation of old age in Poland, which have so far been limited due to the poor condition of public health services and the low income of older Poles, have been significantly reinforced by the emergence of the pandemic. They have also gained strong social legitimacy, stemming from the ideology of protecting older people from the consequences of coronavirus infection. The protection of the older adults has strengthened the tendency towards their social isolation. In our opinion, the experience of the pandemic will contribute to the repositioning of the older adults, medicalisation of their problems and separating them from other social groups.

Another thesis we put forward relates to the impact of the pandemic on the shaping of a new paradigm of working with and for the older adults. The paradigm of socialising people and places, derived from Simmel's understanding of socialisation, makes it possible to see the high-level goals of social work. They are aimed at creating weaker ties of older people in 
their living environments and changing the stereotypical, negative image of older people in Poland. We believe that in the long run, an unintended result of the pandemic, which should be treated as an anticipated reversal effect, will be: (a) the crystallisation of the concept of social work with and for the older adults in Poland, which takes into account the effects of the pandemic, (b) the development of new social practices, resulting from the involvement of social work in building a moral space in the living environment of older people, and (c), increased interest of representatives of helping professions and social politicians in the concept of the caring potential of the family and community (Kawczyńska-Butrym 2008; Wieczorkowska 2018).

\section{The SARS-CoV-2 epidemic in Poland and the older adults: statistical data}

According to official government data in Poland in September 2020 (as of 07.09), since the beginning of the epidemic, over 71,000 infections, over 55,000 recoveries and over 2,000 deaths have been recorded. In September, the current number of patients was almost 14,000. According to the data of the Central Sanitary Inspectorate, in mid-April 2020, in the total number of coronavirus deaths, the share of deaths in the 60-69 age group was about $20 \%$, in the $70-79$ age group - 33\%, and in the $80-89$ age group - almost $30 \%$. The percentages in the remaining age groups did not exceed the value of six percent (Ossowska 2020). These data were confirmed by the Polish Ministry of Health in the subsequent August of the same year. As much as $70 \%$ of the coronavirus fatalities were over 70 years old (Maj \& Skarżyńska 2020). The co-occurrence of additional diseases such as heart disease, diabetes, hypertension, lung and kidney cancer was not without significance. Patients with reduced immunity and those who had organ transplants are particularly vulnerable to infection and death.

Over-representation of deaths in older age categories is a phenomenon that occurs in all countries affected by the pandemic (Kocejko 2020). In addition to many important factors influencing population health data (e.g. availability and quality of health care, behaviour limiting morbidity and mortality), the age structure plays an important role in the analysis of information. In Kocejko’s words,

Age structure (the share of the total population in each age group) alone cannot tell us which countries will be hardest hit in the pandemic but can provide important context in understanding and responding to the crisis. If two countries have the same age-specific mortality rates from COVID-19, the country with an older population would have more deaths per 1,000 people - a higher crude death rate - from the disease than the country with the younger population.

(Kocejko 2020: online document) 
This means that Poland, as a country with an advanced ageing process, will have a relatively high mortality rate due to coronavirus, including in the sub population of older people. In 2018, the share of the population aged 60 and over in the total population was $25 \%$ (Statistics Poland, 2020). Among the sub population of the older adults, about $45 \%$ of people aged 70 and more were recorded. According to the forecasts of the Central Statistical Office, in 2050 the older adults will constitute $40 \%$ of society.

Additionally, the health condition of Polish older adults should be considered. Unfortunately, it is not good. The results show that Poland ranked 88th out of 195 countries when the age-related disease burden rate was taken into account. The age-related disease burden rate is based on the level of disability adjusted life years (DALYS; healthy years lost) per 1,000 adults ages 25 and older (Statistics Poland 2020). This is confirmed by Polish epidemiological data, which indicate multiple morbidity in the older adults (Duszyński et al. 2020). The results of the self-assessment of health made by Polish older adults in 2018 are not optimistic (Statistics Poland, 2020). They rarely indicate good or very good health - only $1.9 \%$ of people over 60 considered their health to be very good, while $23.8 \%$ of older adults indicated "good" as an answer. Sixty-seven percent of people of this age have had long-term health problems or chronic diseases that have (or are expected to continue) for six months or more. In 2018, out of 100 older adults, 69 wanted to receive treatment or testing, of which $87.7 \%$ of them benefited from the test or treatment each time they needed it. Distant appointments, financial difficulties and too long a geographical distance were cited as obstacles to accessing doctors. Additionally, in Poland, we note a low level of development of gerontology in the field of public services. There are 146 geriatric outpatient clinics, with the main locations in three regions: Silesia, Mazovia and Small Poland (Statistics Poland, 2020). Older people in Poland also lack sufficient funds to purchase health services from the private market.

\section{Politicisation of old age in Poland as a precursor to its medicalisation in a pandemic}

In Poland, the Statistics Poland collects data on older people, not only in demographic and epidemiological terms, but also in social dimension. Research on the process of population ageing and the situation of older people is undertaken by researchers from various disciplines and has a long tradition. Those developed from the beginning of the 1990s focus on the aspect of demographic imbalance and the process of population ageing. At the same time, the older adult citizen related policy was conceptualised and started to be implemented, and ageing became a political problem (Duszczyk et al. 2019). The politicisation of the ageing process proceeded with variable intensity and in stages: from retirement demography (ageing and the pension system), through apocalyptic demography (the low fertility trap and the ageing of the population) and institutionalisation of older adult policy (the 
emergence of appropriate government offices dealing with the issue of ageing and old age) to the intensification of such a policy (reform of the pension system, pronatalist program and changes in long-term care) (Duszczyk et al. 2019). The issues of demographic ageing have become a reference point for many specific policies, including health policy, the labour market and social assistance.

As far as social assistance is concerned, it does not have precisely and clearly defined goals of action towards the older adults. In the Act on social assistance in force in Poland (Journal of Laws of the Republic of Poland) there is no provision on guaranteeing social assistance in the event of old age, loneliness and helplessness, which places the older adults in a negative position in relation to representatives of other groups who have guaranteed rights under certain risks. The income criteria adopted, setting thresholds for obtaining financial, material and service benefits for older people, result in a reduction in the number of people receiving social assistance which is not justified in view of the scale of the needs of that group (Sztompka 2002). The current legal regulations do not clearly define the obligations of social services towards the oldest older adults in their living environment (Kaufmann et al. 2016). In addition, the specificity of social work with the older adults (and on their behalf) is defined in the course of supporting the older adults in the environment of their residence and/or stay. It is an expression of the adaptation of values and principles to the institutional and organisational requirements of the implemented practices. The problem of instrumentalising the values and principles of social work with the older adults in social assistance is indicated by research results. In our opinion, the problems outlined above strengthen the processes of politicising old age in the face of many unspecified goals of public tasks. In turn, the politicisation of old age makes it possible to make its medicalisation dynamic in the state of epidemics.

\section{The state of the epidemic and legitimising the medicalisation of old age}

When analysing the population ageing process, Polish social researchers focus not only on its scale and pace, but also on the qualitative aspects of its course. There is evidence that the process of medicalisation of ageing has begun in Poland, but it is not as advanced as in other Western European countries and the USA (Statistics Poland 2018). To medicalise ageing means treating ageing and old age in terms of a disease, not a natural stage in an individual's life (Kanios 2018). It manifests itself in the perception of ageing as a medical problem, which is reflected in various social practices (Kanios 2018). As Nowakowski and Nowakowska conclude, research on old age and ageing undertaken in this approach aims to identify the aetiology of ageing (at the cellular level), which will allow specialists in the field of medicine and pharmacy to intervene in order to inhibit it in specific individuals (Nóżka 
\& Smagacz-Poziemska 2014). Turning old age into a medical problem has consequences in economic, medical and social terms (Golden Book of Good Practices for the Social Participation of Elderly People 2018). Wieczorkowska, based on a review of international literature, indicates the consequences of medicalising old age in the social dimension: strengthening stereotypes about old age, secondary deviation, self-marginalisation and self-blame, dependence on institutions and learned helplessness, lowering the subjective threshold of old age, new nature of the senior-family relationship, escalation of gerontophobia, negation of the possibility of discovering the meaning of natural ageing, ignoring other dimensions of old age, transforming the technological imperative into a moral one (Golden Book of Good Practices for the Social Participation of Elderly People 2018).

The medicalisation process itself is often considered in the context of increasing social control over individuals. It is emphasised that the health care system is intended both to isolate individuals who pose an epidemiological threat and to identify healthy people who are not fulfilling their social roles (Ofiary koronawirusa w Polsce. Jaka jest średnia wieku? [2020]). Social control is supposed to lead to an increase in the self-control of individuals, because health is not only a right of citizens, but an obligation, especially sanctioned during an epidemic. At present, the obligation to estimate health risks and minimise damage to health has been sharpened by legal regulations and by social pressure and ostracism imposed on those who do not listen to government recommendations. In Poland, in social media and news portals, there are heated discussions of outraged citizens who point out the irresponsible behaviour of their compatriots (e.g. the lack of masks in public space), especially young people. Importantly, research shows that people over 55 years of age - compared to other age groups - show the highest degree of obedience to government recommendations and introduced restrictions (Mrowiec 2020a). Despite the emergence of groups denying the existence of a pandemic and rejecting government orders, the discourse of protection, which legitimises the suspension of certain civil liberties, seems stronger than the opposite trend.

In times of a declared pandemic, it seems rational to emphasise taking care of one's own and public health as a civic duty. However, it has current and future consequences for the situation of older people and their social position:

- It seems that focusing the message on the mortality of the old people as a result of SARS-CoV-2 perpetuates a homogeneous image of the older adults (weak organisms, multiple diseases, low physical and mental capacity), who, as passive and defenceless human beings, must be protected. The homogeneity of the perception of a certain category together with a strong belief in the relationship between health, fitness and age form the basis of ageism. In the last decade in Poland, the established stereotype of old people who withdraw from social life 
with age was slowly being deconstructed. We forecast that in the time of a pandemic, this deconstruction process will stop, or perhaps will even be reversed. There may be a chain of feedback loops that will not only restore the status quo, but also change the wider social structure (Trawkowska 2016: 427). It means that not only will the stereotype of a sick and weak senior persist, but there may also be tendencies to isolate the older adults as a method of their effective protection (see recommendations Duszyński et al. 2020: 41). Instead of being included in social life, their institutionalised exclusion will gain social legitimacy.

- Related to the above process is the shift of the subject of tensions in intergenerational conflict. In Poland, due to strong social expectations concerning the support of the older adults by their relatives, this conflict was not very exposed in the cultural dimension. Rather, possible tensions between the categories of young and old people were emphasised against the background of the division of limited public funds allocated to intangible benefits and services. The new dimension of the intergenerational conflict is the biomedical dimension which, along with the strong medicalisation of old age, will point to the social "burden" of old age in the economic dimension (costs of treatment, hospitalisation, social benefits) and due to restrictions on civil liberties (see a statement of the Polish influencer: Scommegna et al. 2020). All manifestations of positive discrimination, e.g. the "hours for seniors" introduced on April 20, 2020 (two hours in retail outlets dedicated only to people over 65) aroused social irritation related to the need to tolerate the privileges of the older-unproductive citizens, despite the generally accepted the ideology of protecting them as vulnerable citizens.

- Exposing health as a superior value that legitimises the restriction of civil liberties also shows a new aspect of citizenship. So far, debates about older adults in Poland have focused mainly on issues of their social citizenship (social benefits, issues of economic status). Along with advanced medicalisation in Western European countries and the USA, and even the genetisation of social life, biological citizenship is revealed, as "the development of genetics makes biology become political" (Domaradzki 2012: 18). It is on the basis of biological criteria that new categorisations of risk groups are created. The language, based on biological categories, which speaks about people, at the same time creates an image of self-aware and responsible patients (...). The goal of the state is largely achieved: individuals become active citizens and not just recipients of biomedical services". (ibidem). So far, the issue of biological citizenship has not been addressed in Poland. We forecast a change in this area and the inclusion of health and fitness as a moral imperative and civic duty. This corresponds to the postulates of active ageing, which assume the reduction of dependence of the older adults as a result of an increase in the average life expectancy in health (LeszczyńskaRajchert 2016: 27). 
The above directions of change seem to be contradictory. However, this is not necessarily the case. Protection and isolation tendencies can be applied en bloc under the state protectorate. At the same time, an alternative image of a healthy older citizen will be promoted, which may be difficult to achieve due to the post-COVID state of the national economy. Nevertheless, the message about protecting oneself against the risk of losing health and fitness as a citizen's duty will be strengthened (Arnoldi 2009). This means that the absence of such actions will be judged as civic negligence and recklessness in relation to the individual regardless of the real possibility of dealing with the risks and uncertainties (Blaxter 2004). In this aspect, the support received in the local environment and the network of institutions, such as social assistance and social work, will be important.

\section{Social work with and for the older adults in Poland after 1990}

In Poland, professional social work with and on behalf of the older adults is in its infancy. After the introduction of the Social Welfare Act (1990) in Poland, which replaced the Social Welfare Act of 1923, not only has there been a significant change in the position of the old people as a beneficiary of social welfare benefits, including social work, but also the very concept of social work with the older adults has been disintegrated. The complexity of the older population in Poland is not conducive to crystallising this concept. Also the use, in the diagnosis and design of care and assistance activities, and in social assistance and in social work for these people, of the typical criteria: gender, age, income, health condition/disability level, family situation, place of residence of the older adults (social assistance home, living with the family or alone) limits or even prevents social work from going beyond the objectives of minimising poverty and alleviating selected consequences of old age in the environment where the older person lives or stays.

This thesis is illustrated by an attempt to organise and describe social work with the older adults, which takes into account the nature of the space for carrying out social work (home space, living environment, institution of 24-hour care) and the degree of independence of the older adults ('dependent/independent seniors'), by Szarota (2015). Independent older adults can benefit from many community-based social support institutions (social welfare centres, counselling centres, senior citizens' clubs, associations and other social organisations (NGOs), third age universities, senior citizens' academies). A dependent senior citizen can use day care facilities, nursing homes, care and treatment facilities, geriatric wards and hospitals and hospices. Services are provided (care, nursing services, neighbourhood care services in the home space) where older adults (dependent and independent) live. The home space may also be a day support centre or assisted housing. Szarota's (2015) proposal clearly indicates that the type of space and the state of independence of an older adult are decisive determinants for the 
entire practice of social work with older adults, of an interventionist and preventive nature.

Another proposal for describing social work with older adults relates to the instruments of a social worker. Models of social work and the method of social work set the typical goals of social work with and for older adults (Kaufmann et al. 2016; Maj \& Skarżyńska 2020): supporting older adults in their development, activating the older adults, preventing marginalisation, improving the quality of life of the older adults, preparation for old age and education for old age. It is assumed that practice patterns in social work, i.e., horizontal models (combining selected, different theoretical approaches in social work) and/or vertical models (combining basic methods of social work) of social work, should serve the achievement of these goals.

After 1990, the belief was systematically expressed that in the Polish context, social work with the older adults and for their benefit should be and is aimed at (Kaufmann et al. 2016):

- $\quad$ professional activity based on principles and working methods specific to the profession of social worker

- a social service integrated with other forms of support for older adults and their families (respite care, neighbourhood care, financial and material benefits, senior citizens' stay at a social welfare home or other 24-hour and day care facilities)

- a social service integrating new and old helping professions that have emerged in the field of assistance, care and activation of the older adults (assistant of an old person)

- a social service that integrates informal social support systems and institutionalised systems, which are set as social policy objectives (including social assistance policies) for older adults and their families. On the basis of regional and local diagnoses, these objectives should be achieved by public and non-governmental social assistance and religious organisations, in cooperation with institutions representing health service, education system, cultural institutions and other institutions important for this phase of life

We believe that the attempts made in the circle of theoreticians and researchers to create models of social work with older adults, based on selected criteria (Kaufmann et al., 2016), as well as standards of social work with older adults developed in cooperation with practitioners (Balon et al. 2011) sanction the status quo in the sphere of social practices. They do not lead to fundamental transformations of the existing models of intervention and prevention, and social practices based on these models, in the institutional space, home and living environment. The main priorities of Polish senior policy: changing the image and situation of older people in society, developing social and care services tailored to the needs of older people, developing an educational offer for old people in areas that meet their needs, 
supporting the development of systemic solutions for the organisation of various forms of learning for older people, including the movement of the Universities of the Third Age, the development of active citizenship of older people, the development of volunteering among older people (Sztompka, 2002), directed the unused potential of "silver social work" in Poland to (Racław, 2011):

- promoting the issue of the rights of older people and disseminating models of successful ageing in the family and in the institutional space,

- development of new specialisations in social work supporting the idea of dignified ageing, such as: oncological social work, social work in palliative care, social work with older and disabled people and their families.

Analyses of practices present in social work with the older adults indicate differentiated use of basic methods of social work in the living space of older people. The predominant methods of assistance for these people and their families are case work and counselling. Small group work, team work and community work models are most commonly used in institutional settings (senior citizens' clubs, day care centres, community centres) (Krzyszkowski 2013). A challenge for social workers and other representatives of the welfare professions is to take preventive and intervention measures in families where there is no interest in the fate of the older adults and where the matter of care in relation to these people is neglected. An attempt by Zofia Kawczyńska-Butrym to define the family's caring potential (Kawczyńska-Butrym 2011; Kijak \& Szarota 2013) was aimed at enriching diagnostic tools in social work with the family, which, in the area of assistance and care for the older adults, is only just becoming institutionalised and is, in comparison with other social work models, the least conceptualised. It cannot be replaced by the transfer of care services and forms of neighbourly assistance that should complement social work with the family. Meanwhile, research shows that these forms of care are territorially dispersed, and at the same time often offered on the basis of non-substantive criteria, which means that they do not reach all people and families in need or satisfy these needs only to a certain extent (Lemke 2010; Szarota 2015).

\section{Could the pandemic help to change the paradigms of social work with and for the older adults?}

After 1990, bottom-up social practices were slowly developing in Poland, which in the area of social work with and for the older adults could be seen as an expression of a change in the attitudes of social assistance workers towards the older adults, as well as a readiness to take up an urgent challenge a change in social attitudes towards the older adults in their living environment and institutional space. In public and media debates, between 1990 and 2013, the ageing of the population as a topic in its own right occupied an 
increasingly important place (Racław 2011), but particularly in the context of changes in the pension system, discussions about the retirement age, the debate about the birth rate and the effects of migration. Significant problems: the health of older adults and neglect in the care of the family, institutional care for older adults as well as the inefficiency and ineffectiveness of local support systems for older adults and families (Sobiesiak-Penszko \& Koziarek 2016), have not, in our opinion, been clearly and consistently brought into the public space. They have become the subject of discourse at a lower level. Internal discourse in social work deals with selected problems of the older adults, their families and the issue of effectively limiting some of the consequences of old age, which are acute at the local level, in the paradigms of care, assistance and activation of the older adults that are relatively better established in social assistance and social work.

The pandemic drew attention to the deficits of public social assistance for older adults and the deficits of non-governmental organisations supporting older adults, their careers and families with the older adults (Krzyszkowski 2013). The research shows that social assistance, non-governmental organisations and local governments during the pandemic struggled with the following problems:

- the need to adapt the functioning of facilities used by the older adults and their careers to the regime and restrictions accompanying the pandemic, which led to changes in the organisation of work of facilities in which gerontological social work is developing;

- the need to develop an appropriate response to the intensity of limitations that have appeared in the everyday life of older people, their families, caregivers in connection with: (a) quarantine and problems that it brought into the lives of people, families and the living environment; (b) a sense of loneliness and the disappearance of social relations among the older adults - clients of social assistance; (c) low digital competences of older adults; (d) difficulties in caring for the older adults, including the provision of care services, clearing access to health and social services, coordinating various services available in the living environment;

- the need to create new practices in helping and caring for older adults, their caregivers and families, in connection with the deterioration of the mental condition of older people, intensification of violence in families and, confirmed by researchers and experts, deterioration of the quality of life of older persons in Poland.

The studies also observed a direct impact of the pandemic on the development of gerontological social work, implemented in social assistance in the living environment of older adults, in social welfare homes and day support centres. The pandemic limited the direct relationships of older persons and their careers with social workers, and thus the possibility of providing emotional support in these relationships, necessary in the event of crises 
experienced by the older adults, their careers and family members. The research showed that social workers experienced three types of difficulties in conducting gerontological social work:

- limitations in interpersonal communication, making it difficult to diagnose the real situation of older adults and to provide emotional support;

- restrictions on access to the most important institutions that provide regular psychosocial and health support, as well as shops and offices;

- coping with the specific reactions of older people and one's own fears resulting from the lack of a sense of security at work in direct contacts with people.

The results of the research conducted by Beata Ziębińska indicate that the pandemic intensified work on a model of crisis intervention as part of gerontological social work conducted in Polish social assistance and created friendly conditions for coordinating support and establishing cooperation in the local environment by representatives of social welfare and volunteers, non-governmental organisations and informal groups. Increased interest in care services on the part of older persons and families with their was observed, as well as intensification of neighbourly help in the living environment of older adults.

We believe that the state of the pandemic clearly highlights some marginalised threads in social assistance and that are important for the emerging concept of social work with and for older adults. The theme of the state of health of Polish older adults, which was systematically raised during the pandemic, may therefore contribute to revitalising the issue of health in social work with and on behalf of older adults in social support institutions and in institutions that educate people for social work. Due to the scale of family involvement in caring for older adults in Poland, as well as the problem of family support noticed by social assistance due to the deteriorating health condition of family members related to care, it is highly probable that local practices will be intensified (in social work schools, social projects) supporting older adults and families with older adults.

Reports of difficulties in providing services in the living environment of older adult citizens (Krasicka 2020), as well as concerns about the safety of service providers and restrictions in the contact between service providers and service users, can be a positive reinforcement in the search for solutions in social work, e.g. in long-term care, in palliative care, and with regard to under-utilised tools in social work, e.g. the case management model for the care of people who are both old and disabled.

It seems to us that the state of the pandemic may strengthen and even intensify the processes of building the identity of social work in the various social support institutions used by older adults. This should take place in occupational therapy workshops, where research shows that the population of disabled people is clearly ageing (Jarosz \& Keneda 2020). 
The potentialand, at the same time, positive consequences of the pandemic for the development of social work with and for the older adults in Poland, as indicated above, lead us to conclude that this difficult situation may accelerate work on the concept of the caring potential of local communities (Wieczorkowska 2018) and the concept of family caring potential (Kawczyńska-Butrym 2008; Kijak \& Szarota 2013), which has begun. Both of these concepts are the starting point for a paradigm shift in supporting the older adults and their family in the local environment. The new paradigm, which stems from the need for greater socialisation of activities to create a senior-friendly social space based on 'dense' relations with and caring for others, stands in opposition to the current understanding of older adults' socialisation as processes of primary and secondary socialisation to the socially expected roles assumed in the ageing process (Nowakowski \& Nowakowska 2010).

A factor conducive to the acceleration of work on the changed paradigm and new concept of social work, and in particular social work with the family and with the community experiencing the consequences of old age, may be observed in studies (Duszyński et al. 2020) in the trend of increasing trust of Polish society in institutions at the local level, which include municipal social welfare centres and family welfare centres. They should therefore have a keen interest in the evaluation of social work. Both concepts can be treated as potential standards against which social work practices should be assessed and evaluated.

We forecast the emergence and further development of new social practices, resulting from the involvement of social work in building moral space in the environment where older people live (Wieczorkowska 2018). This direction has already been noticed, as indicated by good practice projects, in which the theme of intergenerational understanding, integration of generations in education, culture, political activity and voluntary activities, counteracting self-exclusion and isolation of older generations is addressed (Analysis of the activity of occupational therapy workshops in 2008, 2009).

However, the positive consequences of the pandemic that we have noticed: the development of a clearer identity of social work with and for seniors, a coherent concept of this work based on the new paradigm of socialisation of care in the living environment, may be limited or even inhibited. The tension signalled in the relationship between carers and the cared for can be interpreted as traumatic, for both sides, experience of choosing values in a conflicting situation of opposing obligations (between self-protection of the carer and protection of the "fragile" care receiver). At the micro-social level, in the relationship of help and care, tendencies to control and objectify the charges, especially in the conditions of providing care in institutions, towards older people and in poor health, may even intensify. Whereas, older adults using the support of centres and groups in the living environment may be encouraged by representatives of helping professions to greater self-discipline and self-control, which may trigger self-isolation mechanisms among older adults. 


\section{For further discussion...}

Health and taking care of it has become a matter of common concern (Arnoldi 2009) and has been politicised (Blaxter 2004). In the societies of the 21st century, which are described as societies of global risk (Beck 2012), international disasters on a large scale are not always easy to predict, but are inscribed in the specificity of the era. Currently, a health shock event is in the process of being reduced to the technical aspect of risk. Risk factors are estimated for specific population groups. Unlike in earlier eras, death ceases to be accidental and becomes a combination of individual properties (resulting, among other things, from previous negligence), forming the individual's biosocial identity (Leon et al. 2014) and environmental conditions. The pandemic period reinforces the importance of experts who provide guidance based on scientific evidence. However, in Poland, expert discussions and political debates introduce informational chaos, which increases the sense of uncertainty and fear in society (Mrowiec 2020b).

During a pandemic, old routines must be changed. Polish older adults are recommended to limit social contacts (even with relatives) as much as possible and, in the case of necessary contacts, to observe the sanitary regime (Duszyński et al. 2020). As experts from the Polish Academy of Sciences point out, the older adults face a challenge, i.e., 'inventing' a new way of functioning in society, mastering new techniques of communicating with family and friends (e.g. social media), developing new interests (Duszyński et al. 2020). The 'inventing' of a new lifestyle, called preventive practice, becomes the task of a senior citizen with a specific bio-social profile. But will the institutions available in local communities support this process?

Meanwhile, the social work with and for older adults that is being created in Poland faces a double challenge. The first relates to direct practice with and for older adults - how the provision of assistance and care should look like in a situation of requirements and restrictions imposed on the older adults, their careers and institutions providing services in a pandemic situation. Relations at the microstructural level are accompanied by fears and concerns of the providers and receivers of assistance.

The second challenge, present at the meso-structural level, concerns developing a new concept of social work with and for the older adults. In its development, we attribute a significant role to the institutions and organisations dealing with the politicised problem of the pandemic and its effects on the population of older people, who receive various forms of care and assistance from these institutions. There are premises (Duszyński et al. 2020; Analiza działalności warsztatów terapii zajęciowej w 2008 roku., 2009) that routine social work with and for the older adults will be enriched with projects aimed at new goals, creating a more socialised space of local care for the older adults than before. But we cannot rule out another scenario either. In the coming years, it can be expected that the preventive projects developed by local and regional institutions will "replace" projects developed 
from the bottom up by older adults themselves. Our analyses allowed us to formulate the following conclusions:

- The previously observed medicalisation of old age in Poland has intensified during the fight against the COVID-19 epidemic. Life and health became the main value that contributed to the introduction of social isolation as an instrument of protection for the 'weak', i.e., older persons.

- The actions taken by the government in the fight against the pandemic contributed to the consolidation of the social perception of older persons as a homogeneous group, requiring special support and privileges threatening the civil liberties of other social categories.

- In Poland, gerontological social work is only just developing. The shock related to the course of the pandemic made it possible to verify routine care and support practices. It also revealed the need to rethink the relationship between the health care system and social assistance.

- The period of the pandemic fosters the emergence of grass-roots, innovative social practices in the field of assistance and care for older persons and their families in the living environment, strengthening the de-institutionalisation process.

\section{References}

Analysis of the activity of occupational therapy workshops in 2008. (2009). Raport z badania zrealizowanego przez Centrum Badań Marketingowych INDICATOR dla Państwowego Funduszu Rehabilitacji Osób Niepełnosprawnych. Warszawa, maj 2009, https://www.pfron.org.pl/fileadmin/ftp/dokumenty/Badania_i_analizy/ Raport_z_badania_-_Analiza_dzialalnosci_wtz_w_2008_roku.pdf

Arnoldi J., Risk, Polity Press, Cambridge 2009.

Balon K., Rutkiewicz G., Staręga-Piasek J., Stec K., Szmaglińska I., Zielony M., Standard pracy socjalnej z osobą starszą, 2011, s. 9-15, http://www.wrzos.org.pl/ projekt1.18/download/SPS_OS2601.pdf

Beck U., Społeczeństwo światowego ryzyka. W poszukiwaniu utraconego bezpieczeństwa, Wydawnictwo Naukowe Scholar, Warszawa 2012.

Blaxter M., Health, Polity Press, Cambridge 2004.

Domaradzki J., Genetyzacja społeczeństwa. Społeczne konsekwencje nowej genetyki, "Studia Socjologiczne" 2012, Nr 205(2), s.7-26.

Duszczyk M., Lesińska M., Matuszczyk K., Upolitycznienie problemu starzenie się społeczeństwa w Polsce. Teoria i praktyka, WUW, Warszawa 2019.

Duszyński J., Afelt A., Ochab-Marcinek A., Owczuk R., Pyrć K., Rosińska M., Rychard A., Smiatacz T., Zrozumieć COVID-19. Opracowanie zespołu ds. Covid-19 przy Prezesie Polskiej Akademii Nauk, PAN, Warszawa 2020.

Golden Book of Good Practices for the Social Participation of Elderly People editions I-III - Publikacja BRPO, Warszawa 2018.

Kanios A., Postawy pracowników zawodów pomocowych wobec osób starszych, Wydawnictwo Uniwersytetu Marii Curie-Skłodowskiej, Lublin 2018, s. 82-90. 
Kaufmann M., Lewandowski J., Choryński A., Wiering M., Shock events and flood risk management: a media analysis of the institutional long-term effects of flood events in the Netherlands and Poland, "Ecology and Society" 2016, 21(4), 51. https://doi.org/10.5751/ES-08764-210451

Kawczyńska-Butrym Z., Niepełnosprawność - specyfika pomocy społecznej, Wydawnictwo Interart, Warszawa 1996.

Kawczyńska-Butrym Z., Wyzwania rodziny: zdrowie, choroba, niepełnosprawność, starość, Wydawnictwo Makmed, Lublin 2008.

Kijak R. J., Szarota Z., Starość - między diagnozą a działaniem, Centrum Rozwoju Zasobów Ludzkich, Warszawa 2013, s. 42-47.

Krzyszkowski J., Pomoc społeczna wobec starzenia się społeczeństwa polskiego. "Przegląd Socjologiczny" 2013, 62 (2), s. 9-31.

Lemke T., Biopolityka, Wydawnictwo Sic!, Warszawa 2010.

Leon M., Ranci C., Rostgaard T., Pressures Towards and Within Universalism: Conceptualising Change in Care Policy and Discourse, in: M. Leon (ed.), The Transformation of Care in European Societies, Palgrave Macmillan, New York 2014, s. 11-33.

Leszczyńska-Rajchert A., Praca socjalna z seniorami w perspektywie geragogiki, Wydawnictwo Uniwersytetu Warmińsko-Mazurskiego, Olsztyn 2016, s. 79.

Maj K., Skarżyńska K., Społeczeństwo wobec epidemii. Raport z badań, Fundacja im. Stefana Batorego Warszawa 2020.

Marody M., Formatowanie społeczeństwa - o starych i nowych sposobach uspołeczniania działań, in: M. Flis, K. Frysztacki, G. Skąpska, P. Polak (ed.), Co się dzieje ze społeczeństwem?, Wydawnictwo Uniwersytetu Jagiellońskiego, Kraków 2012, s. 145.

Nowakowski M., Nowakowska L., Medykalizacja starości: dylematy i zagrożenia, in: D. Kałuża, P. Szukalski (ed.), Jakość życia seniorów w XXI wieku. Ku aktywności, Uniwersytet Łódzki, Łódź 2010, s. 206-218.

Nóżka M., Smagacz-Poziemska M., Srebrna praca socjalna - adekwatność i potencjał usługi, in: M. Nóżka, M. Smagacz-Poziemska (ed.), Starzenie się. Problemat społeczno-socjalny i praktyka działań, Wydawnictwo Uniwersytetu Jagiellońskiego, Kraków 2014, s. 39-52.

Pawlas-Czyż S., Społeczna rzeczywistość choroby nowotworowej w rodzinie. Profesjonalna praca socjalna w obszarze wsparcia opiekunów nieformalnych osób chorych onkologicznie. Przyczynek do refleksji nad onkologiczną praca socjalną, Wydawnictwo Edukacyjne Akapit, Torun 2018.

Racław M. (ed.), Publiczna troska, prywatna opieka. Społeczności lokalne wobec osób starszych, Instytut Spraw Publicznych, Warszawa 2011.

Sobiesiak-Penszko P., Koziarek M., Jak dobrze mieć sąsiada. Od pomocy sąsiedzkiej do sąsiedzkich usług opiekuńczych. Instytut Spraw Publicznych, Warszawa 2016.

Szarota Z., Uczenie się starości, "Edukacja Dorosłych” nr 1, 2015:s. 54.

Szatur-Jaworska B., Polska polityka społeczna wobec starzenia się ludności w latach 1971-2013, Dom Wydawniczy ELIPSA, Warszawa 2016, s. 333-336.

Sztompka P., Socjologia. Analiza społeczeństwa, Wydawnictwo Znak, Kraków 2002.

Trawkowska D., Potencjał opiekuńczy rodziny - koncepcja i jej konteksty, in: Z. Kawczyńska-Butrym, E. Czapka (ed.), Opieka nad dziećmi i starszymi rodzicami w rodzinach migrujących kobiet, Wydawnictwo Polihymnia, Lublin 2016, s. $17-25$. 
Wieczorkowska M., Społeczne i ekonomiczne konsekwencje medykalizacji starości i starzenia się, „Folia Oeconomica” 2018, Nr 2(334), s. 19-37, DOI: http://dx.doi. org/10.18778/0208-6018.334.02Links used

Jarosz B., Keneda T. (2020). Oldest Areas May Be Hardest Hit: The Importance of Age Structure In Understanding Mortality During the Coronavirus Pandemic, https://www.prb.org/oldest-areas-may-be-hardest-hit-the-importance-of-agestructure-in-understanding-mortality-during-the-covid-19-pandemic/, accessed September 07, 2020.

Kocejko M. (2020). Prawa człowieka mieszkańców DPS to zapomniana sprawa (Opinia), https://publicystyka.ngo.pl/magdalena-kocejko-prawa-czlowiekamieszkancow-dps-to-zapomniana-sprawa-opinia?fbclid=IwAR0CLccASDHEw8s95j0OV83OnMpmyo1qYZP34P2n0wI31MES_DwmLqI2pNc, accessed September 17, 2020.

Krasicka M. (2020). Raport Ministerstwa Zdrowia: kto jest najbardziej narażony na COVID-19?, https://portal.abczdrowie.pl/raport-ministerstwa-zdrowia-ktojest-najbardziej-narazony-na-covid-19, accessed September 17, 2020.

Maj K., Skarżyńska K. (2020). Społeczeństwo wobec epidemii. Raport z badań, Fundacja im. S. Batorego, https://www.batory.org.pl/wp-content/uploads/2020/04/ Badanie-spoleczenstwo-wobec-epidemii-fin.pdf, accessed September 18, 2020.

Mrowiec K. (2020a). Epidemia jest zjawiskiem miejskim - rozmowy socjologów w czasie epidemii (with prof. zw. dr hab. Bogdan Jałowiecki), https://www.ath. bielsko.pl/epidemia-jest-zjawiskiem-miejskim/, accessed September 10, 2020.

Mrowiec K. (2020b). Społeczeństwo ryzyka - rozmowy socjologów w czasie epidemii (with dr hab. Jan Domaradzki), https://www.ath.bielsko.pl/socjolodzy-ospoleczenstwie-ryzyka-rozmowy-w-czasie-epidemii/, accessed September 10, 2020.

Ofiary koronawirusa w Polsce. Jaka jest średnia wieku? (2020). https://www. medonet.pl/koronawirus/koronawirus-w-polsce, ofiary-koronawirusa-w-polsce-jaka-jest-srednia-wieku-, artykul, 26466398.html, accessed September 3, 2020.

Ossowska A., "Wszyscy mamy już dosyć". Sopocka influencerka zabiera głos ws. żółtej strefy (2020). https://esopot.pl/pl/11_wiadomosci/5975_-wszyscy-mamyjuz-dosyc-sopocka-influencerka-zabiera-glos-ws-zoltej-strefy.html, Accessed September 26, 2020.

Scommegna P., Mather M., Kaneda T. (2020). United States Ranks 53 Out of 195 Countries on Aging-Health Problems, https://www.prb.org/older-americansgreater-health-problems-may-make-them-more-vulnerable-to-covid-19s-effects/, accessed September 5, 2020.

Statistics Poland. (2020). The situation of older people in Poland in 2018. https:// stat.gov.pl/en/topics/older-people/older-people/the-situation-of-older-people-inpoland-in-2018,1,1.html, accessed September 27, 2021. 


\section{Ageing and ageism in COVID-19 times \\ Grzegorz Godawa}

The occurrence of the COVID-19 pandemic intensified the ageist attitudes in society. At the same time, the pandemic made it more difficult to identify such attitudes. The aim of this work is to attempt to explore this area. The manifestations of ageism may be observed in the models of social functioning, healthcare and in media. The oldest members of society face the direct consequences of ageism. However, ageism may indirectly affect other people as well. It weakens social relationships, breaks family ties and intensifies the sense of threat which is already heightened because of the pandemic. There are numerous initiatives aimed at supporting older adults. Older adults' involvement for the sake of society shows that they may offer a lot of values visible in initiatives they undertake.

\section{Introduction}

Brad A. Meisner referred to the difficult determinants of functioning in the time of pandemic and remarked: "Although we cannot control the year we were born, we can control how we think about, treat, respect, and empathize with each other - across generations, in solidarity - especially in a time of crisis" (Butler 1975: 5). He emphasized that an ability to control and create one's own views and behaviors is key to friendly relationships in society which are based on empathy and solidarity. It is extremely important to do so during the global crisis which humanity is facing as a result of the occurrence of COVID-19.

The pandemic situation has tremendously changed the functioning of individuals and societies. It may even be said that it has strengthened and polarized human attitudes and social phenomena. Unfortunately, they also include negative phenomena which lack mutual intergenerational respect postulated by Meisner (Meisner 2020:59). One of them is ageism which is a form of social discrimination by the year of birth. During the pandemic, chronological age took on a new meaning as it was the older adults who 
became particularly prone to infection and all its consequences. Consequently, certain words and behaviors which discriminate against older adults surfaced in different areas of life.

On the other hand, it may also be observed that older adults are perceived and treated in a different, positive way. Care for their safety and health led to numerous initiatives which are not as accessible to the public as the cases of ageism are. The aim of this work is to show the manifestations of ageism and prosocial behaviors in the functioning of global society affected by the coronavirus. In order to achieve it, it will be necessary to outline the issue of older adults facing COVID-19 and the essence of ageism.

\section{Older adults facing COVID-19}

The World Health Organization (WHO) declared SARS-CoV-2 as a pandemic on March 11, 2020. It was the beginning of a very difficult time, especially for older adults. According to research, older individuals are more likely to get COVID-19 and have much worse outcomes compared with the general population, in particular with young people. In addition, the level of mortality of the SARS-CoV-2 pandemic in older adults has been striking. If they have certain comorbidities, they may be at a greater risk of infection and suffer worse outcomes. The use of vaccinations against the virus to a great extent prevents the disease from spreading, but it does not completely eliminate the sense of threat.

Health risks lead to many other problems because a range of pandemic exceeds the area of medicine. It is important to underline the social context of the epidemic situation. The global recommendation for older populations includes social isolation. It involves staying at home and avoiding contact with other people for some period of time, currently estimated to be between three and four months, depending on the regulations in particular countries. Older adults in need of care are particularly dependent on family and friends. However, social isolation includes avoiding close direct contact with family members and friends if they do not live together. Older adults may also rely on the support of voluntary services and social care. They can organize the delivery of essential items, such as groceries and medications (Brooke \& Jackson 2020: 2044).

Some older adults are facing additional difficulties at this time. The spread of COVID-19 in nursing homes is taking a devastating toll on older adults' lives. Some distressing reports indicate instances of neglect or mistreatment. Some older people who are in quarantine or locked down with family members or caregivers may also face higher risks of violence, abuse and neglect (United Nation 2020: 3).

Joanne Brooke and Debra Jackson emphasize the need to recognize that older people who previously had not reported being lonely may disproportionately experience the requirements of social isolation due to COVID-19. It may happen because of the removal of social contacts which normally 
occur during attending community groups and places of worship and other day-to-day activities. In these circumstances, social isolation and loneliness increase older people's risk of anxiety, cognitive disfunction, depression, heart disease and mortality. In addition, older people may also be affected by ageism which leads to the belief that life of older people is not as important as loss of life of other age people (Brooke \& Jackson 2020: 2044).

\section{Ageism}

Robert N. Butler was the first who used the term "ageism" to describe prejudice against older adults, defining it as "a process of systematic stereotyping of and discrimination against people because they are old" (Butler 1975: 12). Over the next 50 years, this classical definition was coined, modified and completed by adding more well-known forms of prejudice. One of the most complete and up-to-date definitions has been offered by Thomas N. Iversen, Lars Larsen and Per E. Solem, who defined ageism as

negative or positive stereotypes, prejudice and/or discrimination against (or to the advantage of) older people on the basis of their chronological age or on the basis of a perception of them as being "old" or "elderly." Ageism can be implicit or explicit and can be expressed on a micro-, meso-, or macrolevel.

(Iversen et al. 2009: 15)

This definition describes the most important areas of ageism: three classical psychological components of the ageist attitude, conscious and unconscious, positive and negative aspects and the diverse scope of ageism. It needs emphasizing that the expression "elderly" used in the definition is currently perceived as a verbal form of ageism (Avers et al. 2011: 153-154).

Although ageism may relate to the young as well, and in such cases it is called "adultism," from the perspective of social issues ageism is mainly related to older adults. There are very strong negative attitudes toward older adults, prejudices against them and stereotypes about them in society. They are based on the biological diversity of humans which is connected with the process of aging. Moreover, they are related to the competences and needs of people depending on their chronological age. As a result, the calendar age is used to separate groups whose access to various social resources is subject to systematic control (Szukalski 2009: 61-62). Positive ageism involves attributing certain qualities to older adults. Qualities such as kindness or wisdom result from their lifelong experience. Older age is a factor which may contribute to more lenient treatment in court, deeper understanding when it comes to shortcomings and organizing different forms of support which are available after reaching a certain age. Negative ageism is a form of exclusion and may be expressed in the social rejection of older adults or 
in self-ageism. It may be observed when older adults start to believe in these negative stereotypes. The internalization of stereotypes contributes to discrimination against older adults in the area of employment, medical care, institutional support and even in the family (Palmore 2015: 873).

Ageism may be caused by various determinants of functioning of individuals and society. According to Lev, Wurm and Ayalon, the reasons for ageism can be seen in terror management theory, stereotype embodiment theory and social identity theory (Lev et al. 2018: 52). Terror management theory provides an explanation for the reasons and motives of ageism toward old age groups among the young, middle aged groups and young-old age group. In this case, ageism is connected with the threat of death, the threat of animality, and the threat of insignificance. Prejudice and intolerance are based on the fear of death. An inability to peacefully coexist with others results from an inability to share one's worldview with those who do not agree with us and do not buffer our anxiety (Greenberg et al. 2020). Stereotype embodiment theory explains the roots of ageism among the youngold and old-old age groups. Negative attitudes and stereotypes about older adults which an individual has internalized during their life are often unconsciously embodied during old age, whereas social identity theory is connected with interpersonal and intergroup behaviors. Interpersonal behavior is determined by individual characteristics and interpersonal relationships. Intergroup behavior is determined by respective membership in various social groups or categories. The social behavior of individuals combines these two aspects. Subordinate and minority groups in society often tend to internalize a social evaluation of themselves as "second class," which leads to self-ageism (Lev et al. 2018).

It seems that the root of ageism should not be searched for only in the psychological and sociological area. Personal dignity plays a particularly important role in this matter. Personal dignity and human rights arising from it were confirmed by the Universal Declaration of Human Rights. The Preamble to the Declaration states: "Recognition of the inherent dignity and of the equal and inalienable rights of all members of the human family is the foundation of freedom, justice and peace in the world" (United Nations 1948). Unfortunately, there are many factors which may undermine personal dignity of older adults. As a result, they experience exclusion. Pope Francis emphasizes the importance of this problem in the following words:

We have created a 'throw away' culture which is now spreading. It is no longer simply about exploitation and oppression, but something new. Exclusion ultimately has to do with what it means to be a part of the society in which we live; those excluded are no longer society's underside or its fringes or its disenfranchised - they are no longer even a part of it. The excluded are not the 'exploited' but the outcast, the 'leftovers'.

(Pope Francis 2013) 
Older adults frequently face such a situation. How and to what extent does their situation change when the circumstances of everyday life change radically?

\section{How ageism affects older adults during the COVID-19 pandemic}

Traumatic experiences cause a strong reaction in almost every human being. Tension mounts in extreme situations, which perpetuates traumatic experiences. Such experiences affect the social context of human life, hinder social functioning and increase tension between people. The coronavirus pandemic has intensified some negative social behaviors, e.g., ageism. The other authors of this book also write about them. It is worth extending the scope of some forms of ageism.

\section{"Boomer remover"}

One of the manifestations of the influence of the pandemic on daily life are changes in spoken language in which vocabulary related to the pandemic is used. Language is sociable by nature. It is inseparably connected with people who are its creators and users. Language grows and develops together with the development of society. In the social consciousness, the role of language is not limited to being merely a communication tool. Language plays an important role as a concept itself and as a subject of evaluation. Therefore, its quality and level are really crucial. The evaluation of language should not limit its development but encourage reflection, initiate social debate and implement educational action in areas where controversial, yet popular terms point to deficiencies in language.

Neologisms coined during the pandemic express social moods. They are a form of stress relief and at the same time, they facilitate communication, especially among younger generations. They may have an opinion-forming significance and in this way, they may contribute to the intensification of ageism. They include expressions referring to the coronavirus and older adults who are at risk such as "Boomer Doomer," "Senior Deleter" or "Elder Repeller." However, the best-known expression used in memes is "Boomer Remover," which was a trending topic and hashtag on Twitter in March 2020 (Meisner 2020). The term "Boomer Remover" is a modified form of the expression "Ok, Boomer" which was popular with the members of $\mathrm{Y}$ and $\mathrm{Z}$ generation in 2019. It was used to refer to the representatives of the generation of Baby Boomers born between 1945 and 1964. In common usage, this phrase refers to an older adult when one wants to end the conversation with them, expressing a disrespectful attitude toward them.

When referred to the coronavirus which poses a threat mainly to older adults, the expression "Boomer Remover" implies a process of demographic cleansing of society of people above 60 years of age. The term is humorously 
interpreted as a harmless reaction of the young generation to the oldest members of society. However, a deeper analysis shows that in the media this phrase tends to be used to express hostility toward older adults and disrespect for them (Haffower 2020). The purpose of using this name is to address global and domestic overpopulation, decrease the burden that older adults put on health care and tax systems, remove older adults from society in order to provide more jobs, opportunities and resources to younger and healthier people and reduce the number of right-wing conservative voters, too (Meisner 2020). There is no doubt that these expressions can be perceived as a manifestation of ageism. As a result, we may observe a new category of ageism in the mass media which present older adults as "sitting ducks," vulnerable and helpless against COVID-19. High mortality amongst older adults is considered an "inevitable" and "normal" outcome of this pandemic (Fraser et al. 2020).

\section{Herd immunity}

The idea of herd immunity was presented to the public in the early stage of the development of COVID-19 in Europe. It was related to the fact that the process of adopting a model of combating the coronavirus differed from country to country. Some countries introduced tough restrictions while other ones did not. One of the discussed models assumes that the immunity of a given population may be achieved by infecting around $70 \%$ of society. Therefore, countries where the model was implemented did not decide to severely limit social contacts. The statement that emphasis should be placed on treating the ill rather than on prevention aroused great controversy which has ageist reference in line with the following assumption: the herd immunity, protect the economy, and if that means some pensioners die, too bad (Bufacchi 2020). The model assumes that older adults are protected, but it does not sufficiently protect them against infection, which is proven by a lot of cases of infection in nursing homes. According to Haley E. Randolph and Luis B. Barreiro, "the consequences of this model are serious and far-reaching - a large fraction of the human population would need to become infected with the virus, and millions would succumb to it" (Haley \& Barreiro 2020: 741). The process of producing and using vaccinations against the virus weakened the ageist dimension of attempts to achieve herd immunity.

\section{Is age still the first criterion?}

Nowadays, older adults are rarely given a voice and are seldom considered when making decisions. The pandemic creates numerous situations in which making decisions is necessary but extremely difficult, especially in the ethical dimension. It applies to the use of limited sources of support, e.g., respirators. If their number does not satisfy the current need of society, 
decisions about the priority to use them must be made. The analysis of recommendations and ethical opinions reveals a substantial discrepancy in this matter (Pawlikowski 2020). There are regulations regarding patients' equality which assumes that race, age, disability, ethnicity, ability to pay or social worth cannot be taken into consideration when making decisions. In this approach, the patient's age cannot become a criterion in the use of limited sources of support, e.g., The New York State guidelines for ventilator allocation rejected the use of advanced age as a criterion as discrimination against older adults (American Psychological Association 2020).

However, there are also opinions that the age criterion is significant. In this case, they refer to the following rule: "Younger individuals should receive priority, not because of any claims about social worth or utility, but because they are the worst off, in the sense that they have had the least opportunity to live through life's stages" (White \& Lo 2020: 1773). Making the age criterion significant or giving it priority which determines whose life to save first is a manifestation of ageism. Adopting the age criterion as one of the basic determinants of decision-making is a risky and medically unjustified proposal in the context of wide diversity of biological potential of people of different chronological age (Pawlikowski 2020).

\section{Overcoming ageism}

Despite a lot of examples which indicate that the problem of ageism became more serious during the COVID-19 pandemic, there are also manifestations of deep concern for older adults. The common denominator of these activities is care for the oldest members of society. It is an expression of selfless, emphatic interest in people who need help due to current circumstances. Concern for others may have different reasons, e.g. altruism, solidarity, faith in God and religious beliefs as well as close relationships with other people. Manifestations of care for others may be observed at the microsocial, local and macrosocial level. Numerous initiatives in local communities are a response to the call for society to help older adults. They were promoted by politicians, celebrities and other well-known people. Such initiatives are, first of all, an expression of love and concern for the oldest family members who expect being noticed and need care, kindness and practical help during this special time.

\section{"It is everyone's business"}

There are a lot of campaigns aimed at supporting older adults. They show a growing interest in older adults' needs as well as the active involvement in the process of satisfying them. Support offered to older adults by governments has become indispensable and made it possible to introduce regulations which protect older adults at the legislative level.

A growing awareness of older adults' needs may be observed as society is more and more conscious of the fact that older adults are at a high risk of 
getting infected and at the same time, they constitute an important social group. Consequently, governmental and informal initiatives were launched in the media in order to identify the specific needs of older adults. In this context, on behalf of WHO, Kluge emphasized that older adults' life is at risk. He postulated:

Supporting and protecting older people living alone in the community is everyone's business. I am reminding governments and authorities that all communities must be supported to deliver interventions to ensure older people have what they need. This support includes safe access to nutritious food, basic supplies, money and medicine to support physical health and access to social and mental health support and information to maintaining emotional well-being. All older people should be treated with respect and dignity during these times. Remember, we leave no one behind. (...) "Physical distancing" is not "social isolation."

(Kluge 2020)

These words convey a message which highlights not only older adults' specific needs and ways of offering support to them, but it also refers to the social perception of older adults. The phrase "It is everyone's business" aims to raise social awareness and calls for a mental change, thanks to which support offered to older adults is perceived as an activity which brings benefits for every member of society.

\section{"We are all in this together!"}

Care for older adults is expressed in solidarity with them, which is proven by numerous initiatives launched by governmental organizations and other institutions. Funds provided by organizations were given to adults directly or with the help of volunteers. In many cases, contact between donors and older adults would not be possible without the involvement of young volunteers. It is worth noting that their involvement counterbalances ageism:

Despite clear indications of ageism, there are also encouraging signs of intergenerational solidarity during this pandemic. There are myriad examples of younger people supporting older adults during their isolation: dropping off groceries, looking after their garden and working to keep them socially connected.

(Fraser et al. 2020: 3)

This form of help is most often offered at a local level, without the media.

Adults and young adults have become necessary links in the process of offering support to older adults. First of all, they help their family members, but in many cases they support people who are not their relatives. The involvement of volunteers makes it possible to get to those who need help. Thanks to 
them, funds provided by governments and non-governmental organizations satisfy the current needs of older adults. It needs emphasizing that overcoming the barriers of social isolation which results from social distancing is equally important. It takes place in meetings between those who offer help and those who need it. However, these "meetings" are often limited to knocking at the door and dropping off shopping or initiating contact via communicators. Pope Francis called for young people to overcome older adults' loneliness by showing them gestures of tenderness directly or with the use of communicators. This initiative was heartily approved of in society (Watkins 2020).

In this respect, the involvement shown by young people is of great significance both at the individual level and at the level of youth organizations. It is confirmed by research conducted by OECD among youth organizations in 48 countries. Research shows that the involvement of young people who belong to various organizations contributes to improving quality of older adults' life (OECD 2020).

\section{Locked down with old people}

Apart from action taken in families and local communities there are also initiatives which go beyond the scope of support already described in the chapter. It is worth highlighting the importance of voluntary work and readiness to assist older adults and other people who stay in nursing homes. During the pandemic nursing homes became places where older adults were at risk of death, and sometimes they suffered from the lack of proper care and attention. It occurred that they were subjected to unacceptable abuse (AGE Platform Europe 2020). The difficult situation caused fatigue among staff, and the lack of appropriate equipment aroused the feeling of helplessness. In such a situation, the only solution was to involve volunteers in supporting them. Volunteers showed heroic concern for older adults. They had to make a decision which had longterm consequences, because support offered to nursing home residents was related to an increased risk of infection and the need to stay isolated with them.

Polish nuns and monks showed their readiness to help and responded to the call for support from nursing home directors. During the initial period of the pandemic in Poland, over 3,000 nuns helped those who needed help, e.g., older adults. Some nuns and a group of monks voluntarily "locked themselves" in nursing homes and provided nursing and care services to residents. At the same time, they had to follow the rules of isolation for several weeks. The attitude of volunteers and their help made it possible to support older adults and ill people staying in nursing homes (Goławski 2020).

\section{Older persons' response to social needs}

The pandemic has shown that older adults are not only a group which requires a lot of social support, but they are primarily needed in society. Their contribution to its functioning may be observed on many levels. One of 
them is their involvement in helping other older adults, firstly their relatives, but also people in a wider social dimension.

According to American Psychological Association, many older adults actively contribute to society as family caregivers, health care providers on the front line of the COVID-19 pandemic by providing essential services in health and long-term care settings or in supportive functions such as housekeeping and food services. If some parents work in essential services or healthcare, grandparents play an equally vital role in facilitating their ability to work. Moreover, retired medical professionals, for example in New York and Florida were called to return to work. In effect, tens of thousands volunteered to do so. Likewise, many older adults are caregivers for family members who are frail. Spouses are the primary caregivers for over a third of older adults. In addition, almost 2 million older people are caregivers for their grandchildren and $25 \%$ of children under five are taken care of by grandparents in place of parents who are working (American Psychological Association 2020). It shows their great generosity and highlights their role in society.

Similar initiatives were launched in other countries. It is worth noting that the involvement of retired doctors led to consequences. At the beginning of July 2020, the number of doctors who died of COVID-19 in Italy reached 172, including retired doctors (Kluge 2020). Thanks to their involvement, older adults gained recognition in society. It also made people appreciate their role and reduced the impact of ageism.

\section{For further discussion...}

The analysis of positive and negative attitudes toward older adults during the pandemic does not provide sufficient quantitative justification of how significant these phenomena are. Only some examples of attitudes toward older adults were chosen and analyzed. This analysis is of qualitative significance as although it does not make it possible to exactly determine the scope of the phenomenon, it shows its complexity. It also reveals the complex determinants and mechanisms of ageism as well as the context of adopting prosocial attitudes.

An increase in ageism during the COVID-19 pandemic is easily noticeable, and its manifestations cause well-founded fear. They occur at the level of verbal communication and in the area of healthcare. They are also visible in any other activity which marginalizes older adults. The mass media contribute enormously to the problem as it promotes and strengthens ageist attitudes. At the same time, the same mass media provide the opportunity to promote respect for older adults. Therefore, it is important to make use of this potential to defend everyone's rights, regardless of age.

Ageism visible in healthcare is frequently related to the current complex situation of healthcare workers. The need to make decisions about saving patients' lives and about who should receive priority had been quite rare. During the pandemic there was a growing need to make such decisions in 
hospital teams, which resulted in stress and ethical dilemmas. It seems that in the decision-making process there was often not enough reference to the opinions of ethics committees, which together with inevitable haste and stress contributed to adopting solutions which limited the rights of older adults. The presence of such committees in hospitals is a postulate which gained special significance during the pandemic.

Care for older adults, both the close ones and strangers, provides the basis for the prosocial attitude. It was expressed in a variety of ways and was full of empathy, creativity, and even heroism. As a result, the oldest members of society were noticed and their needs received careful attention. The ways of satisfying them were indicated. An interesting manifestation of this attitude is the involvement of older adults in supporting other people in need. Consequently, society benefited greatly, and older adults showed that they remain an irreplaceable social group.

The way of functioning and the directions of social change remain an open question. In the social dimension of functioning, these changes, in particular the ones in mentality, will supposedly take place at a specific pace. Therefore, it is important to make use of the present time and focus on social education which includes the process of forming attitudes toward older adults. In the near future, the beneficiaries of this kind of education will be people who are currently helping older adults or receiving help from older adults in families. Such an exchange of good is one of the most effective forms of becoming mature both as society and as individuals and rising to modern, difficult challenges.

Ageism will still be observed in societies when the threat posed by the coronavirus is reduced. However, the awareness of ageism cannot be used as an excuse for not analyzing the situation of older adults and not undertaking initiatives to counteract this kind of social inequality. On the contrary, experiences gained during the pandemic should inspire further scientific research and encourage social support. The source of this activity is the dignity of old adults. A key issue is social education which may emphasize this dignity. However, social education should be balanced. Otherwise, it may lead to adultism - a form of ageism which discriminates against younger people. Such a form of education opens broad perspectives of social activity.

\section{References}

AGE Platform Europe, COVID-19: with great challenge must come great solidarity, 2020. Available at: https://www.age-platform.eu/special-briefing/covid-19-greatchallenge-must-come-great-solidarity [Accessed 7 August 2020].

American Psychological Association, Ageism and COVID-19, 2020. Available at: https://www.apa.org/topics/covid-19/research-ageism [Accessed 21 July 2020].

Avers, D., Brown, M., Chui, K.K., Wong, R.A., Lusardi, M., Use of the term "elderly", Journal of Geriatric Physical Therapy, 34(4), pp. 153-154, October/ December 2011. 
Brooke, J., Jackson, D., Older people and COVID-19: Isolation, risk and ageism, Journal of Clinical Nursing, 29(13-14), pp. 2044-2046, 2020.

Bufacchi, V., How coronavirus exposed our society's inherent ageism, New Statesman, 2020. Available at: https://www.newstatesman.com/international/2020/05/ coronavirus-old-age-over-60s-risk-care-homes-herd-immunity-deaths [Accessed 21 July 2020].

Butler, R.N., Why survive? Being old in America, Harper and Row, New York 1975.

Fraser, S., Lagacé, M., Bongué, B. et al., Ageism and COVID-19: What does our society's response say about us? Age and Ageing, pp. 1-4, 2020.

Goławski, P., Wolontariat w DPS-ach, zbiórki pieniędzy, pomoc psychologiczna $i$ modlitwa. Działania Kościoła w walce z COVID-19, 2020. Available at: https:// www.polskieradio24.p1/5/1222/Artyku1/2511839,Wolontariat-w-DPSachzbiorki-pieniedzy-pomoc-psychologiczna-i-modlitwa-Dzialania-Kosciolaw-walce-z-COVID19 [Accessed 15 July 2020].

Greenberg, J., Solomon, S., Pyszczynski, T., Terror management theory of selfesteem and cultural worldviews: Empirical assessments and conceptual refinements, Advances in Experimental Social Psychology, 29, pp. 61-139, 2020.

Haffower, H., A certain horrible subset of the internet is calling the coronavirus 'boomer remover', Business Insider Australia, 2020. Available at: https://www. businessinsider.com/millennials-gen-z-calling-coronavirus-boomer-removerreddit-2020-3?IR=T [Accessed 2 August 2020].

Haley, E.R., Barreiro, L.B., Herd immunity: Understanding COVID-19, Immunity, 52, pp. 737-741, 2020.

Iversen, T.N., Larsen, L., Solem, P.E., A conceptual analysis of ageism, Nordic Psychology, 61, pp. 4-22, 2009.

Kluge, H.H., Statement - Older people are at highest risk from COVID-19, but all must act to prevent community spread, Copenhagen 2020. Available at: https:// www.euro.who.int/en/health-topics/health-emergencies/coronavirus-covid-19/ statements/statement-older-people-are-at-highest-risk-from-covid-19,-but-allmust-act-to-prevent-community-spread [Accessed 3 August 2020].

LaRepubblica, Coronavirus, salea172l'elencodeimedicimortidainiziopandemia, 2020. Available at: https://www.repubblica.it/cronaca/2020/07/06/news/coronavirus_ sale_a_172_1_elenco_dei_medici_morti_da_inizio_pandemia-261159772/ [Accessed 3 July 2020].

Lev, S., Wurm S., Ayalon, L., Origins of Ageism at the Individual Level. In: L. Ayalon, C. Tesch-Römer (eds), Contemporary perspectives on ageism. International perspectives on aging, pp. 51-73, vol. 19, Springer, Cham 2018.

Meisner, B.A., Are you ok, boomer? Intensification of ageism and intergenerational tensions on social media amid COVID-19, Leisure Sciences, pp. 1-6, 2020.

OECD, Youth and COVID-19: Response, recovery and resilience, 2020. Available at: http://www.oecd.org/coronavirus/policy-responses/youth-and-covid-19response-recovery-and-resilience-c40e61c6/ [Accessed 15 July 2020].

Palmore, E., Ageism comes of age, Journals of Gerontology: Social Sciences, 70(6), pp. 873-875, 2015.

Pawlikowski, J., Etyczny wymiar decyzji priorytetyzacyjnych i alokacyjnych dotyczacych stosowania zaawansowanych technologii medycznych $w$ kontekście pandemii COVID-19, Medycyna Praktyczna, 4, 2020.

Pope Francis, Apostolic Exhortation "Evangelii gaudium" on the Proclamation of the Gospel in Today's World, no 53, Vatican 2013. 
Szukalski, P., Ageizm - przejawy indywidualne i instytucjonalne. In: M. Halicka, J. Halicki, A. Sidorczyk (eds), Człowiek dorosty i starszy w sytuacji przemocy, pp. 59-68, UwB, Białystok 2009.

United Nations, Universal declaration of human rights, Paris 1948. Available at: https://www.un.org/en/universal-declaration-human-rights/ [Accessed 1 August 2020].

United Nations, Policy brief: The impact of COVID-19 on older persons, 2020. Available at: https://unsdg.un.org/sites/default/files/2020-05/Policy-Brief-The-Impactof-COVID-19-on-Older-Persons.pdf [Accessed 3 August 2020].

Watkins, D., Covid-19: Vatican launches \#sendyourhug campaign to support elderly, 2020. Available at: https://www.vaticannews.va/en/vatican-city/news/2020-07/ coronavirus-laity-family-life-campaign-closeness-to-elderly.html [Accessed 10 July 2020].

White, D.B., Lo B., A framework for rationing ventilators and critical care beds during the COVID-19 pandemic, JAMA, 323(18), pp. 1773-1774, 2020. 


\title{
6 Age division and ageism in the public debates regarding COVID-19
}

\author{
Intergenerational solidarity and \\ antagonisms in the era of the \\ coronavirus pandemic ${ }^{1}$
}

\author{
Jaroslava Hasmanová Marhánková
}

The fact that coronavirus disease 2019 (COVID-19) affects age groups differently, has impacted the wider introduction of age-based measures and restrictions as part of the strategy to minimise the negative outcomes of the pandemic. It also led to a re-labelling of intergenerational encounters as a major risk factor for older people. The idea that age-based lockdowns (or other strategies involving age segregation) could be a possible solution gained a rather prominent position in the discussions regarding economically sustainable solutions to the pandemic. These debates bring fundamental challenges for gerontology and related disciplines, within which there is a long-term consensus on the benefits and fundamentally positive role of intergenerational ties.

\section{Introduction}

In December 2019, the World Health Organisation (WHO) first reported the occurrence of cases of a new form of respiratory disease in Wuhan in China. On the 11th of February, the general director of World Health Organization (WHO) announced that this disease would be named COVID-19 as an acronym for 'coronavirus disease 2019'. The statistically different rates at which serious manifestations of COVID-19 are experienced by different age groups represents one of the most significant features of this pandemic, which also shapes its media image. ${ }^{2}$ One of the most widely read national newspapers in the Czech Republic, for example, referred to the coronavirus in one of its headlines as 'the disease of the old, which mercifully omits children'. 3 As Gilleard and Higgs (2020) pointed out, our current knowledge regarding the effects of this disease suggest that it does amplify but does not change the chronology of life and death. If this disease were to significantly 
change the chronology of life and death, its social and psychological effects would probably be fundamentally different and, in many ways, more dramatic. This fact made it possible to symbolically incorporate COVID-19 into the course of life, not necessarily as a natural part of it, but at least as something that does not contradict the order of things. It is, therefore, not surprising that the emphasis on the fact that the serious progression of the disease mainly affects older people appears as such an essential part of the representation of this pandemic. The reference to chronological age has become an integral component of reports of deaths caused by COVID-19. In the subtext, it is also an essential element of efforts to calm the exaggerated atmosphere of fear. Reference to the fact that the fatal impact of the disease especially affects older people makes constantly visible the evidence that nothing changes significantly in the 'chronology of life and death'. The importance of membership in certain age groups, thus, has become the distinguishing feature of the pandemic. From the beginning, the COVID-19 epidemic has been portrayed primarily as a 'problem of the elderly' (Ayalon, 2020).

The essentialization of chronological age as a synonym for risk and definition of health condition in public debates regarding the COVID-19 outbreak has paradoxically led to the invisibility of the essence of vulnerability, which is the greater likelihood of the presence of health problems. However, these health problems are not determined by age, nor are they limited to a group of people above a clearly defined age limit. Homogenization of age groups obscures this fact and presents all older individuals as automatically vulnerable and all younger people as not at risk. This perception of age groups in relation to the pandemic produces problematic effects. For example, according to this logic, chronological age becomes a relevant criterion for determining access to certain goods that were not previously perceived as being allocated based on age. The Italian Society for Anesthesia, Analgesia, Resuscitation and Intensive Care Medicine (SIAARTI) has issued recommendations in connection with the COVID-19 pandemic for healthcare professionals in intensive care units that explicitly mention the possibility of setting an age limit for access to health care and equipment. The authors of the recommendation mentioned that in a crisis situation when equipment necessary for patient survival is limited,

criteria for ICU admission (and discharge) may need to be driven not only by the principles of clinical appropriateness and proportionality of care, but also by criteria of distributive justice and appropriate allocation of the healthcare resources, that may be more limited than usual.

(Vergano et al. 2020: 1)

The patient's age and the estimated number of years the patient's life can be extended by administering treatment are some of the criteria to be considered when deciding who will have access to adequate care ${ }^{4}$ (ibid.). 
These recommendations have provoked a wave of critical debates regarding healthcare ethics, the discussion of which is beyond the scope of this chapter. Nevertheless, this example illustrates that the need to recognize diversity within age groups, which is one of the pillars of contemporary (social) gerontology, is easily forgotten within specific healthcare policies formulated during a crisis situation.

To understand the inability to integrate some key premises of the gerontological agenda of the past decades (such as the emphasis on diversity among older people) into efficient social policies, we also have to address the very roots of gerontology as a discipline. As pointed out by Fletcher (2021), it was inevitable that COVID-19 would be categorised by age in the research because our empirical tradition is based on the study of society through conventional categories. Gerontology as a discipline presupposes the existence of a specific population of older people that can and should be studied via a separate discipline. Fletcher suggests that chronologically based measures are simultaneously pragmatic, evidence-based and ageist. This paradoxical relationship is caused by an often unacknowledged 'epistemic ageism' that is manifested in conventional biosocial research on aging and that represents an understandable means of translating complex realities into a demarcated field of study. He points out that 'The evidence base manifests a type of deep-rooted ageism and is alienated from the circumstances of real persons, yet it simultaneously draws our attention to life-threatening risk and inspires a practicable means of lowering that risk' (Fletcher 2021: 489). We have frequently grounded our study of aging in the paradoxical assumption that there is something special about chronological age that should justify the study of older people as a specific population, simultaneously stressing the heterogeneity of this population, which should lead us toward rejecting the idea that there is something that homogenises the 'older' population as such. The debates regarding age-based measures in the time of the pandemic show how crucial and persistent the category of chronological age was and is in social and health policy.

The way in which the risks surrounding COVID-19 have been portrayed and addressed reflect structural problems related to the perception of the role of older people in society. These problems were not caused by this pandemic. In many cases, however, the coronavirus pandemic has acted as a magnifying glass, making these issues more visible. We believe that critical reflection is needed to analyse what kind of messages are brought to light through this glass concerning old age and the importance of the way chronological age is constructed. Thus, the aim of this chapter is to contribute to the discussion regarding the impact of the coronavirus pandemic on intergenerational solidarity and relationships. We argue that the way the pandemic has been framed in public debates and healthcare policies may influence our perception of age groups and possibly lead to intergenerational antagonisms.

The discussion of the (non)existence of intergenerational conflict has a long tradition in gerontological analysis. Such debates have focused mainly 
on public transfers, suggesting that expenditures related to pensions and health care for the growing number of older people in society may disrupt the social contract between generations (Binstock 2010: 3). This chapter focuses on the assignment of different levels of health risk as a source of potential intergenerational tensions. We argue that the current pandemic may stimulate intergeneration antagonism in a new way. As outlined previously, COVID-19 impacts different age groups differently. This fact may strengthen intergenerational solidarity. (This chapter also addresses how the distribution of different risk levels have facilitated solidarity between generations.) However, we argue that the way chronological age has been mobilized in the debates regarding the pandemic may in the long run contribute more to intergeneration antagonism. In this chapter we outline three processes that have accompanied public discourses on the COVID-19 pandemic and that may significantly shape social perceptions of chronological age and the position of older people in society. Firstly, as already explained, chronological age was established as a significant vector defining human positioning in society during the pandemic. Older age was essentialized as a type of health condition. Age groups, in the public discourse, were constructed as homogenous and united through the idea of (different levels of) risk. Secondly, contact between members of different generations was systematically established as one of the main risks for contracting COVID-19. This situation may further strengthen age segregation and distance between generations. However, the two processes may not necessarily contribute to intergenerational conflict. We argue that it is mainly the way the nature of risks and the character of the pandemic has been communicated that has led to the paradoxical position of systematically describing the lives of older people as more dispensable while simultaneously highlighting their protection as justification for society-wide measures that have a significant impact on all citizens. This chapter suggests that this paradox, together with the essentialisation of chronological age and age segregation, may give rise to new forms of intergenerational antagonism.

\section{Age segregation and the risk of intergeneration contact}

We can already find numerous studies addressing the manifestations of ageism aimed mainly at older people that have accompanied public debates regarding the pandemic and the measures that should be followed (Ayalon 2020; Beridge \& Hoovman 2020; Ehni \& Wahl 2020). We argue that these manifestations need to be interpreted primarily in the context of an agedivided society, which has become part of the communication of the 'fight' against the coronavirus infection. As Hagestad and Uhlenberg (2006) noted, we live in a society characterized by institutional, spatial and cultural age segregation. Without personal contact, the members of different age groups easily became 'the others'. Age segregation reproduces ageism and supports the isolation of older people. Institutional arrangements that 
separate age groups restrict opportunities to form cross-age relationships. In that respect, family represents a crucial context within our age-divided society where people of different generations can gather; indeed, it is becoming one of the last islands where strong relationships are formed across generations (ibid).

Communication on the nature of the risk associated with the pandemic through the language of separate age groups has established relatively impermeable age-group boundaries. Age-based restrictions targeting older people were introduced in some countries. These measures included recommendations regarding self-isolation for people of a certain age $(65+$ or $70+)$, and similarly, even formal restrictions, such as in the case of the United Arab Emirates, where young children under the age of 12 and people over the age of 60 were not allowed to enter malls, supermarkets, and some restaurants. Other states, such as, for example, the Czech Republic, introduced, in spring 2020, special shopping hours for people aged 65+ (in that time, no younger people were allowed in the shop, but older people were not restricted to attending shops outside those special hours). Israel regulated the number of workers who were allowed to work in shared spaces, while employees aged 67-plus were explicitly requested to stay home (CTECH, 2020).

Looking for a way to minimalise social contact, most of the countries that were impacted by the pandemic introduced some type of lockdown. This was, of course, a very expensive and often economically devastating solution. In contexts where a health risk is distributed unevenly among the various groups, the debate regarding intergenerational solidarity inevitably arises. Consequently, this debate was often framed by the idea of age-based lockdowns as a possible (and especially economically sustainable) solution. Suggestions that isolating older people would be a more economically effective and a generally less harmful policy approach compared to full lockdowns were repeatedly made in various contexts. Those debates were framed by the discussion regarding intergenerational solidarity, pointing out that the young had not been treated in a way that was fully ethically justifiable since they were at milder risk from the virus and therefore had less to gain from lockdowns. However, they would simultaneously bear a bigger burden of the economic cost of the policy measures (Rens \& Oswald 2021). The imaginability of this solution is grounded in the idea that it is somehow socially and ethically acceptable to segregate older people because they are not essential for the running of society. This argument not only downplays their role in the economy but also suggests that it is possible for society to function and for younger people to live their lives 'as usual' without the participation of older people. The lightness in which those arguments were integrated into (not only) debates regarding the public measures illustrates the persistent invisibility of older people in the social imagination of 'productivity' and in terms of their social contributions, despite all the effort that has been made to deconstruct such stereotypes. 
A study by Israeli researchers published in October 2020 even suggested that age separation was key to tackling the epidemic. The mathematical model presented in the chapter suggested that if people from just one household came together and excluded any other contacts from different age groups (which could be compensated for by other contacts, but only within their own age group), then the number of deaths associated with COVID-19 would fall by as much as $62 \%$. If people just from the same age group met, the model predicted a reduction in deaths in Israel by up to 93\% (Mizrahi et al. 2020). The authors were aware that restricting social contacts was problematic, especially in the case of older people, as they are more often at risk of loneliness. Therefore, the study did not propose social isolation as a solution, but isolation within age groups.

The COVID-19 pandemic thus brought not only the perception of social contact as a form of threat, but also the re-labeling of intergenerational encounters as a major risk factor (especially for older people, but also for society as a whole). It thus brought with it fundamental challenges for gerontology and related disciplines, within which there is a long-term consensus on the benefits and fundamentally positive role of intergenerational ties. The above-cited study by Mizrahi, Shekhidem, and Stern (2020) suggested that the disease spread not because people met, but because there was contact between people from different age groups. As the authors pointed out, the reason for such a significant decrease in mortality in the monitored models was the fact that the mild course of the disease was characterised by a relatively high number of people who had caught the infection without visible symptoms but were still infectious to those around them. These people did not tend to break off their social contacts. Older people were viewed as less likely to be asymptomatic and, according to the study, they transmitted the disease less often. Thus, the boundaries between age groups were not only established with regard to the different risks of a more severe course of the disease, but also via their different roles in disease transmission. The message about the dangers of intergenerational encounters therefore became an important part of pandemic risk communication. For example, the Israeli Minister of Defense emphasised that the most important thing was to separate young people from older people, and he described the situation where a grandmother would meet and hug her grandchildren as the most dangerous combination (Ayalon 2020). Part of the communication of measures aimed at reducing the spread of the disease was the message that intergenerational contact was a dangerous risk factor.

The emergence of COVID-19 pandemic significantly influenced the discussion regarding intergenerational solidarity and contact. It brought an important change in the way we think about what intergenerational solidarity means. Social contact, touch, and physical presence represent an important way of expressing our concern and care for our close ones. The pandemic led to a dramatic redefinition of what care and concern may mean, proposing social distancing as a way of expressing those feelings. The call to 
reduce contact between extended family members and take precautions in relation to older people who are at greater risk is, of course, not a problem in itself, but rather it is an incentive to think about how intergenerational solidarity can be fulfilled in other ways. As the German Chancellor emphasized in her speech, the emphasis on limiting contact between younger and older family members should be seen primarily as a challenge to look for other, additional forms of intergenerational support inside and outside the family. ${ }^{5}$ In this respect, during the initial stages of the pandemic, we also witnessed (especially, but not only) the vast intensity of intergenerational solidarity and the responsibility that many young people felt towards older people. Krastev (2020) observed that the experience of 'staying home' helped younger people to empathise with their parents and grandparents, who may have already spent more of their time at home and may have experienced health-related anxieties before the onset of the pandemic. This shared experienced may, therefore, potentially reinforce the understanding and solidarity between individuals from different age groups. At the same time, the restriction related to the pandemic made us experience what it means when contact between generations is lacking. Thus, it is possible to hope that, among other things, the importance and need for intergenerational ties have become evident through their short-term involuntary (physical) interruption. However, in the next section of this chapter, we suggest that the problematic position of chronological age and older people in the debates regarding the COVID-19 pandemic have the potential to alienate the experiences of different age groups and stimulate new forms of intergenerational antagonisms.

\section{Narratives of a 'stolen future' and intergenerational antagonism}

The relationship between age and the risk of experiencing a serious progression of COVID-19 has emphasised a key feature of the disease: it significantly affects the dynamics of the relationship between the generations. It has its positive effects that cannot be ignored (whether it is, for example, the activities of young people helping with food delivery or their volunteering in healthcare facilities). However, we suggest that with respect to intergenerational dialogue, age segregation and the discourses that accompany (and legitimise) the measures in response to pandemic will, instead, exacerbate antagonisms between the generations. In his essay, Ivan Krastev predicted that intergenerational conflict will escalate as the duration of the crisis caused by COVID-19 increases. According to Krastev, this conflict is strengthened, on one hand, by different economic effects of the crisis on different generations. At the same time, different levels of risk perception among younger and older people may lead to different patterns of behaviour in response to the pandemic. As a result, older people may feel threatened by young people's reluctance to adapt to rules that may reduce risks 
(Krastev 2020). Both moments that Krastev mentioned point to the possible rise of antagonisms between the generations caused by feeling that the other generation may be 'stealing your future'. The COVID-19 pandemic thus mobilises, among other things, the narrative, which is a key part of the debate on the nature of the intergenerational conflict. The idea that the older generation lives on the debt of the younger generation is an essential element of the debate on the risks of an aging population and the sustainability of the pension funding system (Binstock 2010). Similarly, at the beginning of March in the Czech Republic, economists debated the possibilities of quantifying the value of human life to enable the determination of the limit at which its rescue (at the expense of other societal economic losses) still makes sense. ${ }^{6}$ Although the authors of these considerations do not explicitly address the role of chronological age, its implicit presence cannot be avoided. The governor of Texas summed up this reasoning more explicitly in a television interview, mentioning that grandparents would like to sacrifice themselves for the sake of their grandchildren's economic futures. ${ }^{7}$ The debates over the approach to dealing with the pandemic, therefore, also include the narrative on 'sacrifice', which places fundamental demands on the older generation hand in hand with the idea of a 'disappearing' future for younger generations, 'stolen' by those who have already lived out most of their lives. Such narratives logically represent an explosive cocktail of intergenerational antagonism. Materialisation of this antagonism is reflected in the hashtags 'Boomer Remover' that appeared in March, referring to the idea of COVID-19 as a tool for effectively relieving society of the burden of older people and for solving problems with the pension and healthcare system or unemployment (Meisner 2020).

The coronavirus pandemic alone, of course, cannot be considered as the sole and primary source of this intergenerational antagonism. As Ayalon (2020) asserted, the pandemic entered a society already divided by conflicts, many of which are framed in terms of generational affiliation. The generation of baby boomers (i.e. people born between the mid-1940s and the mid-1960s) is often described as having lived in a time of economic prosperity and at the same time held responsible for a number of environmental challenges facing future generations, the sustainability of pensions or the opportunity for younger generations to reach the same standard of living the boomers enjoyed (Bristow 2015). Such rhetoric often accompanies youth movements that emphasise the need for changes in environmental policy. Members of student environmental movements often criticise the older generation for not being willing to change the lifestyle they have become accustomed to, at the cost of the consequences that those lifestyles will bear on their children and grandchildren. ${ }^{8}$ The idea of a 'stolen future' is certainly not a new narrative. However, the way in which the COVID-19 disease and the policies associated with it are described brings new aspects that change the dynamics of this narrative. 
The fact that the fatal progression of the disease mainly affects older people became a key tool mobilised to calm the public and to avoid the panic caused by the emergence of this new disease. Within the discourses on risk, this feature of COVID-19 symbolically differentiated this pandemic from other similar events in the past or expected other (potentially more serious) epidemics in the future. The reference to chronological age was an integral part of the report on victims of COVID-19 (especially) at the beginning of the pandemic, the purpose of which has undoubtedly been to highlight the fact that the vast majority of victims were advanced in age and that the chronology of life and death has not been fundamentally broken. While the reference to the serious progression of the disease affecting older people more often has undoubtedly served as key information to reassure the public, its unintended consequence is that it has reinforced the idea that the lives of certain people have a potentially different value than the lives of others (and this value may be related, among other things, to their age). As explained by Frazer et al. (2020), in the COVID-19 cases involving the deaths of younger people, the media has provided detailed personal stories, while the deaths of hundreds of thousands of older people have been reported only in the form of statistics.

Some types of vulnerabilities are influenced or reinforced by social factors. We should keep this in mind even when considering the vulnerability of older people. As noted by Berridge and Hooyman (2020: 2), although older people are generally more vulnerable to the more serious progression of the disease, the vulnerability of people living in long-term care institutions is further reinforced by the nature of these institutions, where more people live side by side in a small space and are cared for by a small number of carers. Almost half of all COVID-19 deaths involved clients in longterm care facilities. Available statistics indicate that $53 \%$ of deaths from COVID-19 in Italy, 57\% in Spain and 45\% in France involved clients of longterm care facilities (Comas-Herrera \& Zalakain 2020). In some countries, deaths from COVID-19 that occur in care homes are not recorded in the official statistics. Long-term care facilities for older people were deprioritised in terms of interventions at the beginning of the crisis and experienced a lack of personal protective equipment (Age Platform Europe 2020). The protection of the most vulnerable has become the headline of the need to fundamentally interfere with the running of society. However, the places where the most vulnerable are concentrated have paradoxically too often remained on the margins of interest. These moments reflect the structural disadvantages that older people face in society, regardless of the presence of the pandemic. Nevertheless, the way in which the pandemic has been portrayed and how the response to it has been formulated systematically constructed the idea that the value and meaning of human life can be derived from a chronological age. Older people in this context acted as a group that can be 'left' to die.' 
COVID-19 is presented primarily as a disease that severely affects older people. However, the measures that were supposed to protect the population have an impact on the daily lives of all citizens, probably more fundamentally at the economic level, especially on younger people. In his book, Ivan Krastev (2020) referred to reports that indicated that up to $52 \%$ of people under the age of 45 have either lost their jobs, been forced to go on leave or had their working hours reduced due to policies related to the pandemic. On one hand, older people may feel more endangered by the disease and, therefore, feel the impact of the pandemic more intensively. On the other hand, however, the economic impact of the measures has the potential to have a greater impact on younger and middle-aged people who are in or will be entering the labour market. These measures are taken in the name of a risk that is strongly framed by chronological age and to protect the population (which, given the way in which the risks are presented, mainly involves older people). The way in which the COVID-19 pandemic has affected public policies, thus, sets into motion several processes that reinforce intergenerational antagonism. It alienates the experience of this crisis situation between the various generations, who, moreover, are pitted against each other through the narrative of the 'stolen future' - whether within the narrative of young people who endanger older people with their irresponsibility or older ones whose protection costs young people too much. This sentiment is further reinforced by the paradox that all individuals are expected to subordinate their lifestyle and future economic prospects to protection against something that is described as a risk primarily to those who are systematically constructed as more easily dispensable.

\section{For further discussion...}

In the context of the events associated with the COVID-19 pandemic, we have witnessed the expansion of stereotypical depictions of age groups. As pointed out by of Morrow-Howell, Galucia and Swinford (2020: 4): 'We will have to regain any hard-won advances in reducing the external and internal ageism exacerbated in this pandemic'. This concerns both the problematic conceptions of chronological age and the stereotypical portrayal of older people, as well as the ideas that people are able to internalise regarding their own aging. Most of us have experienced feelings of helplessness in the face of this pandemic. However, no one should feel hopeless because he/she thinks that based solely on his/her age will he/she not receive adequate health care. Discussions about the need for 'sacrifice' in the case of the older generation or the criterion of chronological age when deciding who will receive what health care can easily evoke in older people a sense of distrust about whether their lives matter to others.

The different probability of severe COVID-19 in different groups has understandably and correctly led to the discussion regarding age-based policy measures that could protect the most vulnerable groups and simultaneously 
provide (economically) sustainable conditions in society. Two prominent aspects became part of this discussion. First, that it is the intergenerational contact that it the problem (or at least one of the major problems) and secondly, that to isolate and lock down older people was viewed as a solution (or at least as a short-term solution, possibly until there was a vaccine and/ or other medical treatments). The pandemic situation has led not only to the essentialisation of the category of 'old people' but also to the consolidation of the idea age groups as separate. Contact between members of different (homogenous) generations was constructed as one of the fundamental problems in the spread of the disease. This discussion impacts not only the policies introduced during the time of pandemic but should also be critically analysed to inform our future policies and research outside the debates regarding pandemic-related measures. Those discussions regarding age-based segregation not only challenge some key premises stressed by current gerontological research (e.g., the benefits and crucial role of intergenerational contact) but also reveal some structural problems regarding the way in which chronological age is mobilised in social policies and perceptions of the role of older people in society. We should therefore also use this discussion as a starting point for a critical debate and as a magnifying glass that can enable us to identify fundamental challenges that gerontology and its related disciplines may encounter. The COVID-19 pandemic very seriously disrupted our daily lives and required a number of measures, the nature of which often corresponded to the need to resolve the crisis quickly, sometimes even at the cost of challenging some key principles that have guided our approach to chronological age and older people in our previous policies. As Sarah Harper notes (Harper 2020: 424): 'Pragmatic policy making is one thing in a crisis, long term institutionalised ageism is another'.

The way in which chronological age and the role of older people have been presented in public debates about COVID-19 not only strengthens the age division of society but also intervenes in intergenerational relations and solidarity. Although we have witnessed (especially at the beginning of the spread of the disease) a rise in solidarity aimed at helping older people, the way in which age is mobilised in public discourses and policies reinforces antagonism between members of different generations. This antagonism stems from both the way age is treated in discussions about COVID-19 and the paradoxical position of older people in portraying this pandemic. In the public discussions surrounding the COVID-19 pandemic, the lives of older people are systematically described (and perceived) as more dispensable and implicitly less valuable. At the same time, however, the protection of the older adults as a group is becoming a justification for society-wide measures that have a significant impact on all (and often, very painfully on those who do not feel threatened by the disease due to their age). We believe that this paradox gives rise to forms of intergenerational antagonism that further deepen the age division of society. 


\section{Notes}

1 The work on this study was supported by Czech Science Foundation (grant no. 21-16738S) and by the Charles University Research Programme "Progres" Q18 Social Sciences: From Multidisciplinarity to Interdisciplinarity.

2 Mortality rates are higher for people over 60 and for people with pre-existing health problems [8]. For example, the rate of death in the age group 65-74 is 95 times higher compared with 18- to 29 -years-old (which is the age group that accounted for the largest cumulative number of COVID-19 cases compared to other age groups). The death rate in 75- to 84-years-old is 230 times higher compared with this reference group [7].

3 Baulisová, K.: “Nemoc starých, která děti milosrdně vynechává.” MFDnes 11.3.2020.

4 In Germany, the Ethics Committee (Deutscher Ethikrat) issued an ad hoc statement for situations involving the lack of resources needed to provide adequate health care. These recommendations explicitly reject the age criterion and emphasise the prospect of the successful treatment of the patient, which depends on the individual's medical condition [10].

5 Appeal to the people living in Germany: Angela Merkel's speech about the Corona virus in full. (https://ga.de/ga-english/news/angela-merkel-s-speech-aboutthe-corona-virus-in-full_aid-49639811).

6 Tůma, Z. M, Hampl: "Bývalí šéfové ČNB Tůma a Hampl: necháme v zájmu ochrany života umř́t celou českou ekonomiku?” Hospodářské noviny 19.3.2020.

7 Rodriguez, A.: "Texas' lieutenant governor suggests grandparents are willing to die for US economy." USA Today 24.3.2020. Available at: https:// eu.usatoday.com/story/news/nation/2020/03/24/covid-19-texas-official-suggestselderly-willing-die-economy/2905990001/

8 In this context, it is no coincidence that one of the hoaxes spread in connection with the COVID-19 pandemic in the Czech Republic worked with a fake print screen of the Friday for Future student climate movement Facebook page, where young people praised the benefits of the pandemic for the future well-being of the Earth, as it will enable the next generation to repair the damage done to the environment by the previous ones. The fake contribution sought to exaggerate the degree of intergenerational antagonism that is often present in the narrative of the stolen future' that the student movement mobilises in relation to the inability of political representation (recruited from the older generation) to face climate challenges.

9 The cases of abandoned residents and elderly patients in retirement homes reported from Spain illustrates this approach in a shocking way (https://www.bbc. com/news/world-europe-52014023).

\section{References}

Age Platform Europe. COVID-19 andhuman rights concerns for older persons (updated version 18May2020). [cit 13.8.2020]. Availableat:https://www.age-platform.eu/sites/ default/files/Human $\% 20$ rights $\% 20$ concerns $\% 20$ on $\% 20$ implications $\% 20$ of $\% 20$ COVID $\% 2019 \% 20$ to $\% 20$ older\%20persons_Final_18May2020.pdf

Ayalon L. There is nothing new under the sun: Ageism and intergenerational tension in the age of the COVID-19 outbreak. International Psychogeriatrics, 1-4. 2020. https://doi.org/10.1017/S1041610220000575

Berridge C., Hooyman N. The consequences of ageist language are upon us. Journal of Gerontological Social Work 63 (6-7): 508-512. 2020. https://doi.org/10.1080/01 634372.2020 .1764688 
Binstock R. H. From compassionate ageism to intergenerational conflict? The Gerontologist 50 (5): 574-585. 2010. https://doi.org/10.1093/geront/gnq056

Centers for Disease Control and Prevention. Risk for Covid-19 infection, hospitalization and death by age group. [Updated 2021 Jun 24] [online]. [cit 9.7.2021]. Availableat:https://www.cdc.gov/coronavirus/2019-ncov/covid-data/investigationsdiscovery/hospitalization-death-by-age.html

Comas-Herrera A., Zalakain J. X. Mortality associated with COVID-19 outbreaks in care homes: Early international evidence. [online]. International Long-Term Care Policy Network, CPEC-LSE. 2020. [cit 10.7.2020]. Available at: https://alzheimeriberoamerica.org/wp-content/uploads/2020/04/Mortality-associated-withCOVID-12-April-3.pdf

CTECH. (2020). Israel rolls back Covid-19 restrictions as number of sick stabilizes. https://www.calcalistech.com/ctech/articles/0,7340,L-3809065,00.html, accessed 27 September, 2021.

Ehni H. J., Wahl H. W. Six Propositions against Ageism in the COVID-19 Pandemic. Journal of Aging \& Social Policy 32 (4-5): 515-525. 2020. https://doi.org/10.1080/ 08959420.2020 .1770032

Fletcher, J. Chronological quarantine and ageism: COVID-19 and gerontology's relationship with age categorisation. Ageing and Society 41 (3): 479-492. 2021. https:// doi.org/10.1017/S0144686X20001324

Fraser S., Lagacé M., Bongué, B., Ndeye N., Guyot J., Bechard L., Garcia L., Taler V., Adam S., Beaulieu M., Bergeron, C. D. Ageism and COVID-19: What does our society's response say about us? Age and Ageing 49 (5): 692-695. 2020. https://doi. org/10.1093/ageing/afaa097

Gilleard C., Higgs P. COVID-19 amplifies but doesn't alter the chronology of life and death. [online]. TransformingSociety. 2020. [cit 1.7.2020]. Available at: http:// www.transformingsociety.co.uk/2020/05/20/covid-19-amplifies-but-doesntalter-the-chronology-of-life-and-death/

Hagestad G. O., Uhlenberg P. Should we be concerned about age segregation? Some theoretical and empirical explorations. Research on Aging 28 (6): 638-653. 2006. https://doi.org/10.1177/0164027506291872

Harper, S. The COVID-19 Pandemic and older adults: Institutionalised ageism or pragmatic policy? Population Ageing 13: 419-425. 2020. https://doi.org/10.1007/ s12062-020-09320-4

Israeli rolls back as Covid-19 restrictions as number of sick stabilize. [online]. Calcalist April 20, 2020. [cit 9.7.2021]. Available at: https://www.calcalistech.com/ ctech/articles/0,7340,L-3809065,00.html

Krastev I. Už je zítra?: Aneb jak pandemie mění Evropu. Praha: Nakladatelství Karolinum. 2020.

Meisner B. A. Are you OK, Boomer? Intensification of ageism and intergenerational tensions on social media amid COVID-19. Leisure Sciences, 1-6. 2020. https://doi. org/10.1080/01490400.2020.1773983

Mizrahi L. H., Shekhidem A., Stern, A. Age separation dramatically reduces COVID-19 mortality rate in a computational model of a large population. Open Biology 10 (11). 2020. https://doi.org/10.1098/rsob.200213

Morrow-Howell N., Galucia N., Swinford E. Recovering from the COVID-19 pandemic: A focus on older adults. Journal of Aging \& Social Policy 32 (4-5): 526-535. 2020. https://doi.org/10.1080/08959420.2020.1759758 


\section{Jaroslava Hasmanová Marhánková}

Rens van T., Oswald A. J. Age-based policy in the context of the Covid-19 pandemic: How common are multigenerational households? [online]. Warwick Economics Research Papers No: 1315. 2020. [cit 9.7.2021]. Available at: https://warwick.ac.uk/ fac/soc/economics/research/workingpapers/2020/twerp_1315_-_oswald.pdf

Vergano M., Bertolini G., Giannini A., Gristina G. R., Livigni S., Mistraletti G., Riccioni L., Petrini F. Clinical ethics recommendations for the allocation of intensive care treatments in exceptional, resource-limited circumstances: The Italian perspective during the COVID-19 epidemic. Critical Care 24 (165). 2020. https://doi. org/10.1186/s13054-020-02891-w 


\title{
7 Older adults' coping strategies in a pandemic situation
}

\author{
A Polish case study \\ Celina Timoszyk-Tomczak, Beata Bugajska, \\ and Klaudia Piotrowska
}

In order to prevent and fight COVID-19, certain countries have introduced measures to minimise the threat of infection of SARS-CoV-2 virus. They are addressed in particular to persons from the high-risk groups, older citizens among them as with age. Restrictions set up as a result of declaring the epidemic put older persons under stress connected with the necessary social isolation. The situation forced them to reinterpret their strategies of coping with the problems of everyday life. The goal of the research is to identify emotional responses and coping strategies of people aged 65 and more, connected with the necessity to adapt to new living conditions caused by the pandemic. The important part of the research is identification of the most frequently used strategies of coping with stress.

\section{Introduction}

The beginning of 2020 brought information about the outbreak of an epidemic of the acute infectious respiratory disease COVID-19 caused by SARS-CoV-2 coronavirus. In January 2020, the World Health Organisation (WHO) declared a public health emergency of international concern and in March COVID-19 spread to such a scale that the state of pandemic was declared (WHO 2020). This created an unprecedented situation. In order to prevent the spread of the disease, governments in many countries decided to introduce lockdown and social distancing. The first case in Poland was recorded on 4 March 2020 and since 20 March 2020, according to the regulation of the Minister of Health, the country is in the state of epidemic.

Metanalyses of psycho-social responses of the general population to stress connected with the previous epidemics such as SARS (Severe Acute Respiratory Syndrome), H1N1 (swine flu) or Ebola indicate that the most common symptoms were anxiety, depression, guilt, regret and loss, posttraumatic stress, stigmatisation but also the sense of strength and compassion towards others (Chew et al. 2020). Mental suffering was significantly correlated with age and educational background (Peng et al. 2020). 
During the present COVID-19 pandemic, due to their less efficient immune system and common age-related basic illnesses, older people are considered the group of high risk. Based on the statistics, we know that older persons struggle more with the infection, the mortality rate in this group is also higher and amounts up to $3.6 \%$ among people aged 60-67 whereas for people aged $80+$ it grows to $18 \%$ (Garcia-Fernández et al. 2020). This may increase the pandemic-related anxiety and stress among older citizens (Meng 2020; Kim \& Jung 2021; Strutt 2021). Other important issue is the consequences of quarantine; social distancing strengthen by the pandemic may lead to greater loneliness, increased sense of helplessness, anxiety and depression. It may also boost passivity, disturb daily habits and lead to the increase in undesired behaviours, for example medicine or alcohol abuse (Garcia-Fernández et al. 2020). Older people who are less familiar with modern digital technologies may struggle with the consequences of the lockdown and experience more negative influence of the pandemic on their mental health than the rest of the population. However, studies conducted in different world regions are not coherent. Some confirm the above-mentioned threats, for example residents of retirement homes in France, who suffered from Alzheimer's disease reported higher levels of depression and anxiety during the COVID-19 crisis than before it (El Haj et al. 2020). A large percentage of Americans reported stress and loneliness, an increased sense of isolation and change in daily habits during lockdown (Emerson 2020). In China, older persons aged 60 and more had greater problems with depression and anxiety, women more often than men (Meng et al. 2020). German studies show that older adults consider the risk of COVID-19 as lower than younger people and use the strategy of focusing on the problem by following expert advices and behaving accordingly to the situation (Gerhold 2020). Reports by German researchers from before the pandemic indicated lower stress level among older rather than younger citizens (Klein et al. 2016). Older adults in Spain showed less emotional anxiety in connection with COVID-19 than younger respondents and there were no differences between men and women (Garcia-Fernández et al. 2020). In Austrian studies, for every studied aspect of mental health (depression, anxiety, stress, quality of sleep) the younger group of adults ( $<35$ years) yielded the worst results while the older persons, aged 65 and more, obtained the highest results (Pieh et al. 2020). Older people deal better with the pandemic than younger ones. What is interesting, is that these results are opposite to the ones obtained in Austria before the pandemic, in 2014 when mental health deteriorated with age (Pieh et al. 2020). Thus, the goal of the research presented herein was to identify emotional responses and strategies of coping with stress among older people.

\section{Stress and coping strategies}

The classic concept of stress by Lazarus and Folkman (1994), sees coping as inseparable, together with cognitive appraisal and emotional process, 
element of a stressful situation. In this concept, coping with stress is connected with cognitive variables and behavioural efforts to manage external and internal demands that are seen as taxing or exceeding the resources of the person. Coping has two functions: instrumental (problem-focused) and emotional self-regulation (emotion-focused). These functions may interfere and influence each other (Heszen 2013). The classic concept of stress has been referred to, among others, in the concept of coping styles, which identifies task-oriented and emotion-oriented coping, and adds avoidance-oriented style (Endler \& Parker 1990). Carver et al. (1989), influenced on Lazarus and Folkman's theory, describe ways individuals response to stress. The authors of the COPE scale show similarities and differences as compared to previous tools. The general directions of coping are similar but the opposing tendencies resulting from the structure of motivated action are different (repeated attempts versus withdrawal). As a result, different responses to stress, even the most effective ones, may have different implications to the person who attempts to deal with it. The data on the functioning of people during previous epidemics indicate that respondents often resorted to problem-focused strategies, support searching, avoidance but also positive assessment of the situation (Chew et al. 2020). The longitudinal study conducted during the SARS epidemic show that, compared to younger age groups, older citizens responded better to the crisis evoked by the epidemic and adapted their strategies better to the situation. They experienced less anger and greater reduction of negative emotions thanks to using both problem-focused and emotion-focused strategy. This study shows that during the peak of the epidemic, the dominating strategy was the problem-focused one whereas several weeks later older people preferred emotion-focused coping (Yeung \& Fung 2007).

Recognising the emotional responses of older adults and their coping strategies is important in the context of designing support activities for older adults should the pandemic continue. Thus, the following research questions were formulated:

- What emotional responses occurred among older people during the pandemic?

(a) How was the well-being of older people changing during the pandemic?

(b) What emotions were evoked by the future in the context of the present pandemic?

(c) What difficulties and benefits did older people see during the pandemic?

(d) How did older people see support: who was supporting them and whom did they support?

- What coping strategies did older people prefer during the pandemic? Studies (Yeung \& Fung 2007) allow to formulate the following 
hypotheses: $\mathrm{H}_{1}$ older people prefer active coping strategies and strategies of looking for support and focusing on emotions.

- What are the relationships between the preferred coping strategies and sociodemographic variables and emotional responses?

- What are the relationships between the intensity of negative emotions and preferred coping strategies among older people? $\mathrm{H}_{2}$ the higher intensity of negative emotions, the greater preference to use strategy of looking for support and emotion-focused strategy.

\section{Method}

\section{Respondents}

The sample consisted of 50 persons: 40 women and 10 men, aged 59-90 (the average age was 72.46). The group with maximum number of members was made up of respondents aged 70-74 (36\%), then 65-69 (24\%) and 75-79 years $(12 \%)$. People aged 80 and more were $18 \%$ of the sample whereas only $8 \%$ were people in their early old age (60-64 years) or pre-old age $(2 \%)$. As for educational background, $11(22 \%)$ respondents had higher education, 24 (48\%) were high school graduates, $9(18 \%)$ graduated vocational school and $6(12 \%)$ finished primary school. There were $21(24 \%)$ married people, 19 $(38 \%)$ widowed, $7(14 \%)$ divorced and $3(6 \%)$ were singles. $20(40 \%)$ respondents lived with their spouse, $5(10 \%)$ lived with their families, $21(42 \%)$ lived alone and $4(\%)$ with another person from outside the family. The vast majority of the respondents rated their health condition as good $(46 \%)$ or very good ( $8 \%$ ). Only $8 \%$ declared having poor health and $2 \%$ - very poor. $30 \%$ of the respondents evaluated their health as "neither good nor bad". $90 \%$ of the respondents declared they are believers, while $10 \%$ said there were not believers.

\section{Research tools}

The research was conducted using a structured interview and a modified COPE questionnaire by Weintraub, adapted to Polish conditions by Juczyński and Ogińska-Bulik (2009). The interview consisted of ten openended questions and, where possible, additional five or two degree scales were used. Questions 1-3 referred to: present well-being (where 1 meant very bad and 5 meant very good), any changes in well-being during the pandemic (where $1=$ very little and $5=$ very much) and emotions when thinking about the future (the intensity of the emotions listed was evaluated as $1=$ very weak and 5 = very strong). Question 4 asked what was most difficult during the pandemic. The answers were grouped in five categories: health (lack of information, more difficult access to medical services etc.), contacts with other people (limited direct interactions), social and living (shopping, finances), activity (recreation, rituals), and psychological aspects (loneliness, 
isolation). The 5 th question addressed benefits from this time (where $1=$ very little and $5=$ a lot). In question 6 the respondents were asked to relate to some statements (as described below). Question 7 referred to the sources of support for the respondents (family, friends, neighbours, doctor, priest, social assistance centre, older adult centre) and question 8 asked whether the respondents provided support for someone else (yes and no answers). In question 9 the respondents were asked to compare their coping with the pandemic situation against other people of similar age (where $1=$ much worse and 5 = much better). Question 10 asked the respondents if other older people use stimulants. The interview ended with demographic questions about age, gender, living situation, attitude towards faith, evaluation of health, education and marital status.

The multi-dimensional COPE Inventory to measure coping with stress, developed by Carver, Scheier and Weintraub and adapted to Polish conditions by Juczyński and Ogińska-Bulik (2009), consists of 60 statements respondents relate to using a four-degree scale where 1 means "usually do not do this at all" and 4 means "usually do this a lot". The questionnaire is used to assess the ways of coping with stress and allows to identify 15 response strategies: Active-coping (AC), Planning (P), Instrumental Social Support (ISS), Emotional Social Support (ESS), Suppression of Competing Activities (SCA), Turning to Religion (TR), Positive Reinterpretation and Growth (PRG), Restraint-coping (RC), Acceptance (A), Focus on and Venting Emotions (FVE), Denial (D), Mental Disengagement (MD), Behavioural Disengagement (BD), Alcohol-drug Disengagement (AD), Humour $(\mathrm{H})$. The reliability of the tool is satisfactory and Cronbach's alpha coefficients for certain scales range between 0.48 and 0.94 . Persistency measured in six weeks' interval in the group of 30 persons ranges between 0.45 and 0.82 . Correlations of certain questions with the general result are also sufficient. In the study presented herein, ten scales were used - AC, ISS, ESS, TR, PRG, A, FVE, D, MD and $\mathrm{H}$. As a result of the discussion and literature analysis, the scales $\mathrm{P}, \mathrm{SCA}, \mathrm{RC}, \mathrm{BD}$ and $\mathrm{AD}$ were excluded.

Additionally, the factor analysis enabled identification of three main factors like: active coping (P, PRG, AP, SCA), avoidance behaviours (D, BD, $\mathrm{H}, \mathrm{MD}, \mathrm{AD}, \mathrm{A})$ and seeking support and focusing on emotions (ESS, FVE, ISS, TR). These factors explain 77\% of variances (Juczyński \& OgińskaBulik 2009). For identification purposes, these factors are described as General Active Coping (GAC), General Avoidance (GA) and General Support and Focus on Emotions (GSFE).

\section{Research procedure}

The study was conducted via telephone in June and July 2020. The respondents were the beneficiaries of a Senior Centre (institution managed by a non-governmental organisation, as committed by the local government in Szczecin, which has been the coordinator of older persons support during 
the pandemic). The respondents invited to participate in the study were older adults who previously had asked for a protective mask to be delivered to them. First, the interviewer asked the respondents for their consent, briefly presented the goal of the research and then asked the questions and noted the answers. All participants were informed of the goal of the research and the privacy protection policy and provided informed consent. The study was approved by the Bioethics Committee of the Institute of Psychology at the University of Szczecin and performed in accordance with the Declaration of Helsinki.

\section{Statistical analyses}

The statistical analyses were conducted using IBM SPSS Statistics software, v. 24. The data were collected from the structured interview, therefore there were no missing data. Descriptive mean statistics, standard deviations, skewness and kurtosis were calculated without breach to normal distribution projections for the variables. Reliability of all COPE scale indicators was calculated using Cronbach's alpha. The correlation analysis was conducted using Pearson's coefficient. To determine the hierarchy of the strategies used, the t-test was performed for the dependent samples and to compare the differences between the groups, the Mann-Whitney $\mathrm{U}$ test was performed.

\section{Results}

The descriptive statistics for the certain interview questions were calculated, which allowed to answer the first general research question: What emotional responses occurred among older people during the pandemic? Depending on the scales used, the mean values, the quantity or the percentage indicators were presented. The research question 1a. referred to the respondents' well-being during the pandemic. The mean value for well-being was 3.61 with $\mathrm{SD}=1.25$ (skewness $=-0.88$; kurtosis $=-0.16$ ). The sense of change in the mental well-being at the beginning of the pandemic was 2.86 on average, $\mathrm{SD}=1.36$ (skewness $=-0.09$; kurtosis $=-1.29$ ). The respondents additionally compared their ability to cope in the pandemic with other people in similar age and the mean value was $3.90, \mathrm{SD}=0.86$ (skewness $=$ -0.20 ; kurtosis $=-0.85$ ). This means that the respondents described their well-being as good, without significant changes and evaluated their coping abilities as better than the abilities of others.

The research question $1 \mathrm{~b}$. referred to emotions evoked when thinking of the future in the context of the pandemic. Only nine individuals declared having not very positive emotions (hope), others did not list any. In turn, 38 respondents listed negative emotions (uncertainty, anxiety, fear, terror, helplessness) and most often rated them as strong $(\mathrm{M}=3.16$; $\mathrm{SD}=1.41$, 
skewness $=-0.48$, kurtosis $=-1.04$ ). This indicates that future stimulated mainly negative emotions among the older adults.

The research question 1c. focused on difficulties and benefits of the pandemic. The difficult aspects of the last few months mentioned by the respondents included: health (fear of infection, lack of quick access to medical care, worrying about the health of family members), limited interactions with other people (lack of direct contacts with family and friends) -17 declarations in each category, reduced activity -10 respondents $(20 \%)$ and finally, social and living (bills) and psychological aspects (isolation) - four answers in each category $(8 \%)$. In addition, some persons mentioned wearing masks as a difficulty. Twenty-two respondents (44\%) noticed benefits resulting from the pandemic: reflection, time to invest in development, learning new skills (baking, online shopping, coping with the new situation), ability to solve different e.g. administrative issues remotely, realizing there were other sources of support like more distant family or volunteers.

The research question 1d. referred to the support observed: who supported the respondents and whom they helped. In this category, 35 older adults $(70 \%)$ mentioned family as the source of support, seven respondents $(145 \%)$ declared they received help from their friends, four people mentioned their doctors, one mentioned a priest and two a Senior Centre. Thirty-eight respondents $(76 \%)$ declared that they had supported others, for example their neighbours, friends and spouses. The respondents felt that support was two-way.

Then, the following hypothesis was verified: $H_{1}$ older people prefer active coping strategies and strategies of looking for support and focusing on emotions. First, skewness and kurtosis of the subscales of the COPE inventory and the three general coping strategies were investigated to assess the normal distribution. Values \pm 2 were assumed as acceptable in the normal distribution (Garcia-Fernández et al. 2020). Only one variable exceeded this threshold but to the acceptable degree. The reliability indicators were also calculated and they confirmed the validity of the method used and its subscales (Table 7.1).

Then, in order to study the hierarchy of the preferred coping strategies, the significance tests were performed of differences between the general COPE strategies (Table 7.2) and between the detailed COPE strategies.

The results obtained suggest that the most often preferred strategies are General Support and Focus on Emotions (GSFE) and General Active Coping (GAC). General Avoidance (GA) behaviours are significantly less preferred. In order to further specify the preferences, the analysis of difference between ten investigated strategies of responding to stressful situations. The analysis showed that the most preferred strategy is acceptance (A), then equally: turning to religion (TR), emotional social support (ESS) and focusing and venting emotions (FVE). The third most often preferred strategy is instrumental social support (ISS) and fourth: active-coping (AC) 
Table 7.1 Descriptive statistics for evaluation of coping strategies - ten subscales and three general scales $(\mathrm{COPE})(\mathrm{n}=50)$.

\begin{tabular}{lllcll}
\hline Scales & $M$ & $S D$ & Skewness & Kurtosis & $A$ \\
\hline I. GAC & 2.52 & 0.64 & -0.03 & -1.18 & 0.76 \\
II. GA & 2.29 & 0.34 & 0.38 & -0.17 & 0.55 \\
III. GSFE & 2.60 & 0.62 & -0.10 & -1.04 & 0.86 \\
1. AC & 2.53 & 0.63 & 0.11 & -0.73 & 0.51 \\
2. ISS & 2.26 & 0.81 & 0.31 & -0.85 & 0.76 \\
3. ESS & 2.65 & 0.87 & -0.14 & -0.88 & 0.82 \\
4. TR & 2.85 & 0.10 & -0.45 & -1.19 & 0.94 \\
5. PRG & 2.51 & 0.83 & -0.00 & -0.98 & 0.75 \\
6. A & 3.38 & 0.57 & -0.77 & -0.07 & 0.65 \\
7. FVE & 2.65 & 0.67 & -0.08 & -0.29 & 0.61 \\
8. D & 1.76 & 0.65 & 0.33 & -0.1 .12 & 0.46 \\
9. MD & 2.71 & 0.64 & -0.62 & 0.86 & 0.36 \\
10. H & 1.34 & 0.61 & 1.87 & 2.46 & 0.84 \\
\hline
\end{tabular}

General Active-Coping (GAC), General Avoidance (GA), General Support and Focus on Emotions (GSFE), Active-coping (AC), Instrumental Social Support (ISS), Emotional Social Support (ESS), Turning to Religion (TR), Positive Reinterpretation and Growth (PRG), Acceptance (A), Focus on and Venting Emotions (FVE), Denial (D), Mental Disengagement (MD), Humour (H).

Table 7.2 $\mathrm{T}$ tests for dependent samples between general COPE strategies $(\mathrm{N}=50$, $\mathrm{df}=49)$

\begin{tabular}{|c|c|c|c|c|c|}
\hline \multicolumn{2}{|c|}{ Strategy pairs } & \multirow{2}{*}{$\frac{M}{2.60}$} & \multirow{2}{*}{$\frac{S D}{0.62}$} & \multirow{2}{*}{$\begin{array}{l}t \\
0.72\end{array}$} & \multirow{2}{*}{$\begin{array}{l}P \\
0.477\end{array}$} \\
\hline I & GSFE & & & & \\
\hline & GAC & 2.52 & 0.64 & & \\
\hline \multirow[t]{2}{*}{ II } & GSFE & 2.60 & 0.62 & \multirow[t]{2}{*}{2.98} & \multirow[t]{2}{*}{0.004} \\
\hline & GA & 2.29 & 0.34 & & \\
\hline \multirow[t]{2}{*}{ III } & GAC & 2.52 & 0.64 & \multirow[t]{2}{*}{2.68} & \multirow[t]{2}{*}{0.010} \\
\hline & GA & 2.29 & 0.34 & & \\
\hline
\end{tabular}

General Active Coping (GAC), General Avoidance (GA) and General Support and Focus on Emotions (GSFE).

and positive reinterpretation and growth (PRG). They are followed by denial (D), mental disengagement (MD) and humour (H). ${ }^{1}$

The next step involved answering the third research question about the correlations between the preferred coping strategies and sociodemographic variables and emotional responses. For this purpose, analyses of correlations between the COPE indicators and age $(\mathrm{A})$, gender $(\mathrm{G})$, education $(\mathrm{E})$, subjective evaluation of health (SEH), evaluation of well-being (EW), evaluation of changes in well-being during the pandemic (ECW), evaluation of coping abilities compared to others (ECACO) and intensity of negative emotions (INE). There were no significant correlations between COPE and education so this variable is not presented in Table 7.3. 
Table 7.3 Correlations between COPE subscales and variables: age (W), gender $(\mathrm{G})$, subjective evaluation of health (SEH), evaluation of well-being (EW), evaluation of changes in well-being during the pandemic (ECW), evaluation of coping abilities compared to others (ECACO), intensity of negative emotions (INE) $(\mathrm{N}=50)$.

\begin{tabular}{lcccccc}
\hline COPE strategy & Age & Gender & SEH & EW & ECW & ECACO \\
\hline I. GAC & $-0.28^{*}$ & 0.06 & -0.13 & 0.22 & -0.09 & $0.39^{* *}$ \\
II. GA & $-0.31^{*}$ & -0.13 & -0.07 & 0.17 & -0.11 & $0.46^{* *}$ \\
III. GSFE & 0.11 & -13 & $0.26^{\mathrm{t}}$ & $-0.33^{*}$ & $0.34^{*}$ & -0.11 \\
1. AC & -0.09 & 0.18 & -0.03 & 0.07 & 0.10 & $0.40^{* *}$ \\
2. ISS & -0.01 & -0.07 & $0.31^{*}$ & $-0.36^{*}$ & $0.38^{* *}$ & -0.12 \\
3. ESS & 0.16 & -0.14 & 0.16 & -0.22 & 0.18 & -0.19 \\
4. TR & 0.10 & -0.17 & 0.15 & -0.01 & 0.08 & -0.17 \\
5. PRG & $-0.37^{* *}$ & -0.05 & -0.18 & $0.28^{\mathrm{t}}$ & -0.21 & $0.29^{*}$ \\
6. A & -0.10 & -0.04 & $-0.39^{* *}$ & $0.32^{*}$ & $-0.37^{* *}$ & 0.25 \\
7. FVE & 0.05 & 0.06 & 0.14 & $-0.49^{* *}$ & $0.43^{* *}$ & $-0.33^{* *}$ \\
8. D & -0.21 & $-0.29^{*}$ & 0.15 & -0.04 & 0.02 & 0.19 \\
9. MD & -0.11 & 0.06 & -0.06 & -0.01 & 0.07 & $0.26^{\mathrm{t}}$ \\
10. H & $-0.27^{\mathrm{t}}$ & 0.01 & 0.10 & 0.13 & 0.00 & $0.31^{*}$ \\
\hline
\end{tabular}

General Active-Coping (GAC), General Avoidance (GA), General Support and Focus on Emotions (GSFE), Active-coping (AC), Instrumental Social Support (ISS), Emotional Social Support (ESS), Turning to Religion (TR), Positive Reinterpretation and Growth (PRG), Acceptance (A), Focus on and Venting Emotions (FVE), Denial (D), Mental Disengagement (MD), Humour (H).

${ }^{*} \mathrm{p}<0.05 ;{ }^{*} \mathrm{p}<0.01 ;{ }^{\mathrm{t}} \mathrm{p}<0.1$.

Table 7.4 Correlations between variables: age (W), gender (G), subjective evaluation of health (SEH), evaluation of well-being (EW), evaluation of changes in well-being during the pandemic (ECW), evaluation of coping abilities compared to others (ECACO), intensity of negative emotions (INE) $(\mathrm{N}=50)$.

\begin{tabular}{lcccccc}
\hline Variables & Age & Gender & SEH & EW & ECW & ECACO \\
\hline Age & - & & & & & \\
Gender & -0.01 & - & & & & \\
SHE & $0.25^{\mathrm{t}}$ & -0.05 & - & & & \\
EW & $-0.30^{*}$ & 0.07 & $-0.65^{* * *}$ & - & & \\
ECW & 0.14 & 0.09 & $0.35^{*}$ & $-0.38^{* *}$ & - & \\
ECACO & 0.07 & 0.18 & -0.16 & $0.44^{* * *}$ & $-0.24^{\mathrm{t}}$ & - \\
INE & $0.36^{*}$ & 0.12 & 0.13 & $-0.25^{\mathrm{t}}$ & $0.56^{* * *}$ & -0.21 \\
\hline
\end{tabular}

${ }^{*} \mathrm{p}<0.05 ;{ }^{* *} \mathrm{p}<0.01 ; * * \mathrm{p}<0.001 ;{ }^{\mathrm{t}} \mathrm{p}<0.1$.

Additionally, to better understand the relationships, correlations between age $(A)$, gender $(\mathrm{G})$, education $(\mathrm{E})$, subjective evaluation of health $(\mathrm{SEH})$, evaluation of well-being (EW), evaluation of changes in well-being during the pandemic (ECW), evaluation of coping abilities compared to others (ECACO) and intensity of negative emotions (INE) were studied (Table 7.4). 
The data presented in Table 7.4 indicate that the younger-old persons rated their general well-being (EW) higher and the intensity of negative emotions (INE) lower. Individuals who evaluated their health (SEH) as very good also rated their general well-being (EW) higher and declared less change in general well-being since the outbreak of the pandemic (ECW) (minus results from the reversed scale). The internal correlations suggest that people who rated their well-being (EW) higher also evaluated their health (SEH) as better and saw less changes in their well-being (ECW). They also felt they were coping better than others in the situation of the pandemic (ECACO).

In regards to the variables: living conditions and marital status, the indicators of coping strategies were compared and it resulted from the measuring scales used, Mann-Whitney $\mathrm{U}$ test. Within the general strategies, the significant differences were only visible for general avoidance behaviours (GA) $\mathrm{U}=112.50 ; \mathrm{p}<0.011$ (asymptotic, two-way significance); the mean values for ranks show that individuals who live alone (25.64) prefer this type of coping strategy more often than respondents who live with their spouse (16.13). Within the specific strategies, there was a significant difference for humour $\mathrm{U}=145.00 ; \mathrm{p}<0.040$ (asymptotic, two-way significance); again, the mean values for the ranks show that singles (24.10) more often prefer this strategy compared to older adults living with their spouses (17.75). Also, the differences in coping strategies among the married and widowed respondents were studied. The only significant difference was recorded for general avoidance behaviours (GA) $\mathrm{U}=121.00 ; \mathrm{p}<0.033$ (asymptotic, two-way significance), where the mean value for the ranks shows that married older adults (16.76) prefer suppression strategies less often than widowers (24.63). According to the analyses, the respondents who prefer general, active coping strategies (GAC) and avoidance (GA) are younger (A) and evaluate their coping abilities as higher than those of others (ECACO). Preferring general avoidance strategies (GA) was also connected with living alone and being widowed. Individuals who preferred general support and focus on emotions (GSFE) rated their well-being low (EW) and had noticed greater change in their well-being since the outbreak of the pandemic (ECW); at the tendency level, there was also correlation with evaluating own health (SEH) as poor.

At last, the second hypothesis was verified: $\mathrm{H}_{2}$ the higher intensity of negative emotions, the greater preference to use strategy of looking for support and emotion-focused strategy. For this purpose, the analysis of correlations between the COPE subscales and the intensity of negative emotions (INE) was performed (Table 7.5).

The hypothesis was positively verified in terms of the specific strategies there is a strong correlation between focus on and venting emotions (FVE) and intensity of negative emotions (INE). Within the general coping strategies there was a weak, negative correlation between the general avoidance (GA) and the intensity of negative emotions (INE). There was also a weak correlation between the positive reinterpretation and growth (PRG) and the intensity of negative emotions (INE). 
Table 7.5 Correlations between COPE subscales and intensity of negative emotions INE $(\mathrm{N}=50)$.

\begin{tabular}{llllllllllllll}
\hline COPE & $G A C$ & $G A$ & $G S F E$ & $A C$ & $I S S$ & $E S S$ & $T R$ & $P R G$ & $A$ & $F V E$ & $D$ & $M D$ & $H$ \\
\hline INE & -0.21 & $-0.29^{*}$ & -0.21 & -0.05 & $0.26^{\mathrm{t}}$ & 0.19 & -0.16 & $-0.28^{*}$ & -0.16 & $0.48^{* * *}$ & -0.22 & 0.01 & $-0.27^{\mathrm{t}}$
\end{tabular}

General Active-Coping (GAC), General Avoidance (GA), General Support and Focus on Emotions (GSFE), Active-coping (AC), Instrumental Social Support (ISS), Emotional Social Support (ESS), Turning to Religion (TR), Positive Reinterpretation and Growth (PRG), Acceptance (A), Focus on and Venting Emotions (FVE), Denial (D), Mental Disengagement (MD), Humour (H).

${ }^{*} \mathrm{p}<0.05 ; *{ }^{*} \mathrm{p}<0.01 ; * * \mathrm{p}<0.001 ;{ }^{\mathrm{t}} \mathrm{p}<0.1$.

It is worth adding that despite resignation from the COPE subscale measuring substance abuse, the interview had additional question whether the respondents think that other older adults resort to sedatives or alcohol in the present situation. Sixteen respondents (32\%) stated that other older adults use sedatives or alcohol.

\section{Discussion}

The goal of the research was to identify emotional responses and coping strategies among older people. The research questions posed referred to emotional responses that occurred during the pandemic and the strategies used by older adults to deal with stress. Two hypotheses were formed: the first addressed coping strategies preferred by older citizens, while the other referred to the relations of these strategies with the intensity of the emotions experienced.

The respondents usually evaluated their well-being as good and noticed only slight changes in it since the outbreak of the pandemic. In the majority of the sample, future evoked negative emotions, mainly fear. A small group declared a positive emotion, namely, hope. When analysing the lives of women sent to Siberia in 1940, Obuchowski (1985), points out to the role of hope in sustaining the ability to create future plans and maintain intellectual control over the events. He connects hope with the meaning of life, noticing at the same time that it allows to fight the despair and prevents decision to commit suicide. For the respondents, the most difficult aspect of their daily functioning were issues related with health and interactions with other people. They also notice some benefits like time for reflections and personal development. The most important declared sources of support were family and friends. The respondents also helped other people they felt particularly close to. Despite the disappearing model of multigenerational family, family members are still an important source of support for the older persons, while keeping the so called "distant intimacy". It can be assumed that, compared to the time before the pandemic, lockdown intensified contacts of older adults with their families (more frequent phone calls, use of other communication tools). More family members, also distant, were 
involved in supporting older adults (instrumental, emotional, information support). Social distancing management promoted pro-social attitudes and the needs of older people. In general, the respondents preferred strategies of seeking support and focusing on emotions, and active coping, which is coherent with the results of other studies (Yeung \& Fung 2007). What needs to be interpreted is the fact that detailed analyses locate acceptance as top preference, while this strategy is one of the avoidance strategies, what slightly modifies the hierarchy. It can be acceptance which is the opposite of denial and is a functional coping response because an individual who accepts the reality of the stressful situation seems to make active attempts to cope with it. Additionally, acceptance influenced two aspects of coping process: acceptance of the stressor and acceptance of the present lack of effective coping strategies (Carver et al. 1989). In the present, hardly controllable situation of the pandemic, such acceptance seems to be adequate response (Lazarus \& Folkman 1994).

Correlations between the strategies and sociodemographic variables and emotional responses point out to several aspects which are important from the practical point of view. The general active coping strategies and avoidance behaviours are more often used by younger older adults and individuals who think they are doing better than others in the present situation. General avoidance behaviours were more often declared by the widowed persons and those who lived alone. The respondents who preferred general coping strategies involving seeking support and focus on emotions, declared worse well-being and has noticed greater changes in their frame of mind since the outbreak of the pandemic. The most correlations within the specific strategies were found for acceptance, seeking instrumental support and focus on and venting emotions. Individuals who prefer acceptance feel healthier, experience better mental condition and do not see changes in their well-being since the beginning of the outbreak. Instrumental support strategy is preferred by the older adults who evaluate their health and emotional condition as bad and who notice changes in their well-being. Older people with chronic diseases more often experience fear and depression (Ozamiz-Etxebarria et al. 2020), they are also less independent and rely more on others, which means they require assistance in daily functioning. Preferring the strategy of focus on and venting emotions is correlated with worse mental condition, noticing changes in well-being and sensing that, compared to others, one does not cope well. Younger-old who declared they cope better than others prefer the strategy of positive reinterpretation and growth.

The second hypothesis assuming relationship between the intensity of negative emotions and preferring strategies of seeking support and focusing on emotions was confirmed only regarding specific strategies, that is, individuals who experienced strong negative emotions preferred focusing on and venting emotions. There was no correlation at the level of general support strategies and focus on emotions. An unexpected correlation occurred at the level of general strategies: respondents who preferred general avoidance strategy showed low intensity of negative emotions. Evaluation 
of own coping abilities compared to those of others turned out to be an interesting variable which is strongly correlated with positive well-being and is the leading variable for the opposite preferences: active coping and avoidance behaviours. It proves that regardless of the preferred, even opposite, coping strategies, they can yield positive results. Most likely, it is the result of individual personality predispositions, experiences and ability to control the situation (Lazarus \& Folkamn 1994). The results are consistent with the results of the studies by Fuller and Huseth-Zozel (2021).

The results obtained show that coping strategies used by older people during the pandemic are quite well matched. Young-old prefer to be active or avoid, or more precisely, accept lack of control over the situation. Older adults who struggle more, seek support and focus on their emotions, trying to vent them. Life experience of older people, connected with previously experienced economic and social difficulties in the post-war period helped them cope with stress caused by the pandemic (Ozamiz-Etxebarria et al. 2020). When facing unfavourable circumstances such as the COVID-19 outbreak, eudaimonic well-being plays a protective role (Lopez et al. 2020).

\section{Conclusion}

The results obtained indicate that older persons choose strategies which help them cope quite well with stress during the pandemic. Young-old people choose strategies based on active responses or avoidance which is expressed in accepting the lack of control over the situation. Old-old use strategies focusing on venting emotions and seek support (especially those who struggle more with functioning).

However, the study was limited by the size of the sample and the effectiveness of the strategies used will depend on the duration of the stressful situation. Form the medical point of view, COVID-19 is particularly dangerous for older people and patients with chronic conditions. Due to the greater risk of cardio-vascular, autoimmune, neurocognitive and mental problems, social distancing of older adults is a serious public health concern (Armitage \& Nellums 2020). It is not known who long the pandemic will last and what course it will take. With prolonged isolation, the symptoms of psychical disorders exacerbate (Ozamiz-Etxebarria et al. 2020). Lockdown measures re-imposed in the coming fall/winter season (the Northern Hemisphere) when the infection rates grow, days are shorter and there less sunlight may be another factor with negative impact on the well-being, leading to emotional disorders. Most likely, during exiting the pandemic it will be the oldest citizens who will experience social isolation the longest. In case of removing the lockdown restrictions, every strategy of gradual release should include plans to increase the immunity of people who remain isolated (Webb 2020).Therefore, it would be beneficial for older adults to:

- $\quad$ strengthen their natural coping tendencies;

- concentrate on "taming" the future to reduce fear related to it. 
The reasonable steps to achieve this would be to:

- ensure psychological support for older people to prevent the negative consequences of the lasting pandemic;

- develop remote psychological services adapted to the level of digital literacy of older adults (ability to use electronic devices and applications);

- reduce isolation by learning older people how to use new channels of communication via smartphones;

- reinforce the ability to cope with the consequences of the pandemic in a long-term perspective, by showing in media seniors who cope with everyday struggles despite the pandemic.

The results obtained show that coping strategies used by older people during the pandemic are quite well matched. Younger-old prefer to be active or avoid, or more precisely, accept lack of control over the situation. Older seniors who struggle more, seek support and focus on their emotions, trying to vent them. The results of the study expand the knowledge about the processes of adaptation of older people and determinants of these processes during the pandemic. They enable recommendations regarding support measures for older citizens in the perspective of the long-term pandemic consequences.

\section{For further discussion...}

In order to prevent and fight COVID-19, certain countries have introduced measures to minimise the threat of infection of SARS-CoV-2 virus. They are addressed in particular to persons from the high-risk groups, older citizens among them as with age, they are at more risk of having other underlying medical conditions. Restrictions set up as a result of declaring the epidemic in Poland put older adults under stress connected with the necessary social isolation. The situation forced them to reinterpret their strategies of coping with the problems of everyday life. The goal of the research is to identify emotional responses and coping strategies of people aged 65 and more, connected with the necessity to adapt to new living conditions caused by the pandemic. It is to show the most challenging aspects of the situation experienced, including such areas as: health, social interactions, welfarerelated aspects, activity, psychological consequences of isolation as well as some positive aspects like the sources of support received. The important part of the research is identification of the most frequently used strategies of coping with stress. The research was conducted using the structured interview methods and a modified multidimensional COPE Inventory by Carver, Scheier, and Weintraub, adapted to Polish conditions by Juczyński and Ogińska-Bulik (2009). Modification involved the selection of 10 out of 15 coping strategies and additional examples adequate to the situation of pandemic. To ensure safety of the participants, the research was conducted via phone. The results obtained show that coping strategies used by older 
people during the pandemic are quite well matched. Younger-old prefer to be active or avoid, or more precisely, accept lack of control over the situation. Older seniors who struggle more, seek support and focus on their emotions, trying to vent them. The results of the study expand the knowledge about the processes of adaptation of older people and determinants of these processes during the pandemic. They enable recommendations regarding support measures for older citizens in the perspective of the long-term pandemic consequences.

\section{Note}

1 Due to the volume limitations, data on the test differences for the dependent samples are not presented. The levels presented are identified based on the analysed significant differences. The detailed data are available in the research report.

\section{References}

Armitage, R., Nellums, L. B., COVID-19 and the consequences of isolating the elderly, The Lancet Public Health, 2020, 5(5), e256. https://doi.org/10.1016/ S2468-2667(20)30061-X

Carver, C. S., Scheier, M. F., Weintraub, J. K., Assessing coping strategies: A theoretically based approach, Journal of Personality and Social Psychology, 1989, 56(2), 267-283. https://doi.org/10.1037/0022-3514.56.2.267

Chew, Q. H., Wei, K. C., Vasoo, S., Chua, H. C., Sim, K., Narrative synthesis of psychological and coping responses towards emerging infectious disease outbreaks in the general population: Practical considerations for the COVID-19 pandemic, Singapore Medical Journal, 2020, 61(7), 350-356.

Emerson, K. G., Coping with being cooped up: Social distancing during COVID-19 among 60+ in the United States, Revista Panamericana de Salud Pública, 2020, 44, e81. https://doi.org/10.26633/RPSP.2020.81

Endler, N. S., Parker, J. D. A., Multidimensional assessment of coping: A critical evaluation, Journal of Personality and Social Psychology, 1990, 58(5), 844-854.

Fuller, H. R., Huseth-Zosel, A. Lessons in resilience: Initial coping among older adults during the COVID-19 pandemic. Gerontologist, 2021, Jan 21, 61(1), 114-125. https://doi.org/10.1093/geront/gnaa170

García-Fernández, L., Romero-Ferreiro, V., López-Roldán, P. D., Padilla, S., Rodriguez-Jimenez, R., Mental Health in elderly Spanish people in times of COVID-19 outbreak, The American Journal of Geriatric Psychiatry, 2020, 28(10), 1040-1045. https://doi.org/10.1016/j.jagp.2020.06.027

Gerhold, L., COVID-19: Risk perception and coping strategies, PsyArXiv, 2020, March 25 https://doi.org/10.31234/osf.io/xmpk4

Heszen, I., Psychologia stresu. Korzystne i niekorzystne skutki stresu życiowego. Wydawnictwo Naukowe PWN, Warszawa, 2013.

Juczyński, Z., Ogińska-Bulik, N., Narzędzia pomiaru stresu i radzenia sobie ze stresem. Pracownia Testów Psychologicznych, Warszawa, 2009.

Kim, H. H., Jung, J. H., Social isolation and psychological distress during the COVID-19 pandemic: A cross-national analysis, The Gerontologist, February 2021, 61(1), 103-113. https://doi.org/10.1093/geront/gnaa168 
Klein, E. M., Brähler, E., Dreier, M., Reinecke, L., Müller, K. W., Schmutzer, G., Wölfling, K., Beut, M. E., The German version of the perceived stress scalepsychometric characteristics in a representative German community sample, BMC Psychiatry, 2016, 16, 159. https://doi.org/10.1186/s12888-016-0875-9

Lazarus, R. S., Folkman, S., Stress, appraisal, and coping. Springer, New York, 1994.

López, J., Perez-Rojo, G., Noriega, C., Carretero, I., Velasco, C., Martinez-Huertas, J., Galarraga, L., Psychological well-being among older adults during the COVID-19 outbreak: A comparative study of the young-old and the old-old adults. International Psychogeriatrics, 2020, 1-6. https://doi.org/10.1017/s1041610220000964

Meng, H., Xu, Y., Dai, J., Zhang, Y., Liu, B., Yang, H., Analyze the psychological impact of COVID-19 among the elderly population in China and make corresponding suggestions, Psychiatry Research, 2020, 289, 112983. https://doi.org/10.1016/ j.psychres.2020.112983

Obuchowski, K., Adaptacja twórcza. Książka i Wiedza, Warszawa, 1985.

Ozamiz-Etxebarria, N., Idoiaga Mondragon, N., Dosil Santamaría, M., Picaza Gorrotxategi, M., Psychological symptoms during the two stages of lockdown in response to the COVID-19 outbreak: An investigation in a sample of citizens in Northern Spain, Frontiers in Psychology, 2020, 11, 1491. https://doi.org/10.3389/ fpsyg.2020.01491

Peng, E. Y., Lee, M. B., Tsai, S. T., Yang, C. C., Morisky, D. E., Tsai, L. T., Weng, Y. L., Lyu, S. Y., Population-based post-crisis psychological distress: An example from the SARS outbreak in Taiwan, Journal of the Formosan Medical Association, 2020, 109(7), 524-532. https://dx.doi.org/10.1016\%2FS0929-6646(10)60087-3

Pieh, Ch., Budimir, S., Probst, T., The effect of age, gender, income, work, and physical activity on mental health during coronavirus disease (COVID-19) lockdown in Austria, Journal of Psychosomatic Research, September 2020, 136. https://doi. org/10.1016/j.jpsychores.2020.110186

Strutt, P. A., Johnco, C. J., Chen, J., Muir, C., Maurice, O., Dawes, P., Stress and coping in older australians during COVID-19: Health, service utilization, grandparenting, and technology use, Clinical Gerontologist, 2021, 44(4). https://doi.org/ 10.1080/07317115.2021.1884158

Webb, L., COVID-19 lockdown: A perfect storm for older people's mental health, Journal of Psychiatric and Mental Health Nursing, 2020, https://doi.org/10.1111/ jpm. 12644

WHO, Zdrowie psychiczne $i$ funkcjonowanie psychospołeczne podczas pandemii COVID-19, 2020, WHO-2019-nCoV-MentalHealth-2020.1-pol.pdf

Yeung, D. Y., Fung, H. H., Age differences in coping and emotional responses toward SARS: A longitudinal study of Hong Kong Chinese, Aging Mental Health, 2007, 11, 579-587. 


\title{
8 Support for older adults during COVID-19
}

\author{
How did local authorities in the \\ Pomeranian region respond to \\ the challenge?
}

Anita Richert-Kaźmierska

The COVID-19 pandemic, apart from health threats, has shown the problem of older adults' social isolation and loneliness in aging societies that has been progressing for several decades. Older adults' singularisation, loosening family relations, diminishing families' caring potential, caused that during the lockdown, many older adults without the neighbours' or NGOs' support or the activities undertaken by local authorities - would be left without meeting their basic life and social needs. Authors draw their attention to the different aspects of population aging process and its socio-economic consequences. Nevertheless, the subject of older adults' loneliness and the growing role of institutions (coordinated by local government authorities) in providing them different care services still seems insufficiently researched in the Polish-language literature. In Polish society, citizens prefer that the informal care needs of older adults are assiduously met by family members. However, the months of the COVID-19 pandemic lockdown have clearly shown that this traditional model of informal care is not always possible in practice, and that family members are increasingly turning to regional local authorities to assist them in the care requirements of older and frail relatives . Many family members are not always ready to provide care for older relatives at home due to a lack of appropriate knowledge and assistive aids.

\section{Introduction}

The older adults' support system in Poland is based on the hierarchical compensation care model, where responsibility regarding older adults' care and meeting older adults' needs is treated as a 'family matter': older adults' spouses and/or children are expected to take the full responsibility for providing the support, including long-term care. In small-town and rural societies, asking an institution for help to removing an older adult to a specialised 
centre causes family's stigmatization and accusation of soullessness or lack of gratitude.

The older adults' singularization (living alone) requires a review of this approach and more frequent and intensive inclusion of local self-help networks (neighbours and peer groups), non-governmental organisation and local authorities in the older adults' support system. The need for cooperation of various entities in providing support for older adults (a complementary care model) was experienced during the social isolation caused by the COVID-19. In many cases the assistance received by older adults from their family members proved insufficient.

The purpose of this study is to identify and classify the forms of support that local authorities in the Pomeranian Region offered to older adults during the first stage of lockdown caused by the COVID-19 pandemic. Apart from that, based on such experiences, the author intends to develop the concept of effective ways of supporting older adults during crisis situations in future.

\section{Local authorities in older adults' support system in Poland}

Supporting older adults is about providing them with a variety of resources (emotional, informational, material, financial) when they are experiencing difficulties and are unable to cope with them on their own. The insufficient availability of such support results in the needs of the older adults not being met or not sufficiently met (Błędowski et al. 2017). Ultimately, it leads to the deterioration of their social and living conditions, their health, or even to loss of life. The organisation of the support system for older people depends on many factors and differs from country to country. The differences concern, among others: the forms of support and their availability (Błędowski et al. 2017), the degree of institutionalisation of the system, i.e., the responsibility (formal and customary) of family members and institutions for providing support and care to older adults (Gibson et al. 2003), the rules of functioning of support providers and the way of financing their activities (Jurek 2012; Riedel \& Kraus 2011), as well as the supervisory and control bodies of such a system and the scope of their powers (Genet et al. 2012).

The system of support and care for the older adults in Poland is closest to the hierarchical-compensatory model. ${ }^{1}$ The family is seen as the most desired, natural environment of emotional functioning and life activity of older adults, guaranteeing the satisfaction of their needs. ${ }^{2}$ The responsibility for providing support and care for the older adults rests, respectively, on their children, spouses, siblings, grandchildren and other relatives (CBOS 2019). The support and institutional care ${ }^{3}$ are treated as complementary to family care and the permanent transfer of a senior citizen to a long-term care facility is perceived to be only as the last resort (Cantor 1989). As Janowicz (2014: 162) observes, "in smaller environments it happens that giving a loved one up to a specialist centre results in stigmatization of their family and a 
suspicion of heartlessness or lack of gratitude on the part of their children and grandchildren".

Due to a range of social changes taking place due to women becoming engaged in the labour market and smaller family household, but especially the singularisation of old age (Heinze \& Naegele 2009) and the decreasing caring capacity of families (Błachnio 2016), the demand for active participation of non-governmental organisations and public institutions in the system of support for older adults is systematically increasing. Local government, as the "closest to the citizens", has a special responsibility in this respect. It is a provider of statutorily guaranteed social services to older adults, but also an initiator and a coordinator of activities undertaken locally by other entities. According to the provisions of the Polish Social Welfare Act (Ustawa $\mathrm{z}$ dnia 12 marca 2004 r. o pomocy społecznej (Dz.U.2004, 64: 593), the district is obliged to provide assistance to older adults on the same principles as other groups of beneficiaries "in need of support" (people who, due to age, illness or disability, require partial care and assistance in meeting their vital needs). However, more and more local governments ${ }^{4}$ decide to improve upon the catalogue of compulsory activities related to older adult support and implement local old age policies. They include, among others, activities in the field of health prevention, social activation of older adults, increasing the availability of care services for older adults in their place of residence, or supporting family carers (Table 8.1).

\section{Senior citizens' needs during the COVID-19 pandemic}

Due to their heterogeneity (age, health condition, level of independence, family situation, material situation), older people declare different needs which they are able to satisfy on their own or in relation to which they require support from family members, third parties and/or institutions. Both groups of needs can include material, spiritual, emotional and cultural needs, as well as needs related to daily activities or physiological and health needs (Błędowski 2002). Tibbitis (1967) arranges them into ten groups, which in turn can be arranged according to the hierarchy proposed by Maslow (2009). According to Maslow, humans strive to satisfy their needs sequentially, starting from physiological (life, organic) ones and ending with those related to the desire to realise one's potential and personal development - cf. Figure 8.1.

The needs of older people - as a rule - are not significantly different from those felt at earlier stages of life. However, their hierarchy and intensity may vary. Due to the deteriorating health condition, lower activity and physical fitness, as well as changes in social relations, the need for closeness, acceptance (being needed), support in everyday activities and a sense of security becomes most important in old age (Nosek 2016; Trafiałek 2003).

The COVID-19 pandemic had various social and economic consequences (Peterson \& Thankom 2020). Its impact on the situation of older adults is 


\section{Anita Richert-Kaźmierska}

Table 8.1 The tasks of district self-government in the support system for older adults in Poland

\begin{tabular}{|c|c|c|}
\hline \multirow[t]{7}{*}{ Mandatory $^{\mathrm{a}}$} & $\begin{array}{l}\text { Distribution of } \\
\text { cash benefits }\end{array}$ & $\begin{array}{l}\text { Granting and payment of periodic and special purpose } \\
\text { allowances, } \\
\text { Paying a pension insurance contribution for individuals } \\
\text { resigning from employment because of the need to take } \\
\text { direct personal care of a long-term or seriously ill family } \\
\text { member or their mother, father or siblings who do not live } \\
\text { together, } \\
\text { Paying for the stay of a district resident in a residential care } \\
\text { home }\end{array}$ \\
\hline & Provision of & Social work, \\
\hline & benefits in & In-kind help, \\
\hline & kind (social & Specialist advice and crisis intervention, \\
\hline & services) & $\begin{array}{l}\text { Providing shelter, food and necessary clothes, } \\
\text { Care services in the place of residence, in support centres } \\
\text { and in family care homes, }\end{array}$ \\
\hline & & $\begin{array}{l}\text { Specialist care services in the place of residence and in } \\
\text { support, residence and service centres in the residential } \\
\text { care home, }\end{array}$ \\
\hline & & $\begin{array}{l}\text { Assistance in obtaining appropriate housing conditions, } \\
\text { Training and family counselling }\end{array}$ \\
\hline \multirow[t]{17}{*}{ Optional } & $\begin{array}{l}\text { preventive } \\
\text { healthcare }\end{array}$ & $\begin{array}{l}\text { implementation of preventive programmes (e.g. vaccination } \\
\text { against influenza and pneumococcus, screening) }\end{array}$ \\
\hline & & $\begin{array}{l}\text { financing of rehabilitation procedures, including home } \\
\text { rehabilitation }\end{array}$ \\
\hline & $\begin{array}{l}\text { Promoting social } \\
\text { inclusion and }\end{array}$ & $\begin{array}{l}\text { Implementation of the principles of universal design in } \\
\text { investment projects }\end{array}$ \\
\hline & $\begin{array}{l}\text { combating } \\
\text { discrimination }\end{array}$ & $\begin{array}{l}\text { Adapting the existing district infrastructure to the needs of } \\
\text { older people with reduced mobility and the disabled }\end{array}$ \\
\hline & & $\begin{array}{l}\text { Actions aimed at strengthening intergenerational } \\
\text { cooperation }\end{array}$ \\
\hline & & $\begin{array}{l}\text { Developing neighbourhood and intergenerational } \\
\text { volunteering }\end{array}$ \\
\hline & & $\begin{array}{l}\text { Social campaigns for positive ageing and social inclusion of } \\
\text { senior citizens }\end{array}$ \\
\hline & & $\begin{array}{l}\text { Implementing institutionalised advocacy for the interests of } \\
\text { older people }\end{array}$ \\
\hline & Social activation & $\begin{array}{l}\text { Investing in infrastructure dedicated to the older adults } \\
\text { (meeting places for senior citizens, open gyms) }\end{array}$ \\
\hline & & $\begin{array}{l}\text { Organizing leisure time (financing the activities of senior } \\
\text { citizen clubs and associations) }\end{array}$ \\
\hline & & $\begin{array}{l}\text { Organization of educational, recreational and sports } \\
\text { activities }\end{array}$ \\
\hline & & Cultural offer dedicated to older adults \\
\hline & & Actions for intergenerational integration \\
\hline & & $\begin{array}{l}\text { Support for mobility by providing individual door-to-door } \\
\text { transport services }\end{array}$ \\
\hline & Safety and & Psychological and legal assistance \\
\hline & security & $\begin{array}{l}\text { Home telecare service, with the support of a telecare } \\
\text { assistant }\end{array}$ \\
\hline & & Prevention of various forms of violence against older people \\
\hline
\end{tabular}

${ }^{\mathrm{a}}$ The forms of support for individuals who, due to age, illness or disability, require partial care and assistance in meeting their necessary life needs, that are obligatory for local government units, are defined in the Polish Social Welfare Act [28]. 


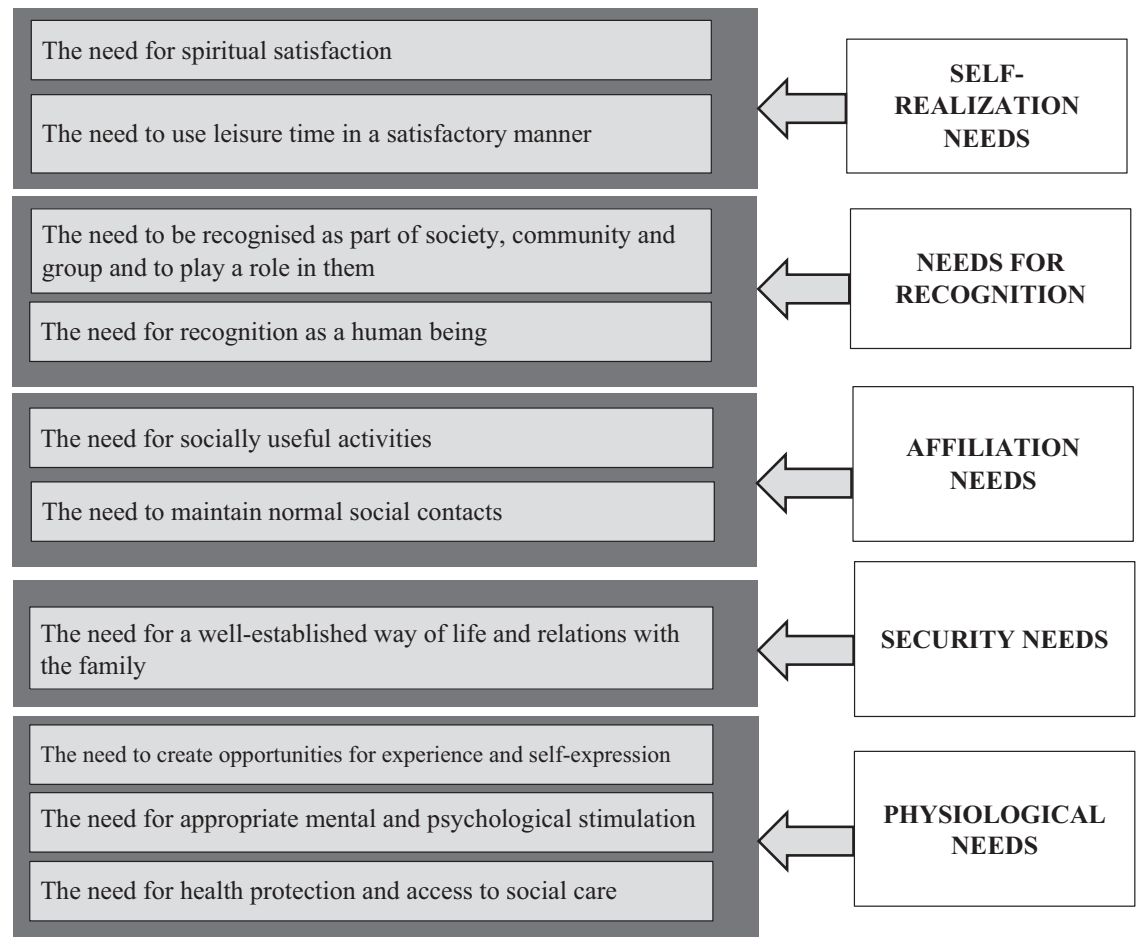

Figure 8.1 The needs of older people in the classification of C. Tibbits hierarchy of A. Maslow.

intensified by the fact that older age is the main risk factor of death in case of SARS-CoV-2 infection (Petretto \& Pili 2020). In the spring of 2020, almost overnight, the older adults became socially isolated as belonging to the highest risk group. For the sake of older people's health, personal contacts between family members were restricted, the activities of institutions organizing leisure time for older adults were suspended, recommendations not to leave home and restrictions on free movement outside the place of residence were introduced, and the availability of various types of social services in a direct personal form (e.g. visits to a doctor, rehabilitation services or participation in religious services) was limited or suspended. The time of the COVID-19 pandemic highlighted - more than ever before - the problems and unmet needs of older people: above all, social isolation and loneliness, age discrimination, insufficient access to health prevention, medical care and care services, as well as lack of or insufficient access to information (Przybył et al. 2020; United Nations 2020).

For many older adults - despite lack of actual infection with the virus COVID-19 has become the cause of a serious life crisis. It disrupted their earlier, "normal" functioning, caused or deepened the feeling of loneliness, increased the feeling of distrust towards strangers, as well as aroused fear 
for the health and life of themselves and their loved ones (Morrow-Howell 2020; Prawa człowieka osób starszych podczas pandemii 2020; Zangh \& Song 2020). As with any crisis situation, the reactions of older adults to a new situation are different (Parker \& Endler 1992): concentration on task, concentration on emotions or concentration on avoidance - cf. Table 8.2.

\section{Activities for the benefit of older adults undertaken by local governments in the Pomorskie province during the COVID-19 pandemic}

The COVID-19 pandemic forced the whole system of state administration to perform new tasks. Both the central government and the local governments faced the challenge of meeting the security needs of citizens by reducing the level of the epidemic itself on the one hand and supporting those affected on the other.

The local government is the organisational structure of the local community, located closest to the citizens in the hierarchy of power in a state. Therefore, the needs for support in crisis situations are first of all reported by citizens to the district authorities. As regards the fight against the COVID-19 epidemic, the activities of local self-government authorities are largely determined by the procedures generated at the government level and should be strictly harmonised with the activities of the government administration and its entities, as well of the local governments at the county and province level. They represent a huge challenge for local authorities - primarily due to the multitude and variety of tasks that fall into the scope of statutory responsibility of districts (own tasks and those commissioned by the government administration), the deficit of local government employees, or the difficult financial situation that had existed in many of them already before the outbreak of the epidemic (Berenda 2020; GUS 2019; Local governments: we help, but we also need support 2020).

According to the Polish Act on special solutions related to preventing, counteracting and combating COVID-19, other infectious diseases and crisis situations caused by them (Act on special solutions related to the prevention, counteraction and combating COVID-19, other infectious diseases and crisis situations caused by them (Dz.U. 2020, 374), article, 10, paragraph, 1), the Prime Minister, at the request of the Minister of Health, may impose an obligation on a local government unit to perform a specific task in connection with counteracting the COVID-19 epidemic. Moreover, in connection with the counteraction of COVID-19, by means of an administrative decision, the territorially competent provincial governor may also issue instructions applicable to all local and regional authorities (Act on special solutions related to the prevention, counteraction and combating COVID-19, other infectious diseases and crisis situations caused by them (Dz.U. 2020, 374), art. 11, par. 1).

In the classification proposed by Klimek, aid activities undertaken by local government units in the fight against SARS-CoV-2 were divided into 
Table 8.2 Senior citizens' attitudes and behaviour towards the COVID19 crisis

\begin{tabular}{|c|c|c|}
\hline $\begin{array}{l}\text { Attitudes } \\
\text { towards a crisis } \\
\text { situation }\end{array}$ & Possible behaviours & $\begin{array}{l}\text { Needs affecting the } \\
\text { specific behaviours of } \\
\text { older adults }\end{array}$ \\
\hline $\begin{array}{l}\text { Focus on the } \\
\text { task }\end{array}$ & $\begin{array}{l}\text { Striving to maintain a positive } \\
\text { attitude towards the surrounding } \\
\text { reality } \\
\text { Continuing previous (routine, } \\
\text { customary) activities outside } \\
\text { home (e.g. going shopping, } \\
\text { participating in senior citizens' } \\
\text { clubs) while observing safety } \\
\text { recommendations } \\
\text { With restrictions on going } \\
\text { outside the place of residence, } \\
\text { maintaining remote (telephone, } \\
\text { Internet) contact within the } \\
\text { network of family and social } \\
\text { relations } \\
\text { Engaging in various tasks and } \\
\text { initiatives (e.g. sewing masks) and } \\
\text { participating in online activities } \\
\text { dedicated to older adults }\end{array}$ & $\begin{array}{l}\text { Striving for "normality" } \\
\text { and functioning at a } \\
\text { fixed rhythm of the } \\
\text { day } \\
\text { The need for security } \\
\text { The need for affiliation } \\
\text { The need to be useful }\end{array}$ \\
\hline $\begin{array}{l}\text { - Focus on } \\
\text { emotions }\end{array}$ & $\begin{array}{l}\text { Focusing on collecting and } \\
\text { analysing (the main topic of the } \\
\text { discussions) information on the } \\
\text { risks associated with COVID-19 } \\
\text { and the actions taken by the } \\
\text { various institutions in this area } \\
\text { Wishful thinking, not taking any } \\
\text { action (remaining in a specific } \\
\text { state of suspension pending a } \\
\text { return to "normality") } \\
\text { Catastrophic thinking often leading } \\
\text { to mental problems (psychoses, } \\
\text { anxiety, depression, aggression) }\end{array}$ & $\begin{array}{l}\text { A disturbed sense of } \\
\text { stability and security } \\
\text { Emotional lability } \\
\text { Feeling lonely in a crisis } \\
\text { situation } \\
\text { The need to relieve } \\
\text { emotions and fear, for } \\
\text { example by talking to } \\
\text { another person } \\
\text { Insufficient access to } \\
\text { reliable information }\end{array}$ \\
\hline $\begin{array}{l}\text { Focus on } \\
\text { evasion }\end{array}$ & $\begin{array}{l}\text { Rejection of thoughts about the } \\
\text { problem } \\
\text { Demonstrating the denial of the } \\
\text { existence of a pandemic and its } \\
\text { associated dangers (affirmation } \\
\text { of a conspiracy theory, ignoring } \\
\text { safety rules) } \\
\text { Indifference to the problem and } \\
\text { dissociating oneself from the } \\
\text { information about the pandemic } \\
\text { coming from the environment } \\
\text { An "escapist" attitude, expressed } \\
\text { as falling into addictions or } \\
\text { above-average engagement in } \\
\text { substitution activities }\end{array}$ & $\begin{array}{l}\text { A sense of } \\
\text { powerlessness and } \\
\text { helplessness } \\
\text { Low self-esteem } \\
\text { Fatalism } \\
\text { Loneliness } \\
\text { Lack or inadequacy } \\
\text { of mental support, } \\
\text { related to missing } \\
\text { family, peer and } \\
\text { social relations }\end{array}$ \\
\hline
\end{tabular}


Table 8.3 Areas of local government support for senior citizens during the COVID-19 pandemic

\begin{tabular}{ll}
\hline & Recipients (beneficiaries) \\
\hline $\begin{array}{l}\text { Area 3: Support for social } \\
\text { assistance units providing } \\
\text { services to older adults }\end{array}$ & $\begin{array}{l}\text { Residential care homes } \\
\text { Day care and 24-hour care facilities for seniors } \\
\text { Area 4: Support for the } \\
\text { senior residents of the district }\end{array}$ \\
$\begin{array}{c}\text { Seniors residing in their flats/houses - residents } \\
\text { of the district } \\
\text { Seniors residing in residential care homes and } \\
\text { other day and day-and-night care institutions }\end{array}$ \\
\hline
\end{tabular}

four areas: support for health care, support for the economy, support for social assistance units and support for residents (Klimek 2020). Activities undertaken by local (district) governments for the benefit of older adults belong mainly to the third and the fourth area - cf. Table 8.3.

In order to identify what kind of actions local governments actually took during the pandemic for the benefit of senior residents, the author conducted a survey among the districts of the Pomorskie province. Out of 123 districts in the Pomorskie province, 10 were selected for the study: 2 urban-rural and 8 rural ones (cf. Table 8.4). Each of them - in accordance with the Act on Access to Public Information (Ustawa z dnia 6 września 2001r. o dostępie do informacji publicznej (Dz. U.2014, 782, 1662; Dz.U.2015, 1240) - was asked (by sending an e-mail to the address of the district office's secretariat) for public information in two areas:

(a) the forms and methods of support for the senior residents of the district which were implemented in the period from 1 March to 31 July 2020 in response to threats and limitations caused by the COVID-19 pandemic,

(b) the institutions and organisations (including initiatives of individuals) which joined in providing support to seniors in the district during the pandemic period.

The scope of the questions met the criteria justifying the right of access to public information, as defined in article 6, paragraph 1 of the Act on Access to Public Information. As a result, all the districts to which the inquiry was addressed sent their replies within 21 days from the date of sending the inquiry. The answers, depending on the district, were sent (as confirmed by the signature on the document or in the return e-mail) by the district leaders, the secretaries of the districts, the managers and employees of the district social welfare centres or the head of the village council responsible for senior citizen matters.

The aim of the study was to diagnose the activities actually undertaken by the pomorskie province districts for the benefit of older adults during the period of social isolation caused by the COVID-19 pandemic and to identify 
Table 8.4 Pomorskie province districts which were inquired about the support for seniors during the COVID-19 pandemic

\begin{tabular}{lllll}
\hline District & County & Type of district & $\begin{array}{l}\text { Total } \\
\text { population }\end{array}$ & $\begin{array}{l}\text { Share of } \\
\text { individuals aged } \\
\text { 60 and more (\%) }\end{array}$ \\
\cline { 4 - 5 } & & & - Data for 2019 \\
\hline Bytów & bytowski & Urban-rural & 25,420 & 21.7 \\
Koczała & człuchowski & Rural & 3,356 & 26.4 \\
Kolbudy & gdański & Rural & 17,839 & 18.1 \\
Konarzyny & chojnicki & Rural & 2,311 & 17.5 \\
Kosakowo & pucki & Rural & 15,589 & 15.7 \\
Lipnica & bytowski & Rural & 5,216 & 20.8 \\
Osiek & starogardzki & Rural & 2,376 & 27.2 \\
Smętowo & starogardzki & rural & 5,185 & 21.9 \\
$\quad$ Graniczne & & & & \\
Wicko & lęborski & rural & 6,019 & 20.4 \\
Żukowo & kartuski & Urban-rural & 40,837 & 15.2 \\
\hline
\end{tabular}

organisations, institutions and people with whom they cooperated in this area. The study was of a qualitative nature and therefore the results obtained do not allow for analyses based on statistical methods. On the other hand, the identified solutions may constitute a base of good practices, in the perspective of the so-called second wave of the pandemic and the necessity of the districts' renewed crisis involvement in additional support dedicated to older adults.

Only three of the surveyed districts declared the implementation of tasks in area 3: support for social assistance units dealing with older adults. First of all, these were the districts of Koczała and Kolbudy, in which there are senior citizens' clubs co-financed by the governmental Senior+ programme. Taking into account the needs of these units, both districts:

purchased personal protective equipment (masks, disposable gloves), as well as disinfectants and equipment necessary for their application, purchased additional equipment (plastic safety barriers) and appliances (thermometers) necessary to ensure the safe stay of older adults and staff working conditions, developed and implemented special security procedures.

In the Koczała district, one of the rooms in the Senior+ Club was additionally arranged to isolate individuals who would show symptoms of disease during classes. The Wicko district, in turn, carried out professional disinfection of all public places where classes dedicated to older adults are held.

Activities in area 4, that is support for older residents of the district, were implemented by all districts in the period from 1 March to 31 July 2020 (Figure 8.2). All districts declared the uninterrupted operation of their 


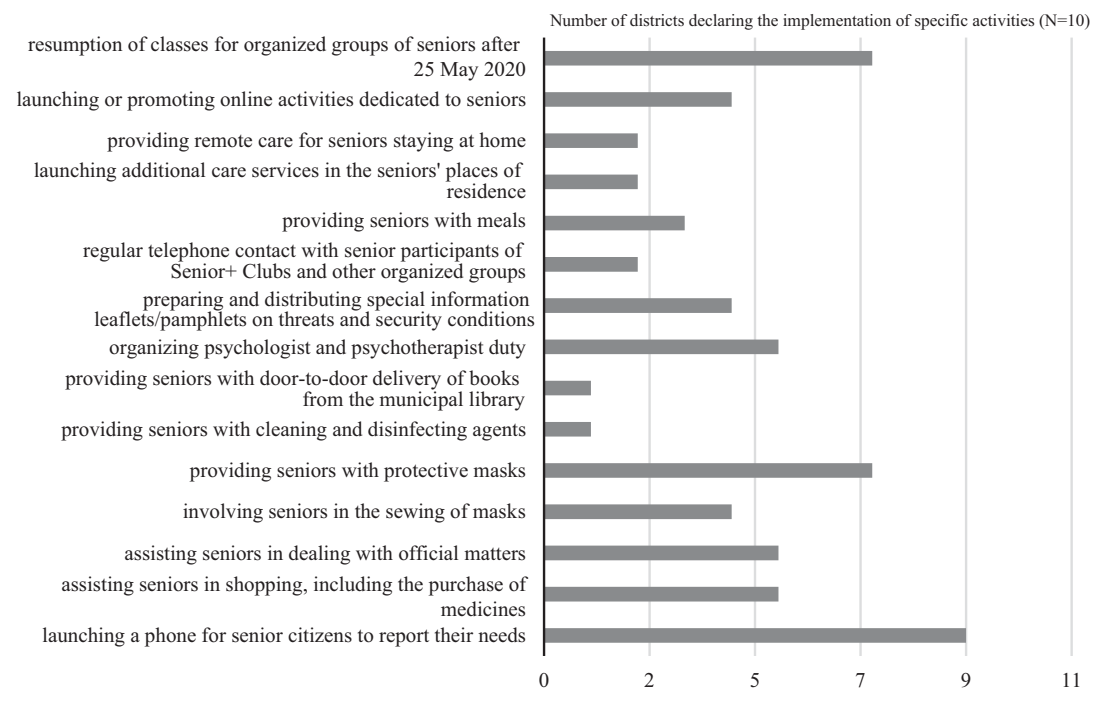

Figure 8.2 Activities supporting older adults during the pandemic, undertaken by local governments participating in the survey of districts.

social welfare centres and the provision of social services to individuals requiring support (including older adults), provided for in the Social Welfare Act Ustawa z dnia 12 marca 2004 r. o pomocy społecznej (Dz.U.2004, 64:593). Almost all of the surveyed districts have launched a special telephone number which can be used by older adults in need of help, e.g., in shopping, buying medicines, arranging an over-the-phone consultation with a physician, dealing with official matters, etc. In the Koczała and Lipnica districts, due to the introduction of such a solution, the working hours of social workers were extended (the phone number dedicated to older adults was operated by employees of the district social welfare centres). In almost all districts protective masks were provided to older adults.

The activities undertaken in the period from 1 March to 31 July 2020 by the local governments involved in the study, in relation to older adults, were mainly in line with three groups of needs, i.e., physiological needs, safety needs and affiliation needs - see Figure 8.3.

The local governments have undertaken activities to support older adults on the basis of the results of a systematic analysis of the needs of the older adults carried out by the district social welfare centre or the district leaders' proxy for senior citizens (Osiek, Kolbudy), ongoing monitoring of the needs of senior citizens carried out by the village leaders (Konarzyny), a questionnaire sent out to senior citizens (Kosakowo), or in response to specific signals reported by the residents of the district to the district office or the district social welfare centre (Lipnica). 


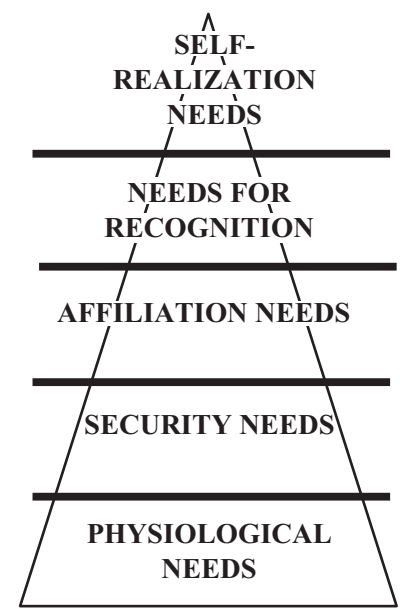

telephone contact with seniors, supplying books from libraries, involving seniors in sewing masks, organizing remote and stationary classes during the pandemic after 25 May 2020

telecare, provision of masks for seniors, provision of disinfectants, distribution of leaflets with reliable information on risks and prevention, on-call duty of and consultations with a psychologist

provision of meals for seniors, assistance with shopping and purchase of medicines, care services at the place of residence of the seniors, financial assistance from the district social welfare centre

Figure 8.3 Activities supporting older adults during the pandemic, undertaken by local governments participating in the survey of districts, in the context of Maslow's hierarchy of needs.

Within activities supporting older adults during a pandemic, local governments performed various functions: they were initiators, coordinators, financing entities or executors. And so, the Żukowo district was i.a. the initiator of the informational and social campaign "Take care of the senior", the aim of which was to encourage the residents to pay more attention to the needs of the older adults in their families, as well as older friends and neighbours, and to offer them help. Konarzyny district (as the District Social Welfare Centre in Konarzyny) coordinated activities supporting older adults carried out in its territory by the Polish Red Cross (acquiring and handing over food parcels), the Association for the Development of the Municipality and District of Debrzno (acquiring and handing over cleaning products to older adults), or the Association for the Support of Children and Youth "Klub Mam" (handing over masks sewn by members of the association to older adults). Kolbudy district funded and purchased protective masks, and the village leaders supplied to the older adults living in their villages. Kolbudy and Koczała funded and purchased the necessary equipment for the Senior+ Clubs operating on their premises in order to ensure the safety of club participants and staff.

The partners of supporting activities during the COVID19 pandemic were e.g. district organisational units, local non-governmental organisations and entrepreneurs, district volunteer fire brigades, as well as village leaders and volunteers (Table 8.5). 
Table 8.5 Partners in the activities of local governments supporting older adults during the pandemic - examples

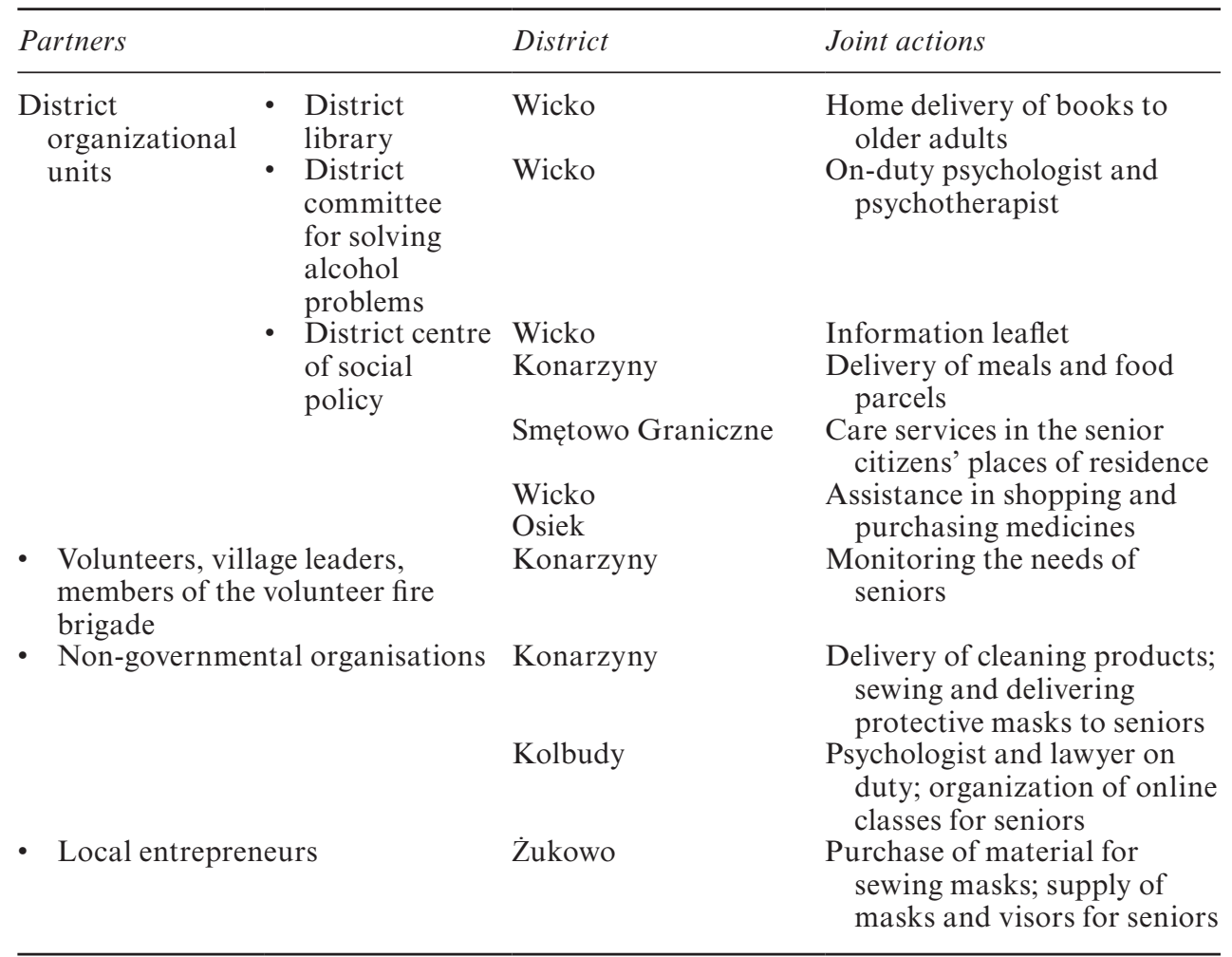

Source: Author's own work.

\section{For further discussion...}

The COVID-19 pandemic represents a double threat for older adults. First of all, a health risk: the infection is most severe (due to reduced immunity and the occurrence of concomitant diseases) among people aged 60 and over, which is reflected in the death rate due to COVID-19 being highest in this group. The second threat is social isolation. Fearful for their health and life, during the pandemic older people were excluded from society more than ever. They were left in their homes, without contact with loved ones and peers. Since a large proportion of them do not have sufficient digital competences, the prosthesis of human relations provided by the Internet is not available to them either. As a result of research carried out in the early stages of the pandemic and national lockdown, it turned out that many older adults are not able to satisfy even their basic - physiological - needs (there is no one to buy them staples or drugs). They also suffered significant deficits in terms of the need for security and affiliation.

The changes that have been taking place for several decades make families and their support for older adults insufficient. Public authorities mainly local governments - must be involved in the process of meeting the 
needs of older people. The crisis situation caused by the COVID-19 pandemic has shown that not all districts are equally prepared for this. Most of them do not have a diagnosis of the needs of older adults (including in the event of an emergency). Their countermeasures were most often ad hoc responses to individually reported signals of necessary assistance. In the answer received from the district of Lipnica, it was explicitly stated that "there was no need to take emergency action as no cases of seniors' requiring support were reported to us in connection with the quarantine or other situations requiring our intervention under the COVID-19 restrictions". The main responsibility for possible satisfaction of the needs of older residents during the pandemic was transferred to the district social welfare centres. It was done despite the fact that few older adults are beneficiaries of this institution on a daily basis and district social welfare centres have no information about such persons.

On an ongoing basis and in a rather chaotic way, partners for cooperation in the field of supporting senior residents of districts were sought. The local leaders in rural districts, i.e., the village leaders, turned out to be most reliable. Among the survey participants, only the Żukowo district indicated good cooperation with a local entrepreneur.

The experience gained during the first wave of the pandemic (from 1 March to 31 July 2020) should form the basis for developing action plans for local governments in the event of a second (autumn) wave of cases or other similar events in the future. The list of important and urgent actions to be taken by the local authorities participating in the survey, but probably also the remaining ones, should also include, among others:

- preparation of a diagnosis of the situation of the older residents, i.e., primarily recognizing the phenomenon of the singularization of old age and assessing the level of caring capacity of their families,

- support in the development and professionalization of volunteering, including neighbourhood volunteering and older adult volunteering,

- developing a system for collecting information on the needs of older adults in crisis situations and a system for providing them with information on the offer of assistance activities available in the district,

- building permanent inter-sectoral partnerships (local government unit/ non-governmental organisation/entrepreneurs), mutually complementary as regards the benefit of the local community, including the older adults (development of local social capital), is concerned.

\section{Notes}

$1 \mathrm{Z}$. Szweda-Lewandowska [24] identifies five types of models for the organisation of senior care systems: the hierarchical compensatory model, the substitutional model, the specificity model, the supplementation model and the complementarity model.

2 According to EuroCarers statistics, $93.5 \%$ of dependent persons in Poland receive care from family carers [30]. 
3 The institutional care for older adults in Poland is implemented in two areas: health care and social assistance. The patients who do not require hospital treatment but nevertheless have significant deficits in health and self-care benefit from long-term care in the health care system, i.e. from care, nursing, rehabilitation, palliative and hospice services, in a specialised facility (inpatient care) or at their home (community care). Care services provided within the framework of social assistance are, in turn, available to individuals who, due to age, illness or disability, require the assistance of other people and are deprived of it [28]. The care services in this case mainly include "assistance in meeting daily life needs, hygiene care, doctor-advised care and, where possible, ensuring the possibility of contact with the environment".

4 The results of the research carried out by the author in the years 2012-2018 indicated that local governments in Poland did not diagnose the demographic changes taking place in their territory, did not recognise the needs of the growing subpopulation of seniors and did not take action to allow for seniors and the ageing of local communities, or such action was insufficient. In recent years, upon participation in multiple research projects and work on local strategies for solving social problems, the author sees a positive change in the attitude of local authorities to the issue of population ageing and actions towards older people.

\section{References}

Act of March 12, 2004 on social assistance (Dz.U.2004, 64:593).

Act on special solutions related to the prevention, counteraction and combating COVID-19, other infectious diseases and crisis situations caused by them (Dz.U. 2020, 374).

Berenda K., Alert gospodarczy: Rola jednostek samorzadu w powstrzymywaniu zapaści gospodarczej, (available 6th of May 2020), https://www.rmf24.pl/raporty/ raport-koronawirus-z-chin/komentarze-ekspertow/news-alert-gospodarczyrola-jednostek-samorzadu-w-powstrzymywaniu, nId, 4424551

Błachnio A., Starość w rodzinie. Opieka nad seniorem wyzwaniem dla dorosłego dziecka czy państwa?, Wychowanie w Rodzinie t. XIII (1)/2016, p. 441-453.

Błędowski P., Lokalna polityka społeczna wobec ludzi starych, Oficyna Wydawnicza Szkoły Głównej Handlowej, Warszawa 2002.

Błędowski P., Szatur-Jaworska B., Szweda-Lewandowska Z., Zrałek M., Model wsparcia społecznego osób starszych $w$ środowisku zamieszkania, In: B. Szatur-Jaworska, P. Błędowski (eds.), System wsparcia osób starszych w środowisku zamieszkania - przegląd sytuacji, propozycja modelu. Synteza. Raport z prac Komisji Ekspertów ds. Osób Starszych przy Rzeczniku Praw Obywatelskich, Biuro Rzecznika Praw Obywatelskich, Warszawa 2017, pp. 13-46.

Cantor M., Social care: Family and community support systems, The Annals of the American Academy of Political and Social Science 503(1)/1989, p. 99-112.

CBOS, Jakiej pomocy potrzebuja osoby starsze i kto im jej udziela?, Komunikat z badań nr 116, CBOS, Warszawa 2019.

Genet N., Boerma W., Kroneman M., Hutchinson A., Saltman R. (eds.), Home care across Europe. Current structure and future challenges, WHO, Copenhagen 2012.

Gibson M.J., Gregory S.R., Pandya S.M., Long-term care in developed nations: A brief overview, Working papers 2003-13, AARP Public Policy Institute, Washington 2003, p. 5-7.

GUS, Gospodarka finansowa jednostek samorzadu terytorialnego 2018, Główny Urząd Statystyczny, Warszawa 2019.

Heinze R., Naegele G., Silver economy in Germany - more than only the economic factor: Old age, Gerobilim 02/2009, p. 37-52. 
Janowicz A., Rola opiekunów nieformalnych w opiece u kresu życia. Przyczynek do badań w ramach projektu European Palliative Care Academy (EUPCA), Pielęgniarstwo i Zdrowie Publiczne, 4(2)/2014, p. 161-167.

Jurek Ł., Ekonomia starzejącego się społeczeństwa, Wydawnictwo Difin, Warszawa 2012.

Klimek M., Działania pomocowe jednostek samorzadu terytorialnego wobec epidemii, In: N. G. Pikuła, M. Grewiński, E. Zdebska, W. Glac (eds.), Wyzwania dla polityki społecznej w kontekście pandemii koronawirusa, Biblioteka Instytutu Spraw Społecznych Uniwersytetu Pedagogicznego im. Komisji Edukacji Narodowej w Krakowie 2020, p. 37-51.

Maslow A., Motywacja i osobowość, PWN, Warszawa 2009, p. 62-76.

Morrow-Howell N., Galucia N., Swinford E., Recovering from the COVID-19 pandemic: A focus on older adults, Journal of Aging and Social Policy, 32(4-5)/2020, p. 526-535.

Nosek K., Starość zapomniana, czyli o specyfice funkcjonowaniu osób starszych $w$ nowoczesnym społeczeństwie, Kwartalnik Naukowy Fides et ratio 2(26)/2016, p. $160-168$.

Parker J.D.A., Endler N.S., Coping with coping assessment: A critical review, European Journal of Personality 6(5)/1992, p. 321-344.

Peterson O.K., Thankom A., Spillover of COVID-19: Impact on the global economy (available 27th of March 2020), https://ssrn.com/abstract $=3562570$

Petretto D.R., Pili R., Ageing and COVID19: What is the role for elderly people? Geriatrics 5(25)/2020, p. 1-4.

Prawa człowieka osób starszych podczas pandemii. wspólne stanowisko Niemieckiego Instytutu Praw Człowieka oraz Rzecznika Praw Obywatelskich Rzeczypospolitej Polskiej, Warszawa 2020 (available 23rd of April 2020), https://www.rpo.gov.pl/ sites/default/files/Wsp $\% \mathrm{C} 3 \% \mathrm{~B} 31$ ne $\% 200 \% \mathrm{C} 5 \% 9 \mathrm{Bwiadczenie} \% 20 \mathrm{RPO} \% 20 \mathrm{i} \%$ 20 DIf MR $\% 20$ w $\% 20$ sprawie $\% 20$ praw $\% 20$ os $\%$ C3 $\%$ B 3 b $\% 20$ starszych $\% 20$ podczas $\% 20$ pandemii.pdf

Przybył A., Jasiówka M., Gorczyca W., Łukasik M., Tomza P., Raport o samotności - epidemia, która jest naszą wspólną sprawą, Stowarzyszenie Wiosna, Warszawa 2020 (available 10th of April 2020), https://www.szlachetnapaczka.pl/ raport-o-samotnosci/

Riedel M., Kraus M., Informal care provision in Europe: Regulation and profile of providers, ENEPRI Research Report 96, 2011.

Samorzady lokalne: pomagamy, ale sami też potrzebujemy wsparcia (available 6th of May 2020), https://wspolnota.org.pl/news/samorzady-lokalne-pomagamyale-sami-tez-potrzebujemy-wsparcia

Szweda-Lewandowska Z., Modele opieki nad osobami niesamodzielnymi, Zeszyty Naukowe Wydziałowe Uniwersytetu Ekonomicznego w Katowicach 197/2014, p. 215-224.

The Act of September 6, 2001 on access to public information (Dz. U.2014, 782, 1662; Dz.U.2015, 1240).

Tibbitis C. (ed.), Handbook of social gerontology. Societal Aspects of Aging, Chicago University Press, Chicago, IL 1967.

Trafiałek E., Polska starość w dobie przemian, Wydawnictwo Śląsk, Katowice 2003. United Nations, The Impact of COVID-19 on older persons, Policy Brief 2020.

Who cares? Securing support in old age, Policy Brief 21/2019 (available 27th of May 2019), https://population-europe.eu/policy-briefs

Zhang Q., Song W., The challenges of the COVID-19 pandemic: Approaches for the elderly and those with Alzheimer's disease, MedComm 1(1)/2020, p. 1-5. 

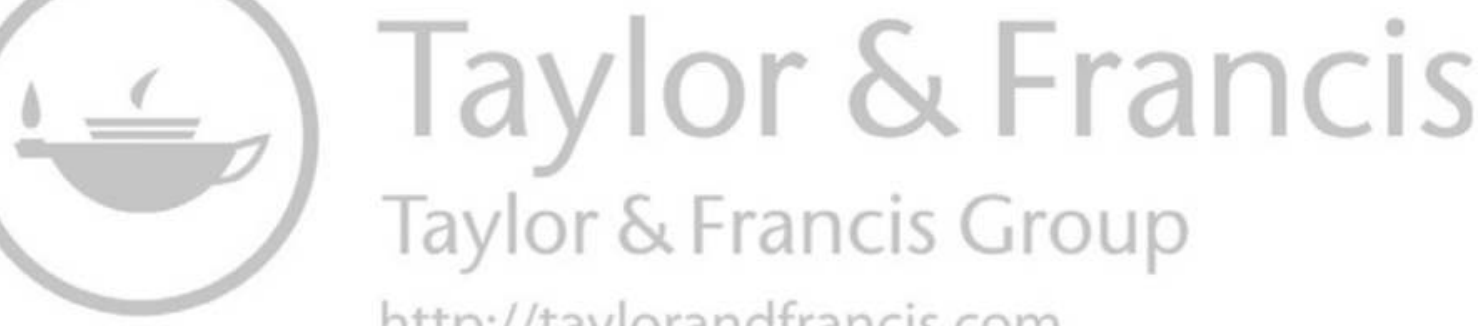
http://taylorandfrancis.com 


\section{Part 3}

Social life 

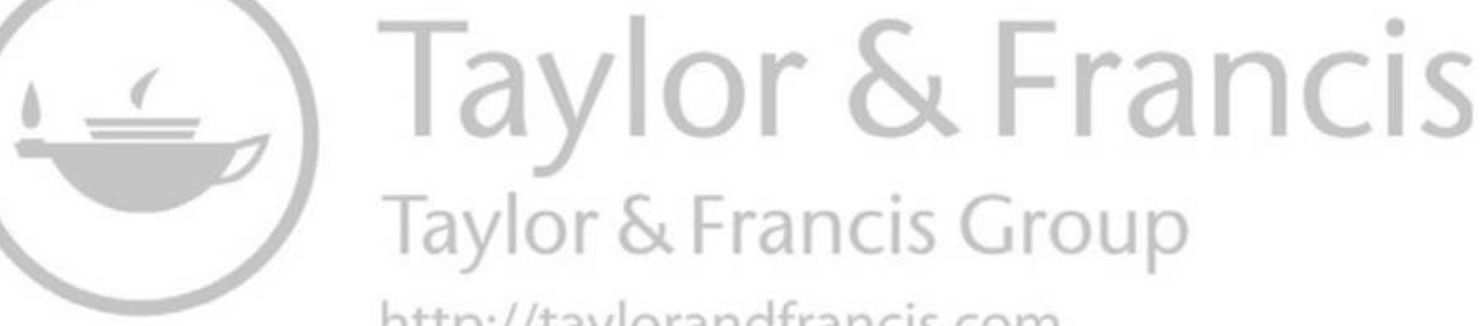
http://taylorandfrancis.com 


\title{
9 Geragogy of everyday life The COVID-19 perspective
}

\author{
Zofia Szarota
}

In the spring of 2020, when I undertook my research, there were no reports on adaptive strategies undertaken by older adults during the COVID-19 pandemic. I found no reports in the literature on informal learning as an individual resilience strategy. In my research, the units of analysis were the spaces of everyday, existential, non-obvious learning of 60-79 year-old under pandemic conditions. The content of the chapter was set in the critical-emancipatory stream of social gerontology. In it, I addressed the problem of supporting voiceless people who subjectively experience social stigmatization and are labeled by social policy as "at-risk individuals and groups". The aim of the study was to reveal individual adaptation strategies, "taming" the new reality and coping with it.

\section{Introduction}

The World Health Organization on 29 January 2020 declared a global public health emergency and on 11 March 2020 identified the epidemic COVID-19 as a pandemic. As a preventive measure, social (basically - physical) distancing and a distance of 1.5-2 meters between persons was recommended. In the countries affected by the pandemic, there was an appeal to stay at home. An administrative quarantine order was introduced for infected and preventively for people coming from abroad. In Poland, the first COVID-19 infection was registered on March 4, 2020, and immediately after that WHO recommendations were implemented under government regulations. Older people, especially those with comorbidities, were considered to be at high risk. A time of pandemic confinement, social quarantine, and official self-isolation orders may have increased loneliness in older people and resulted in their lowered mood, development of anxiety and even depression. Relationships and perceptions of value may have changed. Has it really happened? The study is an attempt to answer this question. The chapter takes 
into account the context of situatedness of human transitions, behaviors, needs and values in everyday life marked by the experience of a pandemic.

\section{Theoretical framework}

Social isolation, understood as physical separation from other people, has negative consequences for the well-being of an older person. Isolation, sometimes equated with social exclusion, is characterized by a lonely life resulting from the shrinking network of social support resources and rare interpersonal contacts. This is due to the declining interest in maintaining wide social contacts with age, shrinking peer group due to natural causes, deteriorating health condition, which reduces social mobility and is sometimes the cause of institutionalization of the life ( $Y u$ et al. 2019). The negligible resources of social support are a consequence of socio-cultural changes and demographic processes that characterize modern families: low fertility, migrations, disappearance of multi-generational households. The extent of social isolation of older people is influenced by social policy for older people, shaping (or not) environments and support groups, environmental integration facilities and meeting the needs of pensioners (Dubas 2017).

Loneliness can be the result of a subjective sense of social isolation: The value of loneliness is appreciated in scientific reflection, it is difficult to deny that loneliness is feared in contemporary culture (Hornowski 2020). Physical (social) solitude

consists in weakening or breaking the natural bond with other people, a very loose connection with society or living outside it (...) Loneliness is the exclusive communion with oneself and one's inner world, it is a refuge - with life and action - in it.

(Wałejko 2007: 47-48)

At the end of his/her journey through life, the older adults face the necessity to face loneliness (loneliness) and - sometimes awaited - solitude, as new dimensions of spirituality and existential concerns (Fabiś 2018), return to 'primal loneliness'. According to John Paul II, the term "primary loneliness" means not only the experiences of the first people and their obligation to understand oneself and the world imposed by the Creator, but also filling man with internal dialogue, self-awareness and self-determination in the spiritual sphere: "solitude also signifies man's subjectivity, which is constituted through self-knowledge" (John Paul II 1979). Meanwhile "because loneliness is associated with suffering and is a difficult experience to bear, difficulties with accepting it intensify in contemporary culture, where loneliness is perceived negatively, leading individuals to try to avoid it" (Hornowski 2020). Thus, solitude gains two contexts - positive, developing and negative, degrading. The negative aspect brings loneliness closer to social exclusion. 
The gerontological theory of activity links the well-being of the old man to his usefulness for himself and society. Social policy towards older people aims to activate older people, to include them in society (Szarota 2015). It is worth noting, however, that experiencing loneliness can become an opportunity to look at reality from a different perspective (see: Hornowski 2020). Adaptation processes, including learning acts that involve in the process of relieving stress, contribute to the familiarization with loneliness, giving it a dimension of activity, self-creation and transgression. When the external world is a source of tension and the space of activity is significantly narrowing, the spiritual development of an ageing person may take place. There is a need to search for internal order, personality integration, self-awareness, integration with the entire life so far, and giving meaning to events. Thought can focus on transcendence, looking for answers to the most important questions in the reflective interior of the old man. Wisdom is then interpreted as orderly experiences, going beyond oneself, emancipation of identity (Kvale 2010):

Social stress in the aging population, therefore, may be defined in part as a response in older adults to an external challenge or stimuli (i.e., stressors) of social nature that may jeopardize their sense of self or sense of social standing or belonging in a relationship, within a group, or within the larger community.

(Nguyen et al. 2020)

Routine strategies can be used to solve problems (Drozdowski et al. 2020: 38 ), which is particularly important for older people. The basic form of collective life and space for the development of older people is the family and the local community. A safe home, a familiar neighborhood, friendly neighborhood build a sense of mental comfort, well-being, good quality of life (Błachnio 2019: 99-102). The learning that takes place there is an irregular process situated in everyday life, in relations with other members of the community. It generates experiences that make up unobvious learning. This is my own term, close to informal learning in terms of Livingstone (Livingstone 1999, 2001), but not identical. Some interpretative clues can be found in the concept of implicit learning, understood as ways of effectively adapting behaviour to constantly changing environmental conditions (Virag \& Nemeth 2016). Similarities can be found in the concept of learning from experiences that

it is learning during life, in organized or incidental situations, related to the implementation of life tasks and undertaken activities, or their omission. It is learning from experience - in a direct way, i.e. in the course of events happening, in the course of certain life situations. It is learning from one's own experiences and the experiences of Others, who are in direct contact with time and space, which are created by situations. 
According to its own concept, unobvious education means learning, as it were, on the occasion, in ad hoc situations in which people - through experience and habitus (understood as acquired skills and competences that define individual ways of perceiving the world, rules of conduct and thinking) they adapt, accustom to new conditions and needs, unexpectedly generate new knowledge for themselves and incorporate it into their behavioural mechanisms. Unobvious education environments are social events and interactions, activities and behaviours occurring in everyday life, customs. The subject, internalizing the consequences of self-experience of reality, most often does not give cognitive episodes an educational meaning, does not know that he/she is learning, making this activity an unintentional, hidden, unconscious act. However, it develops new adaptation and coping strategies. Resilient strategies (coping with stressful situations) I classify as an unobvious education area. It should be remembered that the older adults are reluctant to introduce changes in their personal lives. Ageing and adaptation are opposite processes, therefore it could be expected that the people participating in the research would have a reduced adaptive ability (Cochrane \& White 2020).

\section{Materials and methods}

\section{Research problems}

The aim of the study was to establish individual strategies to minimize the effects of COVID-19 in conditions of compulsory social isolation. The question was to what extent the drama of closure and isolation changed the perception of central themes and the hierarchy of needs of people aged 60 and over. The research was conducted in June and July 2020, in the qualitative research stream using semi-structured life-world interview, which allows "to explore the way individuals experience and perceive their world. It allows for a unique insight into the world of respondents' life, who in their own words describe their actions, experiences and views" (Kvale 2010: 39). Such an interview provides an opportunity to obtain answers to specific research questions, but is open enough to give the researched person the chance to make unlimited statements which may give new meanings to the explored problem (Galetta 2013). Interview instructions focused on experiencing epidemic restrictions. They asked about the reactions triggered by the information about the pandemic (what they felt, what they thought, what they possibly feared); about reactions caused by the need to accept the ban concerning the lockdown and social isolation. An important problem was the scope and type of support received. A significant research issue was the potential changes that took place in their home, family, neighborhood and macrosocial relationships. They were asked about the sources of their knowledge about the potential threat, about the content that contributed 
to (unobvious, unconscious) learning from the pandemic experience. The preventive measures taken by the respondents against the danger COVID-19 were interesting. Interlocutors were asked to formulate a message, a principle that seemed most important to them after experiencing the effects of the pandemic.

\section{Data analysis}

More than ten hours of recordings were obtained. The recordings were transcribed. Significance-oriented analysis was used (Kvale 2010). The transcribed text has been encoded and categorization, then condensation. "Meaning units" were established taking into account the research objective and the rank assigned to them by the interviewee. The description of the results includes information on the main threads of the interview.

\section{Characteristics of the persons interviewed}

According to the Older Persons Act (Ustawa z 11 września 2015 r. o osobach starszych [Act of 11 September 2015 on older persons], Dz. U. 2015 poz. $1705)$ in Poland, an older person is considered to be a man or woman over 60. Respondents - nine women and three men - they were 60 to 79 years old. People living in different parts of Poland (between June and July 2020) were invited to the research: four of the respondents lived in a region with a very high COVID-19 incidence rate, five in voivodships with high incidence rates (5th and 6th position among 16 regions), two people lived in low-disease areas (the last two positions among voivodships). Informed consent was expected from each of the invited persons to participate in the study (Kvale 2010: 64-65). Some of them refused, arguing that they did not believe in the objectivity of the results, "for sure someone ordered and will publish them for mercantile purposes". They were afraid that the researcher had been "hired to search for people who would agree to the interview and give their views on this particular matter", they asked annoyed: "What's the best way to upset someone? Conduct the telephone interview". They claimed: "I do not believe in the noble and true purpose of such interviews". Eventually, 12 people took part in the study using phone calls. In one case the interview was given by the couple, the spouses' responses were analysed separately.

During the research, seven people stayed at home, two on holiday (including one abroad), two were working, and one stayed alone in her home in the countryside. They all had families, no one was alone, although five people lived in widowhood. Apart from one person with German citizenship, the interviewees were Poles. At the time of the research she was in Poland. The interview was conducted in Polish. Four people managed the household individually, independently, four in one generation in a marriage or relationship, three lived on a two-generation household - two people with 
their parents (at the age of 95 and 94), and one with her husband and a studying daughter, one person in a multi-generational family - with the husband and the procreative family of one of their own children. Three people lived in houses, the rest in multi-family buildings. The health status in the selfassessment of seven respondents was good and very good, despite the cases of chronic obstructive pulmonary disease and the state of convalescence after resection of the prostate, three people assessed their health in $s o-s o$ and indicated chronic diseases (pulmonary sarcoidosis, sick thyroid gland, diseased large intestine, convalescence after bone fracture). Two people assessed their well-being as bad and listed a number of comorbid chronic diseases, including diabetes, eye disease, digestive system disease, and cardiovascular disease.

The woman who was the only one who considered her finances to be very good, has run her own business in the tourism industry since her retirement. The second woman worked on a contract of employment, the third on a contract of mandate. The man ran a one-man business activity. Five other people volunteered for the Universities of the Third Age (U3A) as their animators, two of whom gave lectures in foreign languages (Russian and French), and another sang in an amateur vocal ensemble. Three people were active in their own household and hobby activities. Seven people had higher education, five had secondary. The respondents assessed their own economic situation as good. No one received welfare benefits, no one was hospitalized for being poor. When they felt the need, they used medical telephone consultations.

\section{Results}

\section{Pandemic: lockdown}

The interlocutors remembered the moment when the first case of COVID-19 was announced in Poland. The day of introducing the isolation regime was also remembered by them. They pointed to events in their daily life that were either interrupted or significantly modified. Thus, they became significant events. Some of them had an individual dimension, others were related to the necessity to abandon the current cultural and educational activity: "I was in Poland, my husband and I were going home that day, to Germany. They've announced an epidemic and the barrier has closed behind us" (S f 65); "I've been in the hospital, I've been getting information that people have a strange kind of flu that goes from China to other countries" (W m 60);

It happened when my daughter went on a business trip. And I was looking after my grandchildren. Her boss called and said there was a coronavirus and that it was a threat to older people. My son-in-law took me home right 
away. It was March 13. When he drove me, I was spending five weeks in complete isolation.

"It was March 12, the last Thursday of my freedom away from home, the anniversary of my mother's death (E f 69). It was after March 9th, after the Monday performance at U3A" (Li f 69); "They closed our U3A" (A m 76); - We had to cancel $U 3 A$, it was terrible! (Lu f 63); "I remember it perfectly. We were with our band at a concert near Rzeszow. People said something bad was happening, everyone started to be afraid [...] On Wednesday, they cancelled another concert and the end" (J f 70).

As the own research proves, information about the pandemic caused reactions from (i) "I expected it", through (ii) "I had more important problems", to (iii) "I was shocked": (i) "I predicted what might happen because in Wuhan and Italy... I've been waiting for it to be here. I was buying masks before they introduced the warrant" (A m 76); "In Europe they already knew in December, and when did they announce? In February! You can draw conclusions from this!" (S f 65); (ii) "I was getting it, but I didn't care. It might as well be information about Twardowski on the moon" (W m 60) ${ }^{1}$; Before that, I was locked in the house for six months because of a broken leg and that was a problem for me. The government reassured us that we were prepared, I believed that the pandemic would not catch us (K f 75); (iii) "I broke down. I was crying. I was praying a lot" (Lu f 63); "I've been thinking about what will happen in the future, how it will mutate, what will happen to children, to grandchildren" (D f 79); "Those media images were killing me, those mass burials in Italy" (E f 69).

It could be assumed that the older adults would react with fear when they found out they were in a high-risk group. Indeed, some felt existential anxiety. As the research conducted by CBOS [2] showed on a representative group of adult Poles in the second half of June 2020, i.e., at the same time as the reported interviews, $64 \%$ of respondents declared fear of contracting the corona virus, and $20 \%$ described the level of anxiety as high. The oldest people, over 65 years old $(77 \%)$, were most afraid of infections. In my own research, the following terms of emotional states were noted: anxiety, fear, fear, horror, panic. The narrators were afraid for their loved ones, for themselves and other people, for health, for life, for lack of ventilators. They were afraid of the plague and its consequences: "I was afraid that I would die, for my health, I was afraid of public transport" (E f 69); "I didn't realize it was so terrible, this epidemic. I was afraid not to get infected, age is what it is, you can get sick. I was afraid for my children and grandchildren" (T f 70);

I was afraid for my sister, who was 11 years older. How this situation began in Silesia, ${ }^{2}$ and my granddaughter's husband works in the mine, I was very scared for them. 
"Fear, panic, loneliness. I understood the danger, I felt anxious for my mother and how I would do outside the home. About not experiencing a respirator" (Li f 69); "It was shocking, I felt the fear of a terminal illness" (D f 79); "I was afraid for my son, for myself, I didn't sleep, I assessed the risk" (J f 70); "When I had, I did not go to the emergency room for fear of getting infected" (M f 67). But there were also people who - as they claimed - were not afraid of anything:

A healthy body is difficult to attack. If you eat healthy, you are well (S f 65); My main concern was whether after the surgery I would recover that I wouldn't get to the outpatient clinic if they closed the hospital. This concern was more important than COVID. I reminded my mother to wash her hands and wear a mask.

(W m 60)

I wasn't afraid for myself. If it happens - the disease will have to be overcome. After an initial examination of conscience, men are prepared to go into the dark. It can come for a man with this scythe. He'll come, hard, we'll go!" (A $\mathrm{m}$ 76).

An unexpected 'addition' to the narrators' accounts became their memories related to the closure of hairdressing salons. Some respondents said they looked 'terrible': "I couldn't look at myself in the mirror" (M f 67); "Men grew beards and hair, some looked great, others not necessarily-like gorillas" (Lu f 63). Others took matters, or rather scissors, into their own hands: "I was cutting my hair myself" (Lu f 63); "I shave every day, but I couldn't look at myself. I have a hair clipper and I got a haircut in front of the mirror. I even tried to go down to the underground barbershop but it failed [laugh]" (A m 76); "I'm getting a haircut myself, a hairdresser came to my wife, but only in May (W m 60); They opened hairdressing salons so to cheer up my mood I went and cut my hair. I felt better immediately" (E k 69). The opinion of the interviewees regarding the health service seems important. In many of their conversations, they raised the topic of respect, recognition for courage, for the hard work of the medical staff: "We started to respect our own health, we treated differently to the doctor, to the medicines" (A m 76); "Healthcare from the front line deserves medals, applause" (E f 69).

\section{Isolation}

The necessity to undergo physical isolation was understood by almost all interviewees. Their first reactions were in contrast, from rebellion and surprise to self-isolation: "I was surprised that the world could change so much that we humbly sit at home" (K f 75); "I accepted the warnings, but some of them I find stupid - no cycling, no entering the forest, no entering the cemetery. That was a stupid order" (D f 79); "It's stupidity. In Germany, there was no order to sit at home, we went for long walks, because it's healthy and not to 
go crazy (S f 65); I took the warrant as completely incomprehensible" (J f 70); "After the surgery, I had to be home anyway. And then I went for walks in the meadows, in the woods, wearing a mask, like an idiot" ( $\mathrm{W} \mathrm{m} 60$ ).

I spent the first month in complete isolation, at home, as much as for a nearby store, shopping once a week. I took the temperature twice a day, gray soap, I washed my hands often, internal disinfection [laugh], good slivovitz [laugh].

(A $\mathrm{m}$ 76)

"Gloves, masks, space. When I came back from shopping, I took all my clothes off and washed myself completely" (Li f 69); "I locked myself. I did not want to contact either my son or my sister" (E f 69); "Five weeks I was sitting in total isolation, I just going out on the balcony" (T f 70); "Three weeks at home. There was such a suspension, such a sad expectation in social silence" (J f 70); "I understand the idea of isolation, I was just going out of the house to go shopping" (Z m 72); "I've been disinfecting everything with spirit. When I stood in queue, I was afraid, I kept my distance" (M f 67).

Later, a rationalized approach to the problem of isolation prevailed, everyone retained consideration and extreme caution: "After two weeks there was no more panic, only depression. I was task-oriented, I have to go shopping, so I go" (Lu f 63); "I calmed down because I avoided contact, I was safe. I went to the countryside in April and I'll be here until autumn" (T f 70); "I went to work, but so as not to meet anyone, there were shifts at work, there was no contact with anyone" (M f 67); "Then came self-control, shopping for five days, cleaning products. I've become familiar with the threat. I was afraid of public transport, but when I had to - I went to my rehabilitation" (Li f 69); "I tried to be logical, calm and according to the recommendations" (D f 79); "I tried to follow sanitary regulations so as not to endanger myself and others" (A m 76);

You have to live... Deal with it somehow. We live with it, with care, with hygiene, without touching our face. I am irritated by people without a mask and without gloves. In the store, they explore and touch... If this grunge was to shine, you could react.

In my mask and gloves, I went out for walks, I went to rehabilitation. I avoid huddle of people and obsessive thoughts, which I have listened to especially during sleepless nights. When I left the house, the fear was over.

(E f 69)

"We obeyed the recommendations" ( $\mathrm{M} \mathrm{f}$ 67, Z $\mathrm{m}$ 72). The narrators observed the surroundings, implemented preventive strategies which, in their opinion, minimized the risk. 


\section{Social support}

Support is a process of exchanging information, emotions, care, material goods, services, care and help. It weakens the feeling of danger and uncertainty. The narrators appreciated the efforts of other people: "A neighbour asked my wife if we needed anything" (W $\mathrm{m}$ 60); "The younger neighbor offered help with shopping" (K f 75); "The young boy came twice, asked if I needed anything, brought mineral water, all multi-pack" (Li f 69); "Support came after two weeks and I felt that I was not alone. There were phone calls, good day wishes, questions about health, messages 30 a day, WhatsApp and Messenger, a lot of cordiality was circulating on the Internet" (Lu f 63).

All interviewees had family support resources, and there were no lonely people among the respondents. The caring function, expressed in providing parents with purchases, turned out to be equally important. The narrators indicated situations that directly concerned them: "Daughters called very often, almost every day" (A m 76); "My son would bring and leave our groceries in front of the door, we talked through the window" ( $\mathrm{Z} \mathrm{m}$ 72); "Shopping from my family, taking care of my health, God forbid that I would not go anywhere, I had everything brought home" (T f 70); "Support from children, shopping, they take care of me ( $\mathrm{J}$ f 70); The son tried, but without contact with me" (D f 79); "Sister and son tried. They brought shopping, there were telephones" (E f 69); "The son did not want to come because the grandchildren and the daughter-in-law were suffering from flu (maybe it was even COVID), they were afraid for me" (K f 75).

The bottom-up, social initiatives undertaken for aid purposes were remembered: "I know from the media that there were initiatives to help with shopping, taking older people's dogs for a walk" (W m 60); "The young people organized the 'Call the Senior' action" (T f 70); "People were organising themselves from the bottom up, I had calls from former students that they wanted to sew masks. It grabbed my heart that they came out with such an initiative" (J f 70);

My sister sewed hand-made masks from canvas. Neighbors were disinfecting the common space. I have heard about shopping, meals, about putting up advertisements with the given contact, about walking the dogs of people in quarantine, about calling lonely older adults, about volunteering in social welfare homes.

"Sewing masks in the library" (A m 76); "Masks were sewn at the day support center" ( $\mathrm{K} \mathrm{f} 75)$.

Working narrators also indicated protective measures, financial support from the government, the so-called Shield 2.0. They assessed the protective measures directed at private business as efficient and beneficial. Some interlocutors did not notice the community aid activities: "Nobody here" 
(Z $\mathrm{m}$ 72); "I haven't heard of any support" (Li f 69); "We heard what they said on television, I was beyond the reach of such actions" ( $\mathrm{M} \mathrm{f} \mathrm{67);}$

The society was not involved in helping. I know from TV that my neighbors sometimes helped each other, but in Germany there is no social support, families rely on themselves. You know, it's more about the economy than about human life!

Several interviewees indicated themselves as the giver of emotional and material support: "It was me who supported others, I used my black humor in conversations with my sister" (A m 76); "As for my friends, I am disappointed, I initiated contacts with those whom I taught French. But they did not express any concern" (E f 69); "I sewed masks with my neighbor, I gave them to the needy, we sewed from a linen cloth, free of charge, to help those pensioners who cannot afford" (D f 79);

I am so fit that I was helping and sewing masks. I was involved in the action of reading to children, it was organised by the library, each of us read an excerpt, and the children could watch it on the screen.

The narrators rationalised the pandemic tensions by focusing on activities for the benefit of others, on maintaining ties with the outside world.

\section{Changes in relationships: "the shell of fear"}

The narrators usually answered the question about the quality of personal relationships between household members - no changes. The spouses participating in the study provided an encouraging answer: "We are still alive. We never get enough of each other (laugh)" (M f 67 / I Z m 72). The narrator, fleeing from stress, stated:" Since I am alone, I feel fine, I am not afraid that my sister will bring me a plague" (E f 69). Two people in a relationship indicated that frustrating conditions worsened: "The husband takes care of his business (TV, Internet), and my daughter and I are next door" (Lu f 63); "Too much being together, sad, nervous, hard, he [partner] still has a grudge" (K f 75).

Reflections on family relationships were consistent - emotionally unchanged, but contacts moved to phone lines and communicators. Several narrators sadly remembered Easter, which is one of the most important holidays in Polish culture: "The first holidays in life, that neither to church, nor with loved ones, alone. Telephone wishes were, everyone at home. I haven't been going to church since March" (T f 70); "The holidays were sad, the saddest. The Paschal Triduum is very important to me. I was celebrating the palm tree in front of the screen. The priest blessed the food "travelling", we went out 
in front of the houses, he blessed and rode on (Lu f 64); Easter was sad, everyone was at home for the first time. Sad experience" (Li f 69); "My son came to the balcony, we talked, it was very sad. We spoke to our daughter and grandson via the messenger" ( $\mathrm{M} \mathrm{f} 67 \mathrm{i} \mathrm{Z} \mathrm{m}$ 72);

Usually, the older daughter would invite her family to her house. This year it was just me and my son-in-law's mother. We kept our distance, no hugging, no physical contact with our loved ones. I miss it so damn much.

(A $\mathrm{m}$ 76)

With regard to relations with neighbours, some interlocutors saw changes: "Everyone at home, nobody asks for anything" ( $\mathrm{M} \mathrm{f} 67$ and $\mathrm{Z} \mathrm{m} \mathrm{72);} \mathrm{"Emp-}$ tiness around the block. We walk masked, there is no relationship, we didn't sing on the balconies [laugh]" (A m 76); "Only 'good morning"” (T f 70); "Relationships have cooled down, everyone is sitting in their nest. It's normal to talk about nothing over a fence. I don't want to talk about lonely people's diseases to lonely people" (J f 70); "We're next door but not together, the social distance has turned into a reserve" (E f 69).

The social relations shown by the media turned out to be fascinating for the respondents. They were ambivalent in assessing reality: "Young people felt they could help and that's a good thing. And the older generation has dressed up in the shell of fear of contact with others" (J f 70); "The youth mobilised, there was neighbourly support, neighbourly help" (D f 79); "Good committed attitudes have emerged, and, on the other hand, wicked people who wanted to get rich on human harm" (K f 75); "A scandal connected with masks, even a crime, making money from human suffering is wicked" (E f 69); "The bad states are revealed, everyone is swept under him" (Z $\mathrm{m} \mathrm{72);} \mathrm{"People} \mathrm{have}$ become nervous, malicious and aggressive towards other people, fear of getting sick and dying triggers hostility" (Lu f 64);

There are no people in the streets. The funerals with the participation of only the closest ones were sad, and the dead and their families could not be respected. How little it takes for social life to collapse. We've been split up into countries, regions, atomized into families, into apartments! What a fragile organism is society!

(A $\mathrm{m}$ 76)

Sources of knowledge and learning content from pandemic experience

Social quarantine forced a change in the organization of time and daily tasks. People deprived of access to places where they spent their time had to find replacements. The quick response was to move cultural, entertainment and educational activities to the Internet. In this way, everyone who had access to the Internet could read the e-book, read press articles for free, watch selected theater performances, virtually visit the museum, and participate 
in a concert online. During the isolation, the offer of popularizing and educational activities was expanded. Interesting lectures, discussions, meetings were held live, on the laptop screen, many of them could be played back afterwards.

Most of the narrators were very active people, using the offer of U3A, cinema and theater. For them, lockdown turned out to be a difficult experience:

I froze my interests. I don't like indirect forms. To survive, I have to go out, be with people. I stood over the cliff. I stepped back, looking for a safe place for my own existence. We can walk safely for a while, but we cannot go forward, because there is an abyss.

For many, their primary sources of knowledge were television and the Internet, understandable under the pandemic closure: "I followed what the WHO recommended" ( $\mathrm{S}$ f 65). For laymen there is a danger here, because the Internet is full of various contents, and expert knowledge is not easy to find and understand (Jarynowski et al. 2020: 8). Some pointed to preventive information spots, others to interviews with specialists, thematic programs, also on foreign television: "I am amazed at the irresponsibility of some societies, such as people from the USA, and at the consequences!" (A $\mathrm{m}$ 76). They searched the web for content related to health, nutrition, hygiene, and physical conditions: "I am looking for nutritional advice on YouTube, in Facebook discussion groups. If I have immunity, no COVID will win against me. The disease can be kicked out of the body" ( $\mathrm{T} \mathrm{f} 70$ ). Some people avoided the mass media to minimize stress: "I couldn't focus on TV, if there is information, it shows the coffins, then why shout 'don't panic' later?" (J f 70); "I watched a movie about China on the Internet, it was very instructive, I experienced it very much. In Italy, the enormity of these coffins, families who could not say goodbye to their loved ones" (Li f 69).

Respondents read a lot and used home resources for entertainment: "I reduced my anxiety by reading books" (J f 70); "I read books, I don't fall asleep without reading. I choose literature according to the author, I finish one, I start getting to know the next" (Lu f 63); "I read, I reached for new literary genres. Crosswords, calling friends in Paris, is a conversation exercise" (E f 69); "I have a huge collection of books at home, I have plenty to choose from" (A m 76); "Internet, crosswords, books, I read a lot, I have my own series, I'm not bored" (D f 79); "I will read something, write something, solitaire games, search on Facebook" (K f 75). All of the participants in my study were Internet, social media users. The problem of digital illiteracy did not affect them.

\section{Resilience}

The interviewees used various strategies of coping with stress, taming the threat, and reducing anxiety. At first, they isolated themselves, left big cities for the countryside, stocked up disinfectants, practiced almost compulsively 
hygienically, minimizing the risk consciously did not meet with their families, and undertook new activities. Some of the behaviors were barely beyond the usual routine: "No changes, except that I did not go outside, I did not change my lifestyle, I only took more care of hygiene. Daily gymnastics, everyday!" (T f 70); "Morning gymnastics, I have a job at home, I go out to the garden" (J f 70); "The coronavirus did not harm me, it did not change the quality of life. Gymnastics, a glass of water on an empty stomach, a garden, shopping, neighborhood help. Sometimes I don't have time [laugh]" (D f 79). Others sought peace in contemplation, prayer, and nature:

I had my prayer, Nordic walking, meetings with deer and a rosary in the forest. The Gospel says: 'Shut up in your little room, pray in silence there'. When I was denied the opportunity to participate in the sacrament, I felt bad. I returned to the Church on May 10 and cried for the whole mass. I missed it so much.

Loneliness was sometimes perceived as a negative state: "I live so many months in emptiness, no one needs me, people don't talk to each other (E f 69); Functioning without social ties is impossible" (A m 76).

All interviewees knew the symptoms of COVID-19. Everyone also remembered and mostly used preventive treatments such as washing hands, maintaining spacing, disinfecting touch surfaces, applying masks, etc. Half of them negatively assessed the so-called "Hours for seniors" (from 10:00 to 12:00 am), considering this innovation 'stupid', 'sick', 'misfire', 'stigmatisations, 'negative stigma'. Some criticized the requirement to wear gloves: "They wore gloves all day and put them everywhere. It made more sense to wash your hands. I also do not trust disinfectants, they dry the epidermis, it is better to wash your hands than to apply the dirt" (W m 60). Interviewees with a homocentric lifestyle searched for knowledge, remaining in certain television 'information bubbles'. As a result, mechanisms of assimilating messages and adapting to sanitary recommendations appeared: "We obeyed" ( $\mathrm{M} \mathrm{f} 67$ and $\mathrm{Z} \mathrm{m}$ 72). Some were skeptical about the government's announcements: "I am negative about the government's information policy. I used my own experience with other types of infections, different types of flu" ( $\mathrm{W} \mathrm{m} 60)$; "Complete confusion! The health minister spoke mockingly about the masks, and then a 180-degree turn! Suddenly everyone has to!" (D f 9). Others have implemented an avoidance mechanism by displacing incomprehensible and unwanted information: "I will listen in the morning, get angry and then switch to nature films" (A m 76); "I explain to myself that it is difficult, I feel sorry, but I do not experience it too deeply. These events are too far away" (D f 79). Not everyone was wary of fake news, crafted news, operating on the principle of a grapevine: "There is a theory that people vaccinated against tuberculosis endure famine better or do not get sick. And those who were starving are more resistant. And I had a bad, starving childhood" (A m 76); "This COVID 
is a bull. I will refresh in the countryside, the sun, vitamin D3 give me immunity. I will not vaccinate, because it does not help. I eat celery - it's priceless. One day you have to die" (T f 70).

Culturally and socially active people indicated their relationship with U3A: "The U3A Management began to publish lectures and proposals for physical activities on the website. It was very good!" (A m 76);

We call the lonely people, there are duty hours, first we call them, now they call us. There are people who linger over in their homes, lose their condition, fall over, break their hands. We introduced gymnastics via the Internet, lectures, but it's not the same. I miss U3A, education, entertainment, people.

It was not known how long the isolation would take. So, there was a need to find new solutions, new resilience strategies (coping). Some people deprived of access to places where they spent their time found substitutes: "I don't miss U3A, there are more important things" (Li f 69); "We're fine with each other, we drink coffee in the afternoons" ( $\mathrm{M} \mathrm{f} 67$ and $\mathrm{Z} \mathrm{m} \mathrm{72).} \mathrm{Others} \mathrm{or-}$ ganized their time, providing cultural entertainment other than in the prepandemic times: "On Netflix, my daughter and I used to watch TV series after dinner, legs up high, a laptop between us, home cinema, every night!' (Lu f 63).

In the media space, humorous memes, witty texts, tragicomic jokes and anecdotes appeared. There were also those who undertook new types of activities. When in the Internet appeared the so-called wave of "challenges" \#hot16challenge2, ${ }^{4}$ one of the people I got in touch with. This person, who performed in the vocal group of The Senior Singers, did not agree to the interview, but gave me his own recording. With her consent, I provide the content of the song translated into English by the granddaughter of Ms Maria Kramarczyk:

For three months been sitting in my house

Separated from my culture

The people that surrounded us

Are being distanced from us, too

I'm waiting for it to end

But the view is not comforting

Now it's rapid unfreezing

Because elections are on the horizon

What I dearly love doing

I can't now because of COVID

Medicine is powerless against the disease bending us over

All the respect to health service

For caring for us in these hard times

We won't surrender to no one 
Though they're trying to make fools of us

We'll free ourselves from this violence because we're still full of Power

Maria Kramarczyk, \#hot16challenge2. (2020)

\section{Desires, values}

In conversations about the new quality of life, the theme of everyday needs and desires was discussed. All the narrators pointed to the need for safety, security of living conditions, risk avoidance: "I'm getting to risk avoidance" (J f 70); "COVID has not changed anything for me and let it stay that way" (D f 79); "I have objections about the functioning of the non-COVID health service, you can't find a doctor in the clinic, scandal" (E f 69). Many indicated the need for a bond, belonging to a community: "People want to meet, they miss social contact, if only to be able to talk" (Li f 69); "People need closeness, conversation, cooperation, exchange of experience, appreciation" ( $\mathrm{J} f \mathrm{f0})$. The importance of the family was most strongly emphasized: "Family above all, their safety above all (S f 65); The family is the most valuable and the surest value" (J f 70).

Several people have indicated their contribution to building social order: "I have a hobby - my work" (S f 65); "I feel good at work, I love it" (M f 67); "When there is no goal, when there is nowhere to go out, you don't want to live" (K f 75); "I prepared materials for U3A students" (J f 70); "We updated the website of our $U 3 A$ " (Lu f 63). Some postponed the realization of plans and dreams for "someday": "I was thinking of going to Italy for my 70th birthday - but will I live?" (E f 69); "We had a trip to St. Petersburg and Moscow recorded in $U 3 A$, the advances were paid and it didn't work out. But if Allah and health permit, I will go!" [laugh] (A m 76). The messages they would like to address to others are simple: "I'm too small to teach the world. We're running too fast, there came a moment to slow down, to remember, to stop, noticing the things of the closest" (J f 70); "Nobody will take the knowledge from you" (S f 65); "What shall I tell the world? To wash his hands?" (W $\mathrm{m}$ 60); "Remember, tomorrow is also a day!" (A m 67); "People, be kind and sincere to each other" (Lu f 63); "I would say - be a good person, don't hurt anyone" (M f 67); "Respect and forbearance are important" (Z m 72); "My values are constant, the coronavirus has not changed them, you should think about people, about the environment and not about money" ( $\mathrm{K} \mathrm{f} 75$ ). Several people spoke about the need to share with others: "You have to help each other" (Lu f 63); "Live in such a way that something remains of you, which is why I wrote my autobiography [laugh]" (A m 76).

\section{Postscript}

I returned to my narrators a year after the study, in April 2021. All of the interviewees had survived the pandemic. All had been vaccinated. But some only became ill after contracting the disease they so feared and, paradoxically, 
came out of the confrontation strengthened (E f 69). One person gave up gainful employment ( $\mathrm{M} \mathrm{f}$ 67), but one returned to professional, teaching duties in a full-time remote job ( $\mathrm{Lu}$ f 63). Some people (e.g. Li f 69), forced by circumstances, assumed the role of the only informal carer of their old family members. All appeared to be people well-adjusted to the COVID-19 reality. It was as if they had read the residency manual (Cochrane \& White 2020): they were flexible in the face of a dynamically changing situation, they met their own individual needs, they maintained social contacts, admittedly with a sanitary regime, which they fully accepted. They remained faithful to their own values, retained a sense of independence. Fortunately, they did not have to ask for outside help. The one thing they didn't want was rest. They wanted to return to their favourite activities, they craved interpersonal direct meetings and contacts. They have come a long way: from a phase of shock, surprise and horror, through adaptation to the new reality (distance, hygiene, isolation), then rebirth (rationalization of actions, undertaking new activities) and relaxation (usually after receiving vaccinations - opening up to social contacts and socializing, giving oneself pleasure, relaxation) and finally normalization, manifesting itself in a controlled return to the previous lifestyle. However, everyone is still very cautious and anxious about the potential return of lockdown.

\section{For further discussion...}

Social quarantine forced a change in the organization of time and daily tasks. The pandemic, social isolation and quarantine kept us at home and triggered great emotions. Grocery stores have introduced the so-called 'Senior hours'. Senior clubs, U3A canceled classes and all events. Trips and events were suspended. Some workplaces, all schools and universities, parks and forests were closed. Health centers, aid institutions, doctors, pharmacies, banks have become like bastions to be conquered. Social life froze! Lockdown was a critical event, a kind of transition, an experience difficult for the respondents. It could be expected that the older adults would not find the strength to cope with the change. That did not happen. After the initial phase of lowered mood and anxiety attitudes, they found themselves in a modified pandemic of everyday life. Fear-filled expressions characterising their emotions from the beginning of the pandemic turned into statements reflecting the essence of individual coping strategies. I conclude that it happened because they did not have to significantly change the rhythm of everyday life, they did not have to work remotely, use public transport, or fight for economic survival. They submitted to the sanitary regime, had a sense of community in the sense of threat and a community of stress relief experiences (collective behaviour in store queues, in public transport, in public spaces).

What is encouraging - the families of the narrators proved themselves in the era of coronavirus, none of the interlocutors indicated a negative change in family relations, except for the lack of physical closeness. The deprivation 
of their needs has intensified, especially in terms of bonds and belonging, contact with others, and security - avoiding risk. It has become important to be useful, needed, involved in grassroots and spontaneous pro-social activities. The material of their unobvious learning was content made available by television and searched on the Internet. All the interlocutors were Internet and social networking users. It was a matter of time when their socio-cultural activity would move to electronic media. They were looking for knowledge and entertainment, social contacts, communicating with families and friends. Thus, electronic technology has become a factor that mitigates their physical isolation, social distance. But the pandemic "house arrest' annoyed the majority, it caused intrusive and gloomy thoughts and sleepless nights. The interlocutors wanted to go back to the activity before the epidemic restrictions. It can be concluded that the experience of pandemic closure did not significantly affect the attitudes and needs of those involved in the study. Resilience strategies proved to be similar, due to sanitary recommendations. However, they had an individualistic trait, especially when it comes to the emotional sphere. The narrators value system has not changed. Conviction of the interviewee: For our generation time has stopped, we will not develop, there is no point in waiting! (E f 69). There are no patterns or typologies in this research chapter. There are examples of individual approaches to the problem of social isolation, extending competences necessary in pandemic daily life.

\section{Notes}

1 Mr. Twardowski, Master Twardowski, called the Polish Faust - a figure of a Polish nobleman, who, according to the legend, sold his soul to the devil. Legend has it that while escaping from the devil he reached the Moon on a rooster.

2 An industrial, mining region of Poland with the highest COVID-19 infection rate.

3 Gospel according to St. Matthew: Mt 6,6: But when you pray, go into your room, close the door and pray to your Father, who is unseen. Then your Father, who sees what is done in secret, will reward you.

4 Hot16challenge 2 is the challenge of recording 16 rap lines and nominating more people to create their song in 72 hours. Both nominees and fans were able to donate money to help healthcare professionals fight the corona virus.

\section{References}

Age and Ageing journal: Free collection of COVID-19 papers | British Geriatrics Society (bgs.org.uk); Date Published: 01 May 2020.

Błachnio A., Potencjał osób w starości. Poczucie jakości życia w procesie starzenia się [Potential of people in old age. Sense of quality of life in the aging proces]. Wydawnictwo Uniwersytetu Kazimierza Wielkiego, Bydgoszcz 2019.

CBOS, News, Poczucie zagrożenia epidemicznego w drugiej połowie czerwca [The feeling of an epidemic threat in the second half of June], No. 22, 2020. 
Cochrane C., White H., COVID-19: Stress, coping and resilience, 2020, available at: COVID-19: Stress, coping and resilience | British Geriatrics Society (bgs.org.uk)

Drozdowski R., Frąckowiak M., Krajewski M., Kubacka M., Luczys P., Modrzyk A., Rogowski Ł., Rura P., Stamm A., Życie codzienne w czasach pandemii. Raport z drugiego etapu badań [Everyday life in times of a pandemic. Report on the second stage of research], UAM, Poznań 2020. https://www. academia.edu/43755026/\%C5\%BBYCIE_CODZIENNE_W_CZASACH_ PANDEMII_RAPORT_Z_DRUGIEGO_ETAPU_BADA $\%$ C5\%83_WERSJA_ PE\%C5\%81NA_?email_work_card=abstract-read-more

Dubas E., Uczenie się z własnej biografii jako egzemplifikacja biograficznego uczenia się [Learning from your own biography as an exemplification of biographical learning], Nauki o Wychowaniu. Studia Interdyscyplinarne [Educational Sciences. Interdisciplinary Studies], No. 1(4)/2017, p. 63-87. https://doi. org/10.18778/2450-4491.04.05

Fabiś A., Troski egzystencjalne w starości. Ujęcie geragogiczne [Existential worries in old age. Geragogical approach], Wydawnictwo Naukowe Uniwersytetu Pedagogicznego w Krakowie, Kraków 2018.

Galetta A., Mastering the semi-structured interview and beyond. From research design to analysis and publication, New York: New York University Press, 2013.

Horowski J., Education for loneliness as a consequence of moral decisionmaking: An issue of moral virtues, Studies in Philosophy and Education 2020. https:// doi.org/10.1007/s11217-020-09728-7

Jarynowski A., Wójta-Kempa M., Płatek D., Czopek K., Attempt to understand public-health relevant social dimensions of COVID-19 Outbreak in Poland, Society Register 4(3)/2020, p. 7-44. https://www.researchgate.net/publication/ 340504841_Attempt_to_Understand_Public_Health_Relevant_Social_ Dimensions_of_COVID-19_Outbreak_in_Poland

John Paul II, General audience: The meaning of man's original solitude, 1979 http:// www.vatican.va/content/john-paul-ii/en/audiences/1979/documents/hf_jpii_aud_19791010.html

Kramarczyk M. (2020). \#hot16challenge2 https://www.youtube.com/watch?v= sAdw0DIw4U\&feature $=$ share $\&$ fbclid $=$ IwAR 1 oGplpkjx Zm 2008 Svm r D8nQKN5oPcuDpBVFFV3dJRNcPZNXetqXkH13cc

Kvale S., Prowadzenie wywiadów [Doing Interviews]. Wydawnictwo Naukowe PWN, Warszawa 2010.

Livingstone D.W., Adults' informal learning: Definitions, findings, gaps and future research, WALL Working Paper No. 21, 2001. https://tspace.library.utoronto.ca/ bitstream/1807/2735/2/21adultsinformallearning.pdf

Livingstone D.W., Exploring the icebergs of adult learning. Findings of the First Canadian Survey of Informal Learning Practices, WALL Working Paper No.10/1999. https://tspace.library.utoronto.ca/retrieve/4451

Nguyen U.S.D.T., Quach L., Tran T.V., Social stress. In: Gu D., Dupre M. (eds) Encyclopedia of gerontology and population aging, Springer, Cham. 2020. https://doi. org/10.1007/978-3-319-69892-2_513-1

Richardson S.J., Carroll C.B., Close J., Gordon A.L., O’Brien J., Quinn T.J., Rochester L., Sayer A.A., Shenkin S.D., van der Velde N., Woo J., Witham M.D., Research with older people in a world with COVID-19: Identification of current and future priorities, challenges and opportunities, 2020, Age and Ageing 2020; 
49: 901-906. https://doi.org/10.1093/ageing/afaa149; Published electronically 25 June 2020.

Szarota Z., Senior policy in Poland: Compensation of needs and active ageing, $E X$ LIBRIS Biblioteka Gerontologii Społecznej I Polish Social Gerontology Journal, No. 2(10)/2015, p. 99-112. https://www.researchgate.net/publication/337545594_ Senior_Policy_in_Poland_Compensation_of_Needs_and_Active_Ageing

Szarota Z., Uczenie się starości [Learning to age], Edukacja Dorostych [Adult Education] $\mathrm{Nr} 1$ (72)/2015, s. 23-36.

Ustawa z 11 września 2015 r. o osobach starszych [Act of 11 September 2015 on older persons], Dz. U. 2015 poz. 1705.

Virag M., Nemeth D., The negative relationships between executive functions and implicit learning, In: Starość, jak ja widzi psychologia [Old age: The view from psychology], WAM, Kraków 2016, p. 281-290.

Wałejko M., Samotność a osamotnienie - Osobowe stany egzystencjalne człowieka. Analiza etyczno-metafizyczna [Loneliness and solitude - The personal existential states. An ethical and metaphysical analysis], Roczniki Nauk Społecznych [Annals of Social Sciences] 2/2007, p. 45-66.

Yu J., Lee T.M.C., Social isolation. In: Gu D., Dupre M. (eds) Encyclopedia of gerontology and population aging. Springer, Cham. 2019. https://doi.org/ 10.1007/978-3-319-69892-2_422-1 


\title{
10 Online learning for older persons during the COVID-19 pandemic in Malta
}

\author{
The good, the bad, and the ugly
}

\author{
Marvin Formosa
}

The chapter reports on a qualitative research study at the University of the Third Age (U3A) in Malta which, during the COVID-19 pandemic, ceased all its classroom-based education, and adopted an online learning strategy. The aim of the research investigation consisted in exploring the positive and negative impacts of the change in this mode of teaching and learning on U3A members. On one hand, older learners relished a virtual learning environment for its flexibility potential as it allowed them to juggle jobs, family care-giving, and learning schedules without conflicting timings, re-read a lecture or take more time to reflect on some "difficult" material, and mitigating against discriminating factors such as age, physical appearance, disability, and gender. On the other hand, since this shift was not carried out under the supervision of e-learning specialists, the novel learning environment included no dynamic interaction, neither between tutors and learners, nor among learners themselves, so that the latter had no opportunity to articulate responses with as much depth and forethought as in traditional face-to-face educational situations. At the same time, the shift towards online learning faced the pressing issue of digital exclusion. This chapter concludes that the implementation of online learning in later life needs to uphold four principles of good practice: making provisions for older persons who do not have access to online services, ensuring that technology is accessible to all older persons, providing hardware and software equipment and internet access to older learners, and investing in skilling older persons in digital competencies.

\section{Introduction}

Since the identification of the first COVID-19 case in Wuhan, China, in December 2019, one witnessed a steady output of academic articles on the pandemic's wide-reaching impacts. An area that received much global attention constituted that interface between COVID-19 and later life. This was far 
from surprising since COVID-19 proved to be a very serious viral infection for persons aged 80 and over. Literature underlined the pandemic's deadly effect among frail older persons, and how nursing homes for older persons became hot incubators for the coronavirus, as more than half of all COVID-19 deaths in many countries occurred amid residents in longterm care facilities (Ayalon et al. 2020). Other research demonstrated how the COVID-19 pandemic accentuated the exclusion of and prejudice against older adults, as the health crisis led to a disturbing public discourse about ageing that questioned the value of older adults' lives and their valuable contributions to society (Previtali et al. 2020). Moreover, as most governments prohibited older persons from leaving their residences unnecessarily and barred extended family gatherings, much attention was focused on social isolation and loneliness experienced by older adults, and the resulting impact on their emotional wellbeing (Berg-Weger \& Morley 2020).

The study reported herein seeks to continue contributing to the knowledge relating to the impact of the COVID-19 health emergency situation on the quality of life and wellbeing of older persons by focusing on older adult learning - which refers to the process in which older adults, "individually and in association with others, engage in direct encounter and then purposefully reflect upon, validate, transform, give personal meaning to and seek to integrate their ways of knowing" (Mercken 2010: 9). Literature on lifelong learning lists a range of motivational factors inducing participation, but in later life most enrolment stems from the meeting of coping and expressive needs, as many older persons seek to adjust to decreasing physical and social capital, retirement, widowhood, pursuing knowledge for its own sake, and personal developments (Formosa 2019a). This chapter reports on the experiences of the University of the Third Age (U3A) in Malta which, on 12 March 2020, was legally mandated to cease all its classroom-based education, and which instantly took the decision to adopt an online learning strategy. ${ }^{1}$ It includes four sections. While the next section familiarises the reader with older adult learning and U3As in particular, the third part presents key analytic inferences regarding the beneficial, negative, and discriminatory consequences arising from this change in mode of teaching and learning. The final part puts forward a number of conclusions and also highlights recommendations for the good practice of older adult learning during emergency situations that necessitate lockdown and social distancing policies.

\section{The University of the Third Age and e-learning in later life}

Universities of the Third Age (U3As) can be loosely defined as learning centres where older persons may acquire new knowledge of significant issues, or validate the knowledge which they already possess, in an agreeable milieu and in accordance with easy and acceptable methods, with the objective of preserving their vitality and participating in the life of the community 
(Midwinter 1984). As its title postulates, the U3A's target audience are people in the third age phase of their life course. Whilst some centres put age 60 and over as a prerequisite for membership, others allow persons above the age of 50. The U3A movement has not only withstood the test of time but is also marked by an extensive increase of centres and members all over the globe (Formosa 2019b).

U3As are no exception to the e-learning revolution. Although the primary scope of initial experimentation with online courses was solely to reach out to older persons who could not join their peers in the classroom-setting, such as those living in remote areas and the homebound, this stance soon changed (Formosa 2014). As internet connection became a more common feature of daily living in later life (in New Zealand, Canada, Sweden, and the United States almost half the population aged 65-plus go online), and once the coming of the Web 2.0 internet revolution - with its Blogs, Wikis, Moodle, and Podcasts - brought the possibility for interactive learning to previously unimaginable levels, it became evident that virtual learning can provide a reliable and valid learning experience (Moreira 2016). The first international online U3A, named U3A Online, was set up in 1998 and from the outset it had a global focus by comprising learners from Australia, New Zealand and the United Kingdom who recognised the potential of the internet for harnessing the expertise of a worldwide cadre of volunteers who would provide low cost, intellectually stimulating courses and resources for a world community of learners and other volunteers (Formosa 2014). Swindell $(2000,2002)$ conducted a number of studies on possibilities and limitations of U3A Online. He found that older people, even those who live in large cities, tend to experience a sense of isolation that is often not recognised by the majority of the community. Hence, programmes such as U3A Online have the potential to make an important contribution to the wellbeing of those older persons who experience an increasing sense of isolation with age despite their living in seemingly well serviced and well-resourced communities. This overall feeling was summed up by different learners:

Many thanks to you for my being able to enjoy what has turned out to be the most pleasurable weeks of my life.... Thank you for the opportunity to work through this programme ... I have really enjoyed the course and I am sorry it is over. It has inspired me to push on, further afield.

online learners, cited in Swindell \& Vasella (1999: vii)

Moreover, U3A Online was credited for being a smart application of internet technology for helping to bridge the grey digital divide (Swindell et al. 2011). Yet, Swindell's $(2000,2002)$ research also underlined the mistake of not initially screening participants to determine their levels of digital competencies. Since participants were required to register and e-mail some background detail, it was assumed that they would have the necessary computer skills. This supposition was, nevertheless, incorrect for about half of 
the registrants - and especially for less educated individuals and older persons with working-class backgrounds who tend to possess lower levels of cultural capital - as during the first few weeks of the course the tutors spent many hours providing telephone and email advice to individuals about matters like saving stories as text files and attaching files to e-mails. Even when instructions were provided some confusion remained. Indeed, four and five weeks down the line a telephone survey found that many were still frustrated about their inability to handle computer-related tasks. This indicated that even older persons who are digitally literate may face serious obstacles in accessing a virtual learning programme.

Recent studies have confirmed Swindell's results as well as highlighting further barriers to virtual learning by older adults (Formosa 2019c). For instance, since decline in reading comprehension among older adults are related to vision problems rather than cognitive decline, e-learning designers must be aware of these sensory changes when designing courses. Guidelines that ensure that websites are age-friendly include using only sans serif fonts (e.g., "Arial" font), using 12- or 14-point font size, using double spaced text, using left justification, avoiding patterned backgrounds, inserting text alternatives for all graphics, and using a consistent layout throughout the website. Moreover, inappropriate sequencing of courses and course features can cause frustration since older adults engaged in face-to-face software training generally prefer an informal structure instead of a formalised, linear class structure. Other research has highlighted how games are being used in e-learning programmes (Formosa 2019d). However, since users of games are often forced to proceed rapidly, with less time for thought and contemplation, it follows that these types of designs could cause usability obstacles for some older adults given the decline in working memory in later life. Finally, mobile devices and mobile learning present another set of challenges for older adults since the small displays and tiny keyboards present major usability obstacles for those older persons with dexterity problems in their hands and fingers.

\section{The impact of COVID-19 on late-life learning in Malta}

Five days after Malta registered its first case of COVID-19 on 7 March 2020, the government announced an aggressive, "Asian-style," lockdown (Baldacchino 2020). All public servants, teachers and university lecturers, and most employees in the private sector began working "from home." All nonessential public gatherings, including church functions and sport events, were cancelled, and passenger flights in and out of the country were suspended so that Malta became totally isolated from the outside world. The only facilities exempted from such a strict lockdown included supermarkets and pharmacies. The country, one of the world's most densely populated, became strangely quiet. Traffic eased, air pollution went gone down by $50 \%$, and public spaces became deserted. ${ }^{2}$ It was in such circumstances that the 
University of Malta decreed its U3A to close its doors as from 15 March 2020. This did not come as a surprise since in the previous four weeks Malta was characterised by much wide uncertainty and anxiety towards the impending COVID-19 outbreak on the island. Indeed, during the previous week the number of participants had dwindled substantially, and there were constant phone calls asking whether it was safe to turn up for classes.

Following a number of virtual meetings, a decision was taken to shift all teaching and learning through the University's radio and online platforms, as from 20 April 2020. Tutors were asked to choose whether they wished to transmit their lecture via a radio broadcast or as a recorded lecture to be conveyed via an online link. While about one third of facilitators declined to participate in this new format, a decision which was fully respected, the remaining two thirds opted for radio broadcasting and online delivery in relatively equal numbers. Initially, the University asked tutors to conduct the lectures "live" during the exact scheduling of the actual sessions, but this was found not to be possible due to the closure of primary schools, as this meant that many were suddenly borne with constant parent and grandparent care during mornings. Indeed, it is worth mentioning that even those tutors who opted to transmit their lecture via a radio broadcast had to record their session at home and send to the radio station via email attachment due to the enforced lockdown. All lectures, even the ones broadcasted via the radio, remained available on the U3A's website until the end of July 2020.

\section{The good}

Older learners at the Maltese U3A had always resisted any attempt by the University to instil a virtual learning environment. In fact, when members were asked what they gain most from their involvement in U3A activities, the first thing that they usually reported was not related to the learning activities per se but the associated social outcomes such as socialising, making new friends, having the opportunity to achieve personal growth, and finding a support group which helps them through difficult periods in their personal life. However, it was positive to note that this time around the U3A members understood fully the necessity and logic for going virtual, and even applauded the U3A for providing them with alternative learning mediums rather than simply closing the classrooms. In their own words,

I was never in favour of online learning and never will be. Yet, given the circumstances, this was the right decision. I thank the U3A for having gone into such trouble. I am sure that it was not easy, but it was the right thing to do, and we are benefitting from it.

male U3A member, 67 years old

Learning via the computer or the radio is not ideal, but it is better than nothing, and the U3A is trying its utmost, we appreciate that, the most 
important thing is that we are not left idling away, staring aimlessly into space, especially when we are locked down.

female U3A member, 69 years old

They also commented that this new form of teaching and learning regaled them with much needed flexibility. They highlighted how accessing the lectures via either the radio or internet allowed them to participate in high-quality learning opportunities at their convenience which allowed them to juggle jobs, family caregiving, physical activity, and learning schedules without conflicting timings. As some learners claimed,

This is very convenient. As it stands now, with all the lectures available on the internet, I do not have to plan my life around the opening times of the U3A. Rather, I can now decide which two hours best suit my learning interests.

female U3A member, 71 years old

I admit that there are many advantages of having all the lectures available at a click of the mouse. I wake up very early in the morning and I can now use this time productively. I choose at what time I learn. This is very good. I lead a very busy life.

male U3A member, 65 years old

Many celebrated the fact that now they had the opportunity to reread a lecture or take more time to reflect on some "difficult" material before moving on to the next lecture. Interestingly, some learners enjoyed the anonymity that online learning provides. They claimed that discriminating factors such as age, physical appearance, disability, and gender became largely absent, and instead, the focus of attention was clearly on the content of the studyunit and the individual's ability to contribute thoughtfully to the material at hand. As some emphasised,

The best thing about all this is that you can listen to the lectures more than once. Sometimes, I do not always understand what the tutor is trying to explain, and need some time for the information to sink in, this is splendid for me.

female U3A member, 73 years old

Listening to the lectures is beneficial because you do not lose time going to the venue. I am also very self-conscious and feel anxious in large groups. I feel much more comfortable learning over the internet. My favourite teacher is youtube [laughing].

female U3A member, 68 years old

Finally, respondents stated that while at first it was a much tougher challenge accessing the lectures, rather than just turning up in the classroom and sitting 
passively listening to the tutor, in the long run such an experience enabled them to reach higher levels of digital competence and creativity. This occurred as they mastered the location of the right radio channel and understanding how internet links work, learning how to navigate online platforms, and sending emails to either the U3A's administration, tutors or classroom members:

They say that "necessity is the mother of invention," and it is true. I could not figure how to use the internet or send an email just a few weeks ago. Now, look at me! I manage to do all that is required from me. I feel good. I feel in touch with [the year] 2020.

male U3A member, 73 years old

It is thus clear that online learning has the potential to boost older persons' self-esteem and locus of control as they mitigate against the old adage that "old dogs cannot learn new tricks."

\section{The bad}

Despite the positive responses appraised in the previous section, it was clear that the shift towards embedding the U3A in an online learning programme was, at best, only a "work-in-progress." Indeed, older learners highlighted a number of barriers and obstacles that served to hinder an optimal learning experience. The one-way channels of radio and online transmissions resulted in no dynamic interaction between tutors and learners, and among the learners themselves. Within such an online synchronous discussion structure, the learners were not able to reflect and assert themselves on comments made by the tutor, or fellow learners, before the tutor moved on to the next item on the educational agenda. Hence, learners had no opportunity to articulate responses with much as much depth and forethought as in a traditional face-to-face educational situation:

This mode of learning provides you with no opportunity to add to the lecture or to ask a question. We have so many interesting discussions when we meet physically in class but now it is like watching a television programme.

female U3A member, 64 years old

We have always been told that our life experience enables us not only to participate in the learning taking place but also contribute. All tutors tell us how much they not only enjoy this experience but that they also learn a lot from us during the course of the discussion. This is all impossible now.

female U3A member, 68 years old

Moreover, respondents pointed out that at most times they found it difficult to be motivated in checking in, or even to want to switch on the computer or 
radio to listen to the tutor's presentation. Many found this form of learning artificial, "extremely robotic" to cite one interviewee, devoid of the human contact and social spirit that U3As are so renowned for. While the early sessions were listened to relatively rather attentively, without ever missing a meeting, in due course it became increasingly difficult to maintain such motivation and interest as the novelty wore off and tutor's presentations became more monotonous and predictable:

I must admit that after two or three weeks, I was no longer interested in switching on either the radio or computer. I could not bring myself to listen to the tutors simply describing some subject without any interaction from learners. We have the television for that. This is not how the U3A should be! male U3A member, 63 years old

The new online learning format also meant that there was less opportunity for learners to get in touch with tutors to either ask questions or deliver comments. Although learners admitted that this could be accomplished by sending an email, such a mode of communication was not face-less and unnatural, but sometimes tutors either took long to reply or never responded at all. This was very wearisome and frustrating for some learners:

Everybody had the same complaint. The availability of tutors! You cannot reach tutors easily over the radio and the internet, especially when the sessions are recorded. Some of us do not know how to email, and some tutors were not replying to our emails. I know that it was a difficult time for everybody, but if we cannot communicate with tutors, then the whole purpose of the U3A falls apart!

female U3A member, 73 years old

An analogous issue raised by interviewees revolved around the difficulty to interact with fellow learners. Since there was no physical classroom there was no opportunity to greet and catch up with friends in a face-to-face environment, and therefore, extremely problematic to maintain old and build new social relationships. As a result, many claimed that this online learning strategy made them feel isolated from their peers, and that they felt lonely in front of either their radios or computers:

Many U3A members did not even bother to switch on the radio or computer. Many do not attend to simply listen to the lectures. Many attend the U3A to catch up with friends and even make new ones. Many become members because of the social outings. I am not saying that they do not care about the classes but that the U3A is more than an educational organisation. It is a social experience. Remember, older people need social and intellectual stimulation.

female U3A member, 69 years old - emphasis in italics 
I am sure that the intentions were good but this is very, extremely, boring. More than boring, one feels isolated in front of computers. It is true that you are given an opportunity to exercise your mind, but the U3A was never invented to exercise minds in isolation, the human touch is necessary, and with online learning this is completely missing.

male U3A member, 69 years old

Finally, it also resulted that many U3A members experienced complications in following online sessions as they had difficulties staying connected at all times, either because their internet was unreliable or slow, or due to outmoded computers. Some also had sudden malfunctions in their computer, and due to the COVID-19 health emergency situation, it was not possible to get it fixed before the finish of the academic year. This meant that when online learning is deployed, older learners may suddenly find themselves cut off from the virtual classrooms due to technological hiccups which may take weeks to be resolved without a solution in sight.

\section{The ugly}

This final sub-section focuses on specific negative factors that were relatively discriminatory and biased towards either a particular sector or all U3A members. The first point considers the issue of "equity and accessibility." Prior to the commencement of the online learning programme, the U3A neglected to launch an exploratory survey to discern how many members had access to the internet. Consequently, the shift to online learning excluded those members who had no access, whether for economic or logistic reasons, to an online network. As interviewees emphasised, this was especially a concern with respect to older women and other learners living in rural and households experiencing risk-of-poverty lifestyles. The second concern refers to the issue of "digital illiteracy and incompetency." Again, no preliminary analyses were conducted by the U3A to ascertain the extent that learners possess the minimum required level of computer knowledge to master successfully an online learning environment. Since a certain degree of technological knowledge is required to follow a virtual learning programme, many learners who did not know how to operate computers or the Internet found themselves unable to continue the learning journey:

There were a lot of assumptions being made. Most importantly, and this is where the U3A got it wrong, that everybody had access to a computer. This is not correct, there are many older persons, especially widows, who do not possess a computer.

female U3A member, 71 years old

It is true that we are living in the year 2020, where the computer and the internet is something that we take for granted. But this is not the case in 
later life. Many of my friends, I am referring to women here, computers were bought by their husbands, and they do not have access to such machines.

female U3A member, 73 years old

It was a bit too much expecting us to master the computer almost overnight with no training whatsoever. Many could not follow the lectures because they did not know how to use the computer. This highlights the urgent need for further training programmes in information and communication technology for older persons.

male U3A member, 73 years old

At the same time, the U3A did not ascertain itself whether tutors who opted to transmit their learning via the online medium were knowledgeable in virtual instruction. Since the tutors were not properly trained in online delivery and methodologies, this certainly compromised the success of virtual learning programmes, since one must ensure that tutors are able to communicate well in writing and use language before launching an online learning strategy. Most importantly, an online tutor must be able to compensate for the lack of physical presence by creating a supportive environment where all learners feel comfortable participating. Yet, interviewers stated that this was far from the case, and that a good number of tutors acted no differently than if they were presenting their material in a face-to-face classroom environment:

We expected a different teaching format than what we were used in the classroom but it was exactly same, and in some respects, even worse as it was evident that some tutors were not knowledgeable as how to use the virtual environment to their advantage. They just lectured to the camera or their laptop rather than to us. They also need training in the possibilities and limitations of teaching in a virtual learning environment. male U3A member, 69 years old

Finally, interviewees noted that as the online learning strategy took its run, it became clear that some subjects are very difficult to be taught online because a virtual medium may not permit the best suited method of instruction. For example, there is no doubt that hands-on subjects such as public speaking and photography, where physical movement and practice contribute to the achievement of the learning objectives, are best taught in a face-to-face traditional learning environment. Just because it may be technologically possible to simulate a physical learning experience in a virtual environment, this does not necessarily mean that the learning objectives and outcomes will be equally achieved. Indeed, one cannot have the same curriculum serving for both physical and virtual learning environments, since what is successful in the former arena will not always translate to a 
successful online program where learning and instructional paradigms are quite different. Whilst a hybrid teaching and learning programme represents a potential solution to this problem, this was not possible in the midst of the COVID-19 health emergency situation.

\section{For further discussion...}

Three key conclusions may be derived from this study. First, despite the fact that older learners generally resist any attempt by educational providers to shift from a face-to-face classroom environment to a virtual learning setting, in times of crises (such as the COVID-19 pandemic) they do understand and accept the necessity and logic underlying such a change of strategy. Older learners may approach virtual learning with a level of mistrust at the beginning but in due course will experience a number of benefits. Older learners relish a virtual learning environment for its flexibility potential as it allowed them to juggle jobs, family caregiving, physical activity, and learning schedules without conflicting timings, opportunity to reread a lecture or take more time to reflect on some "difficult" material before moving on to the next lecture, as well as mitigating against discriminating factors such as age, physical appearance, disability, and gender. Virtual learning also has the potential to boost older persons' levels of self-esteem and locus-of-control as they found themselves improving their mastering of the internet, email communication and online learning platforms. As Swindell (2000, 2002) found out, this research supports the benefits of e-learning environments in later life by making important contributions to the social and emotional wellbeing of older persons as it attributes them with a new sense of purpose and excitement in their lives, and helping to bridge the age digital divide by motivating older persons to reach better levels of digital competency so as to be able follow the online learning classes with profit. Indeed, engaging with peers in online and virtual learning programmes tends to foster a sense of belonging to a group, improve self-esteem, and helps address isolation and solitude among older adults.

Secondly, the shift from a face-to-face classroom environment to a virtual learning setting is neither straightforward nor simple. Unless this shift is carried out under the supervision of e-learning specialists, the learning environment may result in no dynamic interaction between tutors and learners, and among learners themselves, so that the latter will have no opportunity to articulate responses with as much depth and forethought as in a traditional face-to-face educational situation. Moreover, it may result in low of levels of motivation for potential learners to participate, especially if the tutors' presentations are no different to those portrayed in face-to-face classrooms, and if there is less opportunity for learners to get in touch with tutors to either ask questions or deliver comments. In the wrong hands, an online learning environment may actually be counterproductive to the initial aims of the U3A Online as the difficulty for learners to maintain old and 
build new social relationships may make them feel isolated from their peers and lonely in front of either their radios or computers. Moreover, this study showed that despite the two decades of experience in online learning for older persons the same mistakes continue to subsist. For instance, while the Maltese U3A failed to pre-screen participants to determine how many members had access to the internet and the extent that they possess the minimum required level of computer knowledge to master successfully an online learning environment, no attention was made to the sensory changes when designing courses so that the electronic information being sent and shared uphold the principles of age-friendly digitalisation by using fonts and colours well-defined and sharp enough for older persons.

Finally, one cannot fail to mention that any efforts to implement educational programmes during the COVID-19 pandemic through the online media, included the trial reported herein, met a range of obstacles due to the pressing issue of digital exclusion. Since the very beginning of the lockdown, the gap between those with good and available internet connection, and between those owning electronic devices and others lacking such tools (which have suddenly become essential goods), was apparent. As COVID-19 spurred many more people to use the internet in new ways compared to before the outbreak, it has also further exposed and deepened the divide between the digital haves and have nots (Ipsos MORI 2020). Indeed, many U3A members experienced complications in following online sessions as they had difficulties staying connected at all times, either because their internet was unreliable or slow, or due to outmoded computers. Some also had sudden malfunctions in their computer, and due to the COVID-19 health emergency situation, it was not possible to get it fixed before the finish of the U3A academic year. This meant that when online learning is deployed, older learners can suddenly find themselves cut off from the virtual classrooms due to technological hiccups, that may take weeks to be resolved without a solution in sight. There is no doubt that the virtual world has great potential to reduce social and economic inequalities affecting older people. However, it can also exacerbate pre-existing ones and even create new ones, and to ensure that everyone, regardless of age or ability can communicate, the virtual world must be accessible; in other words, being designed to meet the needs and abilities of as many people as possible, but perhaps especially the ageing population (International Telecommunications Union 2021).

Such conclusions demonstrate clearly the ubiquitous digital poverty in later life. While the long-standing digital divide between younger and older persons, as well as within the older cohorts themselves, has been significantly exacerbated by the pandemic, it also follows that digital inclusion is not just about being online, it is also about using the Internet skilfully and with confidence. Not only older people do not possess such expertise and self-assurance, they are also characterised by a lack of awareness among older adults of the support available. This is an ongoing challenge in digital 
exclusion and one that exacerbates digital poverty in later life (Centre for Ageing Better (2021)). To mitigate against such lacunae, this chapter recommends the following four principles of good practice for online learning in later life: (a) making provisions for older persons who are not online by ensuring that in the event of future lockdowns one finds ways of directly contacting those individuals who are not able to leave their home; (b) ensuring that technology is accessible so that hardware and software can be used by as many people as possible, regardless of environment, device being used, age, social class, gender, digital competence and/or cultural background; (c) providing equipment and internet access by working to expand access to broadband, data packages, and to computer and ICT packages, in particular for individuals and families on low incomes who are most likely to be digitally excluded; and (d), investing in skilling older persons in digital competencies since simply providing access to equipment and the Internet will not be effective if people cannot use the technology or if they see technology as a barrier (Ipsos MORI 2020).

\section{Notes}

1 The Maltese archipelago is a European Union Member State. It consists of three islands - Comino, Gozo, and Malta. Comino is uninhabited, and with Gozo having a population of 33,388 residents, leaves Malta as the major island in this archipelago state, with 460,171 residents (2018 Figures) (National Statistics Office 2020).

2 Although the lockdown was gradually lifted in June, such a far-reaching policy bore much fruit in the short term. At the time of submitting this chapter (6 July 2021), Malta had registered 30,664 COVID-19 cases and 420 COVID-related deaths, with $67 \%$ of the population fully vaccinated.

\section{References}

Ayalon, L., Zisberg, A., Cohn-Schwartz, E., Cohen-Mansfield, J., Perel-Levin, S., Bar-Asher Siegal, E. (2020). Long-term care settings in the times of COVID-19: Challenges and future directions. International Psychogeriatrics, 32 (10), p. 11239-11243.

Baldacchino, G. (2020). Coronavirus and Malta: Weathering the storm. The Round Table, 109 (3), p. 322-323.

Berg-Weger, M., Morley, J.E. (2020), Loneliness and social isolation in older adults during the covid-19 pandemic: Implications for gerontological social work. The Journal of Nutrition, Health \& Aging, 24 (5), p. 546-558.

Centre for Ageing Better (2021). Covid-19 and the digital divide. Centre for Ageing Better, London, United Kingdom. https://www.ageing-better.org.uk/sites/default/ files/2021-07/COVID-19-and-the-digital-divide.pdf

Formosa, M. (2014). Four decades of Universities of the Third Age: Past, present, and future. Ageing \& Society, 34 (1), p. 42-66.

Formosa, M. (2019a). Third age learning for active ageing: The Maltese experience. In: Formosa, M. (ed), The University of the Third Age and active ageing: European and Asian-Pacific perspectives. Springer, Cham, Switzerland, p. 91-93. 
Formosa, M. (2019b). Active ageing through lifelong learning: The University of the Third Age. In: Formosa, M. (ed), The University of the Third Age and active ageing: European and Asian-Pacific perspectives. Springer, Cham, Switzerland, p. 3-18.

Formosa, M. (2019c). Educational gerontology. In: Gu, D., Dupre, M. (eds), Encyclopedia of gerontology and population ageing. Springer, Cham, Switzerland. https://doi.org/10.1007/978-3-319-69892-2_411-1

Formosa, M. (2019d). University of the Third Age. In: Gu, D., Dupre, M. (eds), Encyclopedia of gerontology and population ageing. Springer, Cham, Switzerland. https://doi.org/10.1007/978-3-319-69892-2_412-1

International Telecommunications Union. (2021). Ageing in a digital world - from vulnerable to valuable. International Telecommunications Union, Geneva, Switzerland. https://www.itu.int/myitu/-/media/Publications/2021-Publications/Ageingin-a-digital-world--from-vulnerable-to-valuable.pdf

Ipsos MORI. (2020). The Centre for Ageing Better. The experience of people approaching later life in lockdown: The impact of COVID-19 on 50-70-year olds in England. Centre for Ageing Better, London, United Kingdom. https://www. ageing-better.org.uk/publications/experience-people-approachinglater-lifelockdown-impact-covid-19-50-70-year-olds

Mercken, C. (2010). Education in an ageing society. Odyssee, Baarn, Netherlands.

Midwinter, E. (1984). Universities of the Third Age: English version. In: Midwinter, E. (ed), Mutual aid universities, Croom Helm Limited, Kent, United Kingdom, p. 3-19.

Moreira, T. (2016). Science, technology and the ageing society. Routledge, London, 2016.

National Statistics Office (2020). Regional statistics Malta. National Statistics sOffice, Malta, 2020.

Previtali, F., Allen, L.D., Varlamova, M. (2020). Not only virus spread: The diffusion of ageism during the outbreak of COVID-19. Journal of Aging \& Social Policy, 32 (4-5), p. 506-514.

Swindell, R.F. (2000). U3A without walls: Using the internet to reach out isolated people. Education and Ageing, 15 (2), p. 251-263

Swindell, R.F. (2002). U3A online: A virtual university of the third age for isolated older people. International Journal of Lifelong Education, 21 (5), p. 414-429.

Swindell, R.F., Vasella, K. (1999). Older learners online: An evaluation of Internet courses for isolated older persons. Griffith University, Brisbane, Australia.

Swindell, R.F., Grimbeek, P., Heffernan, J. (2011). U3A Online and successful aging: A smart way to help bridge the grey digital divide. In: Soar, J., Swindell, R.F., Tsang, P. (eds), Intelligent technologies for bridging the grey digital divide. Information Science Reference, New York, p. 122-140. 


\title{
11 Grandparents raising grandchildren during coronavirus pandemic
}

\author{
A challenge or a threat?
}

Joanna Borowik

"COVID-19" is a term that has become a symbol of change in people's lives around the world. Many analyses of the results of research conducted during the pandemic are concerned with the life situation of the older adults. Among them, grandparents raising their grandchildren have found themselves in a particular situation. The purpose of this chapter is to present the factors determining the characteristics of the life situation of grandparents raising grandchildren during the coronavirus epidemic. In the context of the conducted research, it was also important to collect information on their perception of the situation as a challenge or a threat. The theoretical basis for the study was the concept of social anchoring, which can explain the processes that stabilize people's situation in the face of change, which was, in this particular case, forced upon them by the pandemic.

\section{Introduction}

Coronavirus is an epidemic that has caused a world of constant change, time pressure, and deepening social diversity to slow down and stop overnight. People began to view the world from the perspective of danger and the accompanying sense of loneliness and disorientation. Grandparents raising their grandchildren found themselves in a particularly difficult situation. In a period of ongoing social isolation, they struggled with the consequences of being cut off from the surrounding world, but also with fears resulting, among others, from the fact that they, as older people, are most at risk from the coronavirus. Various problems arose with the daily changes in their lives: tasks to be carried out and questions about the future and fate of their grandchildren in a situation where their grandparents' health and life were at risk. Under these circumstances the basic human needs of the grandchildren's guardians, such as a sense of stability and security, have been significantly impaired. In the face of an unexpected threat that caused another change in their daily lives (the previous one took place when they 
took over the care of their grandchildren), problems related to the grandparents' sense of identity intensified. It is clear that in such a situation, the very distinction between roles (being both a grandparent and a parent) can result in complex experiences. All the more so because, as Hooyman and Kiyak claim, the role played by adults is "related to a specific age or stage of life" (Hooyman \& Kiyak 2002: 256). Therefore, it would be worth considering what happens when grandparents engage in educating the young generation and once again take on the roles that are a repetition of earlier stages of their lives. Role identity theory, on the other hand, suggests that having several identities that are related to each other through shared meaning and simultaneous performance may cause some dissonance (Burke 2006). In the case of grandparents raising their grandchildren, the dissonance will be created by the question: "who am I actually? A grandparent or a parent again?" How, then, do they perceive their life situation and what difficulties do older people encounter in the context of "being" a parent again?

One of the key factors contributing to the difficulties grandparents face in raising their grandchildren may be the expectations set for them, because, as Hooyman and Kiyak argue, "age changes not only the roles expected of people, but also the ways in which they are expected to play them" (Hooyman \& Kiyak 2002: 257). Therefore, a younger parent has greater social consent for a certain degree of freedom in matters of upbringing, resulting from the social perception of young people as less competent and inexperienced. On the other hand, it is expected of grandparents that, based on their previous experience, they will easily cope with the "new, yet old" role of a parent. Social expectations become especially important when we try to understand the intricacies of having to adapt to new conditions in the context of the challenges and threats that arise from major events we are dealing with at any given time, such as the coronavirus pandemic. From the moment they take over the care of their grandchildren, grandparents are constantly caught up in various problems and tasks to be accomplished. The moment when they became guardians of their grandchildren has changed the course of their lives, causing a profound shift (Backhouse \& Graham 2012; Hayslip et al. 1998; Kornhaber 1996; Whitley et al. 2015), which only intensifies in a situation of forced isolation. The purpose of this chapter is to present the factors that determine the nature of the living situation of grandparents raising grandchildren during the pandemic. In the context of our research, it was also important to find out whether the situation is perceived as a challenge or threat. The theoretical basis of the study was the concept of social anchoring, which can explain the processes that stabilize the position of people in the face of a change that, in this situation, was brought about by the coronavirus pandemic.

\section{The concept of social anchoring}

The concept of social anchoring was used as the theoretical basis for the presented research. In literature, it is most often brought up when discussing issues of migration in relation to the adaptation and integration of migrants. 
However, in the presented study, the concept of social anchoring refers to the process of grandparents adapting to the changes caused by the appearance of the coronavirus. The factors that emerged in connection with the pandemic and which grandparents raising their grandchildren had to contend with are multi-layered (Xu et al. 2020). The described concept, as noted by Grzymała-Kazłowska (2013, 2016), can be helpful in discussing changes related to the issues of identity, social bonds, and looking for points of support in order to achieve stability in life and rebuild a sense of security.

Social anchoring is defined as an individual's search for "points of reference and support that are important to them - anchors that allow them to achieve relative psychosocial stability in a new situation (...) and form a basis for psychological and social functioning" (Grzymała-Kazłowska 2013: 53). Importantly, according to the author, the search for anchoring is particularly visible in situations of profound change, as well as in the face of crises and limit experiences. Such events include taking over the care of grandchildren by grandparents, which is becoming more and more common all over the world (U.S. Census Bureau 2010), as well as problems that arise from providing care during the coronavirus pandemic.

Among the various types of anchors, we can list those that are subjective and internal, which include, among others, the personality traits of an individual, individually professed ideas and values, as well as objective and external ones, which include legal and institutional (e.g. legal status, using the help of formal institutions), economic (e.g. material resources), and spatial-environmental (e.g. place of residence) anchors. There are also mixed type anchors related to socio-professional roles (e.g. family roles), one's position in the social structure and group affiliation, as well as anchors embedded in culture (e.g. cultural messages, norms, and values) (Grzymała-Kazłowska 2013).

As Grzymała-Kazłowska (2017) points out, anchors are flexible and therefore susceptible to change, which means anchoring is a dynamic process. Therefore, with the passage of time or the appearance of new changes in one's life, some of them may weaken or even be destroyed, while new ones appear in their place. Therefore, the concept of social anchoring seems promising when trying to analyse the factors determining the situation of grandparents raising grandchildren during the coronavirus pandemic. Since the outbreak of the pandemic and the emergence of stay-at-home orders, the situation of children and grandparents caring for them has changed dramatically. The constant need to stay at home together has created new challenges for grandparents who are the primary caretakers of their grandchildren. Moreover, in this situation, it is necessary to identify grandparents' support points, showing the spheres in which they can "cast" their anchors.

\section{Research results}

This chapter focuses on the factors determining the nature of the situation of grandparents raising grandchildren during the coronavirus 
pandemic. In order to obtain information for the research, the qualitative method of case study analysis was used, involving partially structured individual in-depth interviews. This method makes it possible to obtain in-depth knowledge about the situation of grandparents raising grandchildren during the coronavirus pandemic and to characterize the factors determining its nature. The work is based on 20 partially structured in-depth interviews with grandparents (aged 60 and over) living in the region of Podlasie, in the north-eastern part of Poland, who have been formal guardians of their grandchildren for at least three years. The time spent caring for grandchildren was an important criterion for selecting the research sample, because it determined whether subjects would have obtained the experience which makes an analysis of their personal situation in the context of changes caused by the coronavirus pandemic possible.

The study involved 20 grandparents raising grandchildren -14 women and 6 men. The structure of the sample in terms of age, place of origin, education, and time spent caring for grandchildren is presented in Table 11.1.

The interviews were conducted at the turn of May and June 2020 at the respondents' place of residence and the average interview duration was 1.5-2.5 hours. The sample was selected using the snowball method. All interviews were recorded using a dictaphone, with the consent of the people participating in the study, and a review note was also prepared after each meeting. The interviews were then transcribed, which was the basis for the analysis of the collected research material.

Table 11.1 Research sample characteristics

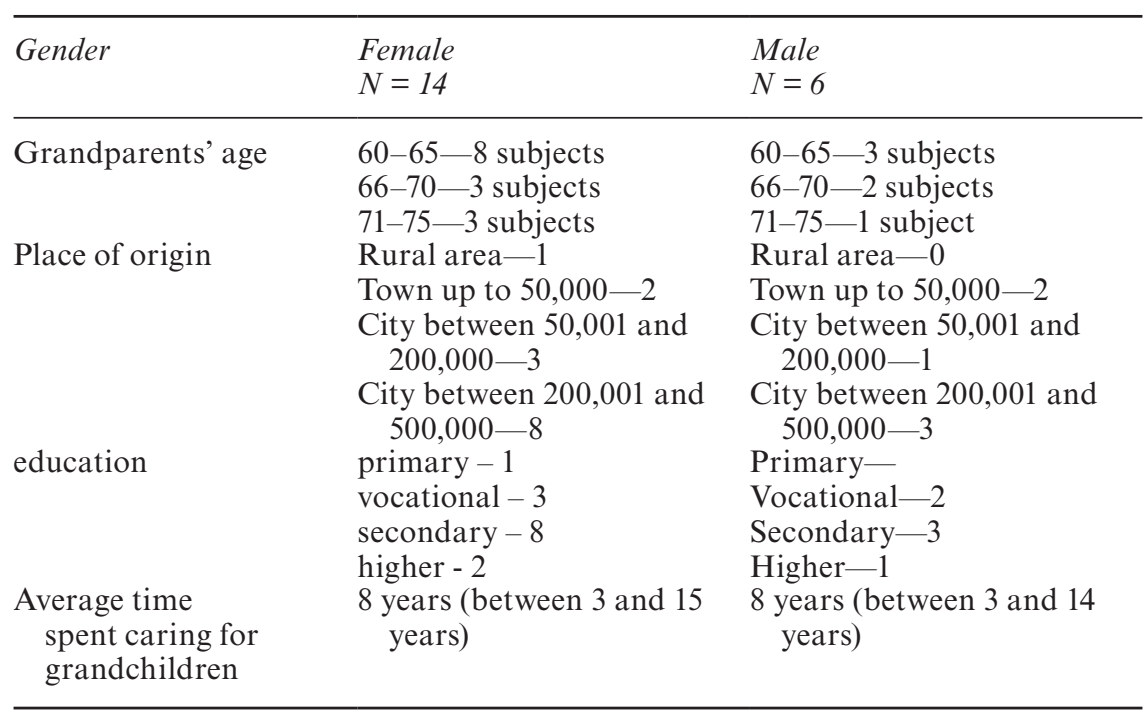




\section{A feeling of insecurity, loneliness and isolation}

The time of a pandemic is a period that contributed to the emergence of many changes in people's lives. In the case of grandparents raising their grandchildren, it turns out that the period of isolation due to the pandemic was a difficult time, often referred to as a time of solitude and isolation. One of the respondents admits:

There were times when I really thought that I would not be able to handle it all, that I was left alone with my granddaughter, her education, and all the daily chores. And I would sit down and cry, you know, from helplessness, fear, and from this feeling that I just can't handle it all.

Anna, 68, 5 years bringing up an 11-year-old grandson, W_11

The respondents also pointed out that the pandemic only increased their anxieties and reduced their sense of security.

These weeks of isolation have exhausted me, I thought it would all end up in depression. I had the impression that the whole world has fallen on my head in an instant. Well, because when you are left alone with all of this, you start to panic. But I am doing better now, I had to figure it out somehow.

Krystyna, aged 63, 9 years raising her granddaughter at the age of $14, \mathrm{~W} \_8$

It was only in isolation that the grandparents began to wonder about their overall health and realized that they had various medical conditions that put them at greater risk of falling ill with the coronavirus. This, in turn, contributed to the emergence of a heightened sense of anxiety about the future of their grandchildren.

From the very beginning, when the whole coronavirus began to be talked about, I was terribly afraid of what will happen. What will happen to the grandchildren if I or my wife are gone? Where will they go, who will take care of them? Will they go to some institution? And then I felt a paralysing fear, so my wife and I tried to do everything not to get infected - we disinfected everything, some things even several times, in boiling water, we did bigger shopping to limit leaving the house to a minimum.

Józef aged 72, 7 years bringing up grandchildren aged 11 and 13, W_5

I cannot describe the horror I felt about the pandemic. My life has been turned upside down and completely changed. All because I am generally a sick person, I have hypertension, diabetes, and Lyme disease. And when I heard that I could get sick and that it was dangerous, even 
for my life, I didn't know what to do. Cause who would take care of the girls. And they need care and they will need it for a long time.

Jadwiga aged 62, 3 years bringing up granddaughters aged 5 and 9, W_3

People also emphasized the importance of the lack of support experienced during this period by 9 out of 20 respondents, which significantly contributed to difficulties with meeting the daily needs of both grandparents and grandchildren. In addition, many grandparents emphasized that the loss of freedom was the cause of their deteriorating well-being and even though emphasis is put on a clear decline in social contacts, replaced with individually and independently coping with the situation, research shows that the vast majority of respondents stress the role of family or friends as a factor helping them survive this difficult time of isolation.

The importance of a support group in the life of grandparents raising grandchildren is confirmed by research (Cox 2000; Strom \& Strom 2000), which proves that it is possible to successfully help the older persons cope with new roles and changes in their lives.

\section{Remote education: perceptions and concerns}

When analysing the situation of grandparents during the pandemic, it was important to know their feelings about the educational requirements related to remote education. It turns out that most interlocutors believe that they meet the educational needs of their grandchildren on a daily basis, but remote education and spending free time during the coronavirus isolation turned out to be more difficult than they expected and most grandparents looking after grandchildren attending the last years of primary or secondary schools had great difficulty in meeting their educational needs. The respondents claimed that they were not able to successfully help them with their homework. They also had problems with motivating their grandchildren to regularly participate in online classes with teachers. The inability to provide effective support in the context of education, but also in coping with the effects of isolation by young people, contributed to the emergence of various fears.

The problems described above increase the stress of grandparents, who were not only struggling with the effects of isolation, but also had to face home education and help their grandchildren survive this difficult time of being cut off from their peers and the realities of life before the pandemic.

It is a difficult time for all of us, nobody expected it... it was difficult to change everything in your life overnight. It was difficult for me, not to mention the young ones; for them it is as if the whole world was turned upside down. And even though it was hard for me, because this school and these lessons and all the household chores, well you can have 
enough of it, but I tried not to show it, because I saw that it was also difficult for my granddaughter - all the time she just asked - how long yet, and when will it be normal, and why can't we go out, go somewhere... and what was I supposed to tell her? Yes, it's that... I don't know, you have to be responsible and manage somehow to... help her somehow. Because I saw how difficult it was for her without girlfriends and... and in this lockdown and there are so many of these lessons that sometimes you have to spend the whole day on them.

Halina, aged 61, 3 years bringing up her granddaughter at the age of 8, W_10

Barriers related to the use of technology were mentioned by grandparents as another factor hindering them in effectively meeting the educational needs of their grandchildren. The respondents stated that so far, they had often felt a lack of trust in learning new technologies and using the Internet. Moreover, until schools began to use computers to record learning outcomes, monitor students' learning, and communicate with teachers, they did not attract much attention from grandparents. Accordingly, during the pandemic, the use of computers and other technologies was a challenge for grandparents. Most of the respondents -14 out of 20 -had difficulties in accessing their grandchild's profile in the electronic register and using educational platforms, which often prevented them from maintaining appropriate contact with teachers, as well as finding information related to the current curriculum and tasks to be done.

Until now, everything has been sorted out, and now sometimes it is too much for me. Since the older one went to school, I knew that someday I would have to start learning it... using a computer, I mean, because so far I had no need for that. You know, if you don't use it, why learn it? But when my older granddaughter went to school, then I started to think that someday she will need help, and all these things that are to be done for school. There comes a time... like now, when you already know that you have to, that you can't move on without it. So I started to do something about it. But now it's a chore... once we did none of these lessons for a week because I did not know that it was there that I should look... until the teacher called. And since then I have been learning, I ask others how it is done... and I hope that soon I will be able to deal with it myself.

Jadwiga aged 62, 3 years bringing up granddaughters aged 5 and $9, W_{-} 3$

The problem of digital exclusion of the older generation became even more important in the times of COVID-19. Obviously, digital technologies have become the new norm today in both health and social care for the older adults, but the issues of digital exclusion and the digital divide between generations 
remain a key obstacle and barrier to enabling the older adults to experience their possible benefits. The 2018 Social Cohesion Survey results published in February 2021 (so even before the pandemic) confirm the significant age differentiation in terms of Internet use in Poland. In the quarter preceding the survey, the percentage of people using the Internet ranged from approx. 15\% among people aged at least 75 to approx. $98-99 \%$ of people from the two youngest age groups included in the study, i.e., between 25 and 34, as well as between 16 and 24 years old. In the case of people aged 65 to 74 the percentage of those using the web was approx. $38 \%$. The most common reasons for their lack of willingness to use the Internet were lack of skills or lack of need ('Quality of life and social capital in Poland Results of the Social Cohesion Survey 2018'). During a pandemic, the needs of the older adults have often turned to necessity, also changing their attitude to using digital technologies. Digital competences can be useful in various situations: from having to deal with official matters, through shopping, maintaining contacts, ending with health issues. In the case of grandparents bringing up grandchildren, these competences turned out to be necessary because of remote education and their absence contributed to frustration and fears related to being unable to assist children in this regard, as well as failure to fulfil assigned tasks. The pandemic forced grandparents to acquire skills related to using digital technologies. The world of remote education made them increasingly open to new opportunities in this area. It should also be remembered that, since grandparents were at higher risk from COVID-19, most of them decided to limit face-to-face contacts, which often contributed to an increased risk of social isolation. In this regard, digital technologies have become extremely important for maintaining contacts and using the means of support for the older adults. However, there are also grandparents who are still outside of the digital world, feeling even more confused and facing barriers to accessing both information and support.

While grandparents spoke both about the challenges and the fears they faced, when referring to their experience of helping grandchildren learn at school during the pandemic, most of them also spoke about the benefits of the situation. These included the opportunity to get to know their grandchildren better by spending time with them each day. Grandparents also saw themselves as those who help young people survive this difficult period. Analysis of the research results shows that grandparents considered their own personality traits, i.e., patience, support, and willingness to sacrifice, as some of the most important factors ensuring their grandchildren's sense of security and stability.

\section{The situation of grandparents raising grandchildren in the time of a pandemic}

The research results show that there are other areas of concern. The first is the economic situation, as the respondents have experienced an unexpected 
financial burden during the pandemic. Financial issues were of great importance to almost all grandparents, who said how difficult it was for them to meet the needs of their grandchildren. The greatest anxiety is caused by the rise in prices and the resulting burden on the household budget from daily expenses, which have increased since they have come to live together with their grandchildren. It should be added that during their stay in institutions, the children were provided with meals financed from social assistance funds. The respondents who are still professionally active are additionally afraid of losing their jobs or of professional degradation, which would significantly lower their standard of living. Similar conclusions can also be drawn from other studies concerning this subject, which emphasize that material difficulties are one of the most serious challenges in households run by grandparents during the pandemic (Xu et al. 2020).

Another issue raised by the respondents, which in their opinion affects their economic situation, is the legally regulated situation of caring for grandchildren. As the respondents themselves admit, they are entitled to various benefits which supplement their salary or pension and significantly improve their financial situation. This is particularly important because, as the respondents themselves claim, during the pandemic the process of regulating legal guardianship is difficult and stretched in time due to changes in the work organization of various institutions. Others argue that having these formalities settled in advance makes it easier for them to function on a daily basis, not only during a pandemic, but also in everyday life.

Another area of concern that most respondents mentioned involved the mental health of the grandchildren. The interviews revealed a number of concerns grandparents had about prolonged isolation and lack of access to professional help, connected to problems with the children, which, according to their carers, started to increase from the moment they were forced to stay at home. Many grandparents mentioned the increased stress that arose during isolation. Lack of contact with peers and limited ability to regulate stress are, according to grandparents, the main reasons for the deterioration of the well-being of their grandchildren. The grandparents of children who had previously been diagnosed with various developmental deficits faced similar problems. This situation resulted mainly from the fact that most of the institutions providing assistance were closed and the grandparents were left without proper help. The following statement by one of the respondents illuminates the great difficulty posed by this situation.

I didn't know what would happen to him. I was really waiting for the worst. Well, what can you expect when the therapy is stopped overnight and at moment like this. Because he was in really bad shape, he stayed locked in his room all day, he could sleep 24 hours a day, nothing could draw him out. And when he started going to therapy, I saw him change, and now this... this pandemic came, they closed everything and no one thought about what would happen. What would happen to people like 
me... parents and most of all children. Because nobody cares. And he got worse again. And how am I not to worry? I try to help him somehow myself, but I don't always know how... then at least I go and just sit with him. Sławomir, 66, 3 years bringing up a grandson at the age of 13, W_7

The age of the grandchildren is not without significance. It turns out that each development phase brings with it new challenges to be faced by caregivers and isolation and remote education additionally diversified the experiences in this area. The respondents bringing up their grandchildren in preschool and early school age emphasized that the kids being at home was a heavy burden on them. On the one hand, this is due to the need to provide assistance in the performance of educational tasks, which often takes up a whole day. On the other hand, grandparents wanted to make the best use of this time to build relationships with their grandchildren by spending their free time together, being aware of their own limitations, which no longer allow them to undertake some activities. One of the respondents admits:

It seems to me that there are many more lessons now. I wake up in the morning and every day is basically the same. From the morning we do all the homework with my older granddaughter and then in the afternoon I sit down with the younger one, because she also has to do various things. And before I know, it's evening already... the next day looks the same. Sometimes we don't have time for anything else, but if we do, we do something else together: we cook, we play games. Well, because you want these children to have fun spending all this time at home, so you just come up with something.

Nina, 67, 6 years bringing up granddaughters aged 6 and 9, W_16

In the case of grandparents bringing up older children, especially adolescents, caregivers had other fears, associated with the need to provide psychological support, motivate to work, and alleviate emerging tensions and conflicts.

Summing up the above considerations, it should be emphasized that a better understanding of the situation of grandparents raising grandchildren is needed, especially in the context of situations such as the one caused by the coronavirus pandemic. Knowledge about the areas of support, as well as resources, challenges, and risks, will help ensure high-quality care for children.

\section{For further discussion...}

Research results indicate that during a pandemic, the number of social anchors is important, as well as their subjective assessment in the context of their importance and usefulness in the coronavirus era. In the case of 
grandparents bringing up their grandchildren, it turns out that it was a difficult time, often described by them as a time of solitude and isolation.

The anchors belonging to the group of the so-called subjective and internal, which include, among others: personality traits of the individual and individually held ideas and values, turned out to be the most important in facing the changes caused by the coronavirus. Despite the feelings of fear and worry that accompanied the grandparents, they were able to cope with the situation and were a support for their grandchildren. The ability to deal with difficult situations has become a key skill helping people get through these trying times. It is obvious that in the case of the grandparents participating in the study, the importance they assigned to the role of parent to their grandchildren was also important, which was manifested through their involvement in this role.

Issues related to economic, institutional, and legal aspects of parenting also turned out to be important anchors. In the case of the former, it can be stated that a fixed income, in the form of a retirement pension, a job that provides a decent standard of living, as well as stability of employment, provide grandparents with a sense of security that allows them to implement plans for both their own and their grandchildren's future. On the other hand, institutional and legal anchors, such as formal foster care, guaranteed benefits related to the care of grandchildren, and institutional assistance provide appropriate support in the event of various problems.

There were also several other factors influencing the perception of their own situation by grandparents raising their grandchildren during the coronavirus, including the age of both grandparents and grandchildren, as well as the time perspective: i.e., the period that has passed since the grandparents took the children into their care, as well as anxiety resulting from fear for their own health and the future of their grandchildren.

In conclusion, the issues related to the situation of grandparents raising grandchildren during a pandemic require further study. Although we are currently dealing with a reduction in public health restrictions and the opening of educational institutions, we still live in the shadow of the pandemic. It should also be remembered that some of the consequences of isolation will only be noticeable after a certain period of time. It remains to be seen whether the grandparents and grandchildren will manage to rebuild the sense of stability and security, or whether they will need additional measures aimed at regaining psychosocial balance.

\section{References}

Backhouse J., Graham A., Grandparents raising grandchildren: negotiating the complexities of role-identity conflict, Child and Family Social Work 2012, 17(3), 306-315.

Burke P. J., Identity change, Social Psychology Quarterly 2006, 69(1), 81-96.

Cox C., Why grandchildren are going and staying at grandmother's house and what happens when they get there, In C. Cox (Ed.), To grandmother's house we go and stay: perspectives on custodial grand-parents, Springer, New York 2000, pp. 3-19. 


\section{Joanna Borowik}

Grzymała-Kazłowska A., From connecting to social anchoring: adaptation and "settlement" of Polish migrants in the UK, Journal of Ethnic and Migration Studies 2017, 44(2), 252-269.

Grzymała-Kazłowska A., Od tożsamości i integracji do społecznego zakotwiczeniapropozycja nowej koncepcji teoretycznej, CMR Working Paper 2013, Nr 64(122).

Grzymała-Kazłowska A., Social anchoring: immigrant identity, security and integration reconnected? Sociology 2016, 50(6), 1123-1139.

Grzymała-Kazłowska A., Zarys koncepcji społecznego zakotwiczenia. Inne spojrzenie na tożsamość, adaptację i integrację imigrantów, Kultura i Społeczeństwo 2013, 3, 45-60.

Hayslip B., Shore J. Henderson C., Lambert P., Custodial grandparenting and the impact of grandchildren with problems on role satisfaction and role meaning. Journals of Gerontology 1998, 53b, 164-173.

Hooyman N., Kiyak H. A., Social gerontology: a multridisciplinary perspective (6th ed.). Allyn \& Bacon, Boston, MA, 2002.

Kornhaber A., Contemporary grandparenting. Sage Publications, Thousand Oaks, CA 1996.

Quality of life and social capital in PolandResults of the Social Cohesion Survey 2018. Available at: https://stat.gov.pl/obszary-tematyczne/warunki-zycia/dochody-wydatki-i-warunki-zycia-ludnosci/jakosc-zycia-i-kapital-spoleczny-w-polsce-wyniki-badania-spojnosci-spolecznej-2018,4,3.html

Strom R., Strom S. (2000). Goals for grandparent caregivers and supportgroups, In B. Hayslip, R. Goldberg-Glen (Eds.), Grandparents raising grandchildren: theoretical, empirical, and clinical perspectives, Springer, New York 2000.

U.S. Census Bureau, Profile America: facts for features. Available at: http://www. census.gov/newsroom/releases/archives/facts_for_features_special_editions/ cb10-ff16.html 2010

Whitley D.M., Fuller-Thomson E., Brennenstuhl S., Health characteristics of solo grandparent caregivers and single parents: a comparative profile using the Behavior Risk Factor Surveillance Survey, Current gerontology and geriatrics research 2015, 2015, 630717.

Xu Y., Wu Q., Levkoff S. E., Jedwab M., Material hardship and parenting stress among grandparent kinship providers during the COVID-19 pandemic: the mediating role of grandparents' mental health, Child Abuse \& Neglect 2020, 110, 104700. 


\title{
12 "Keeping a project during the COVID-19 pandemic alive"
}

\section{Experiences with co-researchers of the participatory STARK project}

\author{
Helene von Stülpnagel, Julia Piel, \\ and Astrid Eich-Krohm
}

- The fanzine method was applied to the conditions of a participatory research project and proved to be an insightful and innovative way to synthesize attitudes and experiences during the COVID-19 pandemic and to continue to work and research together at a distance.

- The older co-researchers in the project became active contributors by working on the STARK-zine.

- The co-researchers explicate issues important to them in relation to the pandemic, such as compliance with confinement measures, which they interpret as an expression of mutual solidarity. In addition, their zine contributions point to a conflict between protection and civil rights and the impact of the pandemic with its ambivalent impacts.

- The co-researchers seemed to be less bothered by the restrictions during the lockdown. It is unclear how the attitudes of the older people changed during the pandemic and furthermore whether coping behavior changed.

\section{COVID-19 as a catalyst on life situations in old age}

At the end of January 2020, first cases of COVID-19 infections caused by the SARS-CoV-2 virus were reported in Germany and other European countries and developed into a pandemic. COVID-19 was a turning point for both German politicians and the society, but also acted as a catalyst in a complex societal structure and accelerated certain developments (for example digital technologies) while at the same time revealed weak points of society (Bühlmann 2020). A public discussion started right at the beginning about 
who would be most at risk during the pandemic. Early on, older people were identified by experts as a high-risk group and therefore considered in need for special protection (Deutsches Zentrum für Altersfragen 2020). In fact, older people in particular were at an increased risk of COVID-19 infections. This applied both to the severity of the disease and its course and to the risk of mortality associated with older age (Deutsches Zentrum für Altersfragen 2020). However, the role of general health and previous diseases of a person and its impact on the severity of the infection was often ignored (Deutsches Zentrum für Altersfragen 2020).

In April 2020, Kessler and Gellert of the German Society for Gerontology and Geriatrics (DGGG) were the first to give recommendations for public communication on "Corona and Aging". They criticized the representation of older people in general as weak and as a group that had to be protected by society.

Instead, the public discussion did not reflect that older people are a heterogenous and diverse group. The general reporting reinforced the perception of a savior-versus-victim narrative that is reflected in the logic of "we as young and healthy versus you as old and sick" (Kessler 2020: 1). Instead, more attention should be given to the potential of older people in coping with the pandemic. For example, the majority of older people showed well-developed strategies for dealing with the challenging circumstances (Kessler 2020).

Under these conditions resulting from the COVID-19 pandemic, the requirements for the implementation of the research project "Social participation and self-determined aging through participatively developed social and digital offerings in the Kannenstieg neighborhood" (STARK) changed.

Therefore, this chapter introduces how the academic researcher of the participatory STARK project handled the challenges during the first lockdown (Robert Koch-Institut, 2020b) ${ }^{1}$ in the COVID-19 pandemic (March until approx. July 2020) and at the same time, used the possibilities that opened up for active participation of older people. Based on the work with older participants from the project, we explored how older people dealt with regulations of social distancing and other restrictions and its impact on their social lives.

\section{Social isolation, loneliness, and social participation in old age during the COVID-19 pandemic}

Social isolation and loneliness are not purely phenomena in later life. People experience phases of loneliness again and again in their lives (Berlin-Institut für Bevölkerung und Entwicklung, Körber-Stiftung 2019). However, an increase in the risk of social isolation and loneliness is only observed in old age (Bundesministerium für Familie, Senioren, Frauen und Jugend 2019; Luhmann 2016). 
In fact, the COVID-19 pandemic shows a $14 \%$ increase in the experience of loneliness among people aged 46 to 90 in 2020 in comparison with previous years. However, when people of different age groups are compared, feelings of loneliness in the first phase of the pandemic were found to be similar for all age groups (DZA 2021). ${ }^{2}$

Social isolation and loneliness can have a significant impact on physical health and promote mental illness. For example, loneliness can lead to an increase of blood pressure and a higher risk of cardiovascular disease. The risk of dying from a myocardial infarction or stroke is even higher for isolated and lonely people (Hakulinen 2017). Furthermore, loneliness and isolation are closely associated with an increased risk of clinical disorders such as depression, anxiety, obsessive-compulsive disorders, and even for dementia (Jacob et al. 2019; Rafnsson et al. 2020).

In the fields of public health and health promotion, social isolation and loneliness are addressed through the concept of social participation (Gesundheitsförderung 2016). It refers to the integration of older people in social networks of families and friends as well as their integration into the community and their social environment (UNECE 2010). In old age, participation in societal life is considered as one important factor in promoting well-being and health that can reduce the risk of loneliness and thus the impact of chronic loneliness on health (DZA 2021).

In times of social distancing to reduce COVID-19 infections, people are increasingly relying on digital technologies to stay in contact with each other. This can be a challenge, especially for older people. A lack of internet access can lead to social exclusion, especially when public life changes to digital formats, as exemplified by the containment measures of the COVID-19 pandemic.

\section{Digitalization in older age during the COVID-19 pandemic}

If access and user competence are limited in certain population or age groups, such as the older or the oldest-old groups, this is referred to as the digital divide or "digital gap" (BMFSFJ 2020: 41). Compared to younger populations, older adults are less likely to have access to and use of the internet and digital technologies as basic infrastructure ${ }^{3}$ (BMFSFJ 2020). Thus, in 2017 the proportion of all retired people with internet access is comparatively high at over $80 \%$. However, there are age differences in this group while in the age group 73 to 78 , it is still $64.4 \%$ it drops to $39.4 \%$ among 80 years and older (Huxhold 2019). In 2020, the percentage of people who have internet access has actually increased and mostly among the 61- to 75-year-old age group. ${ }^{4}$ Especially the age group of 46- to 69-years used the internet more often than before the pandemic. Older people aged 76 and over accessed the internet proportionately less frequently than people aged 46 to 75 (DZA 2021). 
The challenge posed by the complex combination of pandemic conditions, advanced age, and lack of internet usage was also evident at the implementation level in the participatory STARK project. During the first lockdown, digital media would have been a great alternative for project activities. However, there was a risk of exclusion for older project participants who had no affinity for the internet and digital media and carrying the risk of social isolation. Therefore, the question arose about the possibilities available to the academic researcher to continue the project with the older co-researchers.

\section{Background to the STARK research project}

In the fall of 2019 the STARK project began. It takes place in a city in Saxony-Anhalt in cooperation with a service center for older citizens ("ASZ") in the district's community center. The district is populated by one of the highest proportions of older people in the city and dominated by prefabricated slabs (Amt für Statistik, Wahlen und demografische Stadtentwicklung 2019). The high average age and the anonymous residential structures lead to the assumption that a proportion of older people are difficult to reach by the health and consulting services offered in the district. Interviews with social practitioners who work with the older residents reported problems with reaching socially isolated older people.

The aim of the STARK project is to use the participatory research approach to develop strategies to reach older, socially isolated people living in the Kannenstieg neighborhood, to find out the reasons and impacts of social isolation and to develop appropriate offers of social participation.

The STARK project belongs to the research association "Autonomy in old Age" (AiA) (Research ID: ZS/2018/12/96262) funded by the European Union (ERDF-European Regional Development Fund) and the State of Saxony-Anhalt, Germany. The STARK project received a positive approval from the Ethics Committee (Nr. 119/19) of the Faculty of Medicine, Otto-von-Guericke-University Magdeburg. The co-researchers were informed of the project's aims and their rights in the research and all signed consent forms. The presented contributions are not publicly available and for the purpose of this chapter, all personal identifiers are pseudonymized.

\section{Methodological approach: participatory research in the STARK project}

STARK is developed on the research approach of community-based participatory research (CBPR) by involving community members as co-researchers in collaboration with academic researchers and different community actors by conducting joint research practice on the health-related topic social isolation (Unger 2014). The project follows the model of participation in health research outlined by Wright et al. (2010). The model is an instrument and evaluation criterion to discuss and explain participatory research, the degree 
of participation, decision-making processes and the reflection of actual participation of co-researchers within the group. Similar to a continuum the project meetings start with the preliminary steps of information, listening and inclusion of the co-researchers to proceed to the steps of participation, such as co-determination and decision-making power (Hartung et al. 2020; Künemund, Kümpers 2019: 149; Urban 2005; Wright et al. 2010).

In order to better understand the processes and the culture of togetherness at the ASZ and the people acting there, the academic researcher used participant observation and field notes in a research diary. Since August 2019, the latter serves as a medium documenting the entire STARK research process and reflecting the research context. In addition to theoretical and methodological considerations, ideas, observations, reactions, and emotions in specific field situations from the study environment of the Kannenstieg neighborhood are documented (Brüsemeister 2008; Köppen et al. 2020).

The project coordinator were present at the ASZ on two days to find interested seniors to participate in STARK. The researcher used various access and communication channels, for example prepared flyers and announcements for the ASZ and the Kannenstieg district, wrote short press releases, placed ads on the Kannenstieg homepage, and designed a flyer that communicated the project goals and approach in everyday language. In addition, the project was presented at various meetings, such as the "Seniors in Volunteer Work."

At the end of January 2020, the kick-off event of the project took place and was attended by seniors, academic researchers and stakeholders from the Kannenstieg district. Already at the end of the kick-off meeting, attention was drawn to the first official project meeting in February 2020.

\section{Older participants as co-researchers}

Ten seniors participated in the first official project meeting, which was conducted as a focus group (Freitas et al. 1998; Scott and Garner 2013). Narratives on experiences with social isolation, loneliness, and participation were gathered. Four of the older women reported that they were already affected by loneliness themselves. They hoped that participation in the project would improve their situation. In a joint voting process, a date was set for the next project meeting and nine seniors decided to continue participating in further project meetings. With the decision of these nine seniors, the project group was intitiated.

The project group consisted of six women and three men as co-researchers, with an age range of 65 to 80 years. Four of the six women are single or widowed. Two other women and three men of the co-researchers group live with a partner.

The majority of participants come from the Kannenstieg neighborhood itself or adjoining neighborhoods. Six seniors were already active members in one of the seniors' groups at the ASZ. Three seniors did not visit the ASZ 
regularly but wanted to participate in the group. Thus, some seniors already knew each other at the beginning of the meetings.

\section{Research with fanzines}

The COVID-19 pandemic started shortly after the first STARK project meeting in February 2020, and in the course of the first lockdown, the ASZ closed for visitors on March 16, 2020. It was not until mid-June 2020, that the ASZ gradually opened to its visitors again.

In order to stay in contact with and support older people in the community and to avoid isolation during the lockdown, the telephone was the primary tool of communication. Calling the co-researchers proved to be significant in terms of building and maintaining trust with the group, especially at the beginning of the COVID-19 pandemic.

The goal was continuous motivation and ability to work together as a group during the period of contact restrictions. It was a challenge to develop and test a format in which all co-researchers could participate and contribute at an equal level. Starting from this initial situation, the idea was born to create a fanzine together with the older co-researchers who became in the process the contributors of the fanzine.

The term "fanzine" (abbreviated with "zine") is a suitcase word made up of the words "fan" and "magazine" (Sülzle 2018: 5). It can be understood as a "product of cultural practices from juvenile scenes - self-designed and selfdistributed media (mostly printed documents) that are written within a special context, reproduced, distributed, and circulated within communities by mail" (Sülzle 2018: 4f). In zines a polyphony is laid out, that takes up the participatory principle in an advantageous way. The authors see themselves as a medium of self-empowerment, as they are located exactly where a change from consumer to producer takes place (Schmidt 2018: 41). As a kind of "network medium," they further have an important function for community building within a milieu (Sülzle 2018: 14). Therefore, zines fulfill in many ways the demands for an exchange format in the participatory STARK research project:

- With their form of asynchronous transfer of information and experience, they reach all older co-researchers on a low-threshold and equal basis and give everyone a voice.

- They offer the opportunity to express and communicate in writing or in the form of pictures, articles or other forms of contributions to create something yourself from a distance.

- They can also be used to maintain and strengthen identification with the project and cohesion within the project during the contact ban.

The consideration of creating a zine together as a group was transferred to the conditions of the STARK project. The following chapter decribes the process of the steps involved in creating the "STARK-zine." 


\section{First steps to create the STARK-zine: gathering data together}

However, the process to create the STARK-zine, differs from the original idea because the magazine was not intended to be created as part of a leisure activity, but as part of a research project.

Creating the STARK-zine began in April 2020 with the development of guiding questions. The questions were intended to illustrate the topic of the pandemic and at the same time to build a bridge to the project's topic "social isolation and loneliness in older age." The academic researcher formulated eight largely open questions and gave the co-researchers sufficient space and opportunity to contribute their own thoughts and ideas creatively and openly. Table 12.1 illustrates the questions.

Table 12.1 Questionnaire for the STARK-zine

Question Explanation

How was your mood in the last few days?

What have you been happy or perhaps annoyed about in the last few days?

What do you currently deal with a lot or particularly in your everyday life? Have you been able to tackle activities that you have been planning for a long time?

What are you worried about right now? Are there any topics that particularly concern you?

During the contact ban, we had to try out new and creative ways of staying in contact with each other and to establish closeness at a distance. How did you keep in touch? Which (creative) ways did you use?

Are there any positive aspects that you can take with you from the Corona period?

What are you particularly looking forward to when the measures are eased again? What would you like to do again first?

Have you recently come across any interesting articles about our project topics "loneliness, social isolation, social participation"?
The mood is expressed through smileys on a scale.

The selection can be justified in a free text field under the scale.

The questions aim is to discover what the older people have been thinking about or spending their free time with during the lockdown.

A question on current concerns and needs is also part of the key questions.

The questions focus on the new ways of contact and communication tested in many places in younger age groups, namely the question of alternative ways of establishing and maintaining contact during the period of contact suspension.

The question is intended to highlight the potential positive aspects of the Corona pandemic.

The question is intended to direct a positively connoted look into the future.

During the Corona pandemic the topics "social isolation" and "loneliness" become particularly relevant. In this way, the project topics can be skilfully linked between the project topic and the Corona pandemia. 
The design of the questionnaire was finished in May 2020. Then, it had to be distributed to the co-researchers in different ways: Two coresearchers received the questionnaire by e-mail and four by mail. Two co-researchers picked up the questionnaire in person at the ASZ and returned it back there after they finished their contribution. Two coresearchers lived in one apartment and decided to fill out the questionnaire together. In view of the continuous change of the situation, there was a processing and return period of approximately two weeks. Finally, the academic researcher began to sift through and sort the answers and contributions. In this context, the authors would like to point out that we have translated all citations and text passages from German into English ourselves.

\section{Finding access to data analysis}

The analysis of zines poses special challenges, because in many cases analysis procedures are mainly focused on textual data. Methodical, textbased approaches must be supplemented by corresponding methods in order to be able to deal with the compositional character of image and text in zines (Dietrich and Mey 2018). The academic researcher limited the analysis of the material to considering textual data only, omitting the visual material.

Qualitative content analysis was used for this purpose. It is a methodology used in the context of social science research to analyse generated texts with regard to their thematic content (Mayring and Fenzl 2019).

In a first step, the academic researcher determined the units of analysis. The coding unit in the analysis of the text material in the STARK-zine referred to semantic units, sentences, and meaningful sections as a minimal text component. The context unit was the respective answer of the participating seniors to the leading questions. The body of data collected with the questionnaire, including newspaper clippings, photographs and pictures, was considered as the unit of analysis (Mayring and Fenzl 2019). Subsequently, the researcher followed the process of inductive category development and deductive category application in advance through the guiding questions, which could be summarized into a category network. In order to inductively develop categories, the following domains guided the analysis:

1 The different ways of maintaining social contact, with particular reference to digital technologies

2 The change of view to possible positive aspects during the pandemic

3 Thoughts and moods

4 Future perspectives

5 Aspects of social isolation, loneliness, and opportunities for social participation 
After a first screening of the text passages, in a second step it was analysed if the categories could be assigned to the text passages several times (Mayring and Fenzl 2019).

Similar to a presentation of results in a scientific context, the researcher summarized the categories, prepared them and presented each category in individual articles in the style of a newspaper magazine. In June 2020, the participants received the STARK-zine in printed version by mail and in digital version via e-mail.

\section{From co-researchers to contributors: findings from participatory collaboration in times of social isolation}

In the following, we present the analysis of the STARK-zine entries of the co-researchers who became contributors during the process of collaboration. We limit ourselves to the statements that are relevant for this chapter: how did the contributors experience the first lockdown of the COVID-19 pandemic? The entries clearly point to a major dilemma between conflicting values of freedom versus protection. This discrepancy about the contradiction and compatibility of freedom rights and the protection of (older) people is not a new discussion, but it became existential during the COVID-19 pandemic.

\section{Personal freedom or restrictions?}

The answers to one of the questions (what are you most looking forward to after easing the measures) present an inner conflict: Some contributors describe longing to be able to leave their home without restrictions. The overall wish is to have the choice of meeting with anyone at any time and any place, to enjoy restaurant visits and to shop carelessly to regain some former normality. Nevertheless, they seem to take for granted the incongruity between the desire for freedom and compliance with the COVID-19 regulations. Many express their displeasure with the behaviour of the people around them.

Some parts of the population see the restrictions as an attack on their freedoms and rights enshrined in the Basic Law. They immediately start swaggering and describe the consequences of the "lockdown" as excessive and inappropriate... I am annoyed at the infinite stupidity of people who take to the streets for freedom of demonstration and talk about "Corona invention" and "misleading conspiracy theories"!

(Bm3, 73 years)

The longing for freedom and a considerate and protective behavior in relation to other people seems difficult to reconcile. The STARK-zine entries of several contributors underline this dilemma. A particular point 
of contention and criticism relates to public demonstrations during the pandemic. The number of public protest against infection protection measures in Saxony-Anhalt increased during May 2020. The people and their motives for participating in the protests were heterogeneous. A large number of people questioned measures such as the wearing of masks and contact restrictions. Still others questioned the restriction of their basic rights and thus also their fundamentally regulated right to freedom of assembly. The contributors referred to these motives in their statements:

The demonstrators insist on the fundamental right to demonstrate, even though among them may be Corona virus infected and the pandemic, which is already reaching all continents, is getting worse. They reject the precautionary measures (wearing mouth-nose masks, keeping their distance, avoiding the formation of large groups of people, etc.) as it restricts their "freedom". Do these stupid people prefer to accept illness and death? Is this freedom?

(Bw4, 76 years)

The contributors do not only discuss the meaning of freedom in generally. They also raise the question of what freedom still means when the consequences of these rights include illness and in the worst case death of other people. The process of balancing the alternatives reaches a dimension that consists of a specific dramaturgy.

The contributors to the STARK-zine do not see any restrictions of fundamental rights in the protective measures, but a necessary, albeit annoying evil, which however serves "the collective protection" of fellow woman/men and must therefore be accepted.

In particular, the demonstrative disregard for protective measures causes a high degree of incomprehension and displeasure among some contributors. Some participants of STARK consider it a reckless and thoughtless action that questions the solidarity with one another.

However, the disapproval of the demonstrators seems to be an indicator of an assumed lack of solidarity in the population, a much more existential concern of the contributors. They view it as a personal affront that solidarity is not understood in terms of mutual cohesion and sharing of common values and goals. This assumption can be inferred in statements such as the following:

What annoyed me was that many people do not take the mutual protection by mouth/noselmasks seriously.

(Bm3, 73 years)

This also has consequences for the handling of the mouth and nose protection. From the statements of the Federal Government and the RKI [addition by the authors: Robert Koch Institute] we have learned that wearing 
masks is an expression of solidarity and protection for our fellow human beings. Rejecting it can endanger others.

(Bm3, 73 years)

The older people seem to be particularly affected when rules are ignored, i.e., deliberately and intentionally bypassed or simply not taken seriously because it might counteract a national effort to ensure comprehensive protection to which each individual contributes. The demonstrators however, consciously accepted that other people can be infected and the older people consider such violations as personal insults.

\section{Conspiracy myths and control measures}

Another issue was the spreading of conspiracy myths. Some contributers perceived the spreading of untruths or misleading non-scientific assumptions as a lack of solidarity, because there are people for whom this would have far-reaching consequences. For example, one contributer writes about a case in which an old man would not even receive telephone calls. His friend wrongly assumed that COVID-19 could spread over the phone. This lack of solidarity and the selfishness of some people caused incomprehension and anger among the old and was sharply condemned by some contributors.

The blame is not exclusively related to those who deliberately act against the guidelines, but also to the control of the authorities. For example, there seems to be a perception that it is the task of the authorities to control the regulations and to react with appropriate sanctions in case of disregard and missteps. Some would even argue in favor of stronger surveillance and more controls to ensure consistent and collective compliance and implementation of measures.

State regulation regarding the wearing of masks in public transport, I, but also other people observe that many people without masks are sitting in the tram. I called the MVB [public transportation authority Magdeburg)] and reminded them of this. The answer was: "it is better not to take the tram. I go by car. We cannot expel a passenger from the tram, the mask obligation is a recommendation. The public order office (Ordnungsamt) is responsible for this." Answer from the public order office: "The MVB is responsible for its trams." In some West German federal states you pay a fine. In our own federal state it has no consequences.

$(\mathrm{Bw} 7, \text { informant declined to communicate age })^{5}$

In addition to the inadequacy of controls, one contributor also points to the inconsistency of the measures, which leads to irritation and confusion among citizens.

The contributor questions further measures in another entry: for example, he had observed that in self-serving restaurants, it was possible to pick up 
cakes or coffee from the buffet, but the outside area with tables and chairs remained closed to guests. However, a few meters away from the café, he had seen people sitting close together on a wall eating the food that they had previously picked up in the café.

The descriptions of this older man also reveal the ambivalence that many people perceive with regard to infection control measures during the COVID-19 pandemic.

\section{Thoughts about the future after the pandemic}

Occasionally, positions related to the current situation also included a reference to the future with lesson learned from the pandemic. Thoughts about future developments tended to have a thoughtful and questioning connotation. They refered to the personal, individual, as well as to the societal level.

The contributors see the lockdown as a chance to get back to essential things in their lives. One contributor states:

I appreciate health and the small, everyday things that seemed so taken for granted before Corona even more [...].

(Bm1, 80 years)

Some call the lockdown a time of deceleration and perceived it as beneficial. "Everything had to be shut down. Peace has returned to society." (Bw7, informant declined to communicate age)

The situation was described as a phase of stagnation with a cathartic effect of social impact.

There is the aspect of deceleration that is worth taking from the Corona period into the future.

(Bm3, 73 years)

The rush in the stores has also eased. More distance was kept in the stores. (Bw7, informant declined to communicate age)

One contributor asked herself of how society will develop once the COVID-19 pandemic is over or a vaccine for everyone has been developed.

Another contribution can be considered as an answer to this question:

I don't believe that the majority of people will change voluntarily - most will return to their usual self-indulgence.

(Bm3, 73 years)

Based on these considerations, a date in the future (Autumn 2020) was set as scenario in the questions. The question for the contributors was to look 
back at the last months and to think about what might have changed socially during this time - both positively and negatively.

One senior formulates very precisely the striving for maximization and constant growth in Western societies:

It has to be questioned, whether there has to be the oversized supply in certain areas, just because we can. This ever more, ever further was put to the test with this crisis.

(Bm3, 73 years)

Finally, these statements stand for a positive evaluation by the contributors and their concern returning to the value of the "small", "everyday" things of which attention had been lost over the years and brought back by the pandemic. In this way, the seniors consciously question the prosperity of Western societies and question the extent to which lasting maximization and enhancement in all areas of life is meaningful.

This awareness to the "little things in life" is reflected in almost all the contributions in which they express their enthusiasm for nature and their garden. "I observe nature, the birds, [...]" (Bw7) or "I go for a walk and see so many things I did not notice before." (Bw5, 76 years) are phrases that have often been uttered in the context of deceleration and discontinuation of activities. For most of the older informants, a temporary phase of slowing down and readjusting the focus from everyday life to nature did seem to be a good way of handling the lockdown. They note that they enjoy spending their time in the garden and on the balcony or taking walks in the park. These activities turn out to be very beneficial, as they make it possible to combine exercise in the fresh air with something meaningful for them. In addition, gardening or work around the house filled the time and it replaced the activities that the seniors had previously engaged in when they came to the ASZ group activities. Instead, progress in and the state of the garden were reported with pride. Those who did not own a garden used their time instead for creative handicrafts or for further training, for example in the form of online courses. An older woman comments on her talent for improvisation:

I didn't grow up in a "throwaway society" and make a lot out of old things (e.g. pillowcases and patchwork quilts from colourful clothes that are no longer modern, but whose fabric quality is impeccable).

(Bw4, 76 years)

Regardless of age or gender, it was possible to deal with the restrictions quickly and to reorient the activities of daily life. Complaints were hardly expressed in the contributions. Only a slight regret was voiced when usual offers such as sports, card games, or long planned trips were canceled because of the COVID-19 pandemic. 


\section{Being separated from family and friends}

The contributors found it much more difficult to accept the restrictions on contact with close relatives. They described the fact that they cannot see their children and grandchildren for an indefinite period of time, or only see them from a distance, as a stressful situation. There was a great longing for and hope of seeing them again soon based on the fear that because of living apart they might become become strangers during the lockdown. This is expressed in the following statement:

When Corona no longer troubles us, I would like to go to B. and L. to see my children and grandchildren again. I have a great longing and almost the impression that we are drifting apart and do not recognize each other. The voice on the phone is only a consolation.

(Bw4, 76 years)

It should be emphasized that the statements of the contributors on the soonto-be-held reunion of relatives were formulated more as hope than as demands or reproaches. In addition to their preferences, the contributors also considered the ambiguity of the situation, according to which they always adapted and subordinated wishes to the circumstances of the pandemic restrictions.

Contributors expressed a high level of gratitude especially in relation to their own health status during the COVID-19 pandemic. At the same time, they showed concern for their own (mental) health and the health of their relatives. For example, some of them were finding ways to regain physically and mentally fitness after the COVID-19 pandemic. For others, the focus was being concerned about their relatives:

I think of my children and grandchildren, who are currently worried about their jobs, postponing their studies and having to cope with other difficulties, without me being able to help them financially, for example, because I draw a small pension. The main thing in the Corona crisis is to stay healthy and not to get infected.

(Bw4, 76 years)

I also worry about my children that everything is all right. My children all work in the nursing home.

(Bw5, 76 years)

This aim for personal well-being and the well-being of others was also reflected in self-identification as a member of a high-risk group:

I avoid contact with former colleagues or friends, because it is said that 60 to 80 year olds can quickly become infected and ill, as the immune system weakens at that age. 
All senior citizens belong to the particularly endangered population group even without previous illnesses.

(Bm3, 73 years)

Of great importance are symbols and gestures that were interpreted as testimonies that their generation is not forgotten or invisible to society:

I received a greeting from the Bürgerhaus [addition by the authors: "Bürgerhaus" a synonym for ASZ] in the form of a piece of cake in my mailbox - for me this was a sign that our generation will not be forgotten.

(Bw4, 76 years)

The quote illustrates that direct human contact or face-to-face conversation was not necessary for all co-researchers to feel that someone was thinking of them.

\section{Discussion}

The data shows similarities and differences in the experience and behavior of the older co-researchers during the first lockdown of the COVID-19 pandemic. The focus is particularly on the emotional dimension of the pandemic.

Consistencies were found in the simultaneity of different expressions of emotion and the oscillation between several opinions that emerged and manifested over time during the lockdown. In this context, the responses reflect on a minor and individual level what is happening on a societal meta-level. The increasing significance of conflict and polarization between the perspectives is also expressed in the statements of the co-researchers. Conspiracy theories are viewed as an expression of a lack of solidarity or as coping with the pandemic, the conflict of moral values between freedom and protection, the view of the future, which seems uncertain and frightening but at the same time also emphasizes hope and "crisis as opportunity."

In this phase of polarization, however, there is always an opportunity for doubt and questioning to lead to new and constructive solutions in coping with the crisis (Bertelsmann-Stiftung 2020).

The findings suggest that the older co-researchers were composed even more confident, in coping with the restrictions that arose from the pandemic situation. For example, although the co-researchers did express worries and concerns, these related less to their own well-being and more to the development of society during and after the pandemic. Thus, they were certainly concerned with the major issues, such as the denial of containment measures or complained with a vehemence about lack of solidarity. At the same time, they maintained a certain continuity in their way of life despite the pandemic from our point of view. In some cases, the co-researchers also seemed to enjoy retreat and silence and consciously emphasized positive aspects of the pandemic. 
The attitudes and expressions of the participants in the STARK-zine can be interpreted as a specific form of experiential and coping behavior. Findings from other studies in the COVID-19 pandemic support our observations about how older people cope with life's challenges. For example, an exploratory diary study of 776 people aged 19 to 91, Klaiber et al. (2021) drew attention to the fact that of all the groups, those over 60 were the least emotionally distressed. In contrast, younger study participants exhibited lower perceived coping efficacy in the presence of stressors during the first weeks of the COVID-19 pandemic (Klaiber et al. 2021). A study at the University of Georgia of 833 people over the age of 60 demonstrates similar findings. Here, the authors describe that in the 60- to 70-year-old age group, about $36 \%$ were stressed in the wake of the pandemic. Among those aged 71 and older, the rate was only $26 \%$. The research groups attributed these effects to life experience and the habitualized coping strategies of older people (Emerson 2020).

In April 2020, the research team led by Röhr et al. (Röhr et al. 2020) at the University of Leipzig also found that the 1.005 older people aged 65 to 94 participating in a standardized telephone survey showed little change in terms of mental and social health during the COVID-19 lockdown in Germany. Lang (et al. 2021) focused on similar issues in their "Corona and Age"-study on personal experiences, attitudes, concerns, and behaviors regarding COVID-19. A total of 7 online surveys of 2,200 people aged 18 to 95 took place between March and December 2020 (Lang et al. 2021). The research team notes that participants younger than 60 are becoming aware of the fragility of their own lives for the first time. The cohorts born from the 1960s onward had not yet experienced a crisis greater than this one. The fact that life brings threats is more an experience of older age. However, they can also learn to cope better with unexpected situations (Dörhöfer 2020).

This would indicate resilience to the pandemic situation while disproving common age-related stereotypes of weak and vulnerable older people (Röhr et al. 2020). Older people do not represent a homogeneous group and, accordingly, it is not possible to generalize about the experience and behavior of older people in the pandemic. However, the state of research to this point is incomplete.

\section{Conclusion}

The comments made by the co-researchers in the STARK-zine are not sufficient to allow general conclusions about the development of resilience among the older co-researchers with regard to coping with the pandemic.

The questionnaire for the zine was not originally developed with the intention of drawing conclusions about older people's experiences for a scientific publication. Rather, the focus was on using the zine to create a participatory format for exchange, interaction, and further collaboration in the STARK project. 
This reveals for us the specific potential of the approach. In addition to collecting data, the STARK project succeeded in testing and adapting an innovative research method using zines for participatory research. Moreover, the zine reflected the participatory moment of the research project, which not only enabled the heterogeneous group of co-researchers to participate from their different life situations, but also stimulated them in a creative way to reflect and to question their experiences and feelings. The STARK-zine can also be used to trace the development of older people from participants to co-researchers to contributors. Following this, each co-researcher was able to contribute according to his or her own expectations and personal resources, and was subsequently represented in the STARK-zine. It would be conceivable to increasingly use the zine as a method and to develop it further in the context of the participatory research paradigm. Zines can be used in creative and individual ways in participatory research projects. However, this would also require further development of analytical methods for analyzing both textual and visual content of zines. Thus, it should be considered that participatory creating a zine is time-consuming and that the development depends on people contributing.

\section{Notes}

1 The internationally established term "lockdown" can be used to describe cross-sectoral restrictions (e.g. restrictions on contact in the public and private spheres, business and school closing). The restrictions imposed in Germany in March 2020 had a lasting, drastic economic and social impact.

2 Data are based on a postal brief survey on the COVID-19 pandemic in June and July 2020 as part of the German Aging Survey (representative cross-sectional and longitudinal survey of persons in the second half of life, conducted since 1996).

3 Data basis is formed by the data collected since 2002 and most recently in 2017 from the German Ageing Survey (BMFSFJ 2020:62)

4 Data are based on a postal brief survey on the COVID-19 pandemic in June and July 2020 as part of the German Aging Survey (representative cross-sectional and longitudinal survey of persons in the second half of life, conducted since 1996) (DZA 2021:3)

5 No information is available about the co-researcher's age. She only stated that she was receiving a disability pension and had not yet reached the regular retirement age of 65 .

\section{References}

Amt für Statistik, Wahlen und demografische Stadtentwicklung, Statistisches Jahrbuch 2019 Landeshauptstadt Magdeburg. Statistical Yearbook 2019 Capital City Magdeburg, 2019.

Berlin-Institut für Bevölkerung und Entwicklung, Körber-Stiftung, "(Gem)einsame Stadt? Kommunen gegen soziale Isolation im Alter: Fakten, Trends und Empfehlungen für die Praxis von Berlin-Institut für Bevölkerung und Entwicklung und Körber-Stiftung,"; Vol. 2019, 2019. 
Bertelsmann-Stiftung, "Die Corona-Krise und Strategien der Bewältigung: Ergebnisse tiefenpsychologischer Interviews "The Corona Crisis and Strategies for Coping: Results of Depth Psychological Interviews"," 2020.

Brüsemeister, T., Qualitative Forschung. Ein Überblick "Qualitative Research. An overview", 2nd edn., VS Verlag für Sozialwissenschaften; GWV Fachverlage $\mathrm{GmbH}$, Wiesbaden, 2008.

Bühlmann, B., "Wir kümmern uns!: Caring Communities - was ist darunter zu verstehen? Und wie kann die Gemeinde die Sorgende Gemeinschaft stärken? Tagung "Sorgende Gemeinschaft" vom 11. Dezember 2020 in Schenkon "We care!": Caring Communities - what is meant by this? And how can the municipality strengthen the caring community?," 2020.

Bundesministerium für Familie, Senioren, Frauen und Jugend (BMFSFJ), "Achter Altersbericht zur Lage der älteren Generation in der Bundesrepublik Deutschland und Stellungnahme der Bundesregierung: Ältere Menschen und Digitalisierung "Eighth Ageing Report on the Situation of the Older Generation in the Federal Republic of Germany and Statement by the Federal Government. Older people and digitization"," 2020.

Bundesministerium für Familie, Senioren, Frauen und Jugend, "Frauen und Männer in der zweiten Lebenshälfte - Älterwerden im sozialen Wandel: "Women and men in the second half of life - aging in social change"," 2019.

Deutsches Zentrum für Altersfragen (DZA), "Einsamkeit steigt in der CoronaPandemie bei Menschen im mittleren und hohen Erwachsenenalter gleichermaßen deutlich: dza aktuell deutscher alterssurvey "Loneliness increases significantly in Corona pandemic among people in middle and older adulthood alike," No. 04, 2021.

Deutsches Zentrum für Altersfragen (DZA), "Internetnutzung von Menschen in der zweiten Lebenshälfte während der Corona-Pandemie: Soziale Ungleichheiten bleiben bestehen: "Internet use by people in the second half of life during the Corona pandemic: social inequalities remain"," No. 05, 2021.

Deutsches Zentrum für Altersfragen, "Altersdiskriminierung und Altersbilder in der Corona-Krise: "Ageism and Images of Aging in the Corona Crisis"," 2020.

Dietrich, M., and Mey, G., "Inszenierung von Jugend(lichkeit) und Generation(alität): Entwicklungspsychologische Perspektiven auf Szenen "Staging youth(lity) and generation(ality): developmental psychological perspectives on scenes"," Szenen, Artefakte und Inszenierungen, edited by JuBri-Forschungsverbund Techniken jugendlicher Bricolage, Springer Fachmedien Wiesbaden, Wiesbaden, 2018.

Dörhöfer, P., "Umgang mit Corona: "Ihr jungen Leute wisst doch gar nicht, was eine Krise bedeutet": Dealing with Corona: "You young guys don't even know what a crisis means," Frankfurter Rundschau [online], 13.10.2020, https://www. fr.de/wissen/coronavirus-umgang-generationen-alte-menschen-risikogruppefrankfurt-90067762.html, [retrieved 14 July 2021].

Emerson, K. G., "Coping with being cooped up: Social distancing during COVID-19 among $60+$ in the United States," Revista panamericana de salud publica $=$ Pan American journal of public health, published online 29 Jun. 2020; Vol. 44, 2020 , e81. doi: 10.26633/RPSP.2020.81.

Freitas, H., Oliveira, M., Jenkins, M., and Popjoy, O., "The Focus Group, a Qualitative Research Method: Reviewing The theory, and Providing Guidelines to Its Planning," ISRC Working Paper 010298, 1998. 
Gesundheitsförderung Schweiz, Gesundheit und Lebensqualität im Alter. Grundlagen für kantonale Aktionsprogramme "Gesundheitsförderung im Alter" "Health and quality of life in old age. Basis for cantonal action programs "Health promotion in old age"”, Gesundheitsförderung Schweiz, Bern, Lausannne, 2016.

Hakulinen, C., Pulkki-Råback, L., Virtanen, M., Jokela, M., Kivimäki, M., and Elovainio, M., "Social isolation and loneliness as risk factors for myocardial infarction, stroke and mortality: UK Biobank cohort study of 479054 men and women," Heart (British Cardiac Society); Vol. 104, No. 18, 2018, pp. 1536-1542. doi: 10.1136/heartjnl-2017-312663.

Hartung, S., Wihofszky, P., and Wright, M. T., eds., Partizipative Forschung. Ein Forschungsansatz für Gesundheit und seine Methoden Participatory Research. A research approach to health and its methods, Springer Fachmedien Wiesbaden, Wiesbaden, 2020.

Huxhold, O., and Otte, K., "Internetzugang und Internetnutzung in der zweiten Lebenshälfte: "Internet Access and Use in the Second Half of Life"," dza-aktuell: Deutscher Alterssurvey, No. 01, 2019.

Jacob, L., Haro, J. M., and Koyanagi, A., "Relationship between living alone and common mental disorders in the 1993, 2000 and 2007 National Psychiatric Morbidity Surveys," PloS one, published online 1 May. 2019; Vol. 14, No. 5, 2019, e0215182. doi: 10.1371/journal.pone.0215182.

Kessler, E.-M., and Gellert, P., "Öffentliche Kommunikation und Berichterstattung zu, Corona \& Alter': Empfehlungen der Deutschen Gesellschaft für Gerontologie und Geriatrie (DGGG), Sektion III (Sozial- und Verhaltenswissenschaftliche Gerontologie) (Stand 1. April 2020) "Public communication and reporting on 'Corona \& Age': Recommendations of the German Society of Gerontology and Geriatrics (DGGG), Section III (Social and Behavioral Gerontology).," 2020.

Klaiber, P., Wen, J. H., DeLongis, A., and Sin, N. L., "The Ups and Downs of Daily Life During COVID-19: Age Differences in Affect, Stress, and Positive Events," The journals of gerontology. Series B, Psychological sciences and social sciences; Vol. 76, No. 2, 2021, e30-e37. doi: 10.1093/geronb/gbaa096.

Köppen, M. von, Schmidt, K., and Tiefenthaler, S., "Mit vulnerablen Gruppen forschen - ein Forschungsprozessmodell als Reflexionshilfe für partizipative Projekte: "Doing research with vulnerable groups - a research process model as a reflection tool for participatory projects, "Participatory Research.,", Partizipative Forschung, edited by S. Hartung, et al., Springer Fachmedien Wiesbaden, Wiesbaden, 2020.

Künemund, C., and Kümpers, S., "Kommunale Partizipationsmöglichkeiten benachteiligter älterer Menschen im ländlichen Raum - das Beispiel des Forschungsprojektes "Age4Health - Gesunde Stadtteile für Ältere"," Soziale Innovationen: Alter(n) in ländlichen Räumen, edited by M. Alisch, et al., kassel university press $\mathrm{GmbH}$, Kassel, 2019.

Lang, F. R., Rupprecht, F., and Martin, K., "7. Newsletter zu unserer Corona-Begleitstudie: Angst vor COVID-19 nimmt wieder zu "7th newsletter on our Corona monitoring study: fear of COVID-19 is on the rise again"," [online], 2021, https://www.geronto.fau.de/forschung/alternsbilder/COVID-19-studie/, [retrieved 14 July 2021].

Luhmann, M., and Hawkley, L. C., "Age Differences in Loneliness from Late Adolescence in Oldest Old Age," Developmental psychology, No. 2016. 
Mayring, P., and Fenzl, T., "Qualitative Inhaltsanalyse: "Qualitative Content Analysis"," Handbuch Methoden der empirischen Sozialforschung, edited by N. Baur and J. Blasius, Springer Fachmedien Wiesbaden, Wiesbaden, 2019, pp. 633-648.

Rafnsson, S. B., Orrell, M., d'Orsi, E., Hogervorst, E., and Steptoe, A., "Loneliness, Social Integration, and Incident Dementia Over 6 Years: Prospective Findings From the English Longitudinal Study of Ageing," The journals of gerontology. Series B, Psychological sciences and social sciences; Vol. 75, No. 1, 2020, pp. 114 124. doi: 10.1093/geronb/gbx087.

Robert Koch-Institut, (2020a) "Die Pandemie in Deutschland in den nächsten Monaten - Ziele, Schwerpunktthemen und Instrumente für den Infektionsschutz: Strategie-Ergänzung "The Pandemic in Germany in the Coming Months Targets, Focus Areas, and Tools for Infection Control: Strategy Supplement"," 23.10.2020, https://www.rki.de/DE/Content/InfAZ/N/Neuartiges_Coronavirus/ Strategie_Ergaenzung_Covid.html.

Robert Koch-Institut, (2020b) "Informationen und Hilfestellungen für Personen mit einem höheren Risiko für einen schweren COVID-19-Krankheitsverlauf," https://www.rki.de/DE/Content/InfAZ/N/Neuartiges_Coronavirus/Risiko gruppen.html.

Röhr, S., Reiningshaus, U., and Riedel-Heller, S. G., "Mental and social health in the German old age population largely unaltered during COVID-19 lockdown: results of a representative survey," 2020.

Schmidt, C., "Wie Zeitschriften, nur anders! Fanziness als Medien der Bricolage*: "Like magazines, only different! Fanziness as Media of Bricolage*"," Szenen, Artefakte und Inszenierungen, edited by JuBri-Forschungsverbund Techniken jugendlicher Bricolage, Springer Fachmedien Wiesbaden, Wiesbaden, 2018.

Scott, G. M., and Garner, R., Doing qualitative research. Designs, methods, and techniques, 1st edn., Pearson Education, Boston [etc.], 2013.

Sülzle, A., "Forschen mit Fanzines: "Research with fanzines"," Szenen, Artefakte und Inszenierungen, edited by JuBri-Forschungsverbund Techniken jugendlicher Bricolage, Springer Fachmedien Wiesbaden, Wiesbaden, 2018.

Unger, H. von, Partizipative Forschung. Einführung in die Forschungspraxis "Participatory Research. Introduction to research practice", Springer VS, Wiesbaden, 2014.

United Nations Economic Commission for Europe, "Integration und Teilhabe älterer Menschen in der Gesellschaft: UNECE Kurzdossier zum Thema Altern "Integration and participation of older people in society: UNECE policy brief on ageing"," UNECE United Nations Economic Commission for Europe, No. 4, 2010.

Urban, U., "Demokratiebaustein: Partizipation: "Democracy module: Participation,"; BLK program "Learning \& Living Democracy","; BLK-Programm "Demokratie lernen \& leben", 2005, pp. 1-6.

Wright, M. T., Unger, H. von, and Block, M., "Partizipation der Zielgruppe in der Gesundheitsförderung und Prävention: "Participation of the target group in health promotion and prevention," Participatory quality development in health promotion and prevention," Partizipative Qualitätsentwicklung in der Gesundheitsförderung und Prävention, edited by M. T. Wright, 1st ed., Verlag Hans Huber, Hogrefe AG, Bern, 2010. 


\title{
13 The experience of loneliness in older adults during the COVID-19 pandemic
}

\author{
A Polish perspective
}

Ewa Grudziewska

The COVID-19 pandemic made us think more and see the consequences it has for the older adults, especially those living in nursing homes. Isolation and a sense of loneliness have become part of the everyday life of this social group. This text aims to show what factors influence the sense of loneliness of older adults experiencing isolation due to the restrictions caused by the SARS-CoV-2 pandemic. An attempt was made to indicate possible actions in this area, for example by pointing to the use of new technologies, which may significantly contribute to limiting the negative effects of the pandemic on social life. It should be borne in mind that the presented research concerns Polish older adults, however, the COVID-19 pandemic has had its irreversible impact on the lives of people all over the world, both young people and, above all, older adults.

\section{Introduction}

I recently read in a magazine that older adults are dying today not only as a result of COVID-19, but also due to fear, despair and loneliness. For many people, ageing is a difficult stage of life, and now one must additionally face feelings of endangerment and loneliness which are a certain type of borderline experience, especially in times of isolation. At times, a lack of support may lead to death. In recent times, increasingly more studies and analyses whose aim is to demonstrate the way in which the pandemic has impacted people's lives have emerged. For the purposes of this research, the way in which Polish older adults cope in the era of COVID-19 was important. Do they feel lonely? What are the determining factors of their sense of loneliness?

At the beginning of November 2020, the Seniors' Congress took place at the Maria Grzegorzewska University in Warsaw, a cyclical event whose main objective is to show how contemporary older adults' lives, the difficulties they struggle with, and also to present the initiatives which are intended 
to activate older adults. As a participant, I had the opportunity to "meet with" older adults online as the organizers were forced to do so as a result of the COVID-19 restrictions. I was greatly impressed by the older adults who actively took part in the Congress by sharing their thoughts on the current situation. It was shocking that the majority of these people coped with isolation well, showing that even in one's own home, or in a social assistance home, it is possible to actively spend time and not give up. One of the older adults, Stenia (91 years), who was a participant in the Warsaw Uprising (as a nurse), compared the current situation to the occupation of Poland during the Second World War. The conclusion of her speech was that we cannot lose hope or cheerfulness in any of these situations, that we should find joy in the smallest of things, whether this be a phone call from a scout helping older adults, delivering a warm meal or going shopping. Strength for the times of isolation that lie ahead can and should be drawn from this short conversation. Certainly, the challenge faced by people working with older adults is the large-scale use of new technologies in order to counteract social isolation and the feeling of loneliness, especially among older adults living in nursing homes (Cosco et al. 2021).

\section{Old age and loneliness, must they go hand in hand?}

A survey conducted by the National Institute of Seniors (Krajowy Instytut Gospodarki Senioralnej) in August 2020 revealed that one of the most frequent problems that older adults indicated throughout the COVID-19 pandemic was limited access to medical care (including specialists), a lack of reliable information about SARS-CoV-2, and feelings of loneliness (Health of Polish seniors during the pandemic, 2020).

Both old age and feelings of solitude are rarely mentioned in daily conversations, and this includes representatives of academic disciplines dealing with these issues. It is more frequently possible to find studies that create an image of active older adults, who manage themselves well with daily activities, have many passions and interests, who develop due to having more free time, meet with friends, take part in various initiatives organized in their place of residence and travel. It should be kept in mind that there are also older adults who struggle with several illnesses that complicate their daily lives, require assistance and support, and who experience intense solitude or even loneliness (Fopka-Kowalczyk \& Krajnik 2019).

The need for social interaction is part of human nature. Loneliness can affect anyone regardless of age or social position. It is a universal, timeless, ahistorical phenomenon and constitutes a specific sign of our times. Longterm loneliness that is not the result of our own decision may result in a depressed mood, depression, physical illnesses and a reduction in quality of life. Aside from their negative impact on well-being, loneliness and social isolation have a significant detrimental effect on the mental and physical health of older adults (Steptoe et al. 2013). The outbreak of COVID-19 has 
contributed to the loneliness of older adults who have already been affected by this problem to a great extent.

In terms of definition, loneliness and solitude are used interchangeably (De Jong Gierveld et al. 2006; Grenade \& Boldy 2008). In gerontological literature, these terms are defined as separate concepts. Thus, loneliness is "a state resulting from one's own choice and consists in spending time only with oneself," while solitude

results from an underdeveloped inner world, lack of order in which we create for ourselves a rhythm of existence different from that of the external world, other ways of measuring values and in which we are free of defeat, humiliation, triumph(...)It is a world free of suffering caused by others.

(Szczepański 1984)

It can be said that loneliness is searching for oneself, the ability to concentrate on one's inner world, and a certain type of indifference to the world. Loneliness gives a person distance, readiness to retreat and a sense of internal self-sufficiency, however, in the case of solitude, people do not find help in others and in their own inner world.

Dołęga differentiates three types of loneliness: (i) social loneliness (physical, objective), which is characterized by a lack of social bonds or belonging to a community, experiencing isolation and marginalization, a sense of being ignored or unneeded, or being unsatisfied with one's social relationships; (ii) emotional loneliness (subjective) that manifests itself in a deficit of positive emotions and relationships with significant others, and also a sense of lacking close and satisfying emotional bonds, often related with a negative self-image as a partner in social relations; and (iii), existential loneliness, which is characterized by the lack of identification with generally accepted values, life goals and norms, and also not being anchored in the world and not accepting and agreeing with a specific image of the world (Dołęga 2006; Sendyk 2011).

The Association of the Little Brothers of the Poor conducted a survey in 2018 which revealed that three in ten Poles aged 80 or older mentioned experiencing loneliness, however one in ten stated that they feel lonely very often, if not always. In the group of $80+$ older adults, half of them lived alone, $30 \%$ reported feeling lonely, 30\% did not attend social functions, $20 \%$ did not have anyone to spend their free time with, and $10 \%$ of the surveyed older adults did not have anyone they could speak with about daily life (Social situation of people aged $65+, 2020$ ). The determining factors of loneliness in older adults may include:

- cultural factors associated with e.g., changing one's place of residence (in a care and treatment facility or in a social assistance home) as the result of a deterioration in health, therefore, older adults must change their habits and adjust to the prevailing daily rhythm and habits; 
- a lonely lifestyle, which is mainly a feature of residents of large cities;

- the loss of a close relative (widowhood) - this type of loneliness impacts solitude, and may also be the cause of depression or the deterioration of one's physical condition. Older adults approach death in a different way than young people, as in a certain sense, they are closer to it, because their family members, friends and neighbours are passing away;

- awareness of the inevitability of death - it can be said that the more older adults find themselves at the end of their lives, the more they may experience feelings of loneliness and solitude. A change in temporal perspective can also be observed in older adults, i.e., concentrating on the past and present, but without a future perspective (Dąbrowska 2011: 84-90);

- the manner old age is treated in society, social reception and stereotypes;

- having a family does not prevent feelings of solitude, although it may serve as a factor that minimizes its experience (Janiszewska \& Barańska 2013).

In his analyses, Klimowicz presented the following three types of loneliness, making their occurrence dependent on their source causing them: (a) interpersonal loneliness - "longing for" caused by death or departure of close people, (b) social loneliness - triggered by isolation from or rejection by one's environment, (c) cultural loneliness - evoked by a feeling of being different in the context of functioning in a group, (d) cosmic loneliness - being "beyond" the meaning, experience of hopelessness and meaninglessness of life, (e) psychological loneliness - experiencing alienation from one's own "self." This differentiation seems to be particularly relevant when we attempt to relate it to the experience of older people. All of the categories may be attributed to the experiences of older people (Klimowicz 1988).

A consequence of isolation caused by the COVID-19 restrictions is a prolonged uncertainty about the future, a very high level of stress, hopelessness, anxiety mixed with a sense of being overwhelmed, as well as helplessness. This experience makes it difficult to cope without the assistance of one's environment. Therefore, it is important not to leave older adults alone as loneliness narrows one's field of view. This causes that attention is directed towards a person's deficits, e.g., physical illness, difficulties moving around, etc. The impact of COVID-19-related insulation is confirmed, among others, by studies by Tomaz et al. (2021) that loneliness during lockdown was higher than reported norms for this age group before the pandemic. A larger social network, more social contact, and better perceived social support seemed to be protective against loneliness and poor wellbeing. Moreover $\mathrm{Wu}$ analyzed the impact of SARS-CoV-2 isolation on the older adults and the possibility of helping maintain social relationships using technology (Wu 2020).

\section{The author's own research}

Ethical approval for this study was obtained from the informed consent and was given on the first page of the online survey or orally by telephone for 
the phone version. All participants provided consent for their participation. This study adheres to the guidelines described in the Declaration of Helsinki Ethical Principles for Medical Research Involving Human Subjects (WMA - The World Medical Association 2020). Sixty older adults took part in the study, whose number of samples was to a large extent conditioned by the COVID-19 restrictions. The average age of the participants was 76 - the youngest was 61, and the oldest, 91. Analyzing the gender of the surveyed older adults, $66.7 \%$ were women, while $33.3 \%$ were men. The largest group of participants in terms of place of residence consisted of older adults from cities with a population of more than 500,000 inhabitants $(61.7 \%)$, while the smallest group was made up of people living in cities of from 50,000 to 150,000 people $(5 \%)$. In terms of marital status, $63.3 \%$ of the surveyed older adults were widows or widowers, and only three participants were divorced (5\%). The older adults were also asked if they had children, which from the point of view of the analyzed variable, was significant. Of the surveyed older adults, $83.3 \%$ maintain contact with their children, while $16.7 \%$ did not. As far as level of education is concerned, the largest group of participants was made up of people with secondary education $(41.7 \%), 31.7 \%$ of the respondents had vocational education, $10 \%$ completed elementary education, while $16.7 \%$ possessed higher education. From among the surveyed older adults, $13.3 \%$ were professionally active, and combined their employment with retirement benefits $(11.7 \%)$ or disability allowances $(1.7 \%)$. The largest group constitutes older adults whose main source of income was retirement benefits alone $(81.7 \%)$ (Table 13.1).

For the purposes of collecting the empirical materials, the Revised Loneliness Scale (R-ULCA) adapted by Kwiatkowska et al. (2017) was used. The R-UCLA includes 20 items reflecting satisfaction or dissatisfaction with social relations, half of them being formulated positively. In previous analyses (Russell et al. 1980), each of the items had a discriminating power higher than 0.40 , and, as in the case of the previous and further version, the reliability was perfect $(\alpha=0.94)$. Originally developed as a unidimensional measure, recent research suggests more complex interpretation possibilities, i.e., treating the loneliness as a construct established through two or the three distinct factors (Austin 1983; Hawkley et al. 2005; Wilson et al. 1992). B.A. Austin (1983) proposed that the loneliness can be defined not by two, but by three factors. These three factors of loneliness can be described as follows: (1) Intimate Others, which refers to solitude, rejection, withdrawal, feeling of exclusion and the breaking of social relations with other people, it is related to the unpleasant feeling of solitary confinement and being alone in the literal meaning of the word; (2) Social Others, which refers to not having a social network to connect with and lack of the feeling of closeness in relation with other people (in terms of their availability), it refers to the lack of contact with close relatives or trusted people who form a sense of safety and support; and (3) Belonging and Affiliation, which refers to a lack of a sense of group identity (affiliation) and bonds with a community, it refers to 
Table 13.1 The features of the surveyed older adults

\begin{tabular}{|c|c|c|c|}
\hline & & $N$ & $\%$ \\
\hline \multirow[t]{2}{*}{ Sex } & Women & 40 & 66.7 \\
\hline & Men & 20 & 33.3 \\
\hline \multirow[t]{4}{*}{ Place of residence } & Village & 9 & 15.0 \\
\hline & City up to 50,000 people & 11 & 18.3 \\
\hline & City of from 50 to 150,000 people & 3 & 5.0 \\
\hline & City over 500,000 people & 37 & 61.7 \\
\hline \multirow[t]{4}{*}{ Marital status } & Miss/bachelor & 3 & 5.0 \\
\hline & Married & 16 & 26.7 \\
\hline & Widow & 38 & 63.3 \\
\hline & Divorce & 3 & 5.0 \\
\hline \multirow[t]{2}{*}{ Maintain contact with children } & Yes & 50 & 83.3 \\
\hline & No & 10 & 16.7 \\
\hline \multirow[t]{4}{*}{ Education } & Primary & 6 & 10.0 \\
\hline & Vocational & 19 & 31.7 \\
\hline & Secondary & 25 & 41.7 \\
\hline & Higher & 10 & 16.7 \\
\hline \multirow[t]{2}{*}{ Professional situation } & Professionally active & 8 & 13.3 \\
\hline & Professionally inactive & 52 & 86.7 \\
\hline \multirow[t]{5}{*}{ Surveyed } & Retirement benefits & 1 & 1.7 \\
\hline & Retirement benefits & 49 & 81.7 \\
\hline & Disability allowances & 2 & 3.3 \\
\hline & $\begin{array}{l}\text { Employment with retirement } \\
\text { benefits }\end{array}$ & 7 & 11.7 \\
\hline & $\begin{array}{l}\text { Employment with disability } \\
\text { allowances }\end{array}$ & 1 & 1.7 \\
\hline
\end{tabular}

the weaker links with a social group and feeling more like an individual than a part of a group (Austin 1983; Hawkley et al. 2005).

The obtained results of the study were analyzed statistically. The values of the analyzed measurable parameters were represented by the average value and standard deviation, while the unmeasurable parameters were represented by numbers and percentage. The independent student's t-test was applied investigating the differences between the two groups. The Pearson's correlation coefficient and linear regression were used to verify the dependencies between the variables. The statistical significance was $p<0.05$. The database and statistical test were conducted in the SPSS 27.0 package.

\section{Results}

At the outset, it was decided to determine the general average result for loneliness and its dimensions. Detailed results are presented in Table 13.2.

The conducted analyses revealed that in the Intimate Others scale, the minimum score was 10 points, the maximum score was 35 points, while the average score amounted to $\mathrm{M}=22.83$. In terms of Social Others, the minimum score was 5 points, the maximum score was 17 points, and the average 
Table 13.2 Loneliness: descriptive statistics

\begin{tabular}{lrrrr}
\hline & \multicolumn{1}{c}{$M$} & \multicolumn{1}{c}{ SD } & \multicolumn{1}{c}{ Min } & Max \\
\hline Intimate Others & 22.83 & 5.82 & 10.00 & 35.00 \\
Social Others & 8.77 & 3.49 & 5.00 & 17.00 \\
Belonging and Affiliation & 10.98 & 3.38 & 6.00 & 21.00 \\
Loneliness & 42.58 & 11.18 & 21.00 & 67.00 \\
\hline
\end{tabular}

Table 13.3 Gender and loneliness in the surveyed older adults

\begin{tabular}{|c|c|c|c|c|c|c|}
\hline & \multicolumn{2}{|c|}{ Women } & \multicolumn{2}{|l|}{ Men } & \multirow[t]{2}{*}{$t$} & \multirow[t]{2}{*}{$P$} \\
\hline & $M$ & $S D$ & $M$ & $S D$ & & \\
\hline Intimate Others & 22.80 & 6.29 & 22.90 & 4.91 & -0.062 & 0.951 \\
\hline Social Others & 8.72 & 3.20 & 8.85 & 4.09 & -0.130 & 0.897 \\
\hline $\begin{array}{l}\text { Belonging and } \\
\text { Affiliation }\end{array}$ & 10.95 & 3.21 & 11.05 & 3.79 & -0.107 & 0.915 \\
\hline Loneliness & 42.47 & 11.16 & 42.80 & 11.50 & -0.105 & 0.917 \\
\hline
\end{tabular}

score amounted to $\mathrm{M}=8.77$. As far as Belonging and Affiliation is concerned, the minimum scare was 6 points, the maximum score was 31 points, while the average score amounted to $\mathrm{M}=10.98$. In terms of Loneliness, the minimum score amounted to 21 points, the maximum score was 67 points, and the average score was $\mathrm{M}=42.58$.

The next step in the conducted analyses was to determine if the surveyed older adults' gender differentiated their sense of loneliness. The analyses conducted by using the (independent) student's t-test revealed that this sociodemographic variable does not statistically significantly differentiate loneliness. It can be observed that a slightly higher average score was obtained by the surveyed men in all three of the analysed dimensions, i.e., Intimate Others, Social Others and Belonging and Affiliation, as well as in Loneliness. Detailed data is presented in Table 13.3.

It was then decided to verify if the age of the surveyed older adults significantly differentiates their sense of loneliness. As a result, as a dividing point for comparing the groups, the average age of 76 was adopted. The group of people under 76 consisted of 29 older adults, while 31 people were found in the 76+ group. Detailed results are presented in Table 13.4.

The independent student's t-test revealed statistically significant differences between the compared groups of older adults in terms of age. The conducted analysis revealed that people aged 76 and older $(M=25.71)$ experience Intimate Others to a greater extent than participants under $76(\mathrm{M}=19.76$; $\mathrm{p}<0.000)$. As far as Social Others is concerned, significant differences between the compared groups of older adults were also observed. It turns out 
Table 13.4 Age and loneliness in the surveyed older adults

\begin{tabular}{lrrrrrr}
\hline & Up to 76 years & \multicolumn{1}{c}{$\begin{array}{l}76 \text { years and } \\
\text { more }\end{array}$} & $t$ & $P$ \\
\cline { 1 - 5 } & $M$ & $S D$ & \multicolumn{1}{c}{$M$} & $S D$ & & \\
\hline Intimate Others & 19.76 & 3.86 & 25.71 & 5.92 & -4.576 & $0.000^{*}$ \\
Social Others & 7.59 & 3.04 & 9.87 & 3.57 & -2.661 & $0.010^{*}$ \\
Belonging and Affiliation & 10.07 & 3.16 & 11.83 & 3.41 & -2.082 & $0.042^{*}$ \\
Loneliness & 37.41 & 8.51 & 47.42 & 11.32 & -3.849 & $0.000^{*}$ \\
\hline
\end{tabular}

** Significant at 0.01

*Significant at 0.05

Table 13.5 Maintaining contact with children and loneliness in the surveyed older adults

\begin{tabular}{|c|c|c|c|c|c|c|}
\hline & \multicolumn{2}{|c|}{$\begin{array}{l}\text { Contact with } \\
\text { children }\end{array}$} & \multicolumn{2}{|c|}{$\begin{array}{l}\text { Not contact } \\
\text { with children }\end{array}$} & \multirow[t]{2}{*}{$t$} & \multirow[t]{2}{*}{$P$} \\
\hline & $M$ & $S D$ & $M$ & $S D$ & & \\
\hline Intimate Others & 22.06 & 5.84 & 26.70 & 4.11 & -2.391 & $0.020^{*}$ \\
\hline Social Others & 8.24 & 3.22 & 11.40 & 3.75 & -2.756 & $0.008 *$ \\
\hline Belonging and Affiliation & 10.64 & 3.33 & 12.70 & 3.27 & -1.791 & 0.079 \\
\hline Loneliness & 40.94 & 10.82 & 50.80 & 9.58 & -2.676 & $0.010^{*}$ \\
\hline
\end{tabular}

*Significant at 0.05

that older adults aged 76 and older experience Social Others to a greater extent $(M=9.87)$ than people under 76 years of age $(M=7.59 ; p<0.010)$. A complete or partial lack of Belonging and Affiliation is more frequently a feature of older adults aged 76 and older $(M=11.83)$, and the conducted analyses revealed statistically significant differences $(p<0.042)$. In terms of Loneliness, the difference is also significant, in which a higher intensity of this variable is present in older adults from $76+$ group $(p<0.000)$. Similar results were obtained in research conducted by Nowicki et al. (2018), in which it turned out that the older a person is, the higher the sense of loneliness.

Next, it was decided to verify whether maintaining contact with children differentiates the surveyed older adults' sense of loneliness during the COVID-19 pandemic. Therefore, the independent student's t-test was applied. The conducted statistically analyses showed differences in the surveyed group of older adults in relation to two scales. Detailed data is presented in Table 13.5.

The obtained results should not come as a surprise, because, as it turns out significantly higher average scores are characteristic of the surveyed older adults who do not maintain contact with their children. In terms of Intimate Others, the difference is significant at the level of $p<0.020$, however, in Social Others $\mathrm{p}<0.008$. Significant differences were not noted in 
Table 13.6 Loneliness and age, gender and contact with children: correlations

\begin{tabular}{llll}
\hline & Sex & Age & Contact with children \\
\hline Intimate Others & - & $0.515^{*}$ & $0.299^{* *}$ \\
Social Others & - & $0.330^{* *}$ & $0.340^{*}$ \\
Belonging and Affiliation & - & $0.264^{* *}$ & - \\
Loneliness & - & $0.451^{*}$ & $0.331^{* *}$ \\
\hline
\end{tabular}

* Correlation is significant at the 0.01 level (2-tailed).

** Correlation is significant at the 0.05 level (2-tailed).

- Correlation is not significant.

Table 13.7 Regression results

\begin{tabular}{|c|c|c|c|c|c|}
\hline & $\begin{array}{l}\text { Dependent } \\
\text { variable }\end{array}$ & $\begin{array}{l}\text { Intimate } \\
\text { others }\end{array}$ & $\begin{array}{l}\text { Social } \\
\text { others }\end{array}$ & $\begin{array}{l}\text { Belonging } \\
\text { and } \\
\text { affiliation }\end{array}$ & Loneliness \\
\hline & $\begin{array}{l}\text { Independent } \\
\text { variables }\end{array}$ & $\beta$ & $B$ & $\beta$ & $\beta$ \\
\hline Sex & & - & - & - & - \\
\hline Age & & $0.518^{*}$ & $0.317 * *$ & - & $0.447 *$ \\
\hline $\begin{array}{l}\text { Contact with } \\
\text { children }\end{array}$ & & $0.246^{* *}$ & $0.310^{* *}$ & - & $0.286^{* *}$ \\
\hline$N(\mathrm{df})$ & & 56 & 56 & 56 & 56 \\
\hline $\mathrm{R}^{2}$ & & 0.341 & 0.211 & 0.115 & 0.298 \\
\hline
\end{tabular}

* Significant at 0.01 .

** Significant at 0.05 .

- Not significant.

Belonging and Affiliation. Maintaining contact with children significantly differentiated Loneliness $(\mathrm{p}<0.010)$.

It was also decided to verify, by means of the Pearson's correlation coefficient, which sociodemographic variables correlate with the sense in loneliness of the surveyed older adults. The obtained results (Table 13.6) show that the age of the surveyed older adults reveal significant correlations between all of the dimensions of loneliness and the global sense of loneliness. On the other hand, no correlations were found between any of the analysed dimensions of loneliness, however, maintaining contact with children significantly correlates with Intimate Others, Social Others, and Loneliness.

Finally, it was verified whether the analysed sociodemographic variables create models with loneliness and its dimensions. Therefore, the regression analysis was applied (Table 13.7). The obtained results showed that both age and maintaining contact with children are predictors of loneliness in 
older adults. The variables in the model explain $30 \%$ of the variances for Loneliness, $21 \%$ of variances for Social Others and $34 \%$ of the variances for Intimate Others. The most significant predictor of Loneliness is the age of the surveyed older adults $(\beta=0.447)$, as in the case of Intimate Others $(\beta=0.518)$ and Social Others $(\beta=0.317)$.

\section{For further discussions...}

The conducted analyses showed that older adults are characterized by a low level of loneliness both in the global dimensions and in terms of Intimate Others, Social Others and Belonging and Affiliation, which revealed the averages for the surveyed sample. Looking at the differences in terms of loneliness in relation to the sociodemographic variables such as age, gender or contact with children, it was observed that gender does not determine loneliness in older adults. However, the intensity of loneliness and its dimension increases with age, which is consistent with research carried out in this age group, i.e., people $60+$, confirmed by studies conducted by Perissinotto et al. (2012) and Singh and Misra (2009). Maintaining contact with close relatives (children) also significantly contributes to loneliness in older adults. These dependencies were confirmed by the Pearson's correlation coefficient and the linear regression analysis. Of course, these findings may be interpreted in relation to this specific sample and not to the entire population of older adults, however, this is certainly a trend that should be verified in a larger number of participants. How can loneliness and solitude be prevented in older adults lives? In terms of the consequences of isolation caused by COVID-19, it is obvious that all age groups have been negatively affected. Is it possible to avoid this type of effects both in terms of physical, but above all, mental health? With all certainty, a brief telephone conversation with close friends and relatives (children, grandchildren, friends, or acquaintances) would be a "medicine" for many people, after all, daily conversations are a very important elements of our lives. Mobile phones with video functions, computers with Internet access are available (provided that one is able to operate them, although increasingly more older adults are perfectly able to manage themselves with new technologies). In the absence of close friends or relatives, assistance is provided by non-governmental organizations or special hotlines, e.g. The National Helpline for Older adults operating under the auspices of the Association of the Little Brothers of the Poor.

In Poland, a series of activities have been introduced in response to the implemented restrictions, which are aimed at supporting older adults in their daily functioning, e.g., delivering warm meals, shopping, buying medication. These activities are carried out by social assistance centres and non-governmental organizations. At the governmental level, the Solidarity Assistance Corps for Seniors has been established, thanks to which Polish older adults can receive necessary help throughout the pandemic. Within the framework of support, volunteers may assist with shopping, taking dogs for a walk, housework, or dealing with official matters, and perhaps most 
importantly, simply speaking with older adults. The need to have conversations with others may be the impulse for acquiring knowledge and new skills by people who have not had the need to use new technology.

\section{References}

Austin, B.A. (1983). Factorial Structure of the UCLA Loneliness Scale. Psychological Reports, 53, 883-889. DOI: 10.2466/pr0.1983.53.3.883.

Cosco, T., Fortuna, K., Wister, A., Riadi, I., Wagner, K., \& Sixsmith, A. (2021). COVID-19, Social Isolation, and Mental Health Among Older Adults: A Digital Catch-22. Journal of Medical Internet Research, 23(5), e21864. DOI: 10. 2196/21864.

Dąbrowska, P. (2011). Samotność osób starszych i sposoby jej przeciwdziałania. Kwartalnik Naukowy, 6(2), 84-90.

De Jong Gierveld, J., van Tilburg, T.G., \& Dykstra, P.A. (2006). Loneliness and social isolation. In D. Perlman \& A. Vangelisti (Eds.), The Cambridge handbook of personal relationships (pp. 485-500). Cambridge, UK: Cambridge University Press.

Dołęga, Z. (2006). Samotność młodzieży - analiza teoretyczna i studia empiryczne. Katowice: Wydawnictwo Uniwersytetu Śląskiego.

Fopka-Kowalczyk, M., \& Krajnik, M. (2019). Expectations and self-care of family members in palliative care. The analysis of needs and workshop plan. Educational Studies Review, 29(2), 91-110.

Grenade, L., \& Boldy, D. (2008). Social isolation and loneliness among older people: Issues and future challenges in community and residential settings. Australian Health Review, 32(3), 468-478.

Hawkley, L.C., Browne, M.W., \& Cacioppo, J.T. (2005). How can I connect with thee?: Let me count the ways. Psychological Science, 16, 798-804. DOI: 10.1111/j.1467-9280.2005.01617.x

Janiszewska, M., \& Barańska, A. (Eds.) (2013). Samotność i osamotnienie osób starszych wiekiem. W: J. Zimny (red.). Samotność: rzeczywistość czy fikcja. Stalowa Wola: Wyd. KUL.

Klimowicz, G. (1988). Przeciwko bezradnejsamotności. Warszawa: Nasza Księgarnia.

Kwiatkowska, M.M., Rogoza, R., \& Kwiatkowska, K. (2017). Analysis of the psychometric properties of the Revised UCLA Loneliness Scale in the Polish adolescent sample. Current Issues in Personality Psychology, 5, 1-7. DOI: 10.5114/ cipp.2017.69681

Perissinotto, C.M., Cenzer, I.S., \& Covinsky, K.E. (2012). Loneliness in older persons: A predictor of functional decline and death. Archives of Internal Medicine, 172(14), 1078-1083.

Russell, D.W., Peplau, L.A., \& Cutrona, C.E. (1980). The revised UCLA loneliness scale: Concurrent and discriminant validity evidence. Journal of Personality and Social Psychology, 39, 472-480. DOI: 10.1037/0022-3514.39.3.472

Sendyk, M. (2011). Osamotnienie jako konsekwencje zaburzeń więzi emocjonalnych w rodzinie. Wychowanie w Rodzinie, 4, 139-150.

Singh, A., \& Misra, N. (2009). Loneliness, Depression and sociability in old age. Industrial Psychiatry Journal, 18(1), 51-55.

Social situation of people aged $65+-$ wyniki badania zrealizowanego dla Stowarzyszenia mali bracia Ubogich przez ARC Rynek i Opinia, https://www. malibracia.org.pl/aktualnosci/samotnosc-polskiego-seniora/ (access: 12.12.2020). 


\section{Ewa Grudziewska}

Steptoe, A., Shankar, A., Demakakos, P., \& Wardle, J. (2013). Social isolation, loneliness, and all-cause mortality in older men and women. Proceedings of the $\mathrm{Na}$ tional Academy of Sciences of the United States of America, 110(15), 5797-5801.

Szczepański, J. (1984). Sprawy ludzkie. Warszawa: Wydawnictwo Czytelnik.

Tomaz, S.A., Coffee, P., Ryde, G.C., Swales, B., Neely, K.C., Connelly, J., Kirkland, A., McCabe, L., Watchman, K., Andreis, F. et al. (2021). Loneliness, wellbeing, and social activity in scottish older adults resulting from social distancing during the COVID-19 pandemic. International Journal of Environmental Research and Public Health, 18, 4517.

Wilson, D., Cutts, J., Lees, I., Mapungwana, S., \& Maunganidze, L. (1992). Psychometric properties of the Revised UCLA Loneliness Scale and two short-form measures of loneliness in Zimbabwe. Journal of Personality Assessment, 59, 72-81. DOI: 10.1207/s15327752jpa5901_7

WMA - The World Medical Association. WMA Declaration of Helsinki-Ethical PrinciplesforMedicalResearchInvolvingHumanSubjects. Availableonline:https:// www.wma.net/policies-post/wma-declaration-of-helsinki-ethical-principlesfor-m edical-research-involving-human-subjects/ (access: 9.01. 2021).

$\mathrm{Wu}, \mathrm{B}$. (2020). Social isolation and loneliness among older adults in the context of COVID-19: a global challenge. Glob Health Res Policy 5, 27. DOI: https://doi. org/10.1186/s41256-020-00154-3

Zdrowie polskich seniorów w czasie pandemii. Krajowy Instytut Gospodarki Senioralnej, Warszawa 16.09.2020 - https://kigs.org.pl/wp-content/uploads/2020/09/ 20200902_Raport_Zdrowie-w-pandemii-002.pdf (access: 6.01.2021). 


\title{
14 Older adults' religiosity during the COVID-19 pandemic
}

\author{
Catholic Church in action
}

\author{
Bolestaw Karcz
}

Diseases of all kinds, especially contagious ones that destroyed societies, mobilized the Church community to help. This is what happened in the present situation. The Church has not forgotten her faithful; he met them in a difficult social situation. The pandemic changed the possibility of religious engagement, both personal and family and social, of seniors. They were not able to participate directly in the Holy Mass, receive Communion and other sacraments. They also had to change the routines of spiritual and religious life. Virtual reality had to replace the real one, but the Catholic Church has always tried to stay close to society. The ministry had to be implemented in a virtual formula. Nevertheless, various ideas for pastoral care in a pandemic situation on the part of the Church were used. The activity of the Catholic Church has become the basis for the implementation of the new evangelization based on virtual activity, and the Church has joined in this narrative and activity within the framework of the propagated social principles of the Church: the principles of the common good, the principles of solidarity and subsidiarity. This chapter presents the activities of the Catholic Church in the face of the COVID-19 pandemic and spiritual help for the elderly at risk of this virus.

\section{Religiousness of older adults}

On the basis of social cohesion research, the Central Statistical Office developed an indicator of religious commitment based on declarations regarding attitudes, activity, religious beliefs, as well as the sense of belonging to a religion or religious institutions. It was about the sense of belonging to the Church, community or religious organization, manifested in membership and shared responsibility, as well as devoting time to community work within this community and the frequency of performing this work; attendance at events or activities organized by that organization, community (and the frequency with which it occurs); membership of the Church or religious 
association. The self-declaration of faith was also taken into account attitude to religious faith, religious practices assessed as the frequency of participation in holy masses, services or religious meetings, the frequency of prayers, sense of connection with a parish, church, local church, own religious community, and finally the importance of religious faith as a value in life. The older adults are clearly characterized by the highest level of religiosity. This mainly affects people aged 75 and over, but also people aged 65-74. Among people aged 75 and over, more than half (approx. 51\%) are people with at least an average level of religious commitment, including the fact that over $10 \%$ was included in the very committed group. The group of the oldest people is also characterized by the lowest share of people not religiously involved and not related to any religion (18\% in total). Among people aged 65-74, the total percentage of people who were not religiously involved and not related to any religion amounted to $28 \%$, while people who were moderately or very religiously committed to about $41 \%$, including very committed - almost 8\% (Główny Urząd Statystyczny 2018: 1-6). It is true that this is a study for 2015-2018, as there are no current data for the last two years, but the level of religiosity is probably similar, although it definitely took a different form during the pandemic. However, it is important, that older adults are the largest group involved in religious practices.

To better define the essence of religiosity, we must look at its definition. PWN (State Scientific Publisher) defines religiosity as:

- in Christian theology, the moral virtue consisting in showing God due honor through internal worship (adoration, trust, love), as well as through external worship (sacraments, prayer, asceticism);

- in psychology and sociology of religion, the attitude of a person or a social group towards dogmas, orders and religious customs in force in a given religion, which is manifested through the assimilation of these principles, their acceptance and compliance with them; research on religiosity is empirical in nature and uses research techniques typical of psychology and sociology.

And although religion itself eludes empirical research, it should be stated that what can be observed is the fact that religion influences people and entire communities. This also cannot be investigated directly but through the religious acts of a specific individual. People's involvement in various forms of worship, meditation on God, talking to him in prayer, deepening religious knowledge and conforming to ethical standards resulting from religion and acting in a spirit of love for one's neighbour - this is what we call religiosity (Adamski 2011).

In the context of a pandemic, individual faith and religiosity take on new meaning. Shocking events, enormous experiences of losses, a feeling of helplessness in the face of the power of COVID-19, forces that are not dependent on man, create a huge spiritual emptiness. The most important questions 
are asked: about the meaning of life, illness, death, about what is most important in life. They can transform the entire thinking system of mankind. The epidemic that is lived through, as an invisible force with a mysterious effect, but bringing death to many thousands of people, becomes a challenge for the spiritual and religious life of everyone who lives it.

The coronavirus crisis may become a wake-up call in times when the perceptions related to temporality dominate. Many people think of various paradises on earth where our human longings can come true - these are paradises: huge financial resources, leisure, travel into the unknown, countless shopping, extreme sports, for which people work hard just to get these "material paradises." Today it is necessary to go beyond these temporal-centered images to come to a true and complete understanding of humanity. This may become possible when we break these worldly visions and open ourselves to the perspective of heaven. This paradise belongs to God, but the way to it is made through a creative life for others, resignation from self-centeredness, avoiding self-destructive actions and destroying the bonds and living bases of others (Augustin 2020: 90-91). George Augustin read perfectly on the ethical and spiritual level, the abbreviation COVID (Corona Virus Disease) encoded in our memory by the epidemic. He proposes that we read it as follows:

C- confidence (trust God)

$\mathrm{O}$ - opportunities (take advantage of opportunities)

$\mathrm{V}$ - values (rediscover essential values)

I - intelligence (to discern spirits in wisdom)

$\mathrm{D}$ - dedication (give a gift to God by committing yourself to people and the world)

It can be said that this is a spiritual and ethical program for everyone in the current pandemic (Augustin 2020).

For the purposes of this study, the above abbreviation COVID, proposed by the theologian Georg Augustin, was adopted in order to recognize the religiosity of older adults in the current situation.

C: confidence read as trust in God becomes the basis of religious life. The Church therefore calls for the experience of the pandemic to be interpreted as God's "signs of the times." It is significant that the time of the coronavirus crisis appeared shortly after the beginning of Lent. Many of the faithful interpreted this sign as a kind of extension and continuation of the mystery of Holy Saturday. In the Christian liturgy, it is a reflection on the day of the mystery of God's burying, His hiding and silence in human history, therefore it is also the day of the feeling of human hopelessness. This Holy Saturday of 2020, during the pandemic, has become a symbol of the difficult life situation of mankind - a symbol of the enormity of fears for one's own and loved ones' lives, fears for the future and the constantly asked question: when will the current crisis end and what will life after it look like (Koch 2020). 
In view of the great unknown about the future, a question arises as to how to read this crisis and how to react to it. Should this experience be accepted as naturally occurring from time to time in history? Should we trust only on the experience of scientists and wait for a scientific-medical solution? Or should it also be read in the context of faith - trust in God? Christianity can reconcile all currents in the perspective of the "signs of the times" that God gives to live this time spiritually - reflecting on the appreciation of the gift of life, being a child of God, the transience of the world, looking at earthly life as a transitional place to live with God in eternity, the discovery of the family bond and the general human community. This is the time to trust God. This trust is justified by the fact that the Holy Scriptures, with all their respect for nature, place great hope in God's grace and therefore constantly invoke their help in prayer, in the conviction that the deepest essence of prayer is the call of SOS, i.e., a call for help in the original meaning of this abbreviation: Save our Souls... Such trust in God's grace does not interfere with taking seriously the recommendations of experts who know the secrets of nature, which God created (Koch 2020). Older adults who have a lot of experience in life and those who experience its decline are more sensitive to transcendence and an eschatological view. They experience the trust of God's Providence more deeply, hence their prayer commitment - a conversation with a loving Father who takes care of his children and shows that "our homeland is in heaven".

\section{O: opportunities is the use of opportunities}

The Pontifical Council for the Laity in the document entitled The dignity and mission of the elderly in the Church pointed out that the pastoral care of people of the third and fourth age should make it easier for elderly people to participate in the celebration of the Eucharist, to enjoy the sacrament of reconciliation, to participate in pilgrimages, retreats and days of recollection. Elderly people should also be accompanied spiritually. They should be given the opportunity to receive the Anointing of the Sick and Viaticum. As older people make up a large percentage of media audiences, especially as radio listeners, TV viewers and readers, it is important to ensure that programs and publications are particularly suited to them, so that they offer them not only material for relaxation and recreation, but also an aid to the ongoing formation that is desirable in all ages (Dziedzic 2015: 102).

In this difficult pandemic time, the availability of the holy sacraments changed dramatically, especially to the Sunday or holiday Eucharist and to the sacrament of penance. The Holy Father Francis and the Episcopates of individual countries have made unprecedented decisions to limit the faithful participating in Holy Masses, and in some countries even completely cancelled them. It was dictated by the concern to limit the spread of the C-19 virus in the name of the most important commandment of love of God and neighbour. 
Instead of actually attending Mass, many parishes have introduced Internet transmissions from their churches so that the faithful can unite in the prayer of the church community. Statistics showed that this kind of participation enjoyed the greatest participation of the absent participants of the Mass liturgy. Likewise frequent radio and television broadcasts. During this time, the faithful were introduced to such content as perfect repentance for sins and spiritual Holy Communion, which so far had been used by people living in non-sacramental relationships, i.e., those who could not receive sacramental absolution under ordinary conditions and receive Christ's Body (Ziębińska 2010).

Numerous communities of the Church introduced evangelization content in interesting forms of expression into virtual reality and social media. Little-visited websites of individual parishes so far became a place of very active contact with parishioners, where information about the latest parish life and initiatives was provided. Many people who had not taken much religious participation so far have made virtual contact with priests. Paradoxically,

it was during the period of social distance, isolation and quarantine that pastoral ministry developed in the virtual space, and the Church strengthened despite the lack of access to the sacraments of believers and the experience of a community physically gathered in the same place.

(Skworc 2020: 6)

A very significant element of contact was telephone conversations with priests of a pastoral nature and organization of charity aid for the older people suffering from disease, quarantine and isolation.

V: values reads as rediscovering relevant values. Many people today ask themselves: Why do we have to deal with this type of crisis? But such a question will not take us too far. Rather, you have to ask yourself: What is this crisis for? It is up to each person what to learn from this difficult experience, what conclusions they draw and what they will do to contribute to a better personal and social life. The experience of the pandemic makes us realize that the question of life, the problem of noticing conditio humana in all its splendour and poverty, remains constantly relevant. It is the mystery of life that we can consider from different sides. We are even more aware that our earthly and biological life is limited, which gives rise to another reflection on the meaning of death and the transition to eternal life. It is a way to appreciate the value of life as a gift from God. In the biblical sense, life is directed towards God and towards communion with Him. It is life in God and with God that is realized in living with others. All life takes place in the living presence of God: in the arising, in becoming and sustaining of a single life, as well as in its limitation through death, and in the hope of a living community that transcends this death (Augustin 2020). 
The virus made us very brutally aware of human fragility and transience, as we realized even more clearly that we are mortal - threatened by a deadly disease that consumes thousands of people a day. Thus, death makes us aware of the mystery of life, which was very accurately expressed by St. Augustine, experiencing the pain of the death of his friend: "And I became a big question to myself" (Augustin 2020: 77), and

When we perceive our life as a gift, then God in Christ appears to us as a Giver... As a creature, I can trust that even after earthly life does not cease to fellowship with Him, which in itself is life.

(Augustin 2020: 83).

The value of life as a whole, i.e., earthly and eternal life, is the supreme value in times of crisis:

Faith, therefore, illuminates the mystery of death and illuminates with its light old age, which is no longer perceived and lived as a passive waiting for the moment of annihilation, but as a harbinger of the imminent achievement of full maturity. These years should be lived in an attitude of trusting entrustment to God, to a generous and merciful Father; this time should be used creatively, striving to deepen the spiritual life through more intense prayer and zealous service to brothers in love.

(John Paul II, pt 16)

The second value is the experience of a family community. Already in the pages of the New Testament, the Christian family is presented as the domestic church. The Acts of the Apostles describes the first converted families and homes that became communities of worship, mission, and Christian help, and St. Paul describes communities of believers, i.e., the Church, assembling at the house of Aquila and Priscilla [cf. 1 Cor 16,19; Rom 16,5], Philemon in Colossi [Philem 2], Nymphs [Col 4,15], as well as Gaius [Rom $16,23]$. In the 1st centuries of Christianity, there were as yet no special places of God's worship, and believers in Christ flocked to ordinary houses. It was the family home that was the place of prayer, singing psalms, and most of all celebrating the Eucharist, and the place where attitudes of Christian help were shaped. St. John Chrysostom, who lived in the 3rd century, was the first who called the family a little church, where the liturgy was celebrated, the texts of the Bible were considered, the truths of faith were taught, and alms were organized for the sick and the poor. He had a similar understanding of the family to St. Augustine. Following this idea, the Second Vatican Council called the family "home Church" [LG 11], where the faith is first transmitted through mutual love and common prayer, the family joins the liturgical worship of the Church and is a place where virtues are practiced and good works are performed (Przygoda 2020). 
While the pandemic limited participation in services in churches and places of worship, it did help many families to understand better the essence of the domestic church, common prayer and the organization of help for others in the Christian spirit.

So far, in the efforts of parents who want to provide the best possible life for their children and the whole family, there has often been no time for themselves, for common conversations, and for their interest in children's experiences - their passions, progress in school education, sharing the time of adolescence, first infatuations and discovering love, puberty and making serious decisions about the future. The time of pandemic isolation forced to some extent to spend time together with the family. Many parents, as well as children and adolescents, worked and studied remotely at home, spent a lot of time with each other, having the opportunity to talk, get to know each other better and appreciate the gift of the family community. In many houses, people gathered together to experience the Sunday Eucharist through broadcasts or to participate in other services online. Many families have rediscovered the power of daily family prayer. The family, rediscovered in its essence, as a community of life and love [GS 48], is able to satisfy the need for care, friendship and security (Przygoda 2020).

The third value is the perception of older adults in family and social life. It is in the family community that the presence of older adults plays a huge role. Nowadays, when older people are perceived as "superfluous people", it is even more important to note that many people are reaching old age. Even today, young people or middle-aged people should remember this. In his Letter to my brothers and sisters - older people, John Paul II drew attention to the immensely important role played by older adults in society:

We all know old people who can be an eloquent example of amazing youth and vitality of spirit. Those who come into contact with them are able to use words to stimulate action, encouraging them by their own example. May society fully appreciate the old people who, in certain parts of the world... are rightly honoured as "living libraries" of wisdom, guardians of the priceless human and spiritual heritage. While it is true that in the physical dimension they usually need help, it is also true that even in old age they can be a support for young people who take their first steps in life and seek their own way.

(John Paul II, pt 12)

The role of older adults in families and communities in the era of the coronavirus has become even more important. In many homes, children learning remotely are looked after by grandparents who help their parents by raising the young generation. They look after them, talk to them, help them learn, and shape their spiritual life through common prayer or participation in catechesis, Holy Masses and online services. It is one of the manifestations 
of religiosity, that is, the external expression of faith, bearing witness to Christian life and evangelizing the families.

However, it should be remembered that the family also has its Christian duty towards older adults, which was emphasized by John Paul II: "Before you go gray, you will respect the face of the old man" [Lev 19, 32]. To honour old people means to fulfil a threefold duty to them: to accept their presence, help them, and appreciate their virtues. In many environments it is a natural way of proceeding, in line with the ancient custom. Elsewhere, especially in the more economically developed countries, it is necessary to reverse the current trend, so that the older can age with dignity without fear of losing relevance. We must realize that a truly human civilization is characterized by respect and love for old people, thanks to which they can feel - despite their weakening strength - they are a living part of society. Cicero wrote that "the burden of years is lighter for those who feel respected and loved by young people" (John Paul II, p. 12).

The fourth value is appreciation of the church as a place of worship, a parish and the role of the clergy in society. Many believers suffer very badly from the lack of direct participation in the Church's liturgy due to the state authorities limiting the number of the faithful in Holy Masses and church services, and limited opportunities to use the sacrament of reconciliation and anointing of the sick. This particularly affects the sick and the older people staying in hospitals or nursing homes. It was also necessary to reform the preparation of children for the First Holy Communion and confession, as well as the formation of young people preparing to receive the sacrament of Confirmation. In many parishes, these ceremonies were postponed, and in other cases, these sacraments were administered in small groups to conform to epidemiological recommendations. It was similar with the preparation of the engaged couple for the sacrament of marriage and the conclusion of this sacrament by them. In the present situation, the possibility of participating in pastoral groups at parishes as well as direct contact with clergy has been limited. Many parishioners express deep pain and sadness at the inability to use the pastoral offers they have participated in and direct conversations with priests (Lipiec 2020).

The fifth value is the Church's chance to open up to those seeking a spiritual path and change of life. Many people who do not identify with the community of the Church and its teachings, lost in the COVID chaos, are looking for answers to the bothering questions about the meaning of life, suffering and death. These searches are most often made in the virtual space, which the Church uses more and more often in its mission. These are contacts by e-mail or on social media and forums directed to parishes, pastoral groups, individual priests or believers, who give testimony of their faith in this space. The Second Vatican Council indicated three ways to open up dialogue: with other Christian Churches, with non-Christian religions and with "non-believers". The Czech theologian Tomas Halik describes the third group as Noni. They include people who do not want to be counted 
among the followers of any existing religion. Noni are not atheists who reject the possibility of God and a spiritual reality, but are a very diverse group, i.e., apateists (religiously indifferent), agnostics, anti-clericals, followers of different spirituality, syncretists, people disappointed or hurt by religious institutions and people who sincerely seek spiritual reality. He considers them a great task in the third way of dialogue, which he calls the third ecumen. In the future, the Church, apart from the traditional pastoral care of believers who belong to parishes or formation groups, will face a new task in addition to missionary activity focused on acquiring new members, that is seeking spiritual accompaniment, which already takes place in hospitals or prisons, where the service of spiritual support, consolation, and various conversations covers all those in need and is not focused on conversion in the ecclesial and religious sense. Nevertheless, conversion in the sense of metanoia is also at the centre of this ministry - a change of life, which Heidegger understood philosophically as Khere (a turn) - a departure from an inauthentic life in constant pursuit of only temporal needs, where you live like everyone else (Heideggerian "oneself," "one lives") to a real life based on the voice of conscience (Halik 2020: 131-152). Thus, the time of the pandemic presents the Church with new tasks.

\section{I: intelligence - to discern spirits in wisdom}

Holy Father Francis on March 27, 2020 in the empty St. Peter, while praying for an end to the pandemic, delivered a very moving homily in which he stated:

Thick darkness has gathered on our squares, streets and cities. They engulfed our lives, filling everything with a deafening silence and a gloomy void that paralyzes everything in its path. You can feel them in the air, notice them in their gestures, your eyes tell about it. We got scared and lost.

(Francis 2021 - online document)

The pandemic has caused an acute fear that takes various forms, that is fear of infection, illness, death of loved ones, economic collapse of unemployment, bankruptcy and lack of development prospects, as well as fear of loneliness, loss of meaning in life and death. There is also doubt in God's Providence and fears about the future of the world. It also causes a natural fear, which is a spontaneous human reaction to the perceived danger. Nevertheless, in the midst of this chaos, there is the dangerous phenomenon of artificial fear inducement generated by the modern prophets of pessimism, the apocalyptic end of the world, and the supposed "hours of punishing God" (Nota Komisji Nauki Wiary 2020: 45). The basic mistake of these false prophets is to express themselves incorrectly and at the same time suggestively on behalf of God, giving erroneous ideas for solving a pandemic 
situation, falsified description of God's providence, which intervenes according to human ideas. This approach results in despair - a sense of hopelessness that leads to doubt and lack of faith in overcoming the threat.

It is wrong and dangerous to obsessively look for the person or groups of people who are responsible for the pandemic by condemning, stigmatizing and blaming them. Equally harmful is the presentation of a distorted historiosophy, invoking false revelations and dreams, misinterpreting biblical texts, as well as questioning contemporary Church teaching, e.g., on the order of nature and grace, the spiritual and material dimensions, which lead to the neglect of safety during the liturgy (Nota Komisji Nauki Wiary 2020).

We also cannot treat magically the sacraments and sacramentals or portray the Church as a "safe ark" that is reserved only for those attending Masses and services held in churches by reciting God's grace to those faithful who unite in the prayers of the church community through the mass media.

Particularly dangerous is the phenomenon of the creating and activity of pseudo-religious sects or groups using human fear related to COVID-19. The time of pandemic, anxiety, fear, isolation and death of loved ones causes depression states to many people who are subject to various types of confabulations and manipulations. It is used by some sects or so-called gurus who prey on people scared by the coronavirus, especially the older and the sick people, separated from their loved ones. Often, they are willing to give up their possessions, such as savings and even housing, to receive a false hope of survival. Since the coronavirus emerged, pseudo-religious groups have been attracting increasingly older people, terrified of the inevitable end of the world as we know it. At the present time, the issue of health is becoming a sensitive issue, and therefore extremely delicate. Be careful... Older people can be manipulated by some group, some self-proclaimed guru, by someone who will come and say that some particular therapy will help solve all problems (https://www.polskieradio.pl/9/325/Artykul/2626431,UwagaKoronawirus-sprzyja-sektom - 27.01.2021).

An example of such activity is the sect Science about Happiness spreading around the world (Japanese Kofuku no Kagaku). It was founded in 1991 in Tokyo by Ryoho Okawe and now finds its followers in Japan, USA, Uganda, Russia and Bulgaria. The sect's offer includes "effective exorcisms against C-19," and Okawa presents himself as having a special relationship with $E l$ Cantara, which is "Higher Spiritual Being" and "Higher Consciousness." El Cantara is the only spiritual being (depicted in the form of an angel with a white dove at his feet sending rays of grace) who combined the values of four religions: Islam, Christianity, Buddhism and Confucianism in order to obtain miracles, healings, deliverance from evil and provide happiness in life. In the temple of this sect in New York, there is distributed the book titled: Spiritual readings on infection with the new strain of the coronavirus originated in China. Okawa calls for faith in El Cantara, assuring that only he can eradicate the C-19 virus. Sect stores sell "exorcisms and blessings" for 
\$100-\$ 400. According to Okawa, the C-19 virus is a biological weapon that has eluded the Chinese supernaturally and turned against the communist, godless Chinese, as well as anywhere in the world where there is no "real faith" (Zwoliński 2020).

Also in South Korea, the apocalyptic sect of Sincheonji (Church of Jesus Christ of Heaven and Earth) founded in 1984 by Li Man Ki, who describes himself as the immortal incarnation of Jesus. Sect leaders forbade their members to follow the hygienic regime during a pandemic by wearing face masks and keeping people distant during collective services. They argued this with "God's wrath" that would reach anyone who did not follow the sect's recommendations, and the refusal to participate in the rites was unacceptable. Li Man Ki said that if you betray our church, you become a dog and a pig; you lose your right to salvation. He also called the C-19 "the devil's act" to discourage people from joining the ranks of Sincheonja. The authorities surveyed over 210,000 members of the sect. Some of them refused to do the tests. The Korean public filed a petition to ban the sect and collected over 1,250 signatures of the citizens. South Korean authorities have brought charges against the guru of this sect regarding, among other things, murder, injury and violation of state laws regarding epidemiological control. Over $60 \%$ of 7,500 people infected C-19 in Korea are Sincheonji followers. The sect has become one of the sources of the epidemic in this country. The sect operates in South Korea, the USA, China, India, New Zealand, Australia, as well as in some European countries, such as England (https://forsal.pl/ artykuly/1460145,1e-monde-epidemia-covid-19-zdemaskowaladzialalnosc-sekty-shincheonji-z-korei-pld.html - 27.01.2021).

In Poland, a sect called New Covenant Church in Lublin propagates various false information about the pandemic. According to them, C-19 is a product of the Chinese Communist Party and Poland still belongs to the communist bloc due to the pandemic. They call the coronavirus a "biological weapon" as well as the "virus of the Chinese Communist Party." They believe that the sect suffered losses by not being able to meet in public, and many of them had to go into quarantine, which contributed to financial and moral losses. The leader of the sect - Paweł Chojecki - founded an independent television called Go against the current, which presents only absurd theories about the virus, preached by the leader. Sect members and viewers of this television are urged not to watch any other information on the subject. There was created a system of mutual observation within the sect, and warnings against making friends and making new acquaintances. There was also organized an action called, which threatened the health and safety of Polish society, and Poles were threatened that all protective measures imported from China were deliberately infected with coronavirus. In his theses, Chojecki also refers to biblical texts, which he interprets as he pleases, bending them to his own false theories (Ziębińska 2010: 285-286).

There are many such sects and pseudo-religious groups in the world. They take advantage of the fear and anxiety caused by the pandemic. So you need 
to be very careful not to succumb to this type of manipulation. Therefore, the Church teaches to discern spirits in wisdom, because "mature religiosity requires human cooperation with God, combining human activities with openness to the gift of God's grace, reliable knowledge with deep faith, daily activity with fervent prayer" (Nota Komisji Nauki Wiary 2020: 47).

D: dedication is to give a gift to God by committing yourself to people and the world. The pandemic drew our attention to mutual love even more. Love for our neighbour is the most important distinguishing feature of biblical ethics. It can even be said that it has become a heritage of world culture. Mentioned in the Old Testament in Leviticus [Lev 19,18] (World English Bible), it was defined by Jesus as the most important commandment [Mark 12,28-34] (World English Bible), while the parable of the Good Samaritan became an image of mercy towards others, extending them beyond the boundaries of Christianity:

the love of neighbour is an ethics that puts the other in front of us, within our sight. It is not condescending but humble, not disrespectful but empathetic. It does not reach far away, but remains close to us, moving and touching. It is a matter of the heart - or it is not love of neighbour.

(Söding 2020: 100)

The commandment of love applies not only to the person of one's neighbour, but it strengthens those who follow it in three ways. First of all, it says: You love, so it is about personal commitment and not for someone else to do it. The second thing is to love your neighbour, that is, not anyone, but someone who lives in our world. This is a dimension of our responsible treatment of other people. And the third thing is that we should "love our neighbour as ourselves" - not selfishly, but also not as part of self-destruction. It is about shaping your humanity by finding fulfilment in helping others (Söding 2020: 106).

The Church over the centuries, using its own capabilities, in the face of the lack of state organizations at that time until the modern times, built its own hospitals (shelters for the care of infected and seriously ill people). They served to care for the sick and isolate them, thus protecting others as well as enable pastoral care for patients and residents. Similarly today, church charities, incl. Caritas, Misereor, Adveniat, Missio, Renovabis help those in need all over the world, regardless of religion, skin colour or belief. In this way, the Church supports sustainable development, reduces risk and prevents social marginalization. The Church also has a duty to follow the rules of social distancing that are dictated by state authorities, based on the recommendations of medical experts, and strongly recommend them to be followed. It is inscribed in the most important commandment - love of God and neighbour (Söding 2020: 119).

During the pandemic, numerous initiatives for older adults also play a very important role: "Therefore, all social initiatives, thanks to which the older can not only take care of their physical and intellectual condition and 
develop relationships with others, but also become useful by giving others their time, skills and experience, deserve recognition" (John Paul II: 16). An important form of activity of older adults are various forms of education, currently mainly on-line. It can be carried out in various institutions - both organized (e.g. schools, universities, courses), and in informal institutions through contact with the press, radio, television or the Internet (GagatMatuła \& Myśliwiec 2011). The rapidly developing universities of the third age also play an important formative and educational role. It is a new quality in the area of lifelong learning and intellectual and psychophysical activity (Ilnicka 2006). These institutions not only help retirees to organize their free time, but also often influence their spiritual development (Dziedzic 2014).

The third age is the stage in life that should be used to engage in supporting others (Lipiec 2020). Despite good health, these people sometimes have no motivation to engage in such pro-social activities. Therefore, those movements and organizations that help the older to abandon the attitude of distrust and resignation and try to make them those who are engaged in the service of love, share their wisdom and are witnesses of hope, deserve attention: let grandparents be active again in families, in the Church and in society. When it comes to families, let grandparents continue to be witnesses of unity in them, values based on fidelity to the one love that breeds faith and joy in life (Benedict XVI 2008).

\section{For further discussion...}

In conclusion, the topic of the religiosity of older adults during Covid-19 based on the example of the activities of the Catholic Church - draws special attention to four aspects related to the social teaching of the Church.

- The sociological and theological reflection indicates that the size and nature of the crisis should be properly assessed, that is, a pandemic is not an apocalypse but a temporal phenomenon, the effects of which can be limited by decisive, appropriate and effective action. It is an experience that should make us reflect and seek a responsible life in security and freedom.

- The crisis gives direction to our ethos, that is, all economic, social and medical activities are intended to emphasize the importance of human dignity. This is the stage of introducing global solidarity, which takes place first in our immediate environment and results in Christians from faith in God, and is carried out within the framework of the most important commandment - love of God and neighbour.

- The Church as a community is to accompany all manifestations of the experience of sickness, suffering, sorrow, care and fears that affect individuals and their families in this pandemic time, as well as to comfort, strengthen, support people and remind people of the hope of eternal life, which does not negate the earthly, but illuminates it with its light. 
- Finally, service to others is also necessary. By undertaking charity work, the Church is there where general needs are met, in health care, in nursing the sick, in work with children and youth, in the field of education. This is done depending on the possibilities and social needs. Many of these actions are now carried out through the media (Söding 2020: 127-129).

The principles of social life, i.e., the principle of the common good, solidarity and subsidiarity, to which the Catholic social teaching calls, are implemented in the pandemic era, going far beyond the boundaries of the Church, embracing spiritual and charitable help every person and above all older adults. It is worth citing the reflection of one of the Internet users who wrote that

mankind got exactly the disease it needed. We stopped respecting health, so the disease made us realize that we should care more about it. We stopped being in families, so the disease locked us in our homes to remind us and teach us how to function with loved ones. We stopped respecting the older and the sick, so the disease exposed them the most so that we would remember how vulnerable they were. We have stopped appreciating health workers and pharmacists, so the disease has allowed us to see how essential they are. We stopped respecting teachers, so the disease closed our schools so that parents could try to teach their children themselves. We paid a lot of attention to our appearance and comparing ourselves, so the disease covered our faces to make us understand that beauty is not in appearance. The pandemic took a lot from us, but at the same time gave us the opportunity to learn and understand what is most important in life.

(Przygoda 2020: 124-125)

\section{References}

Adamski F., Socjologia religii. Wprowadzenie, in: Socjologia religii, (red.) F. Adamski, Petrus, Kraków 2011, pp. 5-7.

Augustin G., Świadczyć o życiu w śmiertelnym świecie, in: Odkrywanie wspólnoty. Wiara w czasach pandemii koronawirusa, (red.) W. Kasper, G. Augustin, Kraków 2020, pp. 61-98.

Benedict XVI, Dziadkowie sa cennym skarbem każdej rodziny, https://opoka.org.pl/ biblioteka/W/WP/benedykt_xvi/przemowienia/dziadkowie_05042008.html

Dziedzic J., Kościół wobec starości. Perspektywa pastoralnoteologiczna, Polonia Sacra 19 (2015) 1 (38).

Dziedzic J., Przeszkody i szanse w poszukiwaniu godnej starości, in: Odnaleźć wykluczonych. Wsparcie terapeutyczno-duszpasterskie pacjentów szpitala Specjalistycznego im. dr. Józefa Babińskiego w Krakowie, (red.) J. Dziedzic, J. Klimek, Wyd. Szpital Specjalistyczny im. dr. Józefa Babińskiego SP ZOZ w Krakowie, Kraków 2014, pp. 213-230. 
Francis, Homilia poprzedzająca błogosławieństwo Urbi et Orbi, https://papiez.wiara. pl/doc/6235496.Franciszek-podczas-modlitwy-o-ustanie-pandemii (27.01.2021).

Gagat-Matuła A., M. Myśliwiec, Wychowanie do starości, in: Starzenie się z godnościa, (red.) S. Steuden, M. Stanowska, K. Janowski, KUL, Lublin 2011, pp. 291-315.

Główny Urząd Statystyczny, Życie religijne w Polsce. Wyniki badania spójności społecznej 2018, https://stat.gov.pl/obszary-tematyczne/inne-opracowania/wyznaniareligijne/zycie-religijne-w-polsce-wyniki-badania-spojnosci-spolecznej-2018,8, 1.html (15.12.2020).

Halik T., Pandemia jako doświadczenie ekumeniczne, in: Odkrywanie wspólnoty. Wiara $w$ czasach pandemii koronawirusa, in: Odkrywanie wspólnoty. Wiara $w$ czasach pandemii koronawirusa, (red.) W. Kasper, G. Augustin, WAM, Kraków 2020, pp. 131-164.

Handerek Katarzyna, Mieszkałam w sekcie, https://www.polskieradio.p1/9/325/ Artykul/2626431,Uwaga-Koronawirus-sprzyja-sektom (27.01.2021).

Ilnicka R., Wychowanie do starości, Edukacja i Dialog 4 (2006), pp. 69-72.

John Paul II, List do moich Braci i Sióstr - ludzi w podeszlym wieku, 16. http:// www.vatican.va/content/john-paul-ii/pl/letters/1999/documents/hf_jpii_let_01101999_elderly.html

Koch K., Koronawirus widziany oczyma wiary, in: Odkrywanie wspólnoty. Wiara w czasach pandemii koronawirusa, (red.) W. Kasper, G. Augustin, WAM, Kraków 2020, pp. 43-60.

Lipiec D., Rozmowa duszpasterska $w$ dobie pandemii, in: Duszpasterstwo $w$ czasie pandemii, Instytut Gość Media, Katowice 2020, pp. 175-183.

Nota Komisji Nauki Wiary Konferencji Episkopatu Polski w zwiazku z pandemia koronawirusa. „Jezus żyje i chce, abyś żyl”, in: Duszpasterstwo w czasie pandemii, Instytut Gość Media, Katowice 2020.

Przygoda W., Wartość Kościoła Domowego w dobie pandemii, in: Duszpasterstwo w czasie pandemii, Instytut Gość Media, Katowice 2020, pp. 119-125.

Skworc W., Słowo wstępne abp. Wiktora Skworca, przewodniczacego Komisji Duszpasterstwa KEP, in: Duszpasterstwo w czasie pandemii, Instytut Gość Media, Katowice 2020, pp. 5-11.

Söding T., Dystans i kontakt, in: Odkrywanie wspólnoty. Wiara w czasach pandemii koronawirusa, (red.) W. Kasper, G. Augustin, WAM, Kraków 2020, pp. 99-130.

Stańko Katarzyna, "Le Monde": epidemia Covid-19 zdemaskowała działalność sekty Shincheonji $z$ Korei Ptd., https://forsal.pl/artykuly/1460145,le-mondeepidemia-covid-19-zdemaskowala-dzialalnosc-sekty-shincheonji-z-korei-pld. html (27.01.2021)

Ziębińska B., Uniwersytety Trzeciego Wieku jako instytucje przeciwdziałajace marginalizacji osób starszych, WN Śląsk, Katowice 2010.

Zwoliński A., Od powietrza... Ludzie w czas zarazy, Petrus, Kraków 2020. https:// ekai.pl/sekta-nauki-o-szczesciu-w-czasie-pandemii-koronawirusa/ (27.01.2021). 

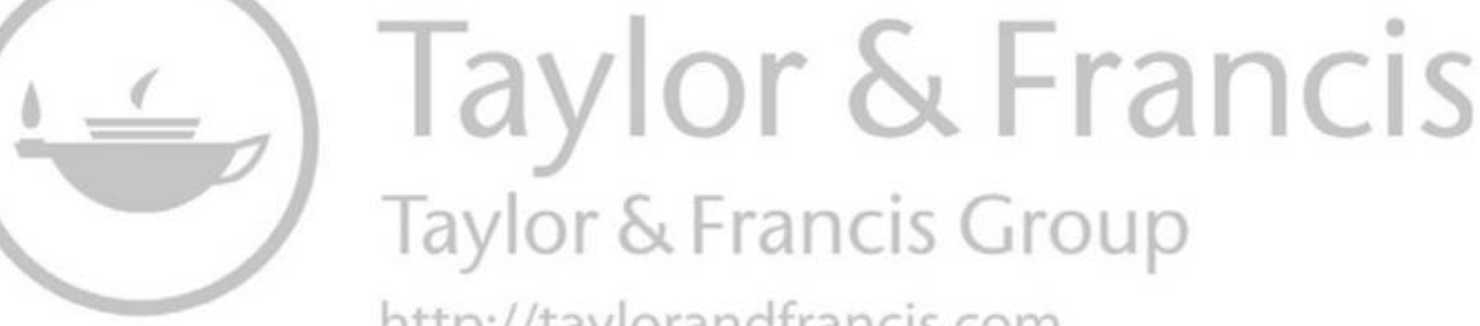
http://taylorandfrancis.com 


\section{Part 4}

Social care and support 

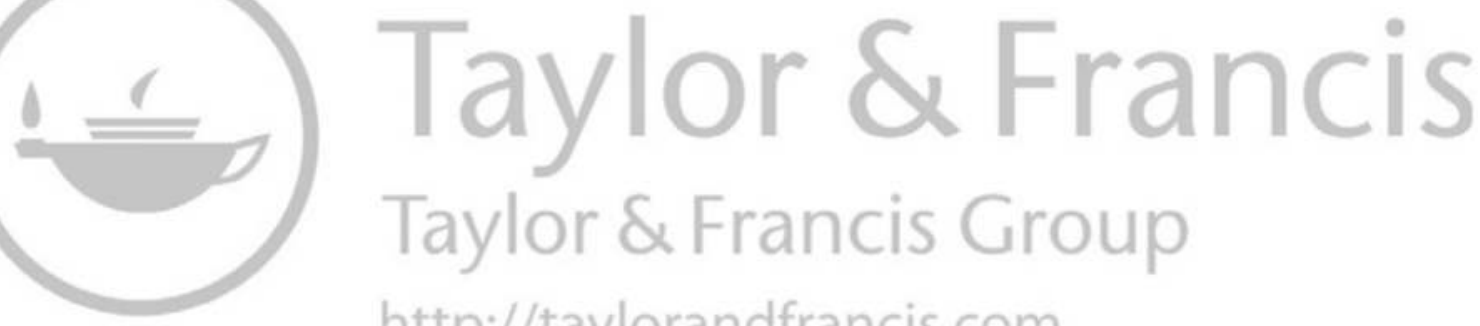
http://taylorandfrancis.com 


\title{
15 To care or not to care? What have we learned from COVID-19 about our attitudes towards older adults?
}

\author{
Linda Garcia, Louise Bélanger-Hardy, \\ and Martine Lagacé
}

The COVID-19 pandemic has had tremendous impact on how we care about the wellbeing of others, especially older adults. The chapter explores how societal attitudes, including ageism, have been exacerbated by both our personal and institutional management of COVID-19 and subsequent caring of and for older adults. The authors reflect on the notion of caring in different contexts: intergenerational perceptions, the choices made in addressing the spread of the pandemic to longterm care settings, the role of non-professional caregivers and finally, caring from a systemic governmental perspective. The chapter then discusses the extent to which lessons can be learned regarding the desire to care for one another using Tronto's seminal work on the ethics of care (Tronto, 1998). Factors such as rapid deconfinement measures and the public behaviours worldwide suggest that effecting meaningful transformation within society will require a profound reflection on caring and the process of aging as we move out of the pandemic.

The COVID-19 pandemic has unveiled and continues to unveil some of humanity's finest moments of empathy and solidarity. Unfortunately, the crisis has revealed the darker side of human conduct as well. Earlier in the pandemic, in speaking about the COVID-19 worldwide, Antonio Gutierres, Secretary General of the United Nations noted that "we see the disproportionate effects on certain communities, the rise of hate speech, the targeting of vulnerable groups, and the risks of heavy-handed security responses undermining the health response" (Guiterres, 2020). As we move towards the end of this pandemic, we must learn from our experiences and reflect on the societies we wish to build in the future.

The Secretary General reminded us that the ethical decisions made during the crisis are intricately tied to matters of human rights. Indeed, as store fronts and communities in Canada displayed signs saying, "we're all in this together," public authorities made decisions about freedom of movement, access to health care, and composition of social circles. Those decisions

DOI: $10.4324 / \mathrm{b} 22774-20$ 
reveal much about how we really care about one another, while significantly challenging the perception that we are really "all in this together."

One of the so-called vulnerable groups targeted at the first signs of the virus were older adults. The significant impact of COVID-19 on individuals with multiple chronic conditions, of which a significant number are older, has been well documented. But, by far, what has left the most lasting impression on our communities was the disproportionate impact of the virus on health and consequently on the number of deaths in the older age group. As the numbers of cases of illness amongst older adults increased, decisions to confine these adults to their homes also grew, without full recognition of the impact this might have on their need to be connected to others. Many countries imposed increasingly restrictive demands to quarantine all groups as they contained the spread of the virus. As a less digital savvy segment of our populations, older adults were further isolated. The image of a vulnerable population in need of help from its fellow citizens quickly emerged. In other words, a discourse of protection of older adults began to materialize.

While this bleak situation was unfolding, a parallel trend occurred worldwide. Some citizens began showing signs of not caring about the plight of older adults. Advocacy groups and scholars documented references to hateful comments on social media about the impact of COVID-19 on older adults, with terms such as \#boomerremover circulating widely on the Internet. As well, at times, generations appeared pitted against each other regarding the spread of the disease. As the crisis slowed down, many citizens ignored deconfinement measures and exhibited a lack of concern for the impact of their conduct on vulnerable groups. An important point to note is that older adults themselves sometime exhibited similar attitudes towards the very aged, the "super seniors" or "vulnerable and helpless" older adults. Some members of both younger and older generations apparently believed that the "we" in "we are all in this together" did not concern "them."

Explaining this type of behaviour is difficult and, while addressing this complexity goes beyond the aim of this chapter, we do argue that the current health crisis has brought to the forefront what appears to be an absence of "caring for the other." This lack of caring has not only occurred at the individual level but more broadly as well. Indeed, in Canada at least, the dismal situation in long-term care homes during the COVID-19 crisis, leading to over $80 \%$ of the COVID-19 related deaths in the country (Hsu et al., 2020), has unveiled a number of serious ongoing problems within the long term care system. The pandemic has simply shined a light on issues that have existed for a long time.

In this chapter, we argue that the COVID-19 pandemic has had a significant impact on our desire and ability to care, and that older adults have been disproportionately affected by society's ineptness at caring, especially in western, high income countries. We suggest as well that our attitudes can be explained, at least in part, through the phenomenon of ageism. Negative 
conceptions of age influence how society values older adults but also, more generally, how we value care.

The first part of the chapter defines and illustrates the notion of ageism. We then examine the concept of care, relying on some of the contributions of scholars such as Tronto and others. We focus specifically on four dimensions of care: between generations, towards the very vulnerable, towards caregivers, and by institutions and governments. We conclude by suggesting that, in the months, and perhaps years to come, our collective and individual efforts to contain the consequences of the COVID-19 pandemic must include genuine compassion and care not only for older adults but towards each other as well.

\section{The unveiling of ageist attitudes}

Within Western culture, the process of ageing and the status of old age are often negatively depicted (Trincaz \& Puijalon, 2010). The fact of growing older is largely associated with physical and psychological decline. Robert N. Butler was amongst the first researchers to study the profound "malaise" expressed by many individuals towards ageing and old age, conceptualizing it as "ageism" (Butler, 1975). Precisely, ageism refers to the "complex, often negative construction of old age, which takes place at the individual and the societal level" (Ayalon \& Tesh-Römer, 2018, p. 3). Ageism underlies a cognitive, affective, and behavioral component, namely (a) negative stereotypes associated with ageing and old age (vulnerability, uselessness, helplessness, lack of autonomy, etc.); (b) prejudice, i.e., negative emotions manifested towards older adults, and (c) discriminatory aged-based behaviors, such as avoidance, negligence, and abuse of older adults (Global Report on Ageism, 2021; Ayalon et al., 2019). Importantly, ageism may be manifested in a subtle way such as patronizing and over-accommodating language as well as overprotective behaviors. Although subtle ageism, also called "compassionate ageism," may stem from a well-intentioned desire to help, it still conveys the predominant perception of older adults as frail, vulnerable, and helpless individuals. Ageism may also take a hostile form such as physical, financial, and verbal abuse. As stated previously, the discourse around older adults conveyed on some social media platforms at the very beginning of the pandemic - whereby the COVID-19 virus translated in the hateful hashtag "boomer remover" - undoubtedly echoes overt and hostile ageism.

Ageism permeates numerous social arenas and is particularly prevalent in health care contexts. Indeed, older patients can be the target of ageism on the part of health care providers - even if manifested in a subtle and well-intentioned way. This is so simply because care providers often perceive older adults as psychologically and physically fragile due to their age. For example, relying on secondary data stemming from surveys and clinical observations, Ouchida and Lachs (2015) argue that during medical encounters, care providers communicate - verbally and non-verbally - in different 
ways with older adults than with younger adults. Specifically, physicians are more impatient and less engaged with older patients. They are also less likely to respond to the issues they raise. Therefore, our very ability to care for older adults is expressed by how we communicate "with" them and how we speak "about" older persons. In the face of a pandemic, and when challenged with decisions regarding the care of patients, it is easy to see that communications that are ageist in their approach can be detrimental to the wellbeing of older adults.

Along the same lines, a substantial number of scholarly studies have documented the use of patronizing language during medical encounters with older patients. The source of ageist communication seems to lie with care providers who may have subconscious misconceptions and stereotypes that older patients are frail, helpless, irritable, and dependent (Atkinson \& Sloan, 2016).

In sum, decades of studies on ageism demonstrate that this form of discrimination is prevalent in many facets of Western culture, for example, work, media, legal systems, and healthcare (Global Report on Ageism, 2021). The negative impact of ageism on older adults is well-documented, increasing physical problems and feelings of social isolation while lowering self-esteem and self-efficiency. Notwithstanding the prevalence and negative impact of ageism, it remains one the most socially condoned form of discrimination. Under-reported cases of abuse and neglect in long-term care homes speak volumes on the prevalence of ageism. As will be argued below in this chapter, the pandemic seems to have exacerbated long time anchored ageist attitudes towards older adults, acting as a magnifying glass in terms of ageism's negative outcomes. This in turn appears to be linked to the absence of a "caring attitude" towards older adults.

\section{Caring in an ageist society}

At the time of the writing of this chapter, the world was still battling the repercussions of COVID-19. As countries struggle with their decisions about whether to open up borders, re-stimulate their economies, support their citizens, and guide them in the best public health response possible, scholars are documenting the more subtle impacts of this pandemic, including social isolation. For some older adults, this has contributed to the phenomenon of age digital divide (Ramsetti \& Adams, 2020).

The remedies for social isolation necessarily include contact with other people and this was severely impacted by containment measures requiring social distancing. Furthermore, academics working in the field of ageing have acknowledged for some time that older adults, in high income countries at least, are at disproportionate risk of social isolation. Should we not, then, be reflecting on how concerned we really are about the care others receive during a disruptive situation such as a pandemic? 
Tronto $(1993,1998,2010)$ and Tronto and Fisher (1990) have written extensively on the ethics of care. In their words, Tronto and Fisher (1990, p. 40) suggest that caring be viewed

as a species activity that includes everything that we do to maintain, continue, and repair our "world" so that we can live in it as well as possible. That world includes our bodies, ourselves, and our environment, all of which we seek to interweave in a complex, life-sustaining web.

Tronto and Fisher's conception of care can often be at odds with the individualistic approach espoused by Western societies. Care presupposes a concern for the effect we have on each other and requires an ethical and moral duty to respond to each other's needs. During the ongoing pandemic, there have been instances where citizens of all ages have shown concern for others and where caring for one another has been at the forefront of individual and community initiatives. However, as the pandemic and its aftermath unfold, we unfortunately continue to see significant evidence of lack of concern for others. The challenges of "caring" occur in a number of contexts including intergenerational interactions, very vulnerable populations, relations with caregivers and finally, public authorities' interventions before, during and after the pandemic.

\section{Caring about other generations}

The public discourse on ageing and older adults - whether conveyed by the media, the government, or the research community - shapes or at least partly shapes individual perceptions and personal experiences of ageing. The process is one of normalization and internalization of social representations of ageing within a person's scheme of beliefs (Renaud et al., 2006); in turn, the process influences how members of different generations perceive and interact with one another.

Within the intergenerational discourse, many studies have concluded that representations of ageing and older adults are mostly negative and polarized (Lagacé, Laplante \& Davignon, 2011). On the one hand, the ageing process is depicted either as a social and economic burden whereby older adults are associated with rising health-care costs, especially older adults living in long-term care facilities. On the other hand, studies point to a mainstream public discourse that praises older adults who manage to counter signs of ageing and embody images of youthfulness. In both cases, as argued by scholars, such polarized representations are fueling ageism at the inter and intra generational levels (Rozanova, Miller \& Wetle, 2016). In the former, negative, and homogenized views of ageing may deepen the gap between younger and older generations, while in the latter case, "false positive" views of ageing may create a divide amongst older adults themselves. 
The COVID-19 pandemic sheds further light on representations of ageing and older adults in the public discourse and the ways younger and older generations perceive and care for one another. Studies conducted at the very beginning of the crisis are quite revealing to this effect, pointing to an exacerbation of ageist stereotypes. For example, Jimenez-Sotomayor, GomezMoreno, and Soto-Perez-de-Celis' (2020) content analysis of the portrayal of older adults in social media shows that almost a quarter of 362 tweets posted during the period of March 12 to 21, 2020 reflected offensive and denigrating content towards older adults. Mainstream media portrayed older adults as "vulnerable" individuals needing to be protected from the virus and its impact (Fraser et al., 2020). It goes without saying that this vulnerability label (applied solely on the basis of age, i.e. persons aged 65 years old or more) not only reinforces ageist stereotypes but positions older adults as victims that cannot take part in a process of collective resilience against the virus (O’Sullivan et al., 2014).

\section{Caring about the most vulnerable}

Older adults living in long-term care homes (LTCH) constitute some of the most vulnerable citizens affected by the COVID-19 pandemic. Many of the residents in LTCH are part of the "oldest old." For example, the Ontario Long-Term Care Association (OLTA), the largest association of its kind in Canada, confirms in one of its recent reports that $82 \%$ of residents (public and private facilities combined) are over 75 years of age and $55 \%$ are over 85 years of age (OLTA, 2019). These statistics, representative of LTCH residents across Canada, are unlike the demographic make-up of residents of 30 or 40 years ago, when residents were younger. Furthermore, due to successful "ageing at home" programs, older adults in LTCH live with more complex and chronic health conditions than yesteryear thus presenting the staff with an increasingly older population with complex needs and in need of increasingly specialized care.

In fact, beyond age, the presence and nature of two or more chronic health problems, i.e., comorbidity, increases the vulnerability of people living in LTCH. It continues to be clear, as it was when COVID-19 presented itself in China and Italy, that those most susceptible to the coronavirus are those with multiple health conditions, particularly diabetes, chronic obstructive pulmonary disease, and cardiac conditions. Why, in Canada, did we not anticipate and, above all, plan for the eventuality of a crisis involving older adults with such conditions?

We wonder as well why the push to provide sufficient personal protective equipment to the staff was not prioritized as it had been when the focus was on acute care. When the pandemic was declared in mid-March 2020, protective measures, including masks and other personal protective equipment, were not available in sufficient numbers. The lack of planning and preventative measures in LTCH must be decried when authorities knew that these 
places were highly vulnerable to the spread of the virus and that the disease could wreak havoc on residents.

One feature of LTCH in Canada is that personal support workers (PSW) who care for the residents' most basic needs and activities of daily living have low wages and their precarious situation leads them to work in more than one LTCH. One of the most publicized issues of the COVID-19 pandemic was the retention of PSWs who, in some cases, left their workplaces due to burnout or inadequate protective equipment. The absence of several employees forced those who remained to continue working in conditions that were not only very difficult, but also more conducive to the further contamination of residents, as employees moved from floor to floor or from LTCH to LTCH. We wonder how this could have been allowed since authorities knew full well, from the outset of the pandemic in Canada, that the COVID-19 virus was highly contagious and could be transmitted by asymptomatic individuals.

In the end, the health crisis caused by COVID-19 exposed a disturbing reality: many of our most vulnerable older adults live in environments where health providers are overworked, poorly paid, and where their specialized skills are neither recognized nor valued. Of note, in Canada, PSWs are not a self-regulated, autonomous profession. However, this may well change, at least in some provinces or territories. For instance, following the worst of the health crisis, the province of Ontario passed legislation to provide a non-compulsory regulatory scheme for PSWs working in a number of settings including LTCH. One of the law's stated objective is to promote safe, competent, ethical and high-quality health and supportive care services and to develop codes of ethics (Advancing Oversight and Planning in Ontario's Health System Act, 2021). This type of measure could assist in ensuring better care provided governments take concrete measures to improve the PSWs working conditions - something that the legislation fails to address.

\section{Caring about caregivers}

The importance of understanding the role of unpaid care has been heightened by the COVID-19 pandemic. About 8 million Canadians provide care to a relative or a friend (Statistics Canada, 2018), comprising more than $80 \%$ of the care needed and contributing to over 25 billion dollars in unpaid work (Hollander, Liu \& Chappell, 2009). This is also not limited to Canada. The demographic change is so great worldwide that no country in the world, whether low-, mid- or high-income will be able to adjust without supporting a strong informal caregiver base. The complexity and importance of care have never been clearer. Faced with the added burden of COVID-19, family and friends are tested as they seek to provide support despite reduced, withdrawn or canceled community respite services and home care.

Yet, while there have been numerous news reports, preliminary studies, commentaries, and political speeches about the effect of the pandemic, very 
few have addressed the needs of this very significant portion of our population. We have known for years that those who care for older adults, especially older adults with dementia, need help from others to carry on (Queluz et al., 2020). We know as well that these needs are often unmet or ignored by formal health care workers. While caregivers of older adults are not homogenous in their needs, all of them require a form of relief from caregiving duties and time for themselves. Queluz et al. (2020, p. 48) found evidence that caregivers' inability to take care of themselves was "directly related to lack of help from others."

The data on the pandemic's long-term impact on caregivers remains to be collected, but we can reasonably presume that results will confirm this impact was significant, especially since we know the experience of caregiving often has negative consequences on caregivers' health and wellbeing (Schulz et al., 2020). Some caregivers of older adults are now left to care for their loved ones with no additional care and support from others, whether they be paid caregivers or family, friends, or volunteers. As well, these caregivers must deal with the effects of the COVID-19 pandemic on their own lives. Greenberg, Wallick and Brown (2020) point out that it is difficult for these caregivers to find down time and respite from the demands placed on them.

Studying a group of caregivers living in India, Vaitheswaran et al. (2020) have described the increased demands made on caregivers of people with dementia during the crisis. This group of older adults may not fully understand the COVID-19 situation, leaving it up to caregivers to manage public health recommendations in addition to dealing with the care they habitually provide. With the pandemic adding to other demands, Vaitheswaran et al. (2020) report additional concerns from caregivers related to issues such as the protection of loved one from disease, managing isolation with older adults who do not understand the situation, and changes in routines which are known to impact some of the behaviours expressed by the unmet needs of the care receiver with dementia.

Fortunately, there has been some level of social support given to older adults during the COVID-19 pandemic and this has filtered to caregivers as well. Technology has helped caregivers who could afford it to stay connected, essential groceries and needs have been provided by kind family members, neighbours and volunteers, and some informal support has been given through advocacy groups through online means and visits from a distance (Lightfoot \& Moone, 2020). However, at the time of the writing of this chapter, we still struggle to manage the new cases of COVID-19 and we continue to push aside the needs of those caring for older adults. As has been noted above, we rely extensively on these individuals to make sure that older adults' needs are met. If not met prior to COVID-19, there is certainly no chance that COVID-19 helped matters. The forgotten group of caregivers of older adults will most definitely need care post pandemic. 


\section{Caring from a systemic/governmental perspective}

The COVID-19 pandemic's disproportionate impact on older adults living in long-term care points to the need for consideration of the role played by governments and by care institutions in managing the crisis. Clearly, in Canada at least, the pandemic has revealed the inadequacies and weaknesses of existing networks and systems. While post-SARS reports led to a number of reforms in Canada, including the restructuring of public health institutions (Fierlbeck \& Hardcastle, 2020), little consideration has been given to pandemic management and the older population. While this may be explained by the fact that both the SARS and 2009 H1N1 outbreaks did not target older adults, we nonetheless believe it is fair to ask why preparedness plans failed to include a part of the population more susceptible to health challenges and comorbidities.

Despite foreseeable demographic changes marked by an ageing population and an increase in the number of frail older people, political and social choices regarding the most vulnerable older adults have had serious consequences during the pandemic. Despite clear indications that many of the problems were well-known for decades, the proper steps to address the risks in caring facilities were not taken early enough, with devastating results. For example, in Ontario, Canada's most populous province, the Canadian Armed Forces (CAF) were called in to assist residents in some LTCH. After a number of weeks, the CAF Joint Task Force Central rendered public a 15-page report (Mialkowski, 2020) based on the observations of its military personnel in the five Ontario LTCH deemed by the province to have required the most support. The report revealed severe instances of regulatory violations and neglect, spanning from non-adherence or non-existence of policies (ex: lack and/or improper use of personal protective equipment (PPE) by staff, use of expired medication, absence or improper charting), inadequate resources including trained staff and medical supplies, poor or little training, deficiencies in infrastructure (ex: insects, inadequate disinfection), concerns about standards of care (ex: poor catheter hygiene, poor or inexistent treatment of pressure ulcers), general neglect (and finally, violence (ex. aggressiveness, forceful feeding and degrading comments about residents). In the neighbouring province, Quebec, the situation in some homes has been dire, with a large number of deaths, severe worker shortages and insufficient PPE. In one particular home, the care was reported as substandard, with residents not adequately fed, and staff deserting the home in the middle of the outbreak.

While one must recognize that not all LTCH in Canada are deficient to the extent described in the Joint Task Force report, we suggest that the information in such reports does not align in any way with a caring society, caring institutions, or caring governments.

But are governments and public bodies in the business of "caring"? The current literature suggests that they should be and highlights the need to 
reflect on how care ethics can be applied to institutions and social policy. For instance, Stensöta (2015, p. 185) notes that "ethics of care" has traditionally been discussed in the context of care-based settings but that, increasingly, the notion is relied on "to dissect the current arrangement of care provision (or rather non-care provision) in policies and administrative procedures." For her part, FitzGerald (2020, p. 255) argues that care ethics in its "political" dimension "provides a more fruitful path forward if our concern is reaching the full radical transformative potential of an ethics of care." To this end, she "imagines" a governmental Department of Care working "towards new distributions of responsibility for care through democratic processes" (p. 257) and

both caregivers (whether professional or otherwise) and care receivers would need to be consulted on an ongoing basis; each programme would have to facilitate the exchange of ideas, concerns, and feedback related to the ways in which the programme is (re)structuring the caring relation.

While the creation of such a governmental department is not imminent (not to say unrealistic), the suggestion makes us reflect on the importance and relevance of "care" in transforming all facets of our societies.

\section{Caring now and in the future}

As countries move towards deconfinement and as our citizens learn to adapt to life during a pandemic, we must start to reflect on the lessons learned and on our approach to caring for one another. Did we learn anything from the COVID-19 pandemic so far? Gary and Berlinger (2020) reflect on this very question. In their commentary, they rely on Tronto's (1993) conception of care to highlight the undervalued status of care workers in our society. This attitude shows that we must reframe the importance given to care and we must see our commitment to caring for older adults as a societal responsibility. Gary and Berlinger (2020) consider the components of the ethics of care concept to examine how societies might respond to the needs of their members rather than neglecting them in moments of hardship. Undeniably, Tronto and Fisher's (1990) four phases of care can help us think about how we have approached care for one another during this pandemic and how we might repair our world as we move forward.

The first phase of the ethics of care, caring about, involves recognizing and listening to the needs of others. Clearly, as noted above, this has not always been the case during the current pandemic. For example, when, during the period of deconfinement, individuals gather in large groups, refuse to follow directives and, in extreme cases, deny the very existence of the pandemic, concluding that some members of society do not "care about" others, 
more vulnerable than they are, is logical. Notwithstanding the exemplary initiatives from many groups, mainly advocacy and volunteer groups worldwide, one seriously questions our collective and individual ability to truly care about the older members of our society.

The second phase identified by Tronto and Fisher, caring for, refers to our sense of responsibility in addressing identified needs. As we have seen in the examples above, we have failed as a society to recognize our responsibility towards older adults in LTCH. Despite having known of the challenges and the demographics in LTCH for many years, we were incomprehensively unprepared for outbreaks in settings where individuals were particularly vulnerable. Only a few months into the pandemic, and after a significant loss of life, did governments step up to mitigate the devastating consequences of the pandemic on LTCH residents.

The third phase of the ethics of care, care giving, refers to the actual action of giving care. Once a need is identified acknowledged action must be taken. Have we, as a society, failed in this regard as well? In large part, we believe we have. As described above, an important segment of society has been left without caregivers, without protection and without resources to address pressing needs. Numerous reports have described how older citizens were left to die alone. From a practical perspective, the tools for caring (personal protection equipment, human resources etc.) were slow in coming (Faghanipour, Monteverde \& Peter, 2020). Caregivers have had to wait a long time before getting help from advocacy groups and others, leaving several care recipients to their own devices. Governments have eventually provided help to LTCH but they have failed to consider the integration of families and volunteers in the circle of care.

The final phase of Tronto and Fisher's ethics of care is care receiving. In this final and very important phase, ethical care is measured as a function of how well the actions respond to the needs of the care receiver. At this point of the pandemic, it is safe to say that most of the care receiving for older adults has been related to the care of the physical self. In other words, the need to live was addressed quickly, but it can be argued that even this need was not met and continues to not being met in certain parts of the world. While older adults are now receiving attention in $\mathrm{LTCH}$, it is unclear whether the caregiving meets the needs of the care receivers (Tronto, 2010). More studies will be required to assess how care receivers are faring.

\section{For further discussion...}

The COVID-19 pandemic has shown that we are as ageist as ever, that we like to blame others for what is happening and that we really were not "all in this together." Older adults are not blameless when it comes to lack of care. As noted, ageist attitudes are not the product of younger generations alone (Global Report on Ageism, 2021). Just like their younger counterparts, many older adults are guilty of not heeding to public health directives. Studies 
have shown that they prefer not to be confronted with their older selves. They can be as guilty of neglecting the needs of older adults as individuals in younger age groups. In the end, we are all in this together when it comes to our collective failure to care.

Unfortunately, there is some indication that we have many challenges ahead of us. Progressive deconfinement in many countries has led to a disregard for public health guidelines, demonstrations worldwide on the requirements needed to keep everyone safe, silence from all of us, including the boomer generation, on what has happened to older adults. We are creating societies where meeting our own needs overrides everyone else's; we make judgments based exclusively on age and we pit generations against each other. Surely this is not the ethical world in which we hope to live.

The current pandemic will end one day. What will happen in LTCH once the worst is over? How will we speak of other generations? What will happen to caregivers and what steps will our governments take to make sure older adults are respected and recognized as contributing members of our society? We must recognize that structural, organizational, administrative, and financial improvements could very well lay the groundwork for better caring of others (especially those in great need). However, we suggest that such measures will not be sufficient if they are not supported by a profound social and political rethinking of the values we hold about ageing and older persons. The first step implies an acknowledgment of the prevalence of ageism and the recognition that the phenomenon affects our ability to truly care for others. Reflecting on our value system in the face of ageing and questioning ageism are colossal tasks, but change is achievable. We propose an upstream measure. Since ageism is a matter of representations that are acquired early in life, we believe that awareness of ageist prejudices and discrimination should be integrated to the educational pathway of the youngest members of society. Moreover, in the workplace, and particularly in long-term care settings, awareness of ageism should be a sine qua non condition of employment for caregivers, managers, and residents alike. We suggest that raising awareness of ageism through education and training would be the starting point for a change in our value system.

However, in order to bring about this change in values, it is necessary to go one step further and put in place political and legal mechanisms that can serve as a springboard for the development of initiatives to address ageism. This is the objective behind, for example, an international convention protecting the rights of older persons. This instrument would give older adults a voice, choices and, de facto, the right to demand that social actors respect their person and their health. Older adults are as diverse as any other age group. A convention is not meant to isolate them from other social groups. Rather, such an instrument aims to protect them from society's lack of recognition, lack of responsibility, lack of action and lack of effort to adequately meet their needs. A UN Convention on the Rights of Older Persons 
would give an additional tool to argue that older adults do indeed have a right to be cared about, cared for, and be both care givers and care receivers.

We are currently living in situations where we must continuously decide how to act, whether to put on a mask, to visit, to support others. As well, as Schimmenti, Billieux and Starcevic (2020) eloquently describe, the COVID-19 pandemic has created fear: fear of the virus, fear for and of loved ones, and fear to make decisions. All these fears are age neutral. And, in this sense at least, we are indeed all in this together. We just need to care that we are.

\section{References}

Atkinson, J.L., \& Sloan, R.G. (2016). Exploring the Impact of Age, Race, and Stereotypes on Perceptions of Language Performance and Patronizing Speech, Journal of Language and Social Psychology, 36(3), 287-305. https://doi-org.proxy.bib. uottawa.ca/10.1177/0261927X16662967

Ayalon, L., \& Tesh-Römer, C. (2018). Contemporary Perspectives on Ageism, International Perspectives on Aging Book Series, 19, 564. https://doi.org/10.1007/ 978-3-319-73820-8

Ayalon, L., Dolberg, P., Mikulionienè, S., Perek-Białas, J., Rapolienė, G., Stypinska, J., Willińska, M., \& de la Fuente-Núñez, V. (2019). A Systematic Review of Existing Ageism Scales, Ageing Research Reviews, 54. https://doi.org/10.1016/ j.arr.2019.100919

Butler, R.N. (1975). Why Survive? Being Old in America (p. 496). Manhattan, NY: Harper \& Row.

Faghanipour, S., Monteverde, S., \& Peter, E. (2020). COVID-19-Related Deaths in Long-Term Care: The Moral Failure to Care and Prepare, Nursing Ethics, 27(5), 1171-1173. https://doi.org/10.1177/0969733020939667

Fierlbeck, K., \& Hardcastle, L. (2020) Have the Post-SARS Reforms Prepared Us for COVID-19? Mapping the Institutional Landscape. In C. Flood, V. MacDonnell, J. Philpott, S. Thériault \& S. Venkatapuram (Eds) Vulnerable - The Law, Policy and Ethics of COVID-19 (pp. 31-48). Ottawa: University of Ottawa Press.

FitzGerald, M. (2020). Reimagining Government with the Ethics of Care: A Department of Care, Ethics and Social Welfare, 14(3), 248-265, https://doi.org/ 10.1080/17496535.2020.1746819

Fraser, S., Lagacé, M., Bongué, B., Ndeye, N., Guyot, J., Bechard, L., Garcia, L., Taler, V., CCNA Social Inclusion and Stigma Working Group, Adam, S., Beaulieu, M., Bergeron, C.D., Boudjemadi, V., Desmette, D., Donizzetti, A.R., Éthier, S., Garon, S., Gillis, M., Levasseur, M., Lortie-Lussier, M., ... Tougas, F. (2020). Ageism and COVID-19: What Does Our Society's Response Say About Us? Age and Ageing, 49(5), 692-695. https://doi.org/10.1093/ageing/afaa097

Gary, M., \& Berlinger, N. (2020, May 1). Interdependent Citizens: The Ethics of Care in Pandemic Recovery. Hastings Center Report. New York: John Wiley and Sons Inc. https://doi.org/10.1002/hast.1134

Greenberg, N.E., Wallick, A., \& Brown, L.M. (2020). Impact of COVID-19 Pandemic Restrictions on Community-Dwelling Caregivers and Persons with Dementia, Psychological Trauma, 12(S1), S220-S221. https://doi.org/10.1037/tra0000793 
Guitteres, A. (2020). We Are All in This Together: Human Rights and COVID-19 Response and Recovery. https://www.un.org/en/un-coronavirus-communications-team/ we-are-all-together-human-rights-and-covid-19-response-and

Hollander, M.J, Liu, G., \& Chappell, N. (2009). Who Cares and How Much? Healthcare Quarterly, 12(2), 42-49.

Hsu, A.T., Lane, N.E., Sinha, S.K., Dunning, J., Dhuper, M., Kahiel, Z., \& Sveistrup, H. (2020, June 4) Report: Understanding the Impact of COVID-19 on Residents of Canada's Long-Term Care Homes-Ongoing Challenges and Policy Responses. Article in LTCcovid.org, International Long-Term Care Policy Network, CPEC-LSE.

Jimenez-Sotomayor, M.R., Gomez-Moreno, C., \& Soto-Perez-de-Celis, E. (2020). Coronavirus, Ageism, and Twitter: An Evaluation of Tweets about Older Adults and COVID-19, Journal of the American Geriatrics Society, 68, 1661-1665. https:// doi.org/10.1111/jgs.16508

Lagacé, M., Laplante, J., \& Davignon, A. (2011). Construction sociale du vieillir dans les médias écrits canadiens: De la lourdeur de la vulnérabilité à l'insoutenable légèreté de l'être, Communication et Organisation, 40, 87-102. https://doi. org/10.4000/communicationorganisation.3553

Lightfoot, E., \& Moone, R.P. (2020) Caregiving in Times of Uncertainty: Helping Adult Children of Aging Parents Find Support during the COVID-19 Outbreak, Journal of Gerontological Social Work. https://doi.org/10.1080/01634372.2020. 1769793

Mialkowski, C.J.J. (2020) OP LASER-Joint Task Force Central Observations in Long Term Care Facilities in Ontario, Canadian Armed Forces Report, https://s3.amazonaws.com/zweb-s3.uploads/carp/2020/05/OP-LASER-JTFCObservations-in-LTCF-in-ON.pdf

OLTCA: Ontario Long Term Care Association. (2019). This Is Long-Term Care 2019. Ontario Long-Term Care Association. https://www.oltca.com/OLTCA/ Documents/Reports/TILTC2019web.pdf

O’Sullivan, T.L., Kuziemsky, C.E., Corneil, W., Lemyre, L., \& Franco, Z. (2014). The EnRiCH Community Resilience Framework for High-Risk Populations, PLoS Currents. DOI: 10.1371/currents.dis.11381147bd5e89e38e78434a732f17db

Ouchida, K.M., \& Lachs, M.S. (2015) Not for Doctors Only: Ageism in Healthcare. Generations (Electronic Edition). https://www.asaging.org/blog/ not-doctors-only-ageism-healthcare

Queluz, F., Kervin, E., Wozney, L., Fancey, P., McGrath, P.J., \& Keefe, J. (2020) Understanding the Needs of Caregivers of Persons with Dementia: A Scoping Review, International Psychogeriatrics, 32(1) 35-52. DOI: 10.1017/ S1041610219000243

Renaud, L., Bouchard, C., Caron-Bouchard, M., Dubé, L., Maisonneuve, D., \& Mongeau, L. (2006). A Model of Mechanisms Underlying the Influence of Media on Health Behaviour Norms, Canadian Journal of Public Health, 97(2), 149-152. https://www.jstor.org/stable/41994707

Rozanova, J., Miller, E., \& Wetle, T. (2016). Depictions of Nursing Homes Residents in US Newspapers: Successful Ageing Versus Frailty, Ageing and Society, 36(1), 17-41. doi: 10.1017/S0144686X14000907

Schimmenti, A., Billieux, J., \& Starcevic, V. (2020). The Four Horsemen of Fear: An Integrated Model of Understanding Fear Experiences during the COVID-19 Pandemic, Clinical Neuropsychiatry, 17, 2, 41-45. https://doi.org/10.36131/CN20200202 
Schulz, R., Beach, S.R., Czaja, S.J, Martire, L.M., \& Monin, J.K. (2020). Family Caregiving for Older Adults, Annual Review of Psychology, 71, 635-59, https://10.1146/annurev-psych-010419-050754

Statistics Canada. (2018). Caregivers in Canada, 2018. https://www150.statcan.gc.ca/ n1/daily-quotidien/200108/dq200108a-eng.htm

Stensöta, H.O. (2015). Public Ethics of Care: A General Public Ethics. Ethics and Social Welfare, 9(2), 183-200.

Trincaz, J., \& Puijalon, B. (2010). Vieillir en terre hostile, In S. Carbonnelle (Ed), Penser les vieillesses. Regards sociologiques et anthropologiques sur l'avancée en âge (pp. 21-36). Paris: Éditions Seli Arslan.

Tronto, J. (1993). Moral Boundaries: A Political Argument for an Ethic of Care. New York: Routledge.

Tronto, J.C. (1998). An Ethic of Care. Generations, 22(3), 15.

Tronto, J.C. (2010) Ethics and Social Welfare Creating Caring Institutions: Politics, Plurality and Purpose, Ethics and Social Welfare, 4(2), 158-171. https://doi.org/10 $.1080 / 17496535.2010 .484259$

Tronto, J.C., \& Fisher, B. (1990). Toward a Feminist Theory of Caring. In E. Abel \& M. Nelson (Eds), Circles of Care (pp. 36-54). Albany, NY: SUNY Press.

Vaitheswaran,S.,Lakshimarayanan, M., Ramanujam,V., Sargunan,S., \&Venkatesan, S. (2020). Experiences and Needs of Caregivers of Persons with Dementia in India during the COVID-19 Pandemic: A Qualitative Study, The American Journal of Geriatric Psychiatry, 28, 1185-1194. https://10.1016/j.jagp.2020.06.026 


\title{
16 Institutional care for older people in Poland during pandemic
}

\author{
Regulations, practice and \\ thoughts about the future
}

\section{Joanna M. Salachna and Anna Szafranek}

The COVID-19 pandemic revealed systemic imperfections with regard to institutional care in every country, which specifically included, and still includes, care aimed at older adults. This weakness is specifically visible in Polish social care facilities, for older persons and somatically ill people, and in hospices (both in stationary hospice facilities as well as hospice home care). Poland has introduced numerous legal regulations concerning social contacts to limit the spread of COVID-19 infections (i.e. maintaining social distancing, limiting the possibility to travel). These regulations applied and continue to apply to the society in general and lack procedures regulating the realm of institutional care aimed at older adults. Moreover, there is a lack of common standards and suggestions in this aspect. This problem, at least to some extent, results from the fact that the discussed institutions are monitored and/or run by local authorities and alternatively by legal entities. However, there is no single, central organ that would coordinate their activity. Additionally, staff working at the aforementioned institutions could not manage the situation and, in fact, preferred to limit the accessibility and physical contact with the institutions and residents, rather than establish procedures to be followed. Apart from the existing epidemic threat, this situation caused a significant dysfunction of social relations. It turned out that even the closest members of a family could not directly contact their older relatives, as well as provide support with the realisation of vital functions and maintain relationships within a family. This internal closure of facilities also meant the inability to use services of the institutions (for instance, stationary hospice facilities) by people who found themselves in a situation requiring urgent support during the pandemic period. All of the mentioned aspects contributed to the deterioration not only of the quality of institutional care but also the condition (both physical and psychological) of older adults - who take advantage of the 
aforementioned support. This situation has shown that it is imperative to elaborate common standards in care aimed at older adults during a crisis for the future. They could be recognised either as guidelines or in the form of legal regulations. Fundamentals of such standards were proposed in this chapter.

\section{Introduction}

As a result of the spreading COVID-19 epidemic, which consequently led to a pandemic, the system of institutional care for older adults was in 2020 challenged with previously unknown problems both in the local as well as global dimension. The new reality exposed systemic imperfections with regard to institutional care, which particularly affected and continues to affect the care of the older persons. These weaknesses manifested themselves clearly in Polish social care facilities, for older and somatically ill people, and hospices (both in stationary hospice facilities as well as hospice home care). On the one hand, Poland implemented legal regulations concerning social contacts to limit the spread of infections (for instance, maintaining social distancing, wearing face coverings in public spaces or restraining the organisation of certain events - both public as well as family gatherings). However, these legal principles have concerned and apply to the general public (or individual provinces or regions of the country), and at the same time there are no detailed provisions regulating the sphere of institutional care for the older persons. Therefore, the aim of this chapter is to review the current legal and social situation in the field of care for the older adults and to answer the following questions: what should be the standards of institutional care aimed at older persons during a pandemic? Who should establish these standards and what should be the methodology of their development? These questions are significant both from the sociological and legal point of view, but also from the humanistic and public health perspectives.

\section{Socio-legal situation during the COVID-19 pandemic}

General rules for the functioning of entities and institutions, as well as regulations that concern decreasing infection numbers, limiting the spread, preventing and fighting consequences, including those socio-economic of the COVID-19 illnesses, have been stipulated by the Polish parliament. These are included in the parliament's Act in force since the 8th of March 2020 (Act of 2 March 2020). Law of 2nd March 2020 on special arrangements for the prevention and combating of COVID-19, other infectious diseases and crisis situations caused by them -- [hereinafter: u.a.cov.], which by mid-July 2021 had already been amended nearly 60 times. More detailed solutions, 
which aim to limit the spread of the epidemic have been, of course, included in different legal acts. Thus, separate parliamentary acts from the

u.a.cov. regulate the functioning of such aspects in the era of epidemic, e.g., implementation of operational programs co-financed by the European Union, awarding public contracts of particular importance in the indicated period, or rules of support for entrepreneurs. It is worth pointing out that so far, the state bodies (parliament and ministers) have issued around 200 legal acts related to the containment of the pandemic and reduction of its effects, including mainly executive regulations (in the number of 176). These include regulations from the Ministry of Health, Ministry of Family, Labour and Social Policy, Ministry of Education. Currently 87 executive regulations are in effect (Internet System of Legal Acts (ISAP), whereas new bills are still being prepared, which are to enable the efficient functioning of the state and basic institutions as well as society in times of pandemic. In addition, Polish local government units are also authorised to issue locally binding acts in connection with the current state of the epidemic, but to the extent permitted by universally binding acts (issued by state authorities).

In Poland, the state of the epidemic due to SARS-CoV-2 infections is in force (on the basis of the ordinance of the Minister of Health issued under the authorisation included in the u.a.cov.) from 20th March 2020. With such a large number of legal acts, as indicated earlier, to ensure uniformity of treatment in combating and preventing infections and illnesses and the negative effects of COVID-19, it would seem that all the necessary basic issues in this area have been settled within almost six months. Namely, issues related both to the functioning of people in the "ordinary" public sphere (e.g., concerning the principles of movement, distance and basic protection measures) and (most importantly) in the "special" spheres, which include health care in the broad sense, including the older adults and the chronically ill. On the other hand, however, the multitude of various acts directly results in legal overregulation (in the sense of the number of legal acts), which by no means results in the consistency of regulations and does not give clear guidelines on how to deal with specific situations. In most public institutions, such as courts, offices and social care facilities, it is the managers who decide individually on the ways of proceeding in a situation of epidemic threat. In practice, this means duplicating patterns of conduct already established in other institutions. However, without a good recognition of the general state and the specifics of the social and institutional environment and the internal organisation of individual entities, such practice is not a good solution. In such cases there is no situational adequacy of rules and procedures.

Here we decide not to present the basic legal regulations that are in force in Poland in the era of a pandemic, as they do not differ significantly from those introduced in most EU countries (Tello Limanco 2020). However, from the point of view of the subject matter of the study, it is important that neither the generally applicable acts (laws and regulations), nor the internal 
acts issued by the relevant services (in Poland, it is primarily the Chief Sanitary Inspector) have any guidelines concerning the rules of contacts and conduct in institutions that are social care facilities or hospices. The only regulation concerning the indicated facilities refers to the possibility of providing work by the employees of such facilities in a situation when they are under quarantine (Act of 2 March 2020, art. 4e u.a.cov.) - if the persons under care agree to it. Therefore, we are dealing with a situation in which the infected personnel can continue to work. In fact, the question of whether or not the residents have consented to this practice is partly illusory (if they do not consent, the residents will be at least partially deprived of care). There are no guidelines as to whether the work of the staff is subject to the consent of all or part of the residents. In addition, the question also arises against the background of the above regulations: is it only the resident who would give their consent individually "under the care" of quarantined staff? There should be no place for such a discussion in times of pandemics or epidemics. Even if the general act leaves certain issues unregulated (it can be assumed that it is deliberately to secure flexibility in individual situations), it should force specific issues to be regulated by the local, central or facility management. Of course, it would be possible - by analogy - to assume that in recognised institutions the regulations and guidelines addressed to typical health care institutions (primarily hospitals) should be applied. Such an assumption, however "convenient" for the staff or managers, is without any factual justification, as other objectives are pursued by typical health care institutions and others by social care facilities and hospices. This in turn is implied by a number of other factors, namely the purpose of the institution and the duration of the guest/patient's stay determine the emergence of a different type of social relationship between the staff and the guests and between the staff and the families of the guest/patients. It is also important to note that the living, psychological and social needs of the guests and their families are different. These considerations argue for the need to develop a methodology for the development of rules of conduct in nursing homes and hospices in relation to epidemic risks and universal recommendations in this area.

\section{Legal basis for the functioning social care facilities in Poland}

In the Polish system of state law there are several entities managing social care facilities (municipal and supra-municipal), which at the same time determines and influences not only the determination of standards (also in the scope of dealing with crisis situations) but also clearly indicates who has the right to set those standards. Local government units (territorial selfgovernment units) are responsible for organising social welfare, among others in the form of running and providing places in social care facilities, and they may cooperate with churches or associations in carrying out this task (Act of 12 March 2004 on social assistance; art. 2 sec. 2 in connection with 
art. 17 sec. 2 of the Act of 12 March 2004 on social welfare - hereinafter: u.p.s.). Thus, the functioning of the social care facilities is possible at the municipal, district and self-government voivodeships level (Act of 12 March 2004 on social assistance; art. 17 par. 1 u.p.s.; art. 19 pt. 10 u.p.s.; art. 21 pt. 5 u.p.s.). It is the duty of municipalities to provide their residents in need of care with a place in stationary institutions, while institutions of a supra-municipal nature take in the residents regardless of their place of residence (Act of 12 March 2004 on social assistance; art. 17.1 .16 u.p.s.; art. 19.10 u.p.s.).

Stationary social care facilities [2; art. 54-56 u.p.s.] are the basic and most important institutions offering support to people who, due to their age or health condition, are unable to function independently and require 24-hour care. It should be noted that in accordance with the regulations in force (Act of 12 March 2004 on social assistance; art. 56 sec. 2 u.p.s.) persons in need are, as a rule, directed to an institution located as close as possible to their place of residence, which is connected with ensuring the sense of safety of the residents, not detaching them from the current environment and maintaining social relations, which in many cases they built throughout their lives.

The basic duties of social care facilities (Act of 12 March 2004 on social assistance; Art. 55, par. 1-2 u.p.s) are to provide residential, nursing, supportive and educational services at the level of the current standard, in the scope and forms resulting from individual needs, with the organisation of the facility, as well as the scope and level of its services taking into account the freedom, intimacy, dignity and sense of security of the residents. The current pandemic situation, as well as the temporary closure of the facilities applied by the authorities, allow us to assume that the above-mentioned assumptions were not fulfilled. It should be remembered that the state of health (especially the mental condition) of an older persons living in an institutional environment is largely dependent on relations with the family and maintenance of regular social contacts. In a situation where meetings with loved ones are limited or completely impossible, the sense of security of the residents may be compromised, which in turn leads to emotional problems and even psychosomatic symptoms. The pandemic has also caused a situation of social isolation, increasing not only loneliness, but above all a sense of alienation, which has a negative impact on mental health (Hossein Javadi \& Nateghi 2020: 1). That is why it is so important to properly prepare social care facilities to function efficiently in any situation (including epidemics).

In accordance with Article 57, paragraph 1 of the u.p.s. (Act of 12 March 2004 on social assistance), social care facilities (with the prior consent of the voivode) may be run by: local government units, the Catholic Church, other churches, religious associations and social organisations, foundations and associations, other legal entities and individuals. In connection with the designated entities authorised to run the social care facilities, a distinction is made between public (run by local government units) and non-public (in accordance with the u.p.s., these are institutions supporting authorities, cooperating with them on a partnership basis) (Sierpowska 2014: 37, 295). 
One of the key documents (apart from the Act on Social Welfare, social care facilities regulations, statutes and plans of individual needs of the residents) affecting the proper functioning of the discussed institutions is also the organisational regulations, developed by the management of a given social care facility. In accordance with $\S 4$ of the Ordinance of the Minister of Labour and Social Policy of August 23, 2012 (Regulation of the Minister of Labour and Social Policy of August 23rd, 2012 on social welfare homes), it must be adopted by the executive body of the local government unit, i.e., the head of the municipality council, the mayor or the president. In the case of a community house, and if the owner of the house is a non-public entity, the organisational regulations are established by that entity.

It should also be mentioned that the individual DPSs function on the basis of plans of individual needs of the residents, and these plans should be developed (assuming that the health of the resident allows for it and the client expresses willingness to participate in creating such a plan) together with the residents. Considering the current social situation, it seems reasonable to re-examine the existing plans and adjust them to the new legal and social requirements related to the Covid-19 epidemic.

\section{Social care facilities in Poland - the actual situation}

To thoroughly analyse the lack of standards for the functioning of social care facilities during an epidemic, it was imperative to establish the number of such institutions, which at the same time outlined the number of older adults and/or chronically, somatically ill people that are under these facilities' care. Table 16.1 presents the number of places in public and non-public social care facilities in Poland, including three particular voivodeships (as at 31st December 2019). From all of the cases, institutions designed specifically for older adults and/or somatically ill people were distinguished.

It has been considered reasonable to compare how stationary facilities (both public and non-public) in particular voivodeships responded to the epidemiological situation and if they induced (if so, under what conditions) any guidelines with regard to the functioning of social care facilities. While deciding upon the voivodeships to analyse, authors followed the contractual division of Poland into three parts: Poland A, B and C, which are classified according to their level of social and economic development, including the transport network, industry and culture, among others. Every chosen voivodeship will be represented by its municipalities, although considering a very specific socio-economic character of Masovian voivodeship (the most developed region, centre of the country, the smallest indigenous population, capital city), it was not taken into account. Additional criteria of choosing voivodeships were: the amount of social benefits paid and municipalities' expenditure on social welfare. As of such, Poland A will be represented by local government units of the Greater Poland Voivodeship, which can be characterised with the highest expenditure (apart from Masovian 
Voivodeship) on social welfare. Poland B will be represented by Podlaskie Voivodeship characterised with the lowest expenditure on social welfare. Poland C will be represented by Lubusz Voivodeship with one of the lowest amounts of social benefits paid (after Opolskie Voivodeship). Moreover, municipalities in Lubusz Voivodeship have the lowest incomes in the country. While assessing the criteria, current data from the Central Statistical Office were consulted (Central Statistical Office 2019: 466-468).

The analysis of data from Table 16.1 indicates how many people in need of help are impacted by the issue of lack of standards/guidelines concerning the functioning of social care facilities in the light of the pandemic, as chronically, somatically ill and/or older adults constitute $36.79 \%$ of all the resident of such facilities. Moreover, both in Greater Poland and Podlaskie Voivodeships nearly half of social care facilities are allocated to chronically somatically ill and/or older adults (older persons account for $39.78 \%$ and $40.97 \%$ of all the residents of these facilities, respectively). In Lubusz Voivodeship, this percentage is slightly lower $(21.30 \%)$, which is nonetheless a significant group.

With the aim of supplementation and review of implemented guidelines, or their absence, in relation to the epidemiological situation, an analysis of randomly chosen websites of social care facilities in the discussed voivodeships was conducted (Table 16.2). It is important to note that the methodology of choosing particular institutions was simplified, the conducted analysis is a pilot study (the sample should not be treated as representative) and presented conclusions are demonstrative. These conclusions most importantly aim to facilitate the development of guidelines on the standards of social care facilities' functioning during the epidemic, but also to simplify establishing methodology to develop such guidelines. In each voivodeship four websites were analysed (initially, two websites were supposed to represent public institutions whereas the other two non-public facilities, located in urban as well as rural areas). However, choosing such a sample was only possible in Greater Poland voivodeship (no non-public facilities function in Lubusz voivodeship, while in Podlaskie voivodeship there is only one non-public social care facility). As a result, in the two remaining voivodeships the analysis was focused primarily on websites of public institutions managed by local governments.

Data presented in the above Table 16.2 indicate misinformation (websites of half of the analysed institutions, i.e., 6 among 12 social care facilities, lack information on their functioning during a pandemic) and the absence of not only specific, but more importantly relatively standardised guidelines on rules for the organisation of social care facilities. It is characteristic that none of the analysed non-public facilities included any information on their functioning during a pandemic while guidelines in the majority of institutions were limited to a statement: "No visitors until further notice". Only two facilities allowed visits, yet one of them limited the possibility to circumstances in which direct contact is absolutely required (voivodeship 
Table 16.1 Number of places and residents in social care facilities (as at 31st December 2020)

Public Non-

facilities public

facilities

Poland in general

Registered social care facilities in total

Number of places in total

Number of residents in total

Including: registered social care facilities for chronically, somatically ill people and/or older adults

Including: number of places in social care facilities for chronically, somatically ill people and/or older adults

Including: number of residents in social care facilities for chronically, somatically ill people and/or older adults

Poland A: greater Poland Voivodeship

Registered social care facilities in total

Number of places in total

Number of residents in total

Including: registered social care facilities for chronically, somatically ill people and/or older adults

Including: number of places in social care facilities for chronically, somatically ill people and/or older adults

Including: number of residents in social care facilities for chronically, somatically ill people and/or older adults

Poland B: Podlaskie Voivodeship

Registered social care facilities in total

Number of places in total

Number of residents in total

Including: registered social care facilities for chronically, somatically-ill people and/or older adults

Including: number of places in social care facilities for chronically, somatically-ill people and/or older adults

Including: number of residents in social care facilities for chronically, somatically-ill people and/or older adults

Poland C: Lubusz Voivodeship

Registered social care facilities in total

Number of places in total

62

6,375

5,901

26

2,233

1,950

$826 \quad 605$

$81,004 \quad 66,223$

$75,133 \quad 61,356$

266

221

14,781

13,777

351

$30,134 \quad 25,026$

5,108

$26,563 \quad 22,094$

4,469

85

4,

$\begin{array}{ll}51 & 11 \\ 5,329 & 1,046 \\ 4,967 & 943 \\ 22 & 4\end{array}$

4

$\begin{array}{lll}21 & 15 & 6 \\ 2,337 & 1,876 & 461 \\ 2,209 & 1,767 & 442 \\ 10 & 9 & 1\end{array}$

$956 \quad 931 \quad 25$

$864 \quad 844 \quad 20$

Number of residents in total

Including: registered social care facilities for chronically, somatically ill people and/or older adults

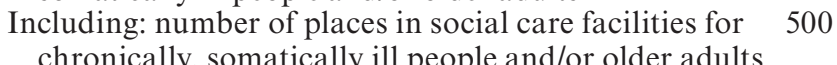

Including: number of residents in social care facilities for 396 chronically, somatically-ill people and/or older adults

$\begin{array}{lll}23 & 21 & 2 \\ 2,337 & 2,225 & 112 \\ 2,113 & 2,001 & 112 \\ 5 & 5 & 0 \\ 500 & 500 & 0 \\ & \\ 396 & 396 & 0\end{array}$

Source: own work based on: Reports on facilities providing care and support, Ministry of Family, Labour and Social Policy, accessible online: https://www.gov.pl/web/rodzina/statystyka-za-2020 [access date: 16.07.2021] 
Table 16.2 Examples of social care facilities for older adults and/or chronically somatically ill people with guidelines implemented as a result of COVID-19

Type of a social care facility Guidelines and its location

Poland A: greater Poland Voivodeship

Non-public social care No guidelines facility (rural municipality)

Non-public social care No guidelines facility (rural municipality)

Public social care facility Visits in the facility are possible every day from 10 a.m. (rural municipality)

Public social care facility No guidelines to 12 a.m. and from 2 p.m. to 5 p.m., however it is forbidden to move freely around the facility without reporting it to staff.

Additional guidelines:

- To enter the facility, visitors are required to notify office no. 2 by ringing a bell and wait for a member of staff to come,

- One resident can be visited by the maximum of two people that are required to wear face masks,

- Before entering the facility, visitors' temperature will be checked by a staff member and they will be required to use a hand sanitiser as advised by staff,

- Information about a visit will be noted in a visitors' registry.

(urban municipality)

Poland B: Podlaskie Voivodeship

Public social care facility (urban municipality)

Public social care facility (urban municipality)

Public social care facility (rural municipality)

Non-public social care facility (rural municipality)

Poland C: Lubusz Voivodeship

Public social care facility (rural municipality)

Public social care facility (rural-urban municipality)

Public social care facility (rural-urban municipality)

Public social care facility (rural municipality)
- No visitors until further notice,

- Restrained activity of residents outside of the facility; only necessary activities allowed (until further notice).

- No visitors until further notice.

- No visitors until further notice.

No guidelines

No guidelines

- No visitors until further notice; if physical contact with a resident is absolutely required, visits will be allowed only after arranging appropriate conditions with the facility's manager or their deputy,

- No visitors until further notice.

No guidelines 
in Poland C) whereas the other one (voivodeship in Poland A) permits visits and their procedure was described in detail. Data suggest that stricter guidelines (mainly limiting the possibility to visit residents) are followed in social care facilities located in urban municipalities (which probably results from greater population density, population in general and more visitors) while in some rural-urban and rural municipalities guidelines allowed visits that follow the sanitary regime. As such, it appears legitimate for all institutions to be obliged to update their websites, whereas in the current epidemiological situation not only to establish guidelines on a regular basis, but also make the information available to the public (on their websites). At the same time, methodology for establishing guidelines should be uniform in the whole country to prevent residents from feeling injustice, when different institutions' organisation and functioning are contradictory (for instance, a complete ban on any visits and the possibility to visit resident while following the sanitary regime).

Another issue, that should have been resolved at the beginning of the pandemic, was the insufficient number of staff in social care facilities, which was caused by the staff's infections with COVID-19 or/and their mandatory quarantine. Poland has recorded numerous, vocal in the media, examples of support offered to residents and staff of social care facilities by volunteers, nuns or other social services. It is important to note that the deficits in staff concern not only its quantity, but also the workers' insufficient professional competence, or its complete lack (i.e. when a social worker is required to pursue responsibilities of a nurse). A study conducted in the US among 161 workers at social care facilities showed that they performed many activities outside of their competence, for instance, physiotherapists performed simple medical tasks in addition to washing and feeding residents. Another challenge was posed by relocating residents to different rooms (in the case of people who had to undergo quarantine) since the majority of residents had been occupying their rooms for years and as a result of quarantine their personal belongings had to be moved (to maintain the feeling of safety) (Seshadri et al. 2020).

Unclear guidelines on accepting new residents in stationary social care facilities cause other difficulties. In Poland, during a period of temporary closure of social care facilities and hospices, accepting new residents was halted. Such a situation should not have occurred since families, which could not care for, or continue to care for, a terminally ill older adult were deprived of the possibility of institutional support, i.e. a place in a stationary hospice. On the other hand, a potential acceptance into a stationary facility would most probably make visiting a patient impossible, which both from a perspective of a dying person and their family should not occur. For instance, in one of the German states, North Rhine-Westphalia, admitting new patients was not limited at all (however, every new patient was subjected to a 14-day quarantine). As a result of housing conditions, the situation of German residents of social care facilities is significantly better than the Polish ones (which is especially important during the pandemic) as the majority of facilities located in particular German states offer single rooms (although double rooms are occasionally offered as well) (Dichter et 
al. 2020). On the contrary, Polish social care institutions single rooms are rarely occupied with the majority of room offered being double, triple or even quadruple rooms, which hinders everyday functioning of residents and staff considerably during the pandemic.

\section{Diagnosis of the problem and recommendations}

In the case of the discussed institutions, there are two basic problems the lack of general guidelines on the functioning of social care facilities and actual closures of such facilities (refusing to accept new residents and excluding residents from contact with the outside environment). Yet the most serious issue appears to be the lack of clear and general guidelines for all social care facilities and hospices. However, considering methodological aspects relating to the type and the changing scale of the threat, that statement is not entirely true. This claim is justified by the variability of the risk in itself, as well as its severity in the country or a region, etc., as well as the specificity of the facility (type of facility, i.e. social care facility/hospice, number of residents, their health condition, location of the facility, number of staff, infrastructure). Hence, authors assumed that the methodology of constructing guidelines must at its base take place at two levels, i.e., nationwide/central and at the individual/given facility's level. Of course, this approach can be accused of a mistake in locating the decision-making centre. For it can be indicated that local authorities have better overview of the situation in a given territory. However, such approach is not correct due to the fact that the authorities at the central level have:

- on the one hand, general data, i.e., data on the situation in the country as a whole,

- on the other hand, analytical data of individual regions relativising their situation, which in turn provides the basis for the development of a nationwide specific map in terms of the threat, intensity and course of the epidemic. In addition, the methodological correctness requires including determinants of an intra-organisational resource nature, i.e. about staff and the use of the facility's infrastructure.

The presented assumptions indicate that guidelines in the discussed subject must consist of two basic elements: general and detailed (individual), while nationwide guidelines (level I) must be created initially. This is because of their fundamental importance and the nature of the data that the central government has at its disposal (as already mentioned). Individual /particular facility's guidelines (level II) should, in turn, regulate two areas/dimensions: intra-organisational (level IIA) and relations with the environment (level IIB). In the individual scope, the intra-organisational rules should be developed first. Intra-organisational rules such as: (1) appropriate training 
of employees (following rules in interpersonal contacts, using equipment, preparing food), which is, in fact, the manner of providing care; (2) the possibilities of using infrastructure (medical and/or rehabilitation equipment, size of rooms, number of toilets) imply maintaining a certain level of safety in a given facility. This level, in turn, is important in determining whether at all and what degree of contact with the outside environment may take place under given circumstances and the facility's conditions.

Considering the dynamics of the epidemic (and epidemics, in general), it is impossible to define guidelines of a general or individual nature in advance. However, it is possible to demonstrate (in the form of guidelines) recommendations as to what these guidelines should not be and/or what provisions they should contain. In this regard, of course, some preliminary assumptions are needed regarding the specificity of the functioning of social care facilities, as well as hospices. The two main assumptions are:

- the need to maintain social relations between the residents of social care facilities (or hospices) as a necessary condition to maintain the proper psychophysical condition of the residents and their family members;

- the need to ensure the functioning of social care facilities and hospices, including providing care to existing residents and accepting new ones.

\section{For further discussion...}

Taking into account the aforementioned assumptions, in the light of previous analysis, it is reasonable to take into account the following principles in the guidelines:

- Temporary closure of social care facilities (limiting contacts with the outside environment to the necessary minimum) cannot mean that the admission of new residents is excluded (which actually occurred in Poland). This claim applies to both nursing homes and residential hospices. The refusal to admit new residents may be treated (in the case of public institutions) not only as a failure to fulfil the tasks imposed on them, but also as actions discriminating against persons who are formally entitled to such care.

- Residents/patients must not be completely deprived of contact with the outside environment. In this respect, a distinction must be made between the resident and their closest relatives (family members or friends) and between the resident and the environment "at large" (e.g. going out to the store, going for a walk). In the former, it is possible to limit the number of people the resident may have contact with, provided that the necessary sanitary requirements are maintained. As far as the latter scope is concerned, in justified cases, it can be suspended entirely - but only temporarily and these restrictions should be consistent with the general social restrictions (the are in force nationally or locally). 
- While the above recommendations are of a substantive nature, one cannot underestimate a guideline of an instrumental nature, i.e., without which it is impossible to plan and implement any guideline correctly. This principle is articulated below.

- It is necessary to introduce general principles of preparing the staff of the facilities in terms of procedures for dealing with a state of epidemic/pandemic, as well as to define the principles of organisation of replacement staff (i.e. people replacing employees excluded from the possibility of working, for instance, due to quarantine). It should be noted, however, that the scope of training should be different for the staff (employees) and different for the management of the facilities. The introduction of top-down rules in this aspect results in the uniformity of the application of procedures and the relatively efficient functioning of the whole care system on a national scale, and at the same time excludes the possibility of overinterpretation in the application of procedures. It also gives the necessary flexibility, i.e., making decisions within a generally defined framework. The training of employees is essential in order to maintain uniform safety standards. It should be emphasised that it is imperative to regulate the rules of behaviour of people working in different entities (including social care facilities), especially medical personnel. It is crucial to determine the rules of replacing employees who cannot perform contractual services. To consider in the latter case is the use of staff (e.g. medical) from primary health care institutions, which during the epidemic are mainly focused on giving medical advice on the phone.

Finally, it is important to note that the established guidelines should be: public (socially accessible); - there is a need to publish both Level I (national guidelines) and Level II (individual facility's) guidelines, which is generally not implemented. The development of the first-level guidelines by central authorities with the participation of a wide range of recognised experts (in the field of medical science, in particular) and practitioners is important for the social acceptability of the guidelines. This body should be known to the public, as should the voting results of this body concerning individual guidelines or groups of guidelines.

\section{References}

Central Statistical Office, Statistical Yearbook of Voivodeships, Warsaw 2019.

Dichter M.N., Sander M., Seismann-Petersen S., Köpke S., COVID-19: it is time to balance infection management and person-centered care to maintain mental health of people living in German nursing homes, "International Psychogeriatrics”, Cambridge University Press: 12 May 2020, p. 1-4. DOI: 10.1017/ S1041610220000897. 
Hossein Javadi S.M., Nateghi N., Covid-19 and it's psychological effects on the elderly population, "Disaster Medicine and Public Health Preparedness", Cambridge University Press: 15 July 2020, p. 1-2. DOI: 10.1017/dmp.2020.245.

Internet System of Legal Acts, https://isap.sejm.gov.pl/ [access date: 18.08.2020].

Rozporządzenie Ministra Pracy i Polityki Społecznej z dnia 23 sierpnia 2012 r. w sprawie domów pomocy społecznej (Dz. U. 2018 poz. 734) / Regulation of the Minister of Labour and Social Policy of August 23rd, 2012 on social welfare homes (Journal of Laws of the Republic of Poland 2018, item 734).

Seshadri S., Concannon C., Woods J.A., McCullough K., "It's like Fighting a War with Rocks:" Nursing Home Healthcare Workers' Experiences During COVID-19", "Infection Control \& Hospital Epidemiology", Cambridge University Press: 05 August 2020, p. 1-7. DOI: 10.1017/ice.2020.393.

Sierpowska I., Pomoc społeczna. Komentarz, Wolters Kluwer, Warszawa 2014.

Sprawozdanie o placówkach zapewniających całodobową opiekę i wsparcie, Ministerstwo Rodziny, Pracy i Polityki Społecznej, accessible online: https://www.gov. pl/web/rodzina/statystyka-za-2020 [access date: 16.07.2021].

Tello Limaco I.J., Prawa podstawowe w czasie pandemii COVID-19 w Hiszpanii, "Prawo i Praktyka" Temidnium: June 2020, p. 47-48.

Ustawa z dnia 2 marca 2020 r. o szczególnych rozwiązaniach związanych z zapobieganiem, przeciwdziałaniem i zwalczaniem COVID-19, innych chorób zakaźnych oraz wywołanych nimi sytuacji kryzysowych (Dz. U. 2020 poz. 374 ze zm.) / Act of 2 March 2020 on special solutions related to the prevention, prevention and combating of COVID-19, other infectious diseases and crisis situations caused by them (Journal of Laws of the Republic of Poland 2020, item 374 as amended).

Ustawa z dnia 12 marca 2004 r. o pomocy społecznej (Dz. U. 2019 poz. 1507 ze zm.) / Act of 12 March 2004 on social assistance (Journal of Laws of the Republic of Poland 2019, item 1507 as amended). 


\title{
17 Internet-telephone consultation service for older persons
}

\author{
Stawomir Tobis, Katarzyna Wieczorowska-Tobis \\ and Agnieszka Neumann-Podczaska
}

The COVID-19 pandemic provoked implementations of novel services incorporating innovative technological and organisational solutions. In the available literature, there were no interdisciplinary approaches which would combine the students of various medical specialties with the expertise of their academic teachers and address the medical and functional needs of older individuals during the pandemic. Our project allowed older individuals to be helped at home with a broad range of issues, which has not been described before in the literature and practice description.

\section{Introduction}

The outbreak of the COVID-19 pandemic caused the introduction of unprecedented limitations in the functioning of society. Restrictions introduced concerned the operation of many institutions but also related to interpersonal contacts. The recommendation to stay at home led, among other things, to reduce the accessibility of health care facilities (e.g., GP and specialist clinics). In Poland, due to the transformation of some hospitals into COVID-19 units, in which only patients with a positive SARS-CoV-2 result are treated, entire teams of specialist clinics operating at these hospitals, from one day to another, ceased to be available to the general public (Pinaks et al. 2020: e924730). In this situation, many older people had no one to turn to when it came to doubts and questions related to drugs, but also everyday functioning.

Moreover, significant restrictions in the functioning of other health care units, resulting from staff limitations and complicated procedures, caused diminished availability of medical consultations. Reports of problems with accessing medical advice are confirmed in many countries. At the same time, it is noted that the reduction in the number of consultations results not only from limited availability but also from the patients' reservations and hence the fear of seeking necessary help. 
Among the factors of increased risk of developing COVID-19, and also those of a severe course of the disease, older age and selected chronic diseases (heart diseases, diabetes, cancer - at present or in the previous three years, and chronic obstructive pulmonary disease - COPD - or severe asthma) are pointed out (Gemes et al. 2020: 401; Neumann-Podczaska et al. 2020: 988). Since age is a risk factor for all these diseases in older persons, it is they who were mainly ordered to remain at home when the pandemic started. This fact is particularly important combined with data showing that frailty, one of the most typical morbidity traits in geriatrics, was one of the essential mortality factors in COVID-19 patients (Hägg et al. 2020). Henceforth, various institutions, including nursing homes, developed targeted strategies (Wrona et al. 2020: e451).

All institutions involved in the activation of older adults were also closed overnight; older adult centres, day centres for older adults and the senior clubs have ceased to function. What's more, the message to the older adults by all involved in activation activities and the media has changed dramatically - also overnight. Previously, much attention was paid to increasing the activity of older persons and their social involvement. They were educated that - in order to function well, stay fit for a long time and live in their own home - they have to leave the house, meet people and be active, both physically and cognitively (Delle Fave et al. 2018: 828; Langhammer et al. 2018: 7856823). Meanwhile, due to the pandemic, they were suddenly supposed to stay at home. Unsurprisingly, the older adults began to ask how to reconcile these restrictions with activity and exercise, which created a sudden increase in the demand for online services, but also for all actions that might be taken to improve the everyday functioning.

Particular attention should be paid to the older people taking into consideration the stress related to uncertainty about the future and the lack of a sense of security resulting from suddenly finding themselves in new circumstances. One of the typical features of the ageing process is less flexibility and a more difficult adaptation to new situations (Van Bookel et al. 2017: 11). Undoubtedly, the pandemic created not only a sense of threat, but also forced a rapid implementation of new solutions - mostly remote, and thus allowing for social distancing and reducing the risk of exposure to the novel coronavirus; there was practically no time to get to know and get used to them.

On the other hand, the forms of classes and courses for students were changed from one day to another. Those whose future work is based on direct contact with the patient/client were deprived of the possibility of interacting with their future caretakers. This is all the more important as contemporary healthcare, and social care paradigms place the person at the centre - the approach known as person-centred care (The American Geriatrics Society 2016: 15). Building a valuable therapeutic relationship between the professional and the patient or client is an essential part of this 
approach. It seemed impossible to simulate this in a remote learning setting. Hence, the search for solutions that could be used in this context began.

\section{Internet-telephone consultation service for older persons: how it works}

Information about the service and its operation was published in the press and television, both local and nationwide. Internet news websites and the website of the Poznań City Hall were also involved in disseminating the info. Additionally, information was spreading by word of mouth, as the older persons themselves informed each other about the possibilities of consultation.

The principle of the service's operation is presented in Figure 17.1.

Older people called the advertised phone number. The information given clearly stated that within it CS, students consulted under the supervision of academic teachers, i.e., that each recommendation issued was discussed with them.

The first contact with the older person was made by the student responsible for the technical aspects of the connection; they set the day and time of consultation and found out what were the older adult's preferences regarding the connection. Video chat via Messenger (Facebook) or WhatsApp was preferred, but telephone contact was also possible. Older people were informed that - if they do not use a communicator yet - once they decide in favour of a video contact, they would receive help from students in installing and launching the appropriate application.

After settling the details, the negotiated calls followed. Each consultation consisted of at least two connections. During the first one, an interview was performed. Before the main part of the conversation, a short recording regarding the protection of personal data and their processing in connection with the General Data Protection Regulation (GDPR) was played. After

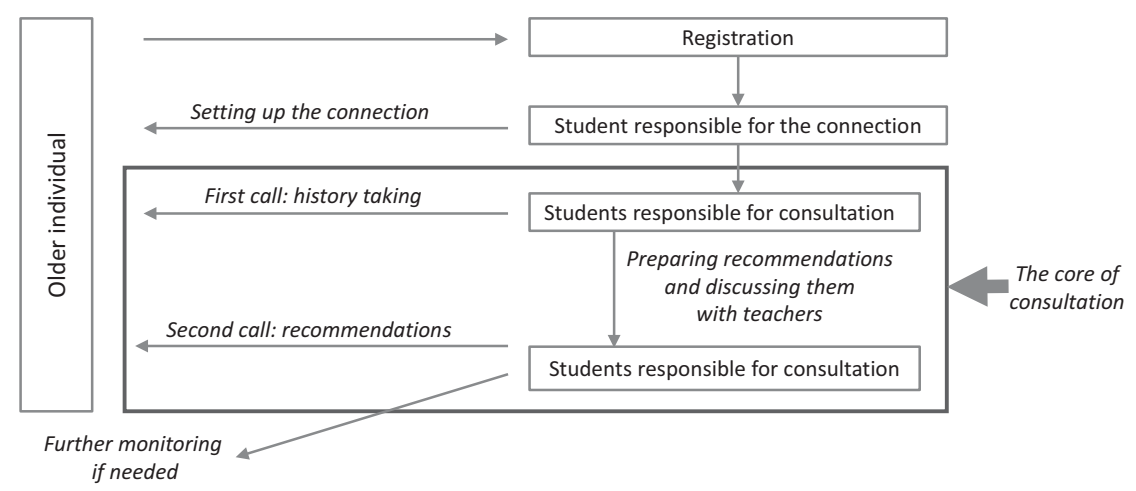

Figure 17.1 The Internet-Telephone Consultation Service (itCS) 
obtaining the older adult's consent to the processing of personal data for consultation purposes, the students collected an interview, which varied depending on the consultation path. During this interview, older adults also raised their doubts or problems with which they turned to the itCS. After collecting the interview, the students made an appointment for a second consultation within a few days.

In the meantime, the students prepared answers to the questions asked by the older adults, solved the reported problems and developed individual recommendations for all patients. The prepared recommendations were discussed with academic teachers.

The second call involved issuing recommendations to the older adults. If necessary, monitoring rules for recommended solutions were also established. Therefore, the dates of further connections were often set to check whether the recommendations brought the desired effect. An additional intervention modifying the originally issued recommendations was also possible.

The students operating the itCS were volunteers. They acted on the basis of the Volunteer Agreement (including also the detailed Regulations for the operation of itCS, which constituted an appendix to the Agreement) concluded between the clinical unit, being an integral organisational part of the Poznan University of Medical Sciences, and the student. This agreement regulated the principles of voluntary activity and secured the students against possible claims of patients related to the consultations received. Two types of the consultation were provided:

- Drug consultations, in which the students of the Faculty of Medicine and Faculty of Pharmacy participated. The purpose of these consultations was to answer questions about the principles of drug use, how to take specific medications (e.g. before or after eating), what to do when, for example, a drug is about to end, or can additional over-the-counter medicines or dietary supplements be added to the treatment? An interview was done about the drugs to which the questions were asked, but also about the laboratory results and hospital discharge cards to ensure that the advice was best possible. A large proportion of the reported problems concerned older adults' doubts about the use of certain groups of preparations. In such a case, the role of the volunteers was to provide comprehensive information on indications for the use of these drugs, including the balance of benefits and complications that may result from applying a given therapy. Volunteers often managed to convince the older patients to start using again medications prescribed by a doctor, often significantly improving the prognosis in a given condition, but having, every now and then, an unjustifiably bad reputation.

- Consultations regarding the occupational status and level of activity provided by students of occupational therapy, with the aim to find and indicate possible activities for older people confined to the own four walls 
and to improve (or at least maintain) their physical and mental fitness and well-being. They were also supposed to meet neither with friends nor with members of their families. All this presented a reversion of the narrative from "go out and be active" to "stay at home and isolate." The consequence was that that the developed solutions and established habits were no more applicable and many of the older adults were at risk of not only declining fitness but also mental problems. The students thus performed thorough interviews to define the occupational status of the older subject in as broad a way as possible, taking into account various physical and social factors. For every client, recommendations addressing their unique needs, requirements, and preferences were elaborated, discussed with academic teachers, and presented to the older person. The solutions proposed ranged from physical exercise adapted to the living space of the client, via cognitive stimulation, to gaming and other pleasing activities.

The academic teachers participating in the consultations were - depending on the path - a pharmacist with a special background in geriatrics and a medical doctor (geriatric specialist) or teachers involved in educating the students of occupational therapy, with preparation in geriatrics (e.g., completed postgraduate studies in gerontology and geriatrics).

\section{Discussion of the project's results}

To assess the results of the project and to understand the perspective of older adults on the undertaken activities, in-depth interviews with older adults were carried out using communicators commonly used for consultations in the itCS. Examples of the characteristics of people who participated in the interviews are presented in Table 17.1.

During the interviews, older adults particularly emphasised the possibility of establishing contact with young people. Occasionally, setting up the connection took longer than the consultation itself, but this process was perceived as a valuable, unique lesson in intergenerational interactions. Whenever a video call was possible, the older adults appreciated the possibility of a visual contact with the consulting students and clearly gained an additional sense of security. Moreover, for those who were able to set up their visual communicator for the first time, it was like opening a new window to the world, because they could also use it in other contexts later on. The first connection attempts were assisted by students who provided the necessary technological support; this was particularly important in the light of a study by Peek et al. who showed that external support could play an important role in this respect, not only for the willingness to use the technology at the moment but also for the stability of the use of technological devices in the future (Peek et al. 2019: 236).

The process of setting up a connection can be viewed as a kind of intergenerational workshop, during which students learned how to communicate 
Table 17.1 Examples of characteristics of people who benefited from consultations

\begin{tabular}{|c|c|}
\hline Characteristics of the consulted person & $\begin{array}{l}\text { Type of consultation } \\
\text { provided }\end{array}$ \\
\hline $\begin{array}{l}\text { A man, } 81 \text { years old, lives with his wife, heard about the } \\
\text { itCS on TV, very active before the pandemic, among } \\
\text { others, involved in educational activities for older adults. } \\
\text { Interested in herbal medicine; during the pandemic, he } \\
\text { began using a large number of dietary supplements to } \\
\text { increase his immunity. }\end{array}$ & Drug consultation \\
\hline $\begin{array}{l}\text { A woman, } 70 \text { years old, lives alone, occasional contacts with } \\
\text { her family; she found her way to the itCS thanks to friends. } \\
\text { She could not cope with the excess of free time during } \\
\text { the lockout; active before the pandemic participated in } \\
\text { numerous activities organised for older adults. }\end{array}$ & $\begin{array}{l}\text { Consultation } \\
\text { regarding the } \\
\text { occupational } \\
\text { status and level } \\
\text { of activity }\end{array}$ \\
\hline $\begin{array}{l}\text { A } 67 \text {-year-old woman, single, found the itCS thanks to } \\
\text { information on TV; unable to cope with the excess of free } \\
\text { time during the lockout; was active before the pandemic, } \\
\text { participated in a wide range of activities for older adults. }\end{array}$ & $\begin{array}{l}\text { Consultation } \\
\text { regarding drugs, } \\
\text { occupational } \\
\text { status and level } \\
\text { of activity }\end{array}$ \\
\hline
\end{tabular}

with the older subjects. In practice, they learned in particular that when you are blazing a trail in an unknown world, and you need to teach someone something new, one of the essential rules is to adjust the pace of the instructions given to the recipient's perception capability. They also learned to cope with frustration, both for themselves and for the patient, if the connection setup was complicated and took a long time to complete. Such training is an important lesson for the young generation, perfectly skilled in technology, as it confronts a different perspective in which what is obvious for them is not obvious for another person; it appears complex, often terrifyingly alien, and also unattainable. Therefore, such experience teaches empathy, which is necessary for future work with another person. One of the students who helped to establish the connection said

first of all, it was an invaluable opportunity for me to gain experience in contact with the patient (...). I learned how to talk, how and what questions to ask to get the information I needed. I learned that everyone should be approached individually, not treated as "just another patient." I was very positively surprised by how open the patients were. I had the idea that younger patients were open-minded rather than older. Meanwhile, itCS has completely changed my opinion about older adults. Previously, I was afraid of contact with an older patient, and now I recall this experience in superlatives.

This statement shows, on the one hand, the fear of a young person from contact with an older patient, and on the other hand, the positive experience of this contact. According to many available studies, education through 
direct contact with older subjects has a positive effect on students' attitudes towards old age (Adelman et al. 2007: 1445; Brikenmaier et al. 2009: 784). Among the potential benefits of such contact, the reduction of the phenomenon of "ageism" is particularly emphasised, as well as greater readiness of young people to undertake activities in the field of gerontology in the future (Cottle \& Glover 2007: 501; Ferguson 2012: 713).

For the students, participation in the project was also an opportunity to gain experience of working in a team, including seeking solutions based on brainstorming. The diversity of problems which older adults reported to the itCS caused that students learned how to deal with various life situations. All this is of special importance, because due to the epidemiological situation, both in Poland and abroad, practical classes where students had daily contact with older persons, were suspended. The itCS activities are in line with the paradigm of education through practice, the need of which has been emphasised for many years, particularly in the area of social work, resulting in not only a superficial contact but also establishing a relationship between the student and the older patient (Adelman 2007: 1445; Allan \& Johnson 2009:1). Thanks to such a relationship, young people's understanding of the problems of old age improves and, as a result, stereotypes are broken, and a better image of old age is constructed (Taylor 2016).

Also in the case of older people who had to face difficulties and overcome many emotions such as fear, anxiety or nervousness while setting up a connection in order to contact the itCS, such education had a multifaceted dimension. First of all, attention should be paid to increasing the competences of older people in the use of smartphones (or computers) and applications such as instant messaging. On the screens, students and academic teachers many times saw the smiling faces of older adults suddenly appearing, often accompanied by loudly spoken words of joy at the meeting. Older adults, accustomed to phone calls, particularly emphasised the value of a conversation conducted not only with the use of sound, but also moving image, and described this form of contact as a more satisfying one. Moreover, when the connection worked, and the patient was able to deal with the (initially) complicated equipment, they felt a sense of satisfaction and driving force. Such experience teaches the older person that it is worth making an effort, even if the task seems at first difficult or impossible to accomplish.

Older adults' ability to establish a connection and use social messaging reduces their level of digital exclusion. It is estimated that digital exclusion concerns about $30-40 \%$ of older adults in Poland, so itCS, by educating older adults who are able to share the attained skills, counteracts the phenomenon of digital exclusion. Indeed, as demonstrated, the majority of older people confirm that contact with younger people helped them acquire new skills, such as computer or internet use. Usefulness is considered to be one of the key elements of technology acceptance (Morris et al. 2003: 425). Moreover, it was also shown that the perception of the social presence 
with the use of technologies impacted the degree of perceived usefulness positively, trust and intrusiveness, which was confirmed in practice by our project (Etemad-Sajadi \& Gomes Dos Santos 2019:713).

COVID-19, unfortunately, put the issue of digital poverty of older adults in the spotlight. It was known before that this age group had less access to the Internet than their younger counterparts. According to the Digital Economy Outlook Report from the Organization for Economic Cooperation and Development (OECD), in 2017, 96.5\% of those who were 16-24-year-olds were connected to the Internet and only 62.8\% of 55-74-year-olds (OECD 2017). Furthermore, it was shown that even if older adults do use the Internet, they are likely do so at a more basic level than younger age groups (Van Boekel et al. 2017: e180). As far as access to telemedicine services is concerned, besides a WiFi connection, video-enabled devices and digital literacy are essential. The study of Utley and colleagues (Utley et al. 2021:1) demonstrated that once older adults were equipped with visual communication devices, only one person in three was able to establish a connection successfully, which shows that technological literacy is a critical issue. Our project, thanks to the activities undertaken by the students, resulted in substantial lowering of this barrier.

For older adults consulted by the itCS, contact with students filled the gap that arose during the lockdown period, when there was a strong recommendation for older people regarding the need to isolate themselves, and not to contact even their loved ones. One of the older adults, talking about how she felt during the pandemic, when she could at long last have contact with students, said: "someone will call, and there is this contact at the moment when there is no direct contact". Social interactions are arguably strongly linked to positive affect, longevity, and good health. While older subjects are known to be at high risk of many dangers related to COVID-19, social distancing and isolation present challenges for their mental health. It is thus imperative to take into account this kind of toll taken on vulnerable older persons while fighting the pandemic (Older Adults, Social Isolation, and Technology During COVID-19 Pandemic 2020). Moreover, loneliness and social isolation are known risk factors for chronic diseases and vice versa, creating a vicious cycle and, additionally, the treatment of socially isolated older adults comes at a substantial annual cost. If they are ordered to stay at home and have their shopping delivered, and consequently avoid social contacts, actions must be taken to compensate for the consequences of social isolation for their physical and mental health.

As demonstrated by the meta-analysis of Wrzus and colleagues found that when the family network was stable in size from adolescence to old age, both the personal network and the friendship network decreased over time (Wrzus et al. 2013:53). Contrariwise, the pandemic affected all social contacts equally, as it introduced the fear that relatives could be infected during the visits, hence even the grandchildren were requested not to visit their grandparents. Henceforth, the itCS was a welcome response to the existing 
situation, as it filled the unmet needs that were present and gave the opportunity to establish contact with another person at a time when any meetings were de-recommended:

I hear that many people suffer from this situation [the epidemic], that their psyche fails. I met these [young] people [students] for the first time, but my tolerance is high, and I recognise that as young people they can behave well and that they are willing to help.

In this statement, the older adult appreciates the possibility of contact with another person, even if it is only a remote one, but at the same time presents his positive attitude towards young people. Such a good attitude of older adults to young people was also shown in the study conducted by Cybulski and colleagues, which showed that as many as $85 \%$ of the older persons surveyed gave a positive answer to the question whether they like the contact with young people, even if these contacts are rare and limited to meetings a few times a year (Cybulski et al. 2013:1099). According to this study, almost half of the surveyed older participants of the University of the Third Age believed that it was necessary to integrate older adults and young people to achieve mutual profits. Among the benefits that older adults may derive from contacts with young people, the greater chance of older adults being more active in many areas of life is emphasised.

The profits of remote contact between an older adult and a student within itCS are thus multidirectional, with not only an individual dimension but also a social one. These effects, although observed particularly "here and now" during the pandemic, are also long-term in nature and apply to both the younger and the older generation. In summary, it is worth quoting the words of one of the older adults consulted by the itCS, who said: "due to the COVID-19 epidemic, the world has changed and the itCS has become a mainstay, a hope [...]."

\section{For further discussion...}

The initiative was created in response to the needs of older adults resulting from the measures introduced during the lockdown and out of concern for older persons. Thanks to itCS, they obtained professional and reliable medical advice on an ongoing basis while reducing exposure to the novel coronavirus. The aim of the activities undertaken was the consultation of older people by means of remote communication, such as instant messaging or telephone. Satisfied patients are the best showpieces of itCS. In conclusion:

- Our project shows the effectiveness of the learning of cooperation between students of various medical specialties in solving problems of older people. 
- A notable innovation of our project is the unique intergenerational lesson. Both students and older subjects learned how to communicate and understand each other and overcome technological barriers.

- We are working on a solution that will allow us to transfer the itCS experience to the post-pandemic times.

\section{References}

Adelman, R.D., Capello, C.F., LoFaso, V., Greene, M.G., Konopasek, L., Marzuk, P.M. Introduction to the older patient: A "first exposure" to geriatrics for medical students. JAGS 2007, 55(9): p. 144-1450

Allan, L.J., Johnson, J.A. Undergraduate attitudes toward the elderly: The role of knowledge, contact and aging anxiety. Educ Gerontol 2009, 35(1): p. 1-14

Birkenmaier, J., Rowan, N.L., Damron-Rodriguez, J., Lawrance, F.P., Volland, P.J. Social work knowledge of facts on aging: Influence of field and classroom education. Educ Gerontol 2009, 35(9): p. 784-800

Cottle, N.R., Glover, R.J. Combating ageism: Change in student knowledge and attitudes regarding aging. Educational Gerontol 2007, 33(6): p. 501-512

Cybulski, M., Krajewska-Kułak, E., Sowa, P., et al. Elderly peoples' perception of young people: A preliminary study. Iran J Public Health 2013; 42(10): p. 1105

Delle Fave, A., Bassi, M., Boccaletti, E.S., Roncaglione, C., Bernardelli, G., Mari, D. Promoting well-being in old age: The psychological benefits of two training programs of adapted physical activity. Front Psychol 2018; 9: p. 828

Etemad-Sajadi, R., Gomes Dos Santos, G. Senior citizens' acceptance of connected health technologies in their homes. Int J Health Care Qual Assur 2019; 32(8): p. 1162-1174

Ferguson, A. Wanted: Gerontological social workers-factors related to interest in the field. Educ Gerontol 2012, 38(10): p. 713-728

Gémes, K., Talbäck, M., Modig, K., et al. Burden and prevalence of prognostic factors for severe COVID-19 in Sweden. Eur J Epidemiol 2020; 35(5): p. 401-409

Hägg, S., Jylhävä, J., Wang, Y., et al. Age, frailty and comorbidity as prognostic factors for short-term outcomes in patients with COVID-19 ingeriatric care. JAMDA 2020, DOI: https://doi.org/10.1016/j.jamda.2020.08.014

Langhammer, B., Bergland, A., Rydwik, E. The importance of physical activity exercise among older people. Biomed Res Int 2018; 2018: p. 7856823

Morris, M.G., Hall, M., Davis, G.B., Davis, F.D., Walton, S.M. User acceptance of information technology: Toward unified view. MIS Q 2003, 27(3): p. 425-478

Neumann-Podczaska, A., Al-Saad, S.R., Karbowski, L.M. et al. COVID 19-clinical picture in the elderly population: A qualitative systematic review. Aging Dis 2020; 11(4): p. 988-1008

OECD Secretariat OECD Digital Economy Outlook 2017. Organisation for Economic Cooperation and Development (OECD) 2017; https://www.oecd.org/digital/oecd-digital-economy-outlook-2017-9789264276284-en.htm

Older Adults, Social Isolation, and Technology During COVID-19 Pandemic. https://www.thectac.org/2020/05/older-adults-social-isolation-and-technologyduring-covid-19-pandemic/B-TACT he Blog to Transform Advanced Care. Advancing Care through Innovation, Observation and Collaboration

Peek, S.T.M., Luijkx, K.G., Vrijhoef, H.J.M., et al. Understanding changes and stability in the long-term use of technologies by seniors who are ageing in place: A dynamical framework. BMC Geriatr 2019; 19(1): p. 236 


\section{Stawomir Tobis et al.}

Pinkas, J., Jankowski, M., Szumowski, Ł., et al. Public health interventions to mitigate early spread of SARS-CoV-2 in Poland. Med Sci Monit.2020; 26: p. e924730

Taylor, N.A., Ageism: Abilene Christian University Students' perception of aging adults. Digital Commons@ACU, Electronic Theses and Dissertations 2016. Paper 24

The American Geriatrics Society expert panel on person-centered care: A definition and essential elements. JAGS 2016, 64(1): p. 15-18

Utley, L.M., Manchala, G.S., Phillips, M.J., Doshi, C.P., Szatalowicz, V.L., Boozer, J.R. Bridging the telemedicine gap among seniors during the COVID-19 pandemic. J Patient Exp 2021; 8: p. 1-4

Van Boekel, L.C., Peek, S.T., Luijkx, K.G. Diversity in older adults' use of the internet: Identifying subgroups through latent class analysis. J Med Int Res 2017, 19(5): p. e180

Wieczorowska-Tobis, K. What does it mean "to be old"? In: Musielak, M. (ed.), Many facies of being old. Health and socio-cultural aspects of aging. Poznan University of Medical Sciences 2006, p. 11-16

Wrona, M., Tobis, S., Wieczorowska-Tobis, K., Neumann-Podczaska, A. COVID-19: Prevention and future initiative within nursing homes. JMS [Internet] 2020, 89(3): p. e451

Wrzus, C., Hänel, M., Wagner, J., Neyer, F.J. Social network changes and life events across the life span: A meta-analysis. Psychol Bull 2013, 139: p. 53-80 


\title{
18 Everyday reality at nursing home care facilities experienced during the COVID-19 pandemic
}

\author{
Małgorzata Halicka, Jerzy Halicki \\ and Krzysztof Czykier
}

Most studies on COVID-19 and ageing are primarily concerned with analysing the issue from a medical science perspective, as ageing itself is an important risk factor for severe illness and death due to COVID-19. However, it must be remembered that the SARS-CoV-2 pandemic, in addition to its profound and still unfolding health effects, also leaves its mark on the daily functioning of older people, both socially and emotionally. In a situation of compulsory isolation, a group particularly vulnerable to loss of meaning and existential comfort are older adults living in social care facilities. In this chapter we would like to share with our readers the opinions of the residents of such facilities regarding their personal experiences of living everyday life in the reality of the coronavirus pandemic.

\section{Introduction}

Humanity lives in an environment dominated by micro-organisms, which constitute $99.99 \%$ of all living creatures that inhabit the Earth. Each of us carries billions of such creatures without realizing that they are our best friends and most dangerous enemies. Some help us digest our food, others cause disease and epidemics (Harari 2014). Most of the infectious diseases that have plagued agricultural and industrial societies originated in domesticated animals and passed on to humans after the agrarian revolution. People living in hunter-gatherer cultures, who had only domesticated the dog, did not experience these misfortunes. Moreover, in agricultural and industrial societies, most people lived in cramped, unhygienic conditions that were a hotbed for diseases (Harari 2014).

Epidemics can change history. The best example of this is the Plague that has re-appeared several times over the centuries. It decimated the population for the first time in the 6th century. With Constantinople at its centre, it lasted only one year and claimed 25 million lives. In the centuries that followed, the Plague killed twice as many people and, according to historians, was 
instrumental in ending Rome's rule. The bacteria causing the Plague came from the East, most likely from China along the Silk Road (Rutherford 2016).

Another Plague epidemic, known as the "Black Death," broke out in China or Central Asia, reached Crimea in 1346, and spread from there to the Mediterranean and to Europe. The disease killed around 200 million people. Plague outbreaks appeared quite regularly until the 18th century (Harari 2014).

In the 16th century, a smallpox epidemic broke out in South and North America, decimating the indigenous peoples of these continents (the Incas and the Aztecs). Plague epidemics broke out in America many times in the second half of the 17th century. The 18th century European Plague epidemic took the lives of some 60 million people. In the 19th century, Plague and cholera pandemics swept the world, claiming over 50 million lives. The 20th century was also not free of epidemics. The biggest of these was the Spanish flu epidemic that broke out in 1918-1919, hit almost all continents, and caused the death of millions (according to various estimates, between 20 and 100 million people). Humanity in the 21 st century is experiencing yet another plague - the COVID-19 pandemic, which has affected people all over the world.

Many questions can be asked about human helplessness in the context of a deadly universal disease. In this situation, it is difficult to argue with the restrictions introduced not only in social welfare institutions, but in all spheres of social life, in order to counteract the spread of the Sars-Cov-2 virus, commonly known as the coronavirus. These actions affected various areas of human life, such as the economy, interpersonal relations, and health. These new regulations have also had an impact on how social care homes work with their residents. The new legal regulations aimed at limiting the spread of the coronavirus caused the institutions to close off from the outside world: family visits and visits to specialists were suspended. The sudden change in the way care facilities operate in Poland and the new regulations made the institutionalization of residents more intense.

In this chapter we want to share with the readers the opinions of the residents of a nursing home regarding their personal experiences related to their daily life during the coronavirus pandemic. We want to show how they dealt with everyday life in this unusual situation. What were the emotions they felt? How did staff carry out their tasks in such an incredibly difficult situation of complete isolation? Could the residents of the facility count on the support of the staff and could the employees of the facility count on the support of the city or regional authorities? We also wanted to learn from the respondents how helpful the clergy were in this situation.

\section{Characteristics of the respondents ${ }^{1}$}

As much as 181 residents live at the Nursing Home in Białystok (Podlasie), but not all of them agreed to participate in the study. Their reasons varied, but most often it was bad health. In a few cases, the residents of the facility were 
reluctant to talk about the coronavirus. Under these extremely difficult conditions, we were able to recruit 35 people to interview. This group included 12 women ( 4 women under 70 and 8 women aged 70 or more) and 23 men (13 of them were not older than 70 and 10 have reached 70 or more years of age). In terms of education, the majority had secondary education (16 people, including eight women and eight men), 13 people (nine men and four women) received vocational education, while six men had primary or incomplete primary education. As far as marital status is concerned, they were mainly unmarried (31 people), including 13 divorced (mainly men -10 people), 10 widowed (six women and four men), while those who had never married were mainly men (7 of them) and only one woman. The largest group of respondents consisted of the deeply and actively religious. Among 16 such people, there were nine men and seven women. There were 13 non-participating believers (nine men and four women), five religiously indifferent respondents (four men and one woman), and only one man who declared himself to be a non-believer. Most of the respondents (14 men and nine women) had children. It is, however, noteworthy that nine men had no children, while only three women were childless. Analysis of the socio-demographic characteristics of the sample explains, in a way, why they ended up living in a care facility.

The results of our research carried out in the group of people described above will be presented below, in relation to three problem areas: the knowledge of the residents of the facility about the coronavirus, the feelings of the residents related to the coronavirus situation, and interpersonal relations during the pandemic. These analyses will be complemented by reports of two professionals employed in two institutions: the nursing home in Białystok, where there was no confirmed outbreak of the coronavirus but full isolation of the residents was nevertheless introduced, and in the nursing home in Choroszcz, where there was a COVID-19 outbreak, as reported by one of the social workers who took care of residents at a COVID sub-unit. ${ }^{2}$

\section{The residents' knowledge about the coronavirus}

All the residents of the nursing home in Białystok had some knowledge about COVID-19. The respondents' statements indicate that they were aware of the vectors and symptoms of infection, the course of the disease, groups of people particularly susceptible to infection, and the possible consequences of infection, including death. Examples: "The virus originating in China from a bat" (W, 72 years old), "It is an infectious disease transmitted by airborne droplets" (M, 71 years old), "Dangerous virus, comparable to biological weapons" (M, 70 years old), "A virus causing respiratory diseases in people over 65 " (M, 64 years old). It is worth adding that a few respondents (four men and two women) have been tested for the coronavirus.

Despite the fact that there were no people infected with the coronavirus among the respondents, they were able to indicate typical somatic symptoms accompanying the disease caused by the coronavirus, i.e., increased 


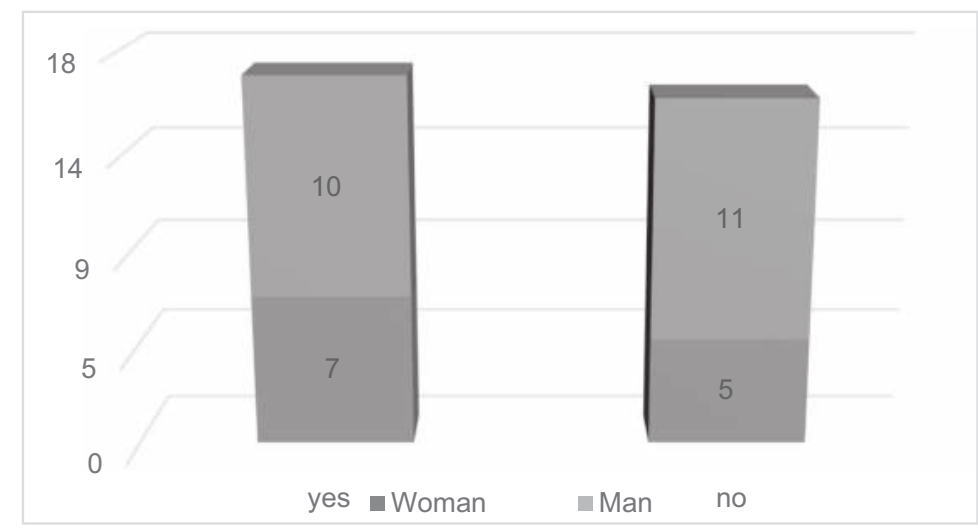

Figure 18.1 Coronavirus training conducted by care home staff

body temperature, cough, shortness of breath, general weakness, lack of a sense of taste and smell. Only one person (male) had known or heard of an acquaintance infected with the coronavirus. However, it should be mentioned that the research was carried out in June 2020 (three months from the introduction of the first restrictions and isolation) before the escalation of infections among older people, including care home residents.

The respondents were not able to clearly determine whether the facility staff instructed them about the coronavirus. Perhaps this was due to the fact that most often the activities meant to improve the residents' awareness of COVID-19 took the form of talks or individual conversations (Figure 18.1). The interview with a director of the facility indicates that many conversations regarding the coronavirus were conducted with the residents.

Thanks to the information about the coronavirus provided by the institution's staff, the residents displayed knowledge of the principles of the facility's functioning in the time of a pandemic and knowledge of the applicable procedures. Each of the respondents pointed out without hesitation the need to inform the caregivers or the facility staff, should suspicious symptoms be noticed in a fellow resident, which could indicate a coronavirus infection. An example of one transparent statement: "Inotify my superiors and caregivers immediately" (M, 60 years old).

The respondents also correctly listed activities related to the prevention of infection. According to experts, today, in the face of the second wave of infections, these activities are the basic and most effective forms of preventing the spread of the virus.

In the opinion of the respondents (both men and women), the most important thing in preventing coronavirus infection is frequently washing or disinfecting hands (Figure 18.2).

It is also important to use protective masks (of the right type, in the right way, and in certain situations) and to keep a distance in relations with other 
40

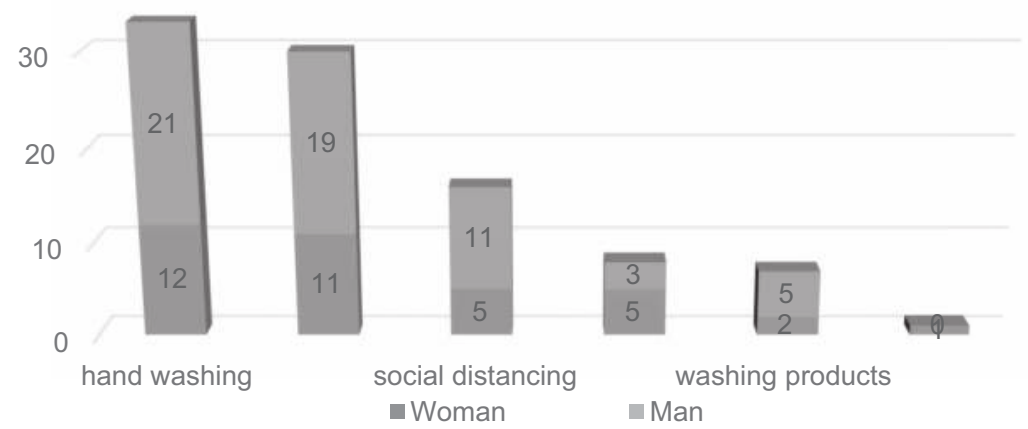

Figure 18.2 Prevention of SARS-CoV-2 coronavirus infection

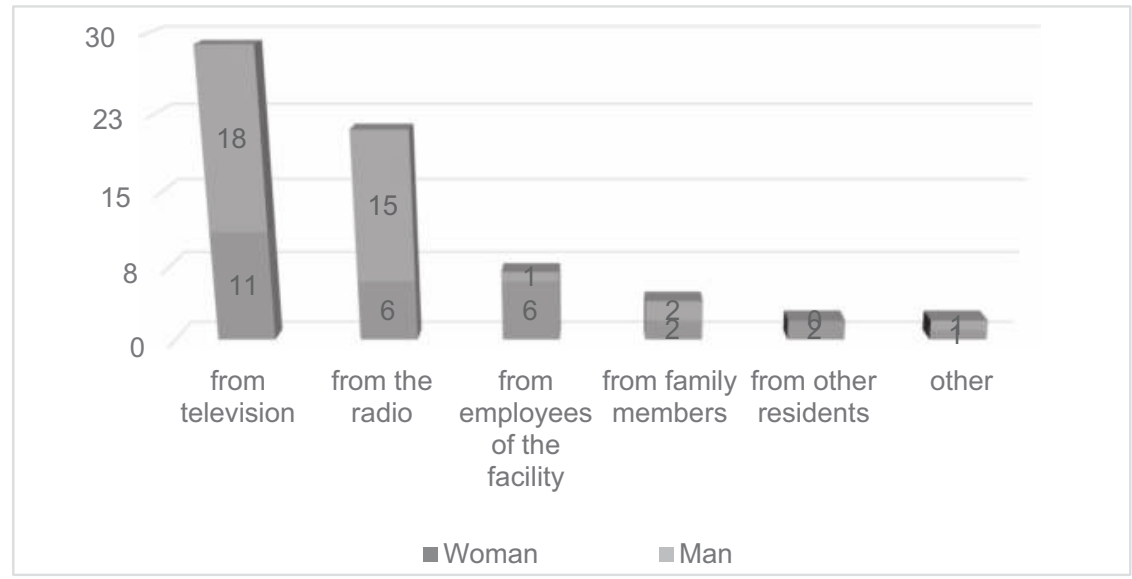

* respondents could choose multiple answers

Figure 18.3 Sources of knowledge about the coronavirus

people. It is also important to disinfect surfaces and objects of everyday use and to maintain hygiene when preparing meals.

As mentioned earlier, the employees of the facility are an important source of knowledge about the coronavirus for the residents.

Most frequently, however, the respondents obtained daily updates on the pandemic from the media - television and radio (Figure 18.3). Family members (mainly through indirect contact) and other residents are also an important source of knowledge. 
In the nursing home where the research was carried out, as in every institution in the field of social welfare and health care, strict security measures were introduced to ensure the protection of residents against coronavirus infection. In the opinion of the respondents, first of all, an absolute ban on visits was introduced in their institution (Chart 4). Every participant knew it and pointed it out (Figure 18.4).

Residents are also forbidden to go outside the facility and to hold and participate in religious services (this was more often indicated by men). Statistical analysis shows a weak relationship between the variables $\left(C_{\text {kor }}=0.25\right)$, however the differences are not statistically significant $(\mathrm{df}=2 ; \mathrm{p}=0.5276)$.

Most of the respondents (17 men and 12 women), despite having lived for many years, claim to never have met a person who had suffered from any infectious disease. Although statistical analysis shows a weak relationship between the variables $\left(\mathrm{C}_{\mathrm{kor}}=0.35\right)$, the differences are not statistically significant ( $\mathrm{df}=2 ; \mathrm{p}=0.2724)$. Most of the respondents (19 men and 10 women) had not experienced any infectious diseases personally.

\section{Emotional responses to the coronavirus}

The relative health of the respondents, at least in the context of infectious diseases (as described above), caused something of a shock in the face of the COVID-19 pandemic, triggering deep feelings of fear, anxiety, and uncertainty about life. Among the feelings accompanying them at the beginning of the pandemic, the respondents most often indicated anxiety, fear, and stress (Figure 18.5). The new, unexpected situation caused a deep concern for their health and life, as well as that of their friends and loved ones.

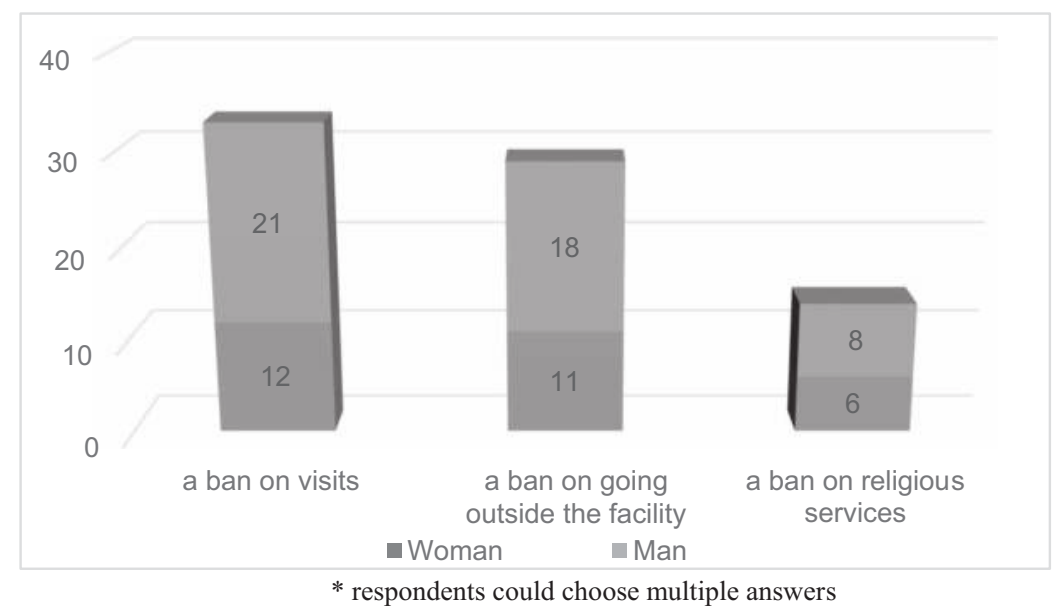

Figure 18.4 Security measures introduced in the care home for the prevention of coronavirus infection 


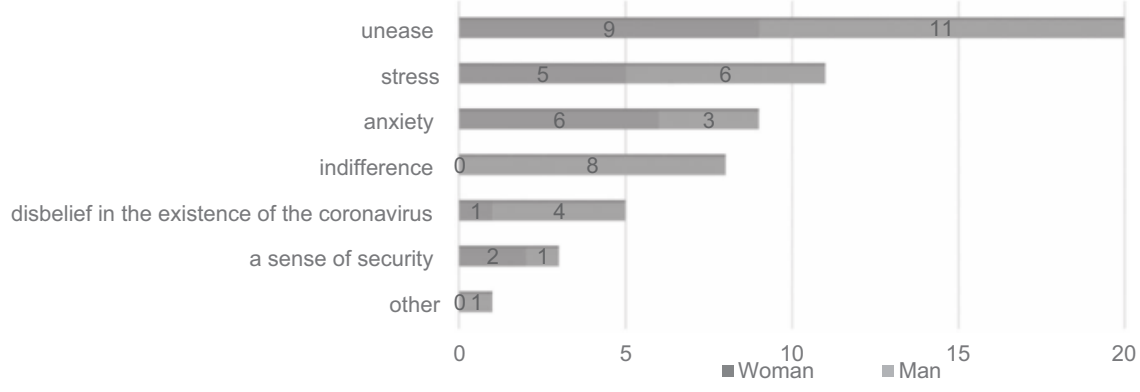

Figure 18.5 Emotions felt by the respondents at the beginning of the pandemic

It is interesting that men, more often than women, were indifferent to the situation, a feeling supported by their disbelief in the existence of the coronavirus. Perhaps it was a consequence of the experience of sudden change that no one was prepared for, a peculiar mechanism of optimistic rationalization, or of repression and denial of the improbable. It is important that some (albeit only a few) of the residents expressed a sense of security, which should be treated as a sign of trust towards the staff.

Interestingly, at this time, after several months of living with the coronavirus pandemic, the respondents experience similar feelings as at its beginning: "Anxiety, fear of infection" (W, 67 years old), "High stress and terror" (W, 66 years old), "Indifference" (M, 69 years old), "The same" (M, 72 years old), "A sense of security" (W, 87 years old). There was also a sense of fatigue, helplessness, and habituation.

These opinions are expressed in the respondents' declarations about what has changed in their perception of the pandemic situation (Figure 18.6). Among these opinions, the feeling of getting used to the situation caused by the pandemic prevails, more so for men than for women.

The isolation of the residents is born of necessity and subject to formal regulations. It is also reflected in the fatigue they feel, mainly caused by the prohibition on direct contact with family and on leaving the facility. An interview with a social worker from the COVID-19 sub-division shows even more of the complexity of the situation and the emotions felt by employees as well in this life-threatening situation. Here is the account of the social worker:

Each subsequent piece of information regarding the positive results of a staff member or resident increased the feeling of exhaustion, tension, fear, uncertainty, hopelessness, and sadness. The first thing I experienced when entering the COVID ward was silence, peace, and a sense of horror, resulting from how I imagined working in such conditions, while I was presented with information on the general rules of conduct. At the beginning it was 


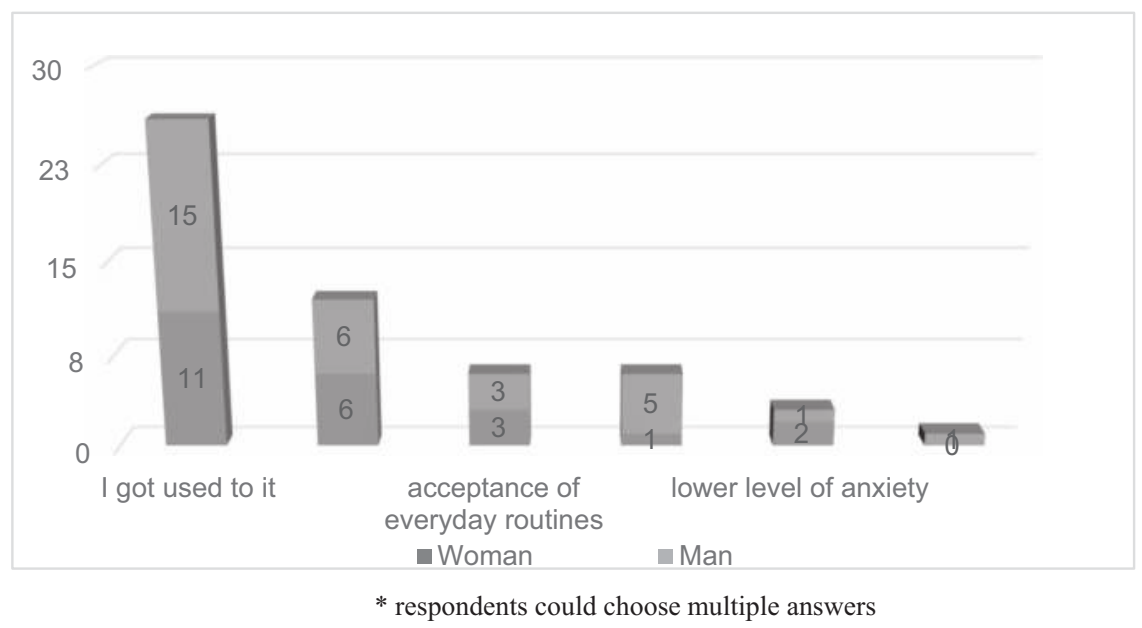

Figure 18.6 Perceptions of the pandemic at the time of the research

exhausting to have to stay focused while putting on all the layers of suits, being careful not to touch the eyes and mouth and during the disinfection process after leaving the COVID ward.

The surveyed residents also expressed acceptance for everyday life as it is. Some respondents claimed that nothing had changed over the three months. The lowest level of anxiety, which was indicated by only a few respondents, may be a consequence of "taming the coronavirus," i.e., learning about the mechanisms of the pandemic, gaining knowledge about protection options and prevention, and learning to live anew in a situation of COVID-19 isolation.

More than half of the respondents try to conduct their everyday life with a sense of security (Figure 18.7). Every third respondent is unable to clearly define their sense of their own security - sometimes they feel safe, other times they do not.

The residents who participated in the research also experienced a feeling of loneliness. During the pandemic, it is a part of the experience of many older people, including the residents of care homes. The situation of total social isolation of the respondents, expressed mainly in the lack of direct contact with the family, significantly deepens the feeling of loneliness. Experiencing a sense of loneliness is common to almost all the respondents. It was confirmed by more than half of men and almost all women (Figure 18.8).

Men said that they often felt lonely more frequently than women. Most women, on the other hand, feel lonely at times. Statistical analysis shows a strong relationship between these variables $\left(C_{\text {kor }}=0.64\right)$ and the differences are statistically significant $(\mathrm{df}=3 ; \mathrm{p}=0.0112)$. Several of the surveyed men stated that they did not experience a sense of loneliness. There were also 


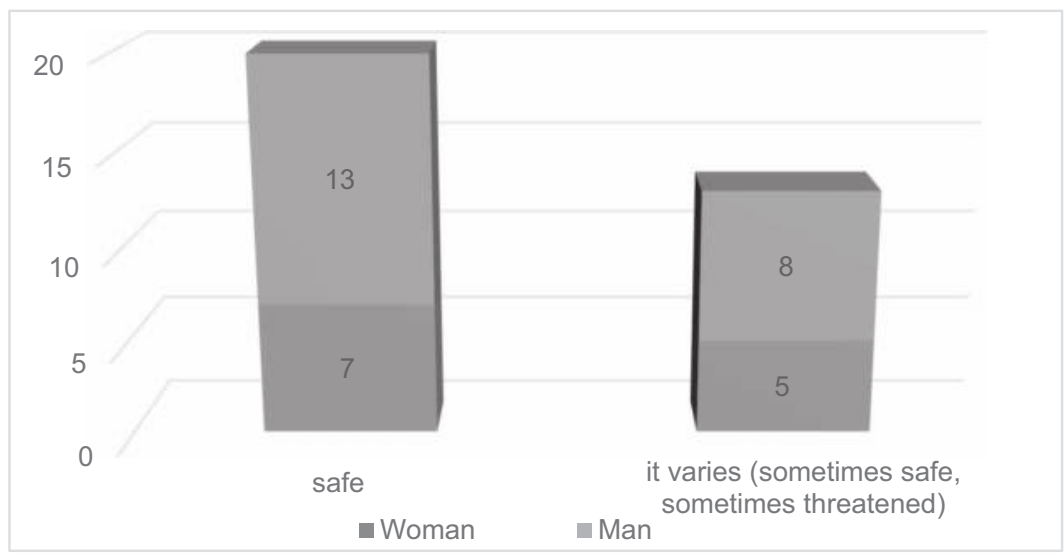

Figure 18.7 Sense of security among the surveyed residents

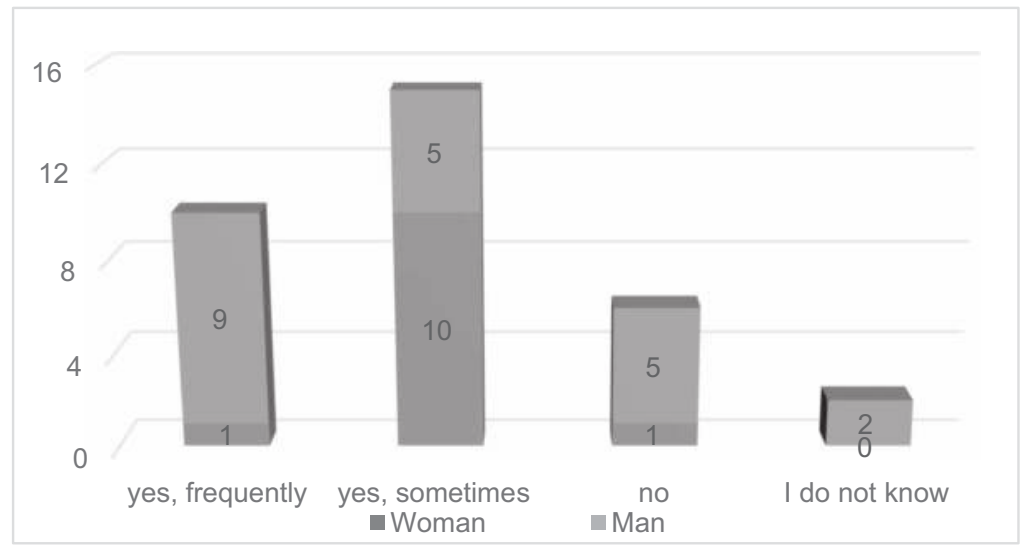

Figure 18.8 The feeling of loneliness among the respondents

those who were unable to take an unequivocal position on this issue. The account of a social worker explains this situation in a way. In his opinion,

At the stage of introducing further restrictions in the facility, resulting from the general epidemiological situation in the country, a coronavirus outbreak in the facility and staff shortages, the feeling of institutionalization and isolation of the residents was growing. For safety reasons, the activities of therapeutic and physiotherapy laboratories and the gym were suspended. The residents were not able to go out into the fresh air. Thus, social rehabilitation, that is, the organized interdisciplinary work of 
empowering residents, treating the participant in a holistic manner, was not possible to a wider extent. This resulted in loneliness, decreased activity, frequent mood swings, depression, as well as excessive agitation, and in extreme cases even acts of aggression.

In their statements, residents pointed out situations that could contribute to the improvement of their well-being. Among the most frequently repeated expectations was a longing for contact with the family and going outside the facility. Residents also pointed towards a more rigorous adherence to the established rules of SARS-CoV-2 prevention. There were also statements expressing a desire to return to what life was like before the outbreak of the COVID-19 pandemic. Examples of statements: "Allow for meetings with family" (W, 78), "Let us out, let our families in" (M, 57), "Obey the prescribed rules" (M, 70), "The facility should be as it used to be" (M, 70). According to the director of the facility,

the lack of broader relations, including with the external social environment, the uncertainty of tomorrow, the lack of prospects, the inability to participate actively in Holy Mass celebrated every Sunday in the facility filled the residents with doubt, pessimism, and disbelief in quick change.

\section{Interpersonal relations in the facility during the pandemic}

We understood interpersonal relations in a care institution in a pandemic situation in two dimensions: as the relationships between residents and staff and as relationships between residents. Concerns about coronavirus infection in their contacts with staff during the pandemic were experienced by 13 respondents, which means that people who did not have such fears constituted the majority.

An even greater number of respondents did not feel any concern about contracting the coronavirus through their contacts with the residents of the facility (22 people). It is noteworthy that men experienced a lack of such concerns twice more frequently than women (15 and seven respondents respectively). Only some people occasionally have such concerns. It is probably related to the knowledge and belief of the residents that no coronavirus outbreak was found in the facility, hence the positive attitude and greater sense of security.

Positive assessment of the relationships between fellow residents is a cause for optimism. This is evidenced by the data presented in Figure 18.9, which shows that 19 people assessed their relations with other residents as good, while 4 men assessed them as very good.

Eight men and four women have an ambivalent attitude towards their relations with other residents. These people evaluate the relationships as neither good or bad, so they could be considered unsatisfactory. Two of the respondents (one woman and one man) do not maintain any relations 


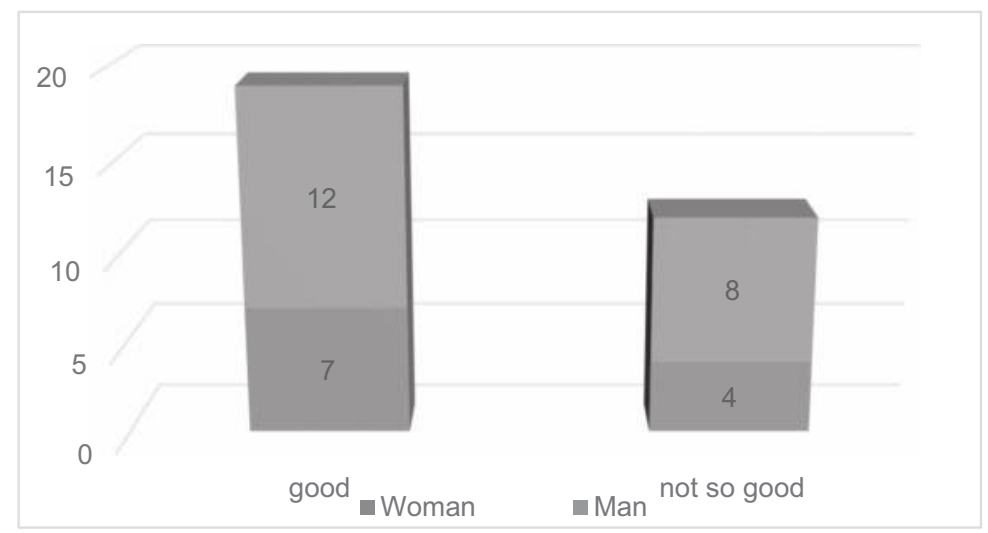

Figure 18.9 Assessment of relations with other residents

with anyone. Perhaps it is related to the individual personality traits of the respondents.

About two-thirds of the respondents answered "yes" to the question "Is the ban on visiting the facility justified?" However, it is noteworthy that 15 of them expressed the opinion that the ban is only partly correct.

The respondents generally negatively assessed everyday life and changes in the facility brought on by the coronavirus. In their opinion, the unfavourable changes relate primarily to the ban on leaving the facility, the ban on visits that they miss and wait for, pointlessly sitting in one place, a feeling of emptiness, monotony, lack of perspectives. This assessment was complemented by the possibility for the respondents to point out three of the most important deficiencies in their experience of daily life in institutional conditions during the pandemic. It showed that the residents suffer the most from a lack of a sense of freedom expressed in freedom of movement outside the facility. This was the opinion of 25 people, only five of whom were women (Figure 18.10). It may be presumed that for some men the lack of freedom to move outside the facility is related to the inability to purchase alcohol. It is no secret that many of them are addicted to it. In the respondents' opinions, the inability to have direct contact with the family is equally important. Nineteen respondents pointed out the inability to meet this need.

A few people indicated that the thing they miss the most is the ability to participate in religious services, which are not held in care homes due to pandemic restrictions. It should be noted that the residents of the facility did not express any other expectations of the staff of the facility, apart from the wish, expressed by four people, that medical visits to the residents would be more frequent. It was the wish of the respondents in the care of the facility that all the residents would be tested and that the pandemic would end. 


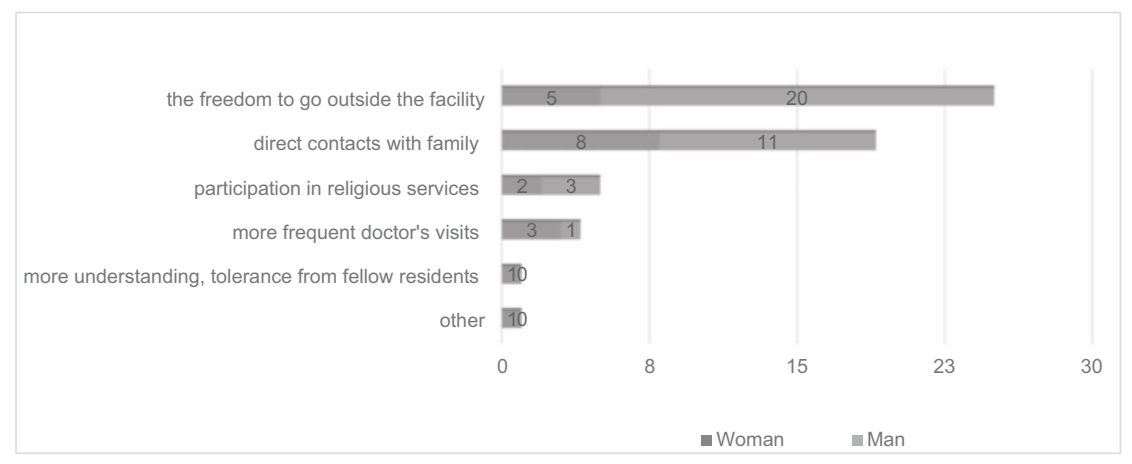

Figure 18.10 The needs of institutional residents during the pandemic

The residents were grateful for the care provided by the employees of the facility and expressed their thanks to the director.

The opinion of a social worker sheds light on the good practices that allow the residents' needs to be met. In his opinion,

efforts are necessary to prevent the residents - as far as possible - from experiencing the negative effects of increased isolation. Modern technologies have been used to diversify social rehabilitation. In order to build a friendly atmosphere in the COVID sub-unit, enabling the creation of a sense of security and peace, we engaged residents in joint, small scale work in the ward, depending on their health, often with music played from a large [...] loudspeaker.

Residents reacted positively to activities that brought variety to everyday life. According to the social worker, private equipment belonging to one of the members of the three-person team was used, specifically a projector and a large screen to display media selected by the residents, i.e., a movie of their choice in the evening, playing relaxing music during the day, or playing computer games together (on a laptop). In the opinion of the social worker,

the implementation of social rehabilitation in this way was meant to provide a substitute for "normality". To meet the needs of the residents, we also managed to organize a birthday party for one of them, attended by all the residents of the COVID sub-unit. While working in the covid sub-unit, we would every day notice new problems of the residents, which made it impossible for them to meet their life needs; one of them was the inability to contact the residents staying in the "healthy" sub-units. We met this challenge using the projector, the Internet, and the Messenger app to communicate; using the web and a webcam we called a carer working in 
the "healthy" sub-unit with a request to share the screen with us and allow friends to see each other and talk remotely. Going further to meet the residents' needs, we began to contact other sub-units in the same way, so that the residents could talk to other people together

The interview with the social worker made us aware of another problem, namely the threat of professional burnout in extreme situations, such as the coronavirus pandemic.

A situation of increased isolation, implementation of new obligations regarding systematic disinfection of the premises, the need to pay special attention to everyday work, increase the probability of the onset or deterioration of burnout symptoms. The tense atmosphere led to many verbal conflicts between the staff, which did not facilitate overall communication and cooperation in combating the coronavirus outbreak at the facility. Chronic stress, tension, a sense of hopelessness resulting from prolonged work hours, incoming information about new coronavirus infections and deaths, meant that even an inconspicuous problem or noticing some irregularity could cause an inadequate reaction to the situation. For this reason, the employees received additional psychological support.

Everyday life experienced by the residents and staff in a care institution during the coronavirus pandemic is a very complex problem and difficult to deal with without the involvement and support of authorities. Official sources tell us that during the coronavirus pandemic the facility where the research was carried out could count on cooperation and support from local authorities, while it was much more difficult to find understanding and support from regional authorities. And yet the needs of the residents of aid institutions should be equally important to those in power both in the city and in the region.

\section{For further discussion...}

The social situation related to the emergence of the coronavirus has changed a lot in the life of every person, but the everyday life experienced in the reality of the coronavirus pandemic by the residents of care facilities and the staff employed there has - as we tried to show above - a specific character. Regardless of whether coronavirus outbreaks occurred in the facility or not, it was necessary to implement new procedures to counteract the spread of the virus. However, these steps strengthened the institutionalization of the inhabitants and their feelings of isolation. A lack of direct relations with the family and a lack of relations with the outside world negatively affected the general well-being of the residents, as well as the staff.

In these difficult, rapidly changing conditions for the functioning of a nursing home, both residents and employees had to go on with their daily 
lives. In a situation of total isolation resulting from the public health restrictions they were in a way forced together and the hitherto routine daily activities turned out to be a challenge.

The statements of the surveyed residents and employees point towards a dynamic in the emotions they experienced and the nature of interpersonal relations in the facility - from initial fear, panic, through indifference, coming to terms with the situation, to relative peace and mutual trust and cooperation. There is no doubt that the isolation experienced by the care home residents and staff members can be seen as a situation of crisis.

When looking for the bright sides of the situation (which is very difficult due to the global and lethal scope of the pandemic), one should remember that every crisis creates the potential to get out of it stronger. Disturbed by the pandemic, long-lasting relationships within the care home, reformulation of the employee ethos, and limited support for the functioning of the institution from external entities, constitute new areas requiring the development of new standards in the post-COVID reality.

\section{Notes}

1 The chapter is based on empirical research conducted among the residents of a Nursing Home in Białystok in 2020 after the outbreak of the pandemic. The research tool was a questionnaire. A diagnostic survey was used as the research method. Due to the complete isolation of the residents, the research was carried out by two employees of the facility using a research tool prepared by the authors. In some cases, the respondents did not answer all the questions. Two telephone interviews with the employees of the facility were also conducted. The research results are presented as absolute numbers.

2 At this point, we would like to thank the Directors of the nursing homes in Białystok and Choroszcz and their employees for enabling us to conduct the research and for the interviews. We also want to express our gratitude to the patients for agreeing to participate in the research. Carrying out scientific research in the difficult conditions of a pandemic was not an easy task. All the greater is the satisfaction of achieving what we thought was impossible.

\section{References}

Harari Y.N. (2014), Sapiens. A Brief History of Humankind. London: Harvill Secker.

Rutherford A. (2016), A Brief History of Everyone Who Ever Lived. London: Weidenfeld and Nicolson. 


\title{
19 Feedback from French nursing staff in gerontology
}

\author{
Health reorganisation \\ acceptance related to \\ COVID-19 crisis
}

\section{Pauline Gouttefarde, Chloé Gaulier, Sébastien \\ Rabier, Vincent Augusto, Caroline Dupré, Solène \\ Dorier, Jessica Guyot and Nathalie Barth}

Faced with the global COVID-19 pandemic, marked by urgency and uncertainty, the French healthcare system had to undergo a completely reorganisation so as to provide a response adapted to the health demands of the region surveyed (Auvergne-Rhône-Alpes, France). In order to protect and foster the health and the quality of work life for caregivers in the region, it is important to be able to anticipate future exceptional health situations. To do this, we need to understand the factors that have influenced the acceptance (or not) by caregivers, of the changes implemented during the first months of the Covid epidemic. The 'ARECOVID' project is a sociological study of the opinions, representations and experiences of caregivers. Through a qualitative and quantitative approach, we have sought to gain an indepth understanding of the subjective reality of caregivers with regard to the extent, nature and complexity of the organisational changes in the healthcare system. A total of 472 participants from all medical sectors (medical and paramedical, hospital and non-hospital, medical and social institutions) were surveyed, with the aim of studying the acceptance (or not) by caregivers, of changes relating to crisis management and of identifying potential levers for improvement, and any related obstacles.

\section{Introduction}

Although several studies have highlighted the major reorganisation of care and the lack of human and material resources faced by care professionals, few have studied the consequences and experiences of caregivers. This study also attempts to shed light on the obstacles and levers to the acceptance of 
organisational changes due to the health crisis by caregivers working with the older persons.

The international alert concerning COVID-19 obliged the French Government, through the directives of the Ministry of Solidarity and Health, to mobilise and restructure the French healthcare system so that it could prepare and cope with the imminent spread of the virus. In France, this mobilisation focused on the detection and management of possible and confirmed cases. Care was mainly provided in Covid-certified establishments and mostly concerned hospitals. Nevertheless, non-hospital facilities (i.e, local doctor's clinic) and the social and medico-social sector have also had a key role in managing the Covid crisis, playing a role in detecting new cases, in isolating suspected or detected cases and in managing and mitigating the spread of the pandemic (Ministère des Solidarités et de la Santé 2020; Organisation Mondiale de la Santé 2020).

The escalation to Level 3 on 14 March 2020, forced the government to make greater demands on healthcare sector participants. In order for the ORSAN REB plan (Organisation of the Health System Response in Exceptional Health Situations for Epidemic and Biological Risks) to be effective, all healthcare sector participants had to be mobilised and coordinated. These unprecedented changes led to major organisational changes in healthcare practices.

Typically, three types of organisational change are identified and defined according to several criteria related to the Extent, Pace and Breadth (or Depth) of these changes (Giroux 1991; Guilhorn \& Trepo 2001). With COVID, we are faced with a so-called 'radical' change, since major by its nature and corresponding to a genuine crisis (Soparnot 2004: 31). Radical change is recommended where there be an unstable context. Radical change profoundly disrupts the usual way of doing things (Guilhon 1998: 98-107; Soparnot 2004: 31-42; Vas \& Ingham 2004: 25-32).

And indeed, the COVID-19 epidemic has led to a major reorganisation of care in France. Since the older persons are potentially the most at risk from the virus, because of the serious forms associated with it (16.6\% of positive cases are between 70 and 79 years old and $18.4 \%$ are 80 years old or older (Verity et al. 2020)), caregivers in facilities caring for the older persons have undergone disproportionately more changes in their work. It is likely that these changes led to difficulties and required significant adaptation efforts by these staff, affecting their perception of the measures taken as well as their acceptance thereof. In fact, several questions can arise: How did caregivers in facilities caring for the older persons perceive and experience the reorganisation of the healthcare system? Did they accept this reorganisation? Did acceptance of the changes differ according to the work contract status of the caregivers? By 'status', we mean that the caregivers either have a full-time employer (i.e., they are 'institutional caregivers' or 'paramedical caregivers') or they are self-employed. What factors were identified as facilitating or hindering acceptance of these changes? 
Several models attempt to capture the modalities inherent in the acceptability (and ultimately acceptance) of using a new tool or embracing a new organisation. For example, the Technology Acceptance Model (TAM) deals with behavioural intention, a factor that leads people to use a technology (Davis 1985). But another model offers a better explanatory capacity for behavioural intention: the 'Unified Theory of Acceptance and Use of Technology' (UTAUT) (Venkatesh et al. 2003:425). This model proposes 4 main factors influencing the behavioural intention and use of a new feature (tool, organisation, system, etc.): performance expectancy; effort expectancy (i.e., the degree of ease associated with use); facilitating conditions, and lastly, social influence (i.e., the influence of the people around the individual and their perception of the new feature) (Bobillier-Chaumon \& Dubois 2009: 355-382; Lewin 1946: 34-46; Venkatesh et al. 2003:425).

Although UTAUT already offered a comprehensive framework for satisfactory acceptance, an extension of this model was subsequently developed. Venkatesh et al. thus added three new constructs to create UTAUT-2 (Venkatesh et al. 2012:157-178). Hedonic Motivation, referring to the satisfaction or pleasure derived from using a new technology; Price Value, referring to the cost of implementing the new feature; and lastly Habit, referring to the extent to which individuals tend to adopt automatic behaviours as a result of learning (Limavem et al. 2007:705). This extension of the original UTAUT model improved the explanation of the variance in behavioural intention, to wit: whereas the first version of UTAUT explained $56 \%$ of behavioural intention, UTAUT-2 allowed for $74 \%$ of behavioural intention to be taken into account (Venkatesh et al. 2012:157-178).

In an attempt to answer the questions set out above, an analysis of the acceptance of these changes, with respect to the UTAUT-2 model, was conducted among caregivers working with the older persons. In the long term, the aim is to better anticipate the impact of the changes within healthcare structures, particularly with a view to future epidemic waves.

The aim of this research was to understand how the reorganisation of healthcare has been experienced by caregivers working with the older persons. From a comprehensive and interventional point of view, the aim was to identify factors identified as facilitating or hindering acceptance of these changes.

\section{Method}

The study used a mixed methodology, combining qualitative (survey by semi-structured interviews) and quantitative (survey by questionnaire) approaches. The aim of the questionnaires was to gauge, over a large sample, the degree of acceptance of the changes resulting from the reorganisation of health services. The aim of the interviews was to analyse and understand the perceptions and experiences of the healthcare professionals surveyed (Corbière \& Larivière 2014; Flick 2020:135-141). 


\section{Survey by semi-structured interviews}

The aim here was to understand the subjective reality experienced by caregivers in the face of the management of the COVID-19 health crisis (understanding and operationalisation of the changes as well as the feelings and experiences associated with it). Our sample was made up of ten caregivers (five men and five women; average age 31.1 years), mainly doctors (seven doctors, one intensive care anaesthetist, one senior nurse, one rheumatology intern), all practising in France in the Auvergne-Rhône-Alpes region (AURA).

All the semi-structured interviews were done by the same interviewer, using a semi-structured interview guide. To start, some socio-demographic data pertaining to the interviewees were collected. Then came the interview guide, structured around four themes: their perception of the changes imposed by the crisis; how the caregivers personally experienced these changes; the acceptability of these changes; and lastly, perspectives ensuing from the reorganisation. The interviews were conducted during the month of May 2020, i.e., just after the first pandemic wave in France. ${ }^{1}$ The analysis of the interviews was carried out using NVivo version 11 software. A horizontal thematic analysis was carried out in order to identify recurring themes (Bardin 2013).

\section{The questionnaire survey}

This survey was conducted among a population encompassing all caregivers practising their profession in the AURA region and caring for older persons patients. More specifically, the survey population was composed of three groups of participants: institutional caregivers (hospitals/medical-social establishments), paramedical caregivers (hospitals/medical-social establishments) and self-employed or home-based caregivers. A sample of 472 voluntary caregivers was recruited using a non-random, voluntary sampling method. Of these, $83.9 \%$ were women and $15.47 \%$ men; average age of 44.38 years (youngest was 18, and eldest was 68). Most of the survey participants were nurses. A large majority of the survey participants came from the field of non-hospitalised medicine, with $51.48 \%$ of professionals working in a private practice, $13.98 \%$ at home, $14.83 \%$ practising their profession in a nursing home and $12.92 \%$ in a hospital.

This questionnaire was developed using LimeSurvey software. It consisted of three main sections: (i) the experience and extent of organisational changes, (ii) the presence and use of psychological support units to the intention of caregivers, and (iii), the acceptance, by caregivers, of how the Covid crisis was managed. This last part has been developed on the basis of behavioural factors identified by the second version of the Unified Theory of Acceptance and Use of Technology (UTAUT-2) (Venkatesh et al. 2012) which has a total of seven factors influencing the behavioural intention to 
use a new feature: performance expectancy (usefulness), effort expectancy (ease of use), facilitating conditions, social influence (influence of relatives and their perception of the tool), hedonic motivation, price value and habit. These different factors were made part of the questionnaire in order to highlight the factors of acceptance or resistance to changes in the practices of caregivers working with older persons people.

The questionnaire was distributed online (by e-mail and social networks) in order to respect the anonymity of the respondents and the confidentiality of the responses for the months of May and June 2020. The results were statistically analysed in two steps: the calculation of position data for the descriptive questions (minimum and maximum responses, percentages or averages) and the analysis of the consistency of scales with calculation of Cronbach's alphas (Cescup 2014).

\section{Results}

\section{A radical reorganisation of healthcare}

\section{Changes in the pace of work}

Recurrently, the participants in this study report that they have witnessed a complete change in the organisation within health establishments (hospitals as well as nursing homes). According to the data collected, these changes appear to be more significant for institutional caregivers (including hospitals) than for self-employed caregivers $(88.2 \%$ versus $51.69 \%)$. Most questionnaire survey participants reported an increase in their workload: $59.21 \%$ of caregivers employed by medical establishments, and $50 \%$ of self-employed caregivers reported having worked more hours than usual: "What also plagued me was managing all the extra work, of which we already had a lot" (senior nurse, Geriatric hospital).

\section{A reorganisation in the sector that facilitated the emergence of new} skills

Caregivers who could no longer perform their usual duties were assigned to these dedicated units. It would appear that some structures/services were much more affected than others. The results show that $79.54 \%$ of the participants say that they had to acquire new work habits quickly (hygiene measures, administration of treatment procedures, etc.). Many outpatient and non-emergency consultation services were suspended, and the premises were fitted out to receive patients with COVID-19. As a result, hospital doctors report many late consultations and more serious pathologies, wounds and problems than usual: "I think above all that they were afraid to come; you have many people who, although with fractures or in a cast, did not want to come" (Sports doctor, Emergencies Unit). 
A lack of personal protective equipment generating a fear of risk, particularly for self-employed caregivers

With regard to the perception of risk, the main change mentioned by the respondents was PPE Management. A full $44 \%$ of respondents considered that they lacked protective personal equipment (PPE) such as masks, gloves and similar. This insufficiency in terms of PPE, noted in all health sectors (hospitals, medico-social establishments, local doctors clinics), seemed, based on the quantitative data collected, even more problematic for self-employed caregivers. Indeed, $43.93 \%$ of self-employed caregivers reported this issue (compared with $29.63 \%$ of institutional caregivers and $22.06 \%$ of paramedical caregivers). Caregivers spoke at length about their difficulties in obtaining PPE and several comments reveal a feeling of insecurity and anxiety regarding these missing resources.

I was very concerned that we would lack PPE. That was sometimes a bit complicated because we really felt we were in a tight spot.

(Doctor, geriatric hospital)

This variable can be linked to the fear of risk and contamination; indeed, $70.84 \%$ of the caregivers expressed a fear of contaminating their family and $68.03 \%$ their patients. The analysis reveals that self-employed caregivers were the most concerned about transmitting the virus. The population sample declaring that they had the greatest difficulty in obtaining the necessary PPE is therefore also the population that expressed the strongest feeling of risk of contamination. Our acceptance scales bear witness to this situation since the "risk perception" variable is very noticeable for self-employed caregivers. This variable would therefore not facilitate acceptance in the management of a health crisis.

\section{End-of-life management: the use of digital tools as an alternative}

Digital tools have played an important role in this context of health crisis. They were mainly used by paramedical caregivers in order to communicate with the families of patients (as reported by $70.55 \%$ of caregivers) and to enable patients to call their families (as reported by $80.89 \%$ of caregivers). Institutional caregivers and self-employed caregivers mainly used digital tools in order to communicate with other healthcare professionals $(74.07 \%$ and $56.76 \%$ respectively). On the whole, the telephone was the most used communications tool ( $80.88 \%$ of caregivers), followed by videoconferencing $(51.85 \%)$ and telemedicine $(29.63 \%)$. Paramedical caregivers considered these communications tools as playing an essential role in maintaining a relationship (healthcare professional <=> family <=> patient). However, although these technologies are perceived as necessary, difficulties persist, particularly with regard to using these technologies and the presence or absence of 
functional equipment. Virtual communications does not compensate for the lack of direct contact among older persons.

They come from a generation that is clearly not at home with our new technologies and for some, seeing their loved ones on a screen was complicated to understand. For some it worked very well, but for most it was not completely satisfactory and it didn't completely make up for the lack of visits, although it's better than nothing.

(Geriatrician doctor, Nursing Home)

End-of-life management is a criterion that particularly impacts healthcare professionals, who reported that they did not always feel they are acting ethically or doing quality work. In our interviews, this feeling of powerlessness with regard to death is expressed.

Sometimes the husband and the wife were in the same service and so we had the wife transferred so that she could hold the husband's hand as he was dying. We tried to be as humane as possible but this was not always the case.

(Anaesthesiologist - Resuscitator, COVID resuscitation)

The issue of end-of-life management and support was raised by the survey participants. However, ancillary and creative solutions enabled families to maintain the connection to COVID-19 residents and patients up to their death. For example, caregivers mentioned the use of digital tools or rituals to make the departure of a patient more humane. Caregivers organised telephone slots dedicated to contacts with families which, they reported, were very beneficial. Although digital tools (videoconferencing, telemedicine, telephone calls) were widely used, they could not be set up everywhere and for all users, particularly the older persons who either didn't know how to use them or did not have the necessary equipment.

We had patients who were very ill and it was difficult to use a digital tool with them.

(MCU-PH, Infectious Diseases Department)

\section{Isolation harmful to patients}

Our survey underlines the negative psychosocial repercussions, on patient health, and in particular on older people, of the organisational changes enacted in response to Covid-19. These new conditions have led to changes in the work of caregivers. Their work evolved into a more supportive and accompanying role with older people. According to replies, the isolation of older persons inside nursing homes, combined with the discontinuance of all social bonds has had a significant negative impact on their mental health. 
It is becoming increasingly difficult for the residents to be cut off from the world (...) it's a kind of tsunami, anxiety, tendency to depression (...), the residents withdraw into themselves, they are much less communicative (...) even with nursing home staff, you can really see that they withdraw into themselves. (...). They feel sad, they have a feeling that they are locked up, in prison, and they miss their family.

(Geriatrician, Nursing Home)

Moreover, visits to older persons persons in nursing home took place under conditions that emphasised protection (plexiglass, social distancing, masks...) and the residents seem to experience difficulties with this.

We can see that there are residents who are almost more disturbed after the visits than before.

(Geriatrician, Nursing Home)

\section{How satisfied were the caregivers with these changes?}

Caregivers are globally satisfied with the new organisation

Overall, caregivers expressed satisfaction with the management of the first pandemic wave. The results of the questionnaire survey show that $88.23 \%$ of institutional caregivers, $75 \%$ of paramedical caregivers and $51.69 \%$ of self-employed caregivers considered that the response reorganisation deployed to deal with the pandemic were on a par with the scale of the emergency.

This overall satisfaction also seems to favour the acceptance of caregivers in the face of this reorganisation. In fact, most of the caregivers interviewed were satisfied with the organisation that had been deployed and found it useful. Furthermore, all the systems put in place in times of crisis seem to have been approved, such as the questionnaires for analysing the state of health of pre-consultation or follow-up of positive patients at Covid-19 at home.

I think it was very well organised and above all with great solidarity.

(MCU-PH, Infectious Diseases Department)

\section{...with nevertheless some reservations}

For $50.05 \%$ of institutional caregivers, the health reorganisation measured deployed to deal with the pandemic did not allow for continuity of care for non-COVID older persons people. Conversely, $66.18 \%$ of paramedical caregivers and $47.3 \%$ of self-employed caregivers responded that this reorganisation sufficiently allowed for continuity of care for non-COVID older persons people. It should be noted that a significant number of self-employed caregivers did not take a position on this issue. Nevertheless, institutional 
caregivers have less trust in government recommendations than do self-employed caregivers. Overall, $24.55 \%$ of survey participants do not trust these recommendations, due to repeated changes in Covid-response measures handed down by the government:

The test procedure that changed every day... and that was a big problem, a source of much anxiety for the teams... one day you were being told to dress the older persons persons and the next day, you were told not to dress them, to help them wash, and not help them wash.

(Doctor, geriatric hospital)

\section{A feeling of support that promotes acceptance}

The caregivers reported feeling valued, both by their colleagues and their loved ones. Overall, $67 \%$ of survey participants felt supported by their family and friends as regards following Covid-response recommendations: $34.27 \%$ of family/friends encouraged survey participants in their work with COVID patients, compared with $28.9 \%$ who did not. More than $66 \%$ of the caregivers felt useful during this pandemic.

Cooperation, Solidarity and Communication between caregivers were the most important aspects highlighted. This cooperation was omnipresent in the decision-making process concerning the care and reorientation of COVID patients, with multidisciplinary choices and decision-making.

We always made decisions as a team to try to find the best solution. There has been a lot of discussion about what kind of care to take.

(Doctor, COVID acute care \& rehabilitation)

\section{Discussion}

Through this study of the acceptance, by caregivers, of organisational changes rolled out in response to COVID-19, we were able to explore how caregivers in the AURA region experienced these changes, as well as their perception thereof. Feedback, opinions and assertions made by the caregivers surveyed allowed us to understand in depth how the healthcare measures implemented in the AURA region were perceived, experienced and accepted by these front-line professionals. The UTAUT-2 model enabled us to identify the factors that influenced the acceptance of caregivers with regards to the new measures and organisation put in place in response to Covid. In the face of an unprecedented epidemic, with no possibility of comparison or reproduction based on past experience, a change in working habits is at the heart of the recommendations for managing this crisis. Therefore, for an effective change in practice, the acceptance, by caregivers, of organisational changes and new rules, can be considered a necessary condition for the effectiveness of public health policies. 


\section{Factors hindering acceptance: what parallel with UTAUT-2?}

\section{The adverse consequences of this crisis on the health of caregivers}

The analysis of our data shows that, above and beyond those changes made in response to Covid, caregivers were exposed to an array of difficulties (PPE, care of non-COVID older persons patients, end-of-life management, patient orientation, pressure from families, etc.). The large workload and the massive influx of patients combined with constantly changing organisational instructions put a heavy strain on the cognitive and adaptive capacities of the caregivers. These decisions, necessarily rapid, repeated and difficult, led to strong psychological tensions and possible cognitive exhaustion (El-Hagea et al. 2020:4). These results converge with those of other studies which reveal that $57 \%$ of institutional caregivers (hospitals/nursing homes/medico-social) claim to have experienced an increase in workload (Fabergas 2020).

On a similar note, several survey doctors reported that they had had disturbed sleep or had taken treatments for anxiety. Similarly, $49.37 \%$ of the caregivers interviewed felt sad (from Sometimes to Frequently). Similar results have been highlighted by the MACSF (mutual insurance company, provider of insurance services for health professionals) found that over $50 \%$ of the surveyed caregivers reported that they continued to experience physical fatigue, anxiety, stress and sleep disorders (MACSF, June 2020).

End-of-life management has been particularly difficult for caregivers. While geriatric caregivers are particularly accustomed to death, restrictions on family visits and limited contact care created a sense of powerlessness in their ranks (Peyrat-Apicella \& Gautier 2020:160-167). It would seem that these negative feelings were not so much caused by death per se, but rather but the suddenness of the onset of death and the support measures (considered inadequate) provided to the dying person (Lefèvre 2020:1). Although the survey caregivers accepted these conditions, in particular in the light of the collective interest, these conditions and this feeling of not staying by the dying person lead to "an internal revolt that is not without consequences for the caregivers and, in particular, hinders their mourning process" (for the deceased older persons person) (Peyrat-Apicella \& Gautier 2020:4).

The repercussions, on the mental health of caregivers, of health emergencies seems to a topic at the heart of current research (Dit 2020; ElHagea 2020; Mutuelle d'assurance du corps de santé français 2020; Peyrat-Apicella \& Gautier 2020; Vignaud \& Prieto 2020). The caregivers surveyed also expressed the wish to have psychological support available onsite, rather than to have a special cell that they have to contact themselves - a remark all the more salient since a large majority of respondent caregivers were not even aware of psychological support services available for caregivers. 
Fear: a brake on acceptance?

The caregivers surveyed commented on the lack of PPE they experienced at the beginning of the crisis. These conditions were a cause for concern amongst caregivers, altering their sense of their professionalism and of their personal safety (El-Hagea et al. 2020:1). 68.03\% of the caregivers surveyed questioned are mainly worried about infecting their relatives or patients. These data coincide with those of other studies, since $14 \%$ of caregivers decided, as a preventive measure, to live apart from their relatives during the pandemic (Mutuelle d'assurance du corps de santé français 2020). This unprecedented health situation forced caregivers to reorganise their personal lives, leading to an upheaval between private and professional life (Vignaud \& Prieto 2020:1). Self-employed caregivers were the least affected by the sweeping changes caused by the Covid. That said, the survey reveals that this was precisely the category that was the least accepting of change. As regards those factors of acceptance of the changes, the Risk Perception variable was very high for self-employed caregivers. Moreover, the survey reveals that this category was the one that most suffered the lack of PPE. A1though self-employed caregivers did not perceive organisational changes to the same extent as other classes of caregivers, those self-employed caregivers who experienced more difficulties replenishing PPE had a strong sense of risk. Self-employed caregivers were also less accepting of the organisational changes deployed in response to Covid. This risk-perception factor, which is part of the UTAUT-2 model, helps to explain the lower acceptance of changes by self-employed caregivers, who did not feel sufficiently protected by the proposed or imposed changes.

\section{Factors facilitating acceptance: the use of UTAUT-2 as an explanatory model}

\section{New work habits that make work easier}

Our study reveals that the caregivers acquired skills and new work habits rapidly (hygiene measures, administration of treatment procedures, etc.) Similarly, according to another study, Covid facilitated the emergence of new working methods for $85 \%$ of caregivers, including $89 \%$ of self-employed caregivers and $81 \%$ of institutional caregivers (Mutuelle d'assurance du corps de santé français 2020). The caregivers responded that they had acquired new skills as a result of having been dispatched to other services where they learned new skills. They spoke of new and rapid work habits. With regard to UTAUT-2 and its Habit factor, individuals tend to adopt automatic behaviours as a result of learning (Limavem et al. 2007). If the behaviour becomes a habit, then users will be more likely to approve of it. This factor is very present here and can promote acceptance of the new organisation. Similarly, these new work habits do not appear to have had a 
significant impact on the sense of efficiency or "performance" as described in UTAUT-2. We can hypothesise that those caregivers who felt overwhelmingly supported, valued and useful have, as a result, been more accepting of organisational change.

\section{Perceived support: a lever for acceptance}

The caregivers surveyed replied that they felt supported and valued, both by their colleagues and their loved ones. The social influence variable in UTAUT-2, which takes into account the influence of the entourage orbiting the individual, indicates that the more the user (here the caregiver) feels that those around him or her are favourable to the adoption of the change (in this case, the new organisation), the more the latter will be inclined to approve of it (Bobillier-Chaumon \& Dubois 2009; Lewin 1946; Venkatesh et al. 2003). We note that the changes rolled out in response to Covid were supported and approved by family and friends, which would encourage acceptance by caregivers. The views of family and friends and society therefore seem to have an impact on the work of professionals and the acceptance (or not) of the changes. Although some cases of violence against caregivers were reported in the media, society at large was supportive of caregivers (clapping each evening at 8 p.m.).

\section{Paradoxically, many changes were well accepted}

Caregivers had to come to terms with a total reorganisation of their work habits. However, the greater the changes (scale, pace, depth, usability, etc.), the more difficult it was for individuals to adhere to them (Bareil 2004; Davis 1985; Hannan \& Freeman 1984; Lewin 1946; Nielsen 1993; Venkatesh et al. 2003). However, caregivers appear to have generally accepted and followed the recommendations. We may wonder about the particularities of this exceptional situation, which has led to many changes that have, in the end, been favourably accepted by caregivers caring for the older persons.

The caregivers have shown a voluntary and determined commitment without which the reorganisation would not have been possible (El-Hagea et al. 2020:1). We can assume that the key role played by the medical professions during Covid had an important impact on the acceptance of health recommendations. Caregivers wanted to feel useful and in their rightful place when the pandemic hit. The favourable acceptance of organisational changes by the caregivers seems to have been impacted by the Performance Expectancy factor. Indeed, change appeared to be unavoidable in order to cope with the COVID-19 crisis. Moreover, most survey respondents replied that they felt more valued by others during the crisis.

However, M-J Del Volgo notes that it is "dangerous to consider caregivers as heroes." To be a hero means to sacrifice yourself, to suffer in silence. The hero does not ask for help nor special resources. The hero is a superman. 
To consider caregivers as heroes is to place immense responsibility upon their shoulders all the while preventing them from recognising "their own vulnerability" (Peyrat-Apicella \& Gautier 2020:1). This societal pressure on caregivers raises questions about the nature of acceptance of change (by caregivers). Indeed, we may wonder whether this acceptance is not strongly induced by social pressure. We can assume that the acceptance of changes rolled out in response to Covid -19 could be a forced acceptance, imposed by forces of an ethical nature, and by the inherent social desirability of the way in which society see the medical professions. According to this reasoning, caregivers are tempted to accept Covid-induced changes so as to adopt the behaviours expected by society (Festinger 1957).

\section{For further discussion...}

The progress and persistence of this health crisis over several months has highlighted the need for a comprehensive approach in order to learn lessons from the first wave of this epidemic. Our research shows that the crisis has had an emotional impact on caregivers (stressful situations, working conditions, death of patients, suffering of residents' families...), and the French Academy of Medicine recommends that particular attention be paid, over a long period of time, to the mental health of the caregivers involved in the COVID-19 crisis. One of the keys to future health crises would be make psychological and social support available for caregivers. This research allows us to start thinking about anticipating future health crises. Indeed, by highlighting the brakes and levers for the acceptance of organisational changes due to a health crisis by the caregivers, it may be possible to optimise the hospital organisation for the future. New technologies are increasingly being used to optimise hospital organisation. For example, real time localisation systems allow to locate patients and professionals in real time in hospitals. Some studies demonstrate the relative acceptance of these new technologies by users (Bowen et al. 2013; Fisher \& Monahan 2012; Kamel Boulos \& Berry 2012). But what about an older audience? Indeed, after the age of 70 , the use of new technologies becomes more rare: for example, $86 \%$ of people over 70 do not have a computer (Besson 2012; Bigot \& Croutte 2007). For several years now, we have been witnessing the phenomenon of the "digital divide," which has slowed down the benefits of new technologies for the care of the older adults.

\section{Notes}

1 Santé Publique France, Agence régionale de santé (ARS) Auvergne-RhôneAlpes, Réseau Sentinelles, SOS Médecins de France, Société Française de Médecine d'Urgence (SFMU), Fédération Française des Observatoires Régionnaux des Urgences (FEDORU), Société Française d'Anesthésie et de Réanimation (SFAR), Société de Réanimation de Langue Française (SRLF), Institut national de la statistique et des études économiques (INSEE), Institut national de 
la santé et de la recherche médicale (INSERM), Institut Pasteur, \& CNR des virus des infections respiratoires. (2020). Point épidémio régional AuvergneRhône-Alpes, Spécial COVID-19. https://www.santepubliquefrance.fr/content/ download/244231/2568258

\section{References}

Bardin, L. (2013). L'analyse de contenu. Paris cedex 14, France: Presses Universitaires de France. https://doi.org/10.3917/puf.bard.2013.01

Bareil, C. (2004). Gérer le volet humain du changement (Transcontinental).

Besson, E. (2012). France numerique2012. Plan de développement de l'économie numérique, 2008. http://francenumerique2012.fr)

Bigot, R., \& Croutte P. (2007, décembre). La diffusion des technologies de l'information dans la société française Rapport du CREDOC. http://www.arcep.fr/ uploads/tx_gspublication/etude-credoc-2007.pdf

Bobillier-Chaumon, M.-É., \& Dubois, M. (2009). L'adoption des technologies en situation professionnelle: Quelles articulations possibles entre acceptabilité et acceptation? Le travail humain, 72(4), 355382. https://www.cairn.info/revue-letravail-humain-2009-4-page-355.htm

Bowen, M.E., Wingrave, C.A., Klanchar, A., \& Craighead, J. (2013). Tracking technology: Lessons learned in two health care sites. Technology and Health Care, 21(3), 191-197.

Cescup. (2014). L'alpha de Cronbach. https://cescup.ulb.be/lalpha-de-cronbach/

Corbière, M., \& Larivière, N. (2014). Méthodes qualitatives, quantitatives et mixtes dans la recherche en sciences humaines, sociales et de la santé. Presses de l'Université du Québec, 720p.

Davis, F. (1985). A technology acceptance model for empirically testing new end-user information systems: Theory and results. https://scholar.harvard.edu/bmiddlet/ publications/technology-acceptance-model-empirically-testing-new-end-userinformation

Dit, B. (2020, mai 22). Vécu psychologique de l'épidémie COVID-19. ISNI. https:// isni.fr/vecu-psychologique-de-lepidemie-covid/

El-Hagea, W., Hingrayc, C., Lemogned, C., Yrondif, A., Brunaulta, P., Bienvenuh, T., Etaini, B., Paqueti, C., Gohiel, B., Bennabim, D., Birmesn, P., \& Sauvageto, A. (2020). Les professionnels de santé face à la pandémie de la maladie à coronavirus (COVID-19). Elsevier Connect. https://www.elsevier.com/fr-fr/connect/psy/ les-professionnels-de-sante-face-a-la-pandemie-de-la-maladie-a-coronaviruscovid-19

Fabregas, B. (2020, juin 3). Les soignants interrogés sur leur vécu de la crise sanitaire. Infirmiers.com. https://www.infirmiers.com/actualites/actualites/covid-19-etimpacts-sur-professionnels-de-sante.html

Festinger, L. (1957). A theory of cognitive dissonance. Row, Peterson.

Fisher, J.A., \& Monahan, T. (2012). Evaluation of real-time location systems in their hospital contexts. International Journal of Medical Informatics, 81(10), $705-712$.

Flick, U. (2020). Hearing and being heard, seeing and being seen: Qualitative inquiry in the public sphere. Introduction to the Special Issue. Qualitative Inquiry, 26(2), 135-141. https://doi.org/10.1177/1077800419857766

Giroux, N. (1991). La gestion du changement stratégique. Gestion, 16(2), 8-14. 
Guilhon, A. (1998). Le changement organisationnel est un apprentissage. Revue française de gestion, 120, 98-107.

Guilhon, A., \& Trepo, G. (2001). Réussir les changements par le développement de l'apprentissage organisationnel les leçons du cas de Shell.". Gérer et Comprendre, septembre, n 65.

Hannan, M.T., \& Freeman, J. (1984). Structural inertia and organizational change. American Sociological Review, 49(2), 149164. https://doi.org/10.2307/2095567

Kamel Boulos, M.N., \& Berry, G. (2012). Real-time locating systems (RTLS) in healthcare: A condensed primer. International Journal of Health Geographics, $11,25$.

Lefèvre, G. (2020, avril 1). Covid-19: Paroles de soignants et d'accompagnants. Portail CFDT.fr. https://www.cfdt.fr/portail/actualites/crise-du-covid-19/ covid-19-paroles-de-soignants-et-d-accompagnants-srv1_1107165

Lewin, K. (1946). Action research and minority problems. Journal of Social Issues, 2(4), 3446. https://doi.org/10.1111/j.1540-4560.1946.tb02295.x

Limayem, M. Hirt, S.G., \& Cheung, C.M.K. (2007). How habit limits the predictive power of intention: The case of information systems continuance. MIS Quarterly, 31(4), 705. https://doi.org/10.2307/25148817

Ministère des Solidarités et de la Santé. (2020). Préparation au risque épidémique Covid-19: Guide méthodologique. https://solidarites-sante.gouv.fr/IMG/pdf/ guide_methodologique_covid-19-2.pdf

Mutuelle d'assurance du corps de santé français. (2020). COVID-19: Quel impact sur les soignants? MACSF.fr. https://www.macsf.fr/actualites/ covid-19-impact-sur-les-soignants

Nielsen, J. (1993). Usability engineering. Morgan Kaufmann.

Organisation Mondiale de la Santé. (2020). La COVID-19 a de graves répercussions sur les services de santé soignant les maladies non transmissibles. https:// www.who.int/fr/news/item/01-06-2020-covid-19-significantly-impacts-health-services-for-noncommunicable-diseases

Peyrat-Apicella, D., \& Gautier, S. (2020). COVID-19: Aux frontières de la folie. Éthique \& Santé, 17(3), 160167. https://doi.org/10.1016/j.etiqe.2020.06.001

Santé Publique France, Agence régionale de santé (ARS) Auvergne-Rhône-Alpes, Réseau Sentinelles, SOS Médecins de France, Société Française de Médecine d'Urgence (SFMU), Fédération Française des Observatoires Régionnaux des Urgences (FEDORU), Société Française d'Anesthésie et de Réanimation (SFAR), Société de Réanimation de Langue Française (SRLF), Institut national de la statistique et des études économiques (INSEE), Institut national de la santé et de la recherche médicale (INSERM), Institut Pasteur, \& CNR des virus des infections respiratoires. (2020). Point épidémio régional Auvergne-Rhône-Alpes, Spécial COVID-19. https://www.santepubliquefrance.fr/content/download/244231/2568258

Soparnot, R. (2004). Lévaluation des modèles de gestion du changement organisationnel: De la capacité de gestion du changement à la gestion des capacités de changement. Gestion, 29(4), 3142. https://www.cairn.info/revue-gestion-20044-page-31.htm

Vas, A., \& Ingham, M. (2004). Réorganisation, optez pour le grand angle. L'expansion Management Review, juin, 2532.

Venkatesh, V., Morris, M.G., Davis, G.B., \& Davis, F.D. (2003). User acceptance of information technology: Toward a unified view. MIS Quarterly, 27(3), 425. https:// doi.org/10.2307/30036540 


\section{Pauline Gouttefarde et al.}

Venkatesh, V., Thong, J.Y.L., \& Xu, X. (2012). Consumer acceptance and use of information technology: Extending the unified theory of acceptance and use of technology. MIS Quarterly, 36(1), 157178. https://doi.org/10.2307/41410412

Verity, R., Okell, L.C., Dorigatti, I., Winskill, P., Whittaker, C., \& Imai, N. (2020). Estimates of the severity of coronavirus disease 2019: A model-based analysis, Lancet Infect Disease, 20, 669-677.

Vignaud, P., \& Prieto, N. (2020). Impact psychique de la pandémie de Covid-19 sur les professionnels soignants. Actualités Pharmaceutiques, 59(599), 5153. https:// doi.org/10.1016/j.actpha.2020.08.013 


\section{Conclusion}

\section{Ageing, COVID-19 and 'new normality'}

\section{Maria Łuszczyńska and Marvin Formosa}

The outbreak of the global COVID-19 epidemic was one of the most shocking events of recent decades. The global scope of this event provoked social reaction stronger than information about the ongoing regional armed conflicts or other social problems such as famines, disease, human trafficking, the migrant crisis, civil revolutions, economic crises and terrorist attacks, which are affecting various countries and continents.

The COVID-19 epidemic has shown the pluralism of human anxiety as it has impacted everyone regardless of race, gender, religion or age. It has equalized economies, political systems and public health care systems. It could be said that it has spread no matter what mitigation efforts were conducted. Older persons were especially affected by the first wave. It revealed that the multimorbidity of this age group exposes them to disease and severe illness in much larger extents. The scale of susceptibility of contracting COVID-19 and the risk of death in people aged over 65 compared to other age groups was disproportionately high, as repeatedly demonstrated in the chapters of this book. The COVID-19 epidemic has shown that the older population is particularly vulnerable to the effects of the global epidemic, not only in terms of health (the scope and scale of the consequences constitute a constantly updated area of research), but also in social, economic, legal, psychological and other dimensions. Older persons have felt the impact of the epidemic in terms of difficulties accessing goods and services resulting from the lockdowns, experience of loneliness and isolation from loved ones, particularly younger generations, due to fear and uncertainty regarding the development of events, and changes in routine daily activities caused by the ban on meeting other people through religious, social, recreational, tourist and sport-related activities). At the same time, volunteer grassroots social support systems have emerged to assist older persons by going shopping, walking dogs and handling official matters. Public mechanisms were also created to enable safer participation in social life (e.g. special shopping hours for older persons, doctor consultations over the phone, online support services, including quick training for using new forms of technology).

In this publication, which was planned and written during the early stages of the global epidemic situation, the authors attempted to conduct in-depth 
analyses of the impact of COVID-19 on the older population and their social environment in specific country locations. Reflections included in this publication should primarily serve as general indications and an ongoing study of this topic. It could not be otherwise in a situation where the scale, range, scope and strength of the virus's impact are only becoming more evident through the unfolding of months. Therefore, the authors of this book have attempted to predict further the future impacts of the COVID-19 virus in the lives of older persons. Their statements outline fields for further research and make recommendations in terms of specific analyses in a preliminary and inspiring way. Some texts have been verified in relation to the results of research conducted after several months. However, this does not change the innovative and pioneering character of this publication. At the same time, one should note the selective nature of the subject area, which resulted from encountering the unknown and thus taking note of socially 'significant' issues. The time to analyse the more subtle, less obvious and unnoticed trends by social researchers at first glance, hidden in the first months of the COVID-19 epidemic, will continue as the COVID-19 epidemic progresses.

There are several general conclusions regarding COVID-19s impact on older people that emerge from the considerations presented in this book. A researcher who wants to undertake a rigorous investigation of old age in a serious manner should take into account the following threads for reflection. These issues may be treated as an area of research in which it is possible to find more significant and less apparent factors impacting the situation of older persons, and include:

\section{Loneliness and isolation}

COVID-19 revealed large-scale feelings of loneliness and objective isolation triggered by the lockdown. On the one hand, in the case of the older population, these experiences could worsen pre-existing problems of marginalisation and self-marginalisation. On the other hand, this situation could result in searching for solutions and ways of accepting the imposed separation from other people. In order to counteract the consequences of older persons' isolation in connection with the COVID-19 pandemic, it is first of all necessary to raise awareness of its impact on the mental health of both older persons themselves and the staff who are with them on a daily basis, as well as their families and relatives.

\section{New technologies}

In order to mitigate against social isolation, it is worth using new technologies that would enable older people to stay in touch with family and friends. Introducing activities based on new technologies may contribute to maintaining social ties of older persons, enabling social interactions and the use of services, e.g. medical. In addition, new technologies can serve as care 
support - in other words, prosthesis for daily functioning - in situations of insufficient care resources.

\section{Care}

The pre-COVID reality in care services revealed many deficits in public welfare systems and the need to depending on informal caregivers, mostly family relatives. COVID-19 resulted in limited access even to this source of care due to fear of exposing older persons to infection, hospitalisation and death. To compensate for the deficits in care services, various initiatives for temporary support emerged - volunteers, neighbours, local support groups and scouts. However, COVID-19 unquestionably revealed how much is yet to be done, particularly in with low generational replacement rates.

\section{Social policies for supporting older persons}

State governments, municipal governments and other units responsible for public health and systems of social support and health care have been confronted with having insufficient fully operational resources to satisfy the social and health care needs of older persons. This situation is all the more worrying since forecasted demographic changes indicate that this situation will be conducive for ageing societies. In the case of future global cataclysms of the sort, we could find ourselves in a situation where the 'law of the fittest' (healthier, younger, wealthier, etc.) dominates, which will, without creating the appropriate strategies and action plans, set out the direction of society's way of coping with uncertainty.

\section{Counteracting age discrimination and stereotypes}

COVID-19 has revealed that current stereotypes are accurate and that there are great resources available for the emergence and creation of positive stereotypes, that in themselves, as is the case with any stereotype, are nothing good, but can contribute to social reinforcement of desired behaviour.

\section{Functioning for support residential care institutions for older persons}

Institutions acting for the benefit of older persons have undergone a great test. This concerned the functioning of residential care facilities in protecting the older adults living in them and caring for the safety of employees. The epidemic situation has also verified the motivation of representatives of social assistance professions to undertake specific activities such as helping older people. Depending on the actions taken, positive and negative coping strategies that meet these needs can be found. When looking through the prism of coping with COVID-19 in the area of institutional care, it is 
necessary to observe the quality and the working method of representatives of medical and social assistance professions, consider ways of supporting workers in their professional development and listen to the needs of this professional group in the context of similar intense situation anticipated in the future. These analyses also demonstrate the role and significance of the "great absence" of the family members of older people staying in 24-hour care institutions (hospitals, hospices, nursing homes, other care facilities or prisons) as a result of the epidemic situation, particularly at the moments of their suffering or death.

\section{Religiosity and spirituality}

The absence of significant people in older persons' lives has drawn more attention to issues related to an area that appears to be existentially important for older persons, namely spirituality and religiosity. Separation from loved ones and restrictions in religious services could have influenced the spiritual experience of their existential situation.

All of the above-mentioned areas lead to one more conclusion resulting from this publication. It is imperative to explore the reality of older adults presented in research based on direct contact with them. In the pandemic era, establishing such contact has been difficult, which could have adversely affected research findings and indeed constitutes a premise for conducting studies. This leads to several important conclusions forced by the need for methodological modifications to the research process:

- It is crucial to search for a platform of direct research contact with older persons.

- It is essential to consider the extent of cognitive bias resulting from increased anxiety, reluctance, helplessness and uncertainty experienced by older persons in the role of respondents.

- It is important to build bidirectional trust, which means enhancing trust by offering older persons ownership of research. Instead of framing elders as passive subjects for research, we advocate a co-creation methodology. While acknowledging both traditional models - the medical and social dimensions of ageing - we embrace the 'Cultural model of ageing' as a means of capturing how older people tackle their own ageing issues (Łuszczyńska 2020).

- It is essential to remember the ethical context of carrying out research with older persons, particularly in the epidemic situation, which could lead to abuse, crossing borders and pushing the ethical aspect of research into the background. It is all the more important to consult neutral bodies such as ethical committees at universities with regards to the research assumptions, course and analyses for in-depth inspection.

- The final and most important remark is about enhancing the role of older adults as active participants in the research process, which is 
essential for the future development of more participatory methods for our common issue: ageing. We must expand roles for those who are the co-creators of our super-ageing society, in which public and statutory authorities must work with older people in planning future services in order to ensure that our communities will be fit for all ages.

COVID-19 brought an end to the world as we know it and affected everyone, irrespective of one's position in the life course. After several months of living under the pressure of the virus and pandemic situation, we are starting to wonder when and how we will return to life before the epidemic outbreak. It is becoming more and more apparent that the COVID-19 virus has irreversibly changed the world to such an extent that people will not be able to return to their original conditions. Questions also arise concerning the 'new normality': What does this entail? How will it be characterized? How are we going to experience it? What solutions that have proved effective will we use? At this point, there are more questions than answers. The basic feature of this "new normality" is its dominant uncertainty, which paradoxically may be the only constant factor in re-creating personal and social reality. It is possible that new optional solutions will be built around this uncertainty, which will be evaluated based on the ability to foresee various scenarios of events.

The experience of the first months of COVID-19 has shown that older people's situation - especially their relatively high exposition to a greater risk of illness and death - has nevertheless pointed out the social resources of older persons and their environment. Older persons have been cut off from contact with the world during the lockdown situation to a lesser extent than expected. Older persons have demonstrated that they can use new technologies quite efficiently to remain in contact with their loved ones and participate in educational or social meetings. The threat to the life and health of older persons has confirmed the value of the representatives of younger generations' relationship with older persons. Grassroots initiatives organized by scouts, volunteers, local action groups and neighbors to support older persons facing difficulties with everyday functioning have emerged. Moreover, family relationships, which have been subject to a significant loosening of intergenerational bonds, have indicated fundamental reference points. It seems that the dynamic situation of older persons has had an impact on perceiving the necessity of supporting them as a social group by central and local authorities by creating and implementing age-focused solutions and strategies. Systemic solutions associated with health care, social assistance, support programs and local government initiatives have indicated just how supportive society as a whole should be for the weakest citizens who deserve assistance in the name of humanistic values and not economic interests.

The reflections presented in this publication were aimed at inspiring researchers of the global phenomenon of ageing societies to explore issues related to COVID-19, an unexpected factor impacting the fate of older persons around the world. The presented analyses may serve comparative purposes 
and also as a seed of in-depth research leads. However, not everything that is associated with COVID-19 and the ageing of the global population occurs immediately.

In conclusion, we hope that this book has provided its readers with genuine inspiration to undertake new research challenges related to the phenomenon of the world's ageing population. We believe that the contents of various parts of this publication have been a source of new ideas, reflections and a guide in bringing to light hidden dependencies and phenomena resulting from COVID-19 to improve the impact on older persons' increasingly efficient social functioning. Increasingly efficient exploration of the needs and challenges associated with ageing societies is not only our passion but also our future. Alongside our colleagues - from various countries and cultures we desire to explore these needs not only as academics but primarily as people whose expected existential experience will grow old and function efficiently in later life.

\section{Reference}

Łuszczyńska M. (2020). Researching ageing: Methodological challenges and their empirical background. London: Routledge. 


\section{Index}

Abramson A. 2

abuse: elder mistreatment 2, 89; elder neglect 89; violence 89

Adamski, F. 228

Adelman, D.R. 280

adultism 90,98

advocacy 134, 246, 252, 255

affective disorders 26

age-divided society 104

age division 101-114

age-friendly 5

ageism 3, 6, 35, 42, 76, 88-98, 101-114,

246-248, 245-258, 280; compassionate ageism 247; discrimination 77, 134;

Global Report on Ageism 247, 248;

hostile ageism 247; internal ageism 91; overt ageism 247; positive ageism 90; prejudices 4; stereotypes 4, 90, 317

Age Platform Europe 96, 109

age segregation 107

age stereotyping 3, 4, 21, 76, 90-91, 210, $218,247-248,250,280,317$

agriculture 17

alienation 14, 22, 264, 62, 218

Allan, J.L. 280

Alzheimer Europe 36

Alzheimer's Disease 23, 24-25

ambivalence 195-214

American Geriatrics Society 275

American Psychological Association 94

angiotensin-converting enzyme II 16

animality 91

antibiotics 17

antidepressants 26

anxiety 23,27

apocalyptic demography 64, 235, 237

Aries, P. 52

Armitage, R. 127

Arnoldi, J. 84 asthma 24

Atkinson, J.L. 248

attitudes $14,21,48,50,53,58-63,80$, $88,90,97-98,126,137,160,166,195$, $210,227,231,280,245-259$

Augustin, G. 229, 231-232

Augusto, V. 286-298

Aung, K.T. 38

Austin, B.A. 219

Australia 171, 237

Austria 8, 116

autonomy 15

Avers, D. 90

Ayalon, L. 91, 102, 104, 106, 170, 247

Baldacchino, G. 34, 172

Baldo, V. 1

Balon, K. 79

Barreiro, L.B. 90

Barros, D. 36

Barth, N. 286-298

Bauman, Z. 52, 55

Beck, U. 84

Bélanger-Hardy, L. 245-259

benefits in kind 134

Berenda, K. 136

Berger, L.P. 52

Berg-Weger, M. 33, 170

Berlinger, N. 254

Berridge, C. 109

Berry, G. 311

Besson, É. 311

Bigot, R. 311

Binstock, R. 108

biocenosis 15

biosocial identity 84

biotope 15

Bjursell, C. 35

Błachnio, A. 133 
Blackhouse, J. 189

Blaxter, M. 78, 84

Błędowski P. 133

Bobillier-Chaumon, M.E. 301

Boldy, D. 217

'boomer remover' 35, 92-93, 108, 247

Borowik, J. 183-194

Bosnia and Herzegovina 3

Bradbury-Jones C. 2

Brodaty H. 36

Brooke, J. 89-90

Brooks, S.K. 2

Brusemeister, T. 199

Buber, M. 55

Bufacchi, V. 93

Bugajska, B. 115-130

Buhlmann, B. 196

Burke, P.J. 184

Butler, R.N. 89, 90, 247

California 25

Canada 3, 25, 38, 171, 245, 246, 250-251, 253

Canevelli, M. 36

Cantor, M. 132

carbapenems 17

care home staff 286-298

care technologies 4

Carver, R.S. 128

case work 80, 96, 208

cash benefits 134

Catholic Church 227-241

Centre for Ageing Better 181

Chew, Q.H 115, 117

child maltreatment 2

China 1, 18-19, 20-21, 39, 101, 116, 154, $161,169,236-237,250,286-287$

Christianity 227-241

Christian theology 227-241

chronological age 104

Chu, H.C. 39

civil liberties $60,77,85$

Clark A. 42

clergy 50, 234, 286

climate change 21

Cochrane, C. 152

Comas-Herrera, A. 109

comorbidities 71, 89, 149, 253

computers $40-43$

confidence 4, 43, 180, 229-230

conspiracy myths 205-206

COPE scale 117

coping strategies $115-130$

Corbiére, M. 301
Cosco, C. 216

Cottle, R.N. 280

counselling 4, 78

Cox, C. 188

Crabb, A. 2

Croutte, P. 311

Czech Republic 3, 8, 101, 195, 108

Czykier, K. 286-298

Dabrowska, P. 218

Davidson, S. 33

Davis, F. 301, 310

day care facilities 78-79

death: 47-67; apparent death 57; Black Death 286; cardiac death 28, 29; dying 47-67; fear of death 56-59; inverted death 52 ; medicalization of death 58 ; mis-understanding of death 59-63; pornography of death 52,58 ; premature death 57; taming death 59, 62-63

dedication 238-239

defense mechanism 27, 56

De Jong Gierveld, J. 217

dementia 4, 23-34, 26, 29, 33, 36-38, 197,252

depression 6, 21-25, 27-29, 33, 35, 37, $39,58,90,115,116,126,149,157$, 187, 197, 216, 218, 236, 294, 306

dietary supplements 277,279

Dietrich, M. 202

digitalization: age digital divide 4, 40-43; digital competencies 169, 179, 181, 195-214; digital exclusion 40-43, 169 , 180, 189, 280; digital literacy 40-43; digital technology 40-43

dignity 91, 95, 98, 230, 234, 239, 264

disability 23-24, 74, 78, 94, 133-134, 144, 169-174, 211, 219-220

Dołęga, Z. 219

Domaradzki, J. 72

domestic violence 2

Dörhöfer, P. 210

Dorier, S. 286-298

Drozdowski, R. 151

drug consultation 277, 279

Dubas, E. 151

Dubois, M. 301

Dupré, C. 286-298

Dziedzic, J. 230, 239

East Germany 195-214

economic crisis 47

Ehni, H.J. 104

Eich-Krohm, A. 195-214 
elder repeller 92

e-learning 169-182

Eliason, G. 56

Emerson, K.G. 116

emotional wellbeing 170

Endler, N.S. 136

end-of-life 304-305, 308

ethical dilemmas 98

ethics of care 245, 249, 254-255

evasion 137

everyday life 149-168

evolutionary psychology 27

faith 227-241

family 24

fatigue 96, 291, 308

Fenzl, T. 202

Ferguson, A. 280

fertility 74,150

Fierlbeck, K. 253

Fisher, B. 249, 254

Fisher, J.A. 311

Fitzgerald, M. 254

Fletcher, J.R. 103

Flick, U. 301

Flisiak, K. 14

Folkman, S. 127

Formosa, M. 33-45, 1-10, 169-182, 315-320

France 3, 286-298

Fraser S. 93, 250

Freitas, H. 199

Freud, S. 55, 65

Fuller, H.R. 127

funeral factory 62

funeral services 48-53

Fung, D. Y.L. 126

Gadamer, H.G. 54

Gagat-Matuła A. 239

Galetta, A. 152

Galucia, N. 110

Garcia, L. 245-259

Garner, M.R. 199

Gary, M. 254

Gaulier, C. 286-298

Gautier, S.A. 308

Gellert, P. 196

gender 2

generations $8,20,40,42,53,83,88,92$, 104-195, 107-108, 110-111, 189, 247. 249-250, 255-256, 315

Genet, M. 132

geragogy 149-168
Gerhold, L. 116

geriatrics 74, 78, 196, 275, 278; geriatrician 25; geriatric wards 78

Germany 3, 6, 8, 41, 154, 156, 159, 198, 210

gerontology 286-298

Gibson, H. 33

Gibson, M.J. 132

Gilleard, C. 101

Giroux, N. 300

Głębocka, D. 71-87

globalization 19-22

Glover, J.R. 280

Godawa, G. 88-100

Goławski, P. 88-100

Gorer, G. 52

Górski, A. 18

Gouttefarde, P. 286-298

Graham, A. 189

grandchildren 183-194

grandparents 183-194

Greenberg, N.E. 251

Grenade, L. 219

Griffths, A.K. 2

groceries $89,158,252$

Grudziewska, E. 215-226

Grzymała-Kazłowska, A. 185

Guilhorn, A. 300

Guterres, A. 246

Guyot, J. 286-298

H1N1 flu pandemic 1

Haffower, H. 93

Hagestaad, G.O. 104

Hajek, A. 41, 42

Hakulinen, C. 197

Haley, E.R. 93

Halicka, M. 286-298

Halicki, J. 286-298

Halik, T. 234-235

Harari, Y.N. 285-286

Hardcastle, L. 253

Harper, S. 111

Hartung, S. 199

Hasmanová M. 101-114

Hawkley, L.C. 219

Hayslip, B. 184, 189

health security $22-28$; services 25 ; care 26

healthy ageing $22,53,74,76,78,156$, 196, 208, 296-297

heart disease 90, 275

Heidegger, M. 55, 235

Heinz, R.G. 133 
helplessness $25,75,96,116,110,116$, 120, 137, 187, 218, 228, 247, 286, 291

herd immunity 93

hermeneutics 47-67

Heszen, I. 117

Higgs, P. 101

Hollander, M.J. 250

Hooyman N. 109

hormones 28

hospices 78, 260-261, 263, 269-271, 318

hospital settings 50, 61, 98, 144, 154, 156, 277, 299, 302-304, 307, 311

Howarth, G. 59

Hsu, A.T. 246

human rights $35,42,75,80,91,97,195$, 198, 203-204, 246, 256

Hungary 38

hunger 20

Huseth-Zosel, A. 127

Huxhold, O. 197

Ilnicka, R. 239

immortality 59, 63

immunity $16,17,18$

India 237, 252

Industrial revolution 50

infections 2, 5, 6, 15, 17, 22, 33-37, $39,62,64,72-73,89,96,104,106$, 115-116, 121, 127-128, 134-142, 149, 170, 196, 204, 206, 235, 261, 287, 289, 290-291, 294, 317

informal carers 4, 36-38, 83, 109, 133, 191

Ingham, M. 300

inheritance 48, 54

intelligence 235-239

intensive care 102

intergenerational relations: intergenerational antagonism 103; intergenerational conflict 77, 103, 104 , 107-108; intergenerational contact 101-114; intergenerational solidarity 101-114; intergenerational transfer 48 International Labour Organization 2

International Telecommunications Union 180

internet 4, 40-43

internet-telephone consultation 274-284

interpersonal relations 29, 57, 91, 286-287, 294-298

Ipsos Mori 180-181

Israel 25, 105-106

Italy $1,155,164,250$

Iversen, T.N. 90
Jackson, D. 89-90

Jacob, L. 197

Janiszewska, M. 218

Janowicz, A. 132

Japan 236

Jarynowski, J. 161

Jimenez-Sotomayor, M.R. 250

John Paul II 8, 59, 150, 232-234, 239

Johnson, A.J. 280

Jung, J.H. 116

Jurek, Ł. 132

Kaczmarek, A. 58

Kamel Boulos, M.N. 311

Kanios, A. 75

Karcz, B. 227-241

Kastenbaum, R. 52

Kaufmann, M. 72

Kessler, E.M. 196

Kim, H.H. 116

Klaiber, P. 210

Klein, M.E. 116

Klimek, M. 136

Klimowicz, G. 218

Kluge, P.H. 95

Kocejko, M. 73

Koch, K. 229-230

Konig, H.H. 41, 42

Köppen, M. von 199

Kornhaber, A. 189

Krastev, I. 107-109

Kraus, M. 132

Krzyszkowski, J. 80

Kübler-Ross, E. 57

Kvale, S. 151

labour market 75, 110, 133

Lachs, S.M. 247

Lagacé, M. 245-259

Lang, F.R. 210

language 47-67

Lariviére, N. 301

Lazarus, R.S. 127

Lee, T.M.C. 150

Lefévre, G. 308

Lemke, T. 80

Lev, S. 91

Levinas, E. 55

Lewin, K. 301

LGBT: bisexuals 33; gays 33; lesbians 33; transgender 33

life course 1-3

life expectancy 25, 50, 77

Lightfoot, E. 251 
linguistic barriers 29

Lipiec, D. 239

living environment 73, 75, 79, 80-82, 89

Livingstone, W.D. 151

Lo, B. 94

lobbying 26

lockdown $3,5,32-43 ; 60,71,101-105$, 115-116, 127-131, 142, 152, 154, 161, $165,172,180-181,189,195,198$, 200-201, 203, 206-210, 218, 281, 282, 315,316

lockdown 5. 33-45

loneliness 3, 32-45; 216, 215-226, 264, 281, 292-294, 235, 316

long-term care 317

Lopes, J. 127

Luhmann, M. 197

Lupton D. 1

Łuszczyńska, M. 1-10, 47-67, 315-320

Makselon, J. 56

Malta 1, 34, 169-182

Maslow, A. 133

mass media 52, 63, 93, 97, 161, 236

Matthewman, M. 2

Mayring, P. 202

media 21

medicalisation of old age 71,72 , $75-78,85$

medications 25, 89, 277

Meeks, S. 35

Meisner, B.A. 92

Mellor, A.P. 52

memory impairment 24

Meng, H. 116

Merchant, G. 40

Mercken, C. 170

metabolism 25

Mey, G. 202

micro-organisms 16, 19

Miller, A.E. 249

minority groups 91

Misra, N. 224

Mizrahi, L. 106

Monahan, T. 311

Moone, P.R. 251

moral space 73,83

Moreira, T. 171

Morley J.E. 33, 170

Morrow-Howell, N. 110, 136

mortality rates 47

mourning 48-53

Myśliwiec, M. 239
Naegele, G. 133

needs: affiliation needs 140; physiological needs 140; recognition needs 140; security needs 140 ; self-realization needs 140

negative stereotypes 91, 247

Neimeyer, R.A. 56

Nellums, B.L. 137

Nemeth, D. 151

neoplastic diseases 24

Neumann-Podczaska, A. 274-284

New Delhi bacterium 18-19

new normality 315-320

new technologies 316

New York 26

New Zealand 171, 236-237

Nguyen, S. 16, 17, 151

Nguyen, U.S.D.T. 151

North America 296

Nosek, K. 133

Nowakowska, L. 75

Nowakowski, M. 75

Numbers, K. 36

nursing homes 26, 38-40, 96, 208, 285-298, 299-314

nursing staff $286-298$

nutrition 25

occupational therapy 82-83, 277-278

older adult learning 149-168, 169-182

online activities 137

online learning 169-182

online schooling 2

opportunities 230-235

Organization for Economic

Co-operation and Development 17 , 96, 281

Ossowska, A. 73

O'Sullivan, T.L. 250

Otte, K. 197

Ouchida, M.K. 247

Ozamiz-Etxebarria, N. 127

pain 26

Palmore, E. 91

Paque, K. 38

Parker, J.D.A. 136

Paton, C. 3

Pawlikowski, J. 94

Peng, E. 115

Perissinotto, C.M. 224

personal freedom 203-205

personality integration 151

person-centred care 275 
Peterson, O.K. 133

Petretto, D.R. 135

Peyrat-Apicella, D. 308

phages 16

pharmaceutical companies 26

pharmacy 75, 277

physical activity 26

physical illness 216, 218

Pieh, Ch. 116

Piel, J. 195-214

Pili, R. 135

Piotrowska, K. 115-130

plague 155, 159, 286, 303

Poland 3, 13-31, 71-87, 115-130, 131-145, 215-226, 260-273, 274-284

Polish Society of Epidemiologists and

Doctors of Infectious Diseases 14

Polish Supreme Audit Office 17

Pomeranian region 131-145

Pope Francis 91, 96

Portugal 36-38

positive ageing 42, 134

post-stroke depression 23

Poznan University 276-277

prejudice 3, 4, 35, 90-91, 170, 247, 256

preventive healthcare 134

Previtali, F. 170

Prieto, N. 308

privacy 20

protective masks 140

Przygoda, W. 240

psychosomatic effects 23

public space $34,47,76,81,165,172,261$

Puijalon, B. 247

quality of life $38-39,79,81,151,164$, $170,190,216$

quarantine $6,22,26,34,62,81,89,116$, $143,149,158,160,165,231,263,263$, 269,272

Queluz, F. 251

Rabier, S. 286-298

Racław, M. 71-87

Rafnsson, S.B. 197

Randolph, E. 90

rehabilitation services 135

religiosity 227-241, 318; religious associations 264; religious practices 227-241; religious services 135

Renaud, L. 249

restrictions 1-2, 35-36, 47, 62, 76-72, $82,84,101,105,115,127-128,135$, 137, 143, 152, 166, 193, 195-196, 200,
203-205, 208-211, 215-216, 218-219, 295, 298, 271, 274-275, 286, 288, 293, 308, 318

Revised Loneliness Scale 219

Richert-Kaźmierska, A. 131-145

Riedel, M. 132

Riegelmen, R. 2

Robert Koch-Institute 196

Rogers S.M. 28

Röhr, S. 210

Rossall, P. 33

Rozanova, J. 249

Russell, D.W. 219

Rutherford, A.C 286

safety 134

Salachna, M.J. 260-273

Salari, N. 28

Schimmenti, A. 257

Schmidt, C. 200

school closure 2

Schreurs, K. 41

Schulz, R. 251

Scott, M.G. 199

Second Vatican Council 232, 234

Second World War 51, 216

security 134 ; security measures 290-292

Seifert, A. 40

self-awareness 23,151

self-creation 151

self-knowledge 150

Sendyk, M. 219

senior citizens clubs 78, 80, 137, 139

'senior deleter' 92

Shekhiden, H.A. 106

silver social work 71,80

Simard, J. 40

Simeone, A. 286-298

Simmel, G. 72

Simpson S.J. 28

Singh, A. 224

Skworc, W. 231

sleep disturbances $26,37,53,116,156$, 166, 191, 308

Sloan, R.G. 248

Smith M.L. 34, 35

social activation 134

social anchoring 184-185

social assistance $75,78-82,119,138-$

139, 144, 191, 216-217, 224, 263-264, $317,318,319$

social distance 5, 33-45, 160, 166, 231

social existence 60

social identity theory 91 
social isolation $3,5,32-45,52,71,72$, $75,79,90,95-96,106,115,127-128$, 131-132, 135, 138, 142, 150, 152, 165$166,170,183,190,196-197,198-199$, 201-203, 248, 251, 281, 292, 316 social media $40-43$

social network $40-43$

social services $75,81,133-135,140$

social work $72,73,75,78,79-83,84,85$, $134,140,269,280,287,291,296-297$

socio-legal situation 261-263

Söding T. 240

Solitary Assistance Corps 224

somatic diseases 27

Song, W. 136

Soparnot, R. 300

South America 286

South Korea 237

Soviet Union 17

Spain 109, 116, 236

spirituality 151, 227-241, 318

St. Paul 232

STARK project 195-214

Statistics Canada 250

Steinman, L.E. 34, 35

Stensöta, O.H. 254

Steptoe, A. 216

stereotype embodiment theory 91

Stern, S. 106

stress 23, 28

Strom, D.R. 188

Strom, K.S. 188

Strutt, P.A. 116

Stülpnagel, H. von 195-214

Sülzle, A. 200

Swardfager, W. 23

Swindell, R.F. 171, 179

Swinford, E. 110

Szafranek, A. 260-273

Szałtys D. 27

Szaniawski, T. 58

Szarota, Z. 80, 149-168

Szczepański, J. 219

Sztompka, P. 80

Szukalski, P. 90

taboos/tabooization 52, 56, 58-59, 63

Taylor, A.N. 280

Technology Acceptance Model 301

Tello-Limaco, I.J. 262

terror management theory 91

Tesh-Römer, C. 247

Texas 108

thanatology 52, 55
Thankom, A. 133

therapy workshops 82-83

third age universities 78

Thomas, L-V. 55

Tibbitis, C. 133

Timoszyk-Tomczak, C. 115-130

Tischner, J. 55

Tobis, S. 274-284

Tomaz, S.A. 218

Tomer, A. 56

Torrossian, E. 35

Trafiałek, E. 133

transcendence 151, 230

transgression 34, 151

Trawkowska, D. 77

Trepo, G. 300

Trincaz, J. 247

Tronto, C.J. 249, 254

Uhlenberg, P. 104

uncertainty 294, 300, 318-319, 22, 57-58, 60, 84, 120, 158, 173, 218, 258, 275, 290-291, 294, 299, 315, 317

unemployment 20

Unger, H. von 198

Unified Theory of Acceptance 301-302

University of the Third Age 169-182

Urban, U. 199

urbanity 26

United Arab Emirates 105

United Kingdom 3, 171

United Nations: United Nations

Children's Fund 2; United Nations

Declaration of Human Rights

42; United Nations Economic

Commission for Europe 2; United

Nations Economic Commission for

Europe 42; United Nations Universal

Declaration of Human Rights 91

United States of America 17, 21

vaccinations $89,93,165$

Vaitheswaran, S. 251

values $6,24,53,63,72,75,83,88,120$, 124, 150, 164-165, 185, 193, 203-204, 209, 217, 229, 231-235, 239, 247, 256,319

Vas, A. 300

Vergano, M. 102

Victor, C.R. 33, 38

video chat assists $40-43$

Vignaud, P. 308

Virag, M. 151

viral infections 16 


\section{Index}

virtual learning 169-182

Volicer, L. 40

volunteers $39,61,82,95-96,117,121$, $224,252,255,269,277,317$

Wahl, H.W. 104

Walter, T. 52

Wang, H. 36, 39

Wang, L. 39

Warsaw uprising 216

Wasilewski, H.B. 13-31

Watkins, D. 96

Webb, L. 127

wellbeing 2, 5, 19, 33, 35, 39, 170, 171, $179,218,226,245,248,252$

Wenger, G.C. 33

Western civilization 15-16

Western medicine 25

Wetle, T. 249

White, B.D. 94

White, H. 152

Whitehead, R.B 35

Whitley, M.D. 184

Wickens, C.M. 2

widowhood 38, 153, 170, 218

Wieczorowska-Tobis, K. 274-284

wills 48, 54, 62

Wilson, D. 219

Wittgenstein, L. 55

women 1-2, 33

World Health Organization 1, 17, 21-22, $34,38,89,101,115,149,161$

Wright, M.T. 199

Wu, B. 218

Wuhan 39, 46, 101, 155, 169

Xu, J. 191

Yalom, I.D 56

Yu, J. 150

Yueng, D.Y. 126

Zalakain, J.X. 109

Zeng. Y. 22

Zhang, Q. 136

Zwoliński A. 237 